NIST GCR 14-917-30

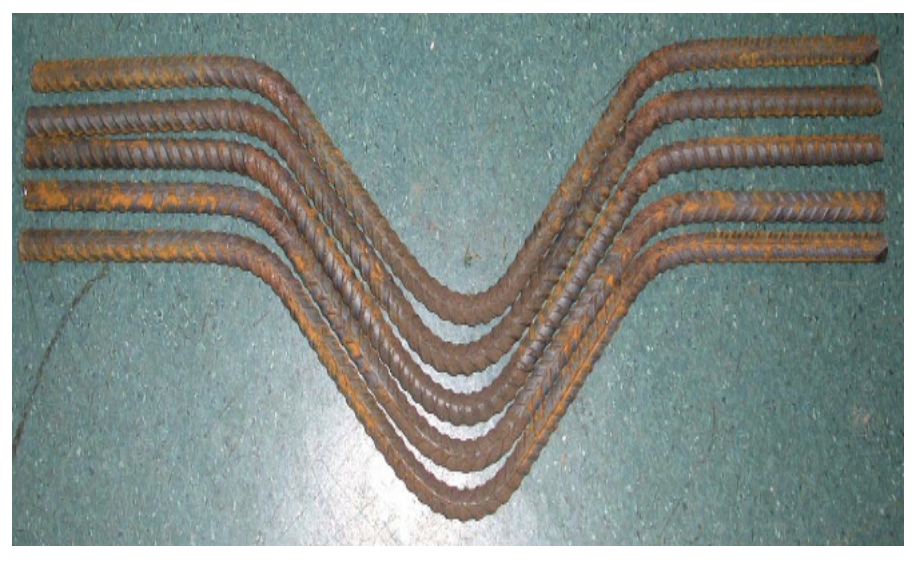

\title{
Use of High-Strength Reinforcement in Earthquake-Resistant Concrete Structures
}

NEHRP Consultants Joint Venture

A partnership of the Applied Technology Council and the Consortium of Universities for Research in Earthquake Engineering
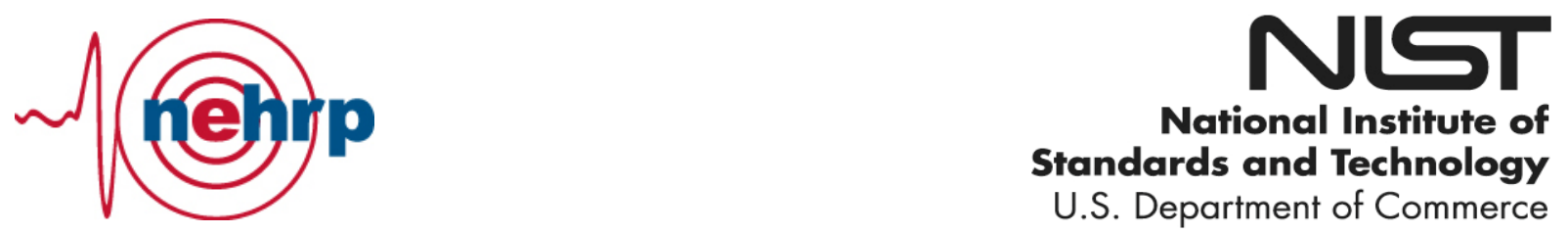


\section{Disclaimers}

This report was prepared for the Engineering Laboratory of the National Institute of Standards and Technology (NIST) under the National Earthquake Hazards Reduction Program (NEHRP) Earthquake Structural and Engineering Research Contract SB134107CQ0019, Task Order 11305. The contents of this publication do not necessarily reflect the views and policies of NIST or the U.S. Government.

This report was produced by the NEHRP Consultants Joint Venture, a partnership of the Applied Technology Council (ATC) and the Consortium of Universities for Research in Earthquake Engineering (CUREE). While endeavoring to provide practical and accurate information, the NEHRP Consultants Joint Venture, the authors, and the reviewers assume no liability for, nor express or imply any warranty with regard to, the information contained herein. Users of information contained in this report assume all liability arising from such use.

Certain commercial software, equipment, instruments, or materials may have been used in the preparation of information contributing to this report. Identification in this report is not intended to imply recommendation or endorsement by NIST, nor is it intended to imply that such software, equipment, instruments, or materials are necessarily the best available for the purpose.

NIST policy is to use the International System of Units (metric units) in all its publications. In this report, however, information is presented in U.S. Customary Units (inch-pound), as this is the preferred system of units in the U.S. earthquake engineering industry.

Cover image - Example bend-rebend test specimens from New Zealand (Hopkins and Poole, 2005, image courtesy of the New Zealand Department of Building and Housing, now part of the Ministry of Business Innovation and Employment). 
NIST GCR 14-917-30

\title{
Use of High-Strength Reinforcement in Earthquake-Resistant Concrete Structures
}

\author{
Prepared for \\ U.S. Department of Commerce \\ National Institute of Standards and Technology \\ Engineering Laboratory \\ Gaithersburg, MD 20899
}

By

NEHRP Consultants Joint Venture

A partnership of the Applied Technology Council and the Consortium of Universities for Research in Earthquake Engineering

March 2014

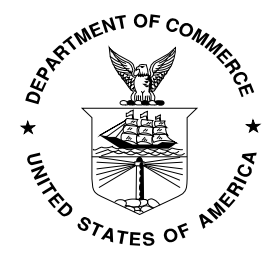

U.S. Department of Commerce Penny Pritzker, Secretary

National Institute of Standards and Technology 



\title{
Participants
}

\author{
National Institute of Standards and Technology \\ John (Jack) R. Hayes, Jr., Director, National Earthquake Hazards Reduction Program \\ Steven L. McCabe, Deputy Director, National Earthquake Hazards Reduction Program
}

\section{NEHRP Consultants Joint Venture}

Applied Technology Council

201 Redwood Shores Parkway, Suite 240

Redwood City, California 94065

www.ATCouncil.org

\section{Joint Venture Management Committee}

James R. Harris

Robert Reitherman

Christopher Rojahn

Andrew Whittaker

\section{Project Technical Committee}

Dominic J. Kelly (Project Director)

Andres Lepage

David Mar

José I. Restrepo

Joseph C. Sanders

Andrew W. Taylor

\section{Working Group Members}

Abby Enscoe

Arpit Nema
Consortium of Universities for

Research in Earthquake Engineering

1301 S. 46 ${ }^{\text {th }}$ Street, Building 420

Richmond, California 94804

www.CUREE.org

Joint Venture Program Committee

Jon A. Heintz (Program Manager)

Michael Constantinou

C.B. Crouse

James R. Harris

William T. Holmes

Jack Moehle

Andrew Whittaker

\section{Project Review Panel}

Tony Ghodsi

James O. Jirsa

Conrad Paulson

Mete Sozen

Loring A. Wyllie, Jr.

\section{Project Managers}

Thomas McLane

Laura Dwelley Samant 

In 2007, the National Institute of Standards and Technology (NIST) awarded the NEHRP Consultants Joint Venture, a partnership of the Applied Technology Council (ATC) and the Consortium of Universities for Research in Earthquake Engineering (CUREE), a National Earthquake Hazards Reduction Program (NEHRP) "Earthquake Structural and Engineering Research" task order contract (SB1341-07CQ-0019) to conduct a variety of tasks. In 2011, NIST initiated Task Order 11305, entitled "Use of High-Strength Flexural Reinforcement in Reinforced Concrete Seismic Design." The objective of this project was to study and make recommendations concerning the utilization of high-strength steel reinforcing bars in concrete structures subjected to earthquake ground motion.

This work grew out of the ATC-57 report, The Missing Piece: Improving Seismic Design and Construction Practices (ATC, 2003), which defines a roadmap for the NIST problem-focused research and development program in earthquake engineering. The ATC-57 report recommended that NIST examine new technologies that can improve construction productivity, such as high-strength reinforcement.

The NEHRP Consultants Joint Venture is indebted to the leadership of Dominic J. Kelly, Project Director, and to the members of the Project Technical Committee, consisting of Andres Lepage, David Mar, José I. Restrepo, Joseph C. Sanders, and Andrew W. Taylor, for their contributions in developing this report and the resulting recommendations. The Working Groups, including Abby Enscoe and Aprit Nema, conducted problem-focused studies. The Project Review Panel, consisting of Tony Ghodsi, James O. Jirsa, Conrad Paulson, Mete Sozen, and Loring A. Wyllie, Jr., provided technical review and commentary at key developmental milestones during the project. A workshop of invited experts was convened to obtain feedback on the preliminary findings and recommendations. The names and affiliations of all who contributed to this report are provided in the list of Project Participants.

The NEHRP Consultants Joint Venture also gratefully acknowledges André Barbosa, Joel P. Conte, David Darwin, and Matthew J. Schoettler for their technical input, Jack Hayes (NEHRP Director) and Steve McCabe (NEHRP Deputy Director) for their input and guidance in the preparation of this report, Laura Samant and Thomas McLane for ATC project management, Ayse Hortacsu, Amber Houchen, Jon Kiland, and Peter N. Mork for ATC report production services.

Jon A. Heintz

Program Manager 



\section{Table of Contents}

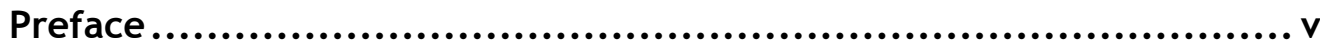

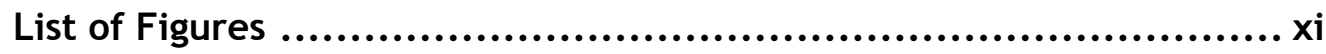

List of Tables.........................................................

1. Introduction ................................................... 1-1

$1.1 \quad$ Report Purpose and Scope ...................................................... 1-1

1.2 Historical Perspective on Use of High-Strength

Reinforcement......................................................................... 1-2

$1.3 \quad$ Report Scope and Development Process ………………………..... 1-4

1.4 Report Organization................................................................... $1-5$

2. Material Characteristics ....................................... 2-1

2.1 Availability of High-Strength Reinforcement............................... 2-1

2.1.1 High-Strength Reinforcement Available in the United States........................................................................ 2-1

2.1.2 High-Strength Reinforcement Available in Other Countries..................................................................... 2-2

2.2 Production of High-Strength Reinforcement .................................. 2-3

2.2.1 Cold Working. ……………………………………......... 2-3

2.2.2 Micro-Alloying .............................................................. 2-3

2.2.3 Quenching and Tempering................................................ 2-4

2.3 Material Properties...................................................................... 2-4

2.3.1 Yield Strength ................................................................. 2-4

2.3.2 Tensile Strength ……………………………………....... 2-5

2.3.3 Elongation.................................................................... 2-6

2.3.4 Ductility ......................................................................... 2-8

$2.4 \quad$ Comparison of Material Properties ................................................. 2-9

2.4.1 ASTM A706 Grade 60 and Grade 80 Reinforcement........ 2-9

2.4.2 USD685 and SD685 Reinforcement................................ 2-11

2.4.3 AS/NZS 500E Reinforcement. ......................................... 2-13

2.4.4 ASTM A1035 Reinforcement............................................ 2-14

2.4.5 SAS 670 Reinforcement ............................................... 2-16

2.5 Comparison of ASTM A615 High-Strength Reinforcement to ASTM A706 High-Strength Reinforcement.............................. 2-17

2.6 Effect of Differences in Stress-Strain Relationships and
Tensile Characteristics on Member Behavior...………………...... 2-20

3. Design and Detailing Considerations ............................. 3-1

3.1 Reinforcement Continuity and Termination ................................... 3-1

3.1.1 Development and Splice Lengths for High-Strength

Reinforcement................................................................ 3-1

3.1.2 Lap Splice Lengths in Members Resisting Earthquake Effects ……................................................................ 3-6 
3.1.3 High Relative Rib Area Reinforcement ...........................3-8

3.1.4 Column or Beam Bond Splitting ....................................... 3-9

3.1.5 Mechanical Splices......................................................... 3-10

3.1.6 Standard Hooks and Headed Deformed Bars.................... 3-11

3.2 Bar Buckling Restraint ................................................................ 3-13

3.3 Strain Limit for a Tension-Controlled Section .............................. 3-18

3.4 High-Strength Concrete........................................................... 3-18

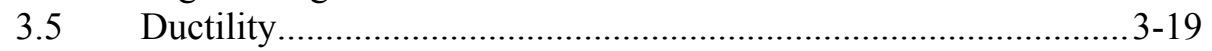

3.6 Minimum Reinforcing Ratios................................................ 3-19

3.7 Strength Provided by High-Strength Shear Reinforcement .......... 3-20

4. Structural System Considerations ................................4-1

4.1 Special Moment Frames.............................................................. 4-1

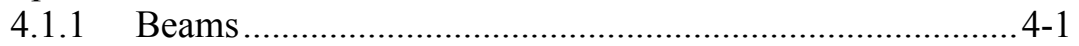

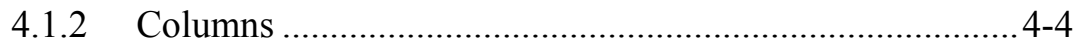

4.1.3 Beam-Column Joints ........................................................ 4-10

4.1.4 Strong Column-Weak Beams....................................... 4-21

4.2 Special Structural Walls .......................................................... 4-21

4.2.1 Characteristics of Special Structural Walls in the United States .............................................................. 4-22

4.2.2 Structural Wall Tests Conducted in Japan with Grade 100 or Stronger Bars.............................................. 4-22

4.2.3 Structural Wall Tests Conducted with Bars of Approximately Grade 80 .

4.3 Members Not Designated as Part of a System Resisting

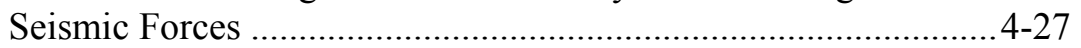

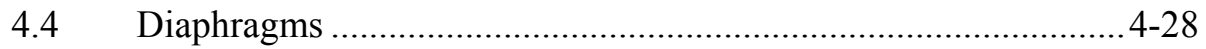

4.5 Foundations .............................................................. $4-29$

5. Analysis of Buildings .......................................5-1

5.1 Modeling Effective Stiffness of Elements for Linear

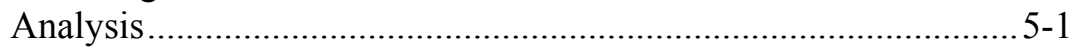

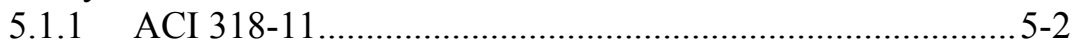

5.1.2 FEMA 356......................................................... 5-3

5.1.3 Paulay and Priestley ................................................. 5-3

5.1.4 Elwood and Eberhard ..................................................... 5-3

5.1.5 Restrepo................................................................. 5-4

5.1.6 Comparison of Methods for Calculating Effective Moment of Inertia ....................................................... 5-4

5.1.7 Calibration to Test Results .............................................. 5-8

5.2 Nonlinear Analysis of a Building with Conventional and High-

Strength Reinforcement.............................................................5-9

5.2.1 Building Description ................................................ 5-10

5.2.2 Building Designs ................................................... 5-12

5.2.3 Analytical Models ................................................. 5-13

5.2.4 Input Ground Motions ..................................................... 5-15

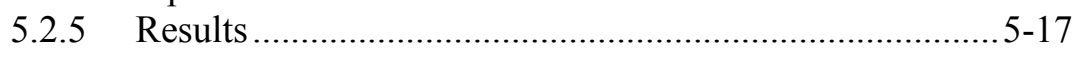

6. Cost and Constructability ........................................6-1

6.1 Cost and Constructability Considerations ...................................... 6-1

6.1.1 Supply Chain ............................................................... 6-2 


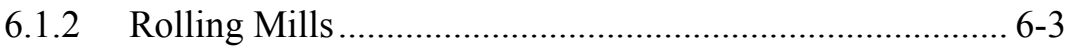

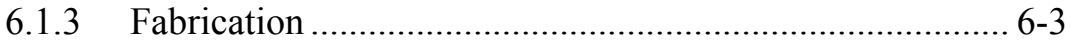

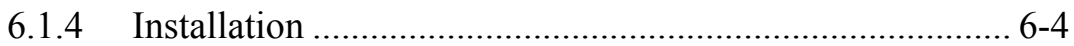

6.1.5 Impacts on Other Trades .................................................. 6-5

6.1.6 Other Considerations ..................................................... 6-5

6.2 Case Studies for Cost Savings .................................................... 6-5

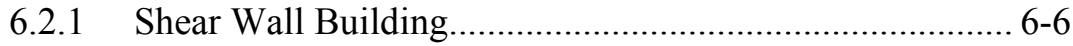

6.2.2 Moment Frame Building................................................. 6-6

7. Conclusions and Recommendations ............................ 7-1

$7.1 \quad$ Conclusions.............................................................................. 7-1

7.2 Recommended Reinforcement Material Characteristics................ 7-1

7.2.1 Recommended Revisions to ASTM A706 Grade 80

Requirements ................................................................ 7-2

7.2.2 Recommended Requirements for Grade 100 and

Higher Strength Reinforcement ........................................ 7-2

7.3 Recommended Changes to ACI 318-11 for Use of Grade 80

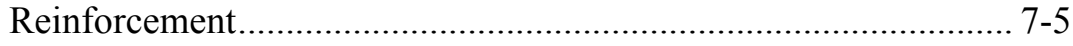

7.3.1 Discussion of Potential Changes to Seismic Provisions ....................................................................... 7-6

7.3.2 Discussion of Potential Changes to Non-Seismic

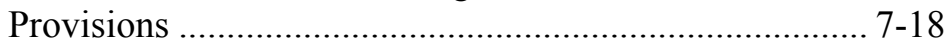

7.4 Recommended Changes to ACI 318-11 for Grade 100 and

Stronger Reinforcement ....................................................... 7-23

7.4.1 Minimum Concrete Strength .......................................... 7-23

7.4.2 Development Lengths, Lap Splices, Mechanical

Couplers, Welded Splices, Hooked, Headed, and Mechanically Anchored Deformed Bars ........................ 7-24

7.4.3 Strong-Column Weak-Beam Design Provisions .............. 7-24

7.4.4 Bar Anchorage in Joints of Special Moment Frames ...... 7-24

7.4.5 Buckling of Bars and Spacing of Confining Reinforcement................................................................. 7-25

7.4.6 Strength and Detailing Requirements for Structural

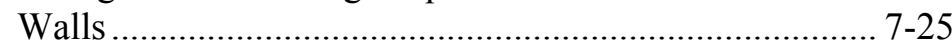

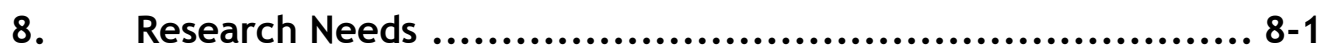

8.1 Material-Related Issues............................................................. 8-1

8.1.1 Impacts of Tensile Characteristics and Shape of Reinforcement Stress-Strain Curve on Member

Behavior..................................................................... 8-1

8.1.2 Impact of Fire on Reinforcement Properties...................... 8-2

8.1.3 Development of a Specification for High-Strength

Reinforcement.................................................................. 8-2

8.2 Bar Continuity and Termination ............................................. 8-3

8.2.1 Development and Splice Lengths ................................ 8-3

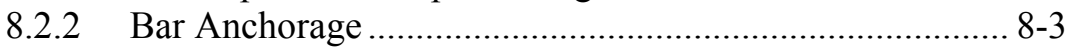

8.2.3 Mechanical Splices ................................................... 8-4

8.3 Design Limits for Reinforcement in Beams, Columns, and

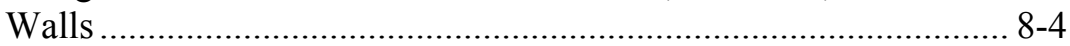

8.3.1 Strain Limit for Tension-Controlled Members .................. 8-4

8.3.2 Minimum Reinforcement Ratios for Walls....................... 8-5 
8.3.3 Member Stiffness ............................................................ 8-5

8.3.4 Transverse Reinforcement Spacing to Restrain Bar Buckling

8.3.5 Shear Reinforcement for Beams, Columns, and Walls

8.4 Moment Frames............................................................... 8-6

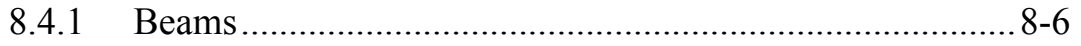

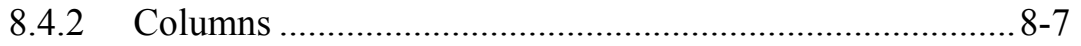

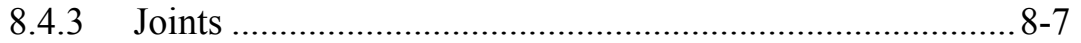

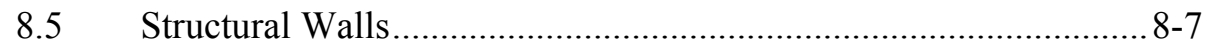

8.6 Full-Scale Tests ...................................................................... 8-8

8.7 Analytical Studies to Confirm Adequate Collapse Resistance........ 8-8

8.8 Considerations Unrelated to Earthquake Resistance...................... 8-9

Appendix A: Study of Deformation Capacity .......................... A-1

A.1 Material Properties ................................................................... A-1

A.1.1 Stress-Strain Relationships for Reinforcing Steel .............. A-1

A.1.2 Stress-Strain Relationships for Concrete Compressive Strength .......................................................................... A-3

A.2 Calculation of Moment-Curvature Relationships......................... A-4

A.2.1 Assumptions ............................................................... A-4

A.2.2 Moment-Curvature Relationships for Beams................... A-5

A.2.3 Moment-Curvature Relationships for Columns ................ A-7

A.2.4 Moment-Curvature Relationships for Walls ..................... A-9

A.3 Calculation of Flexural Deformation Capacities .......................... A-11

A.3.1 Assumptions ............................................................... A-11

A.3.2 Deformation Capacity of Beams ................................... A-13

A.3.3 Deformation Capacity of Columns ............................... A-15

A.3.4 Deformation Capacity of Walls................................... A-17

A.4 Concluding Remarks .......................................................... A-18

Appendix B: Study on Development and Splice Lengths ................. B-1

B.1 Available Methods .................................................................... B-1

B.1.1 ACI 318-11 Methods................................................... B-1

B.1.2 ACI 408R-03 Method ................................................... B-3

B.1.3 ACI ITG-6R-10 Method.................................................. B-5

B.2 Assumptions of the Study ..................................................... B-5

B.3 Study Results.................................................................. B-7

B.4 Discussion of Results ............................................................... B-15

Symbols ..............................................................C-1

References ............................................................... D-1

Project Participants.....................................................E-1 


\section{List of Figures}

Figure 2-1 Idealized stress-strain curve indicating strength and ductility properties (not to scale). . -5

Figure 2-2 Photo of fractured bar being measured for total elongation by measuring across the 8 -inch gage length ...................................... 2-6

Figure 2-3 Photo of uniform elongation being measured ................................ 2-7

Figure 2-4 Example bend-rebend test specimens from New Zealand .............. 2-8

Figure 2-5 Example stress-strain curves for ASTM A706 Grade 60 reinforcement ...................................................................... 2-10

Figure 2-6 Example stress-strain curves for ASTM A706 Grade 80 ............. 2-10

Figure 2-7 Stress-strain curve for USD685A reinforcement ......................... 2-12

Figure 2-8 Representative stress-strain curves for AS/NZS Grade 500E (72.5 ksi) reinforcement.......................................................... 2-14

Figure 2-9 Stress-strain curve for ASTM A1035 Grade 100 and Grade 120 reinforcement ............................................................ 2-15

Figure 2-10 Representative stress-strain curve for SAS 670 reinforcement .................................................................... 2-17

Figure 2-11 Test specimen of beams used to study the effect of the yield ratio.

Figure 2-12 Load-deflection curves of beams with: (a) Yield ratio of 90\% without splice; and (b) yield ratio of $75 \%$ with splice ................. 2-22

Figure 3-1 Bond force transfer mechanisms............................................ 3-2

Figure 3-2 Distribution of developed to calculated values of spliced bars with yield strengths greater than $80 \mathrm{ksi}$ for confined splice tests

Figure 3-3 Developed-to-calculated stress values versus transverse

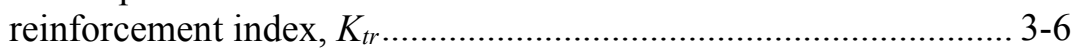

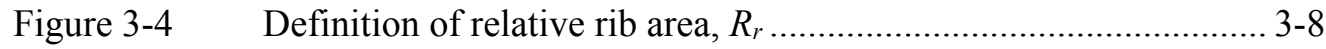

Figure 3-5 Bond index and limiting deflection (\% drift) ........................... 3-10

Figure 3-6 Cracking along the root of the deformation in the compressed side of a buckled reinforcing bar (Restrepo-Posada, 1992): (a) overall view of buckled reinforcing bar; (b) electron microscope view of cracking. 
Figure 3-7 Compressive stress-strain responses of reinforcing bars of different grades and three $s / d_{b}$ ratios and comparison with the mirrored tensile stress-strain response

Figure 3-8 Buckling of bars between hoops and cross ties 3-16

Figure 4-1 Measured stress-strain relationship for longitudinal reinforcement in beam specimens

Figure 4-2 Reinforcement details for beam specimens. 4-3

Figure 4-3 Measured shear versus drift ratio in testing of beams

Figure 4-4 Hysteretic response of circular columns tested by Restrepo et al. (2006) . 4-6

Figure 4-5 Measured stress-strain relationship for longitudinal reinforcement in column specimens

Figure 4-6 Reinforcement details for column specimens

Figure 4-7 Measured shear versus drift ratio in testing of columns.

Figure 4-8

Column specimens at first excursion to drift ratio of $4 \%$ (Rautenberg, 2011): (a) Specimen CC-3.3-20, with Grade 60 reinforcement; and (b) Specimen UC-1.6-20, with Grade 120 reinforcement

Figure 4-9 Bond stress in interior joints of moment frames with beams developing plastic hinges at the joint faces....

Figure 4-10 Hysteretic lateral-force lateral-displacement response of joint Unit 2 with Grade 75 reinforcement tested by Lin et al

Figure 4-11 Recorded slip for longitudinal Grade 75 bars inside an interior joint relative to the concrete surface.

Figure 4-12 Comparison of joint depth to bar diameter ratio, $h / d_{b}$, calculated using modified Lin et al. (2000) approach and Aoyama (2001) approach, for various grades of reinforcement: (a) with Axial load ratio $P_{u} /\left(A_{g} f_{c}^{\prime}\right)=0.1$; and (b) Axial load ratio $P_{u} /\left(A_{g} f_{c}^{\prime}\right)=0.4$

Figure 4-13 View of mechanical connectors used in the joint region in Chang et al. (2008) tests: (a) Specimen 3 with ASTM A1035 reinforcement; and (b) Specimen 4 with ASTM A722 threaded bars.

Figure 4-14 Hysteretic response of cruciform test units anchored with mechanical connectors in Chang et al. (2008) tests:

(a) Specimen 3 with ASTM A1035 reinforcement; and (b) Specimen 4 with ASTM A722 threaded bars....

Figure 4-15 Lateral load versus drift for wall test specimens with reinforcement yield strength close to $80 \mathrm{ksi}$ (Dazio et al, 2009)..... $4-25$ 
Figure 4-16 Details of Walls PW1 and PW2 tested by Lowes et al. (2000) .... 4-27

Figure 5-1 Moment-curvature sketch of members with the same yield strength built with conventional and high-strength bars....

Figure 5-2 Example column sections utilized when comparing effective moment of inertia calculation methods.......................................... 5-5

Figure 5-3 Example beam sections utilized when comparing effective moment of inertia calculation methods.

Figure 5-4 Example wall sections utilized when comparing effective moment of inertia calculation methods........................................... 5-6

Figure 5-5 Plan view of case study building (Barbosa, 2011) ....................... 5-10

Figure 5-6 Elevation of case study building through Gridlines 3 and 8 (Barbosa, 2011).

Figure 5-7 Rendering of the finite element model of the nonlinear analysis case study building (Barbosa, 2011)

Figure 5-8 Response Spectra for 5\% damping of records scaled at MCE (maximum considered earthquake), Mean and Target Spectra (PEER, 2010).

Figure 5-9 Mean maxima roof drift ratios in special moment frames in building with varying grades of reinforcement (Fault Normal component applied in the north-south direction).

Figure 5-10 Mean maxima interstory drift ratios in special moment frames in building with varying grades of reinforcement (Fault Normal component applied in the north-south direction)

Figure 5-11 Mean maxima roof drift ratios in dual system in building with varying grades of reinforcement (Fault Normal component applied in the east-west direction)

Figure 5-12 Mean maxima interstory drift ratios in dual system in building with varying grades of reinforcement (Fault

Normal component applied in the east-west direction)

Figure 5-13 Reduction in lateral system stiffness at the predominant period of response during the design level earthquake for case study building: (a) Moment frame system;

(b) dual system.....

Figure 5-14 Mean strains on longitudinal bars observed at critical sections of elements in the case study building:

(a) Perimeter beam (Level 3, Line 1 between Lines 4-5 at face of column on Lines 1-5); (b) interior column (base of Story 1, Lines $A^{\prime}-1$ ); (c) wall boundary element (base of Story 1, Lines B-4) $5-22$ 
Figure 5-15 Strain time-history recorded for wall corner bars during the building response to the Newhall-West Pico Canyon Road input ground motion of the 1994 Northridge Earthquake

Figure A-1 Stress-strain relationships for reinforcing steel of various grades

Figure A-2 Stress-strain relationships for compressed concrete:

(a) $f_{c}^{\prime}=5 \mathrm{ksi}$; and (b) $f_{c}^{\prime}=10 \mathrm{ksi}$

Figure A-3 Typical beam section used for moment-curvature study......

Figure A-4 Moment-curvature relationships for beams with different concrete compressive strengths and reinforcing steel ratios:

(a) $f_{c}^{\prime}=5 \mathrm{ksi}$ and $\rho f_{y}=0.75 \mathrm{ksi}$; (b) $f_{c}^{\prime}=10 \mathrm{ksi}$ and

$\rho f_{y}=0.75 \mathrm{ksi}$; (c) $f_{c}^{\prime}=5 \mathrm{ksi}$ and $\rho f_{y}=1.5 \mathrm{ksi}$; and

(d) $f_{c}^{\prime}=10 \mathrm{ksi}$ and $\rho f_{y}=1.5 \mathrm{ksi}$.

Figure A-5 Typical column section used for moment-curvature study

Figure A-6 Moment-curvature relationships for columns with different concrete compressive strengths and reinforcing steel ratios, with an axial load of $P=0.2 f_{c}^{\prime} A_{g}$ : (a) $f_{c}^{\prime}=5 \mathrm{ksi}$ and $\rho_{g} f_{y}=1 \mathrm{ksi}$; (b) $f_{c}^{\prime}=10 \mathrm{ksi}$ and $\rho_{g} f_{y}=1 \mathrm{ksi}$; (c) $f_{c}^{\prime}=5 \mathrm{ksi}$ and $\rho_{g} f_{y}=2 \mathrm{ksi}$; and (d) $f_{c}^{\prime}=10 \mathrm{ksi}$ and $\rho_{g} f_{y}=2 \mathrm{ksi}$

Figure A-7 Moment-curvature relationships for columns with different concrete compressive strengths and reinforcing steel ratios, with an axial load of $P=0.3 f_{c}^{\prime} A_{g}$ : (a) $f_{c}^{\prime}=5 \mathrm{ksi}$ and $\rho_{g} f_{y}=1 \mathrm{ksi}$; (b) $f_{c}^{\prime}=10 \mathrm{ksi}$ and $\rho_{g} f_{y}=1 \mathrm{ksi}$; (c) $f_{c}^{\prime}=5 \mathrm{ksi}$ and $\rho_{g} f_{y}=2 \mathrm{ksi} ;$ and (d) $f_{c}^{\prime}=10 \mathrm{ksi}$ and $\rho_{g} f_{y}=2 \mathrm{ksi}$

Figure A-8 Typical wall section used for moment-curvature study A-10

Figure A-9 Moment-curvature relationships for walls with different concrete compressive strengths, with an axial load of $P=0.05 f_{c}^{\prime} A_{g}$ : (a) $f_{c}^{\prime}=5 \mathrm{ksi}$ and $\rho_{b e} f_{y}=1.5 \mathrm{ksi}$; and (b) $f_{c}^{\prime}=10 \mathrm{ksi}$ and $\rho_{b e} f_{y}=1.5 \mathrm{ksi}$

Figure A-10 Moment-curvature relationships for walls with different concrete compressive strengths, with an axial load of $P=0.1 f_{c}^{\prime} A_{g}$ : (a) $f_{c}^{\prime}=5 \mathrm{ksi}$ and $\rho_{b e} f_{y}=1.5 \mathrm{ksi}$; and (b) $f_{c}^{\prime}=10 \mathrm{ksi}$ and $\rho_{b e} f_{y}=1.5 \mathrm{ksi}$

Figure A-11 Idealized curvature distributions for the plastic hinge model: (a) beam, column, or wall; (b) curvature at yield; (c) curvature at ultimate ductility.

Figure A-12 Flexural deformation capacities of beams: (a) $f_{c}^{\prime}=5 \mathrm{ksi}$ and $\rho f_{y}=0.75 \mathrm{ksi}$; (b) $f_{c}^{\prime}=10 \mathrm{ksi}$ and $\rho f_{y}=0.75 \mathrm{ksi}$; (c) $f_{c}^{\prime}=5 \mathrm{ksi}$ and $\rho f_{y}=1.5 \mathrm{ksi}$; and (d) $f_{c}^{\prime}=10 \mathrm{ksi}$ and $\rho f_{y}=1.5 \mathrm{ksi}$ 
Figure A-13 Flexural deformation capacities of columns with an axial load of $P=0.2 f_{c}^{\prime} A_{g}$ : (a) $f_{c}^{\prime}=5 \mathrm{ksi}$ and $\rho_{g} f_{y}=1 \mathrm{ksi}$;

(b) $f_{c}^{\prime}=10 \mathrm{ksi}$ and $\rho_{g} f_{y}=1 \mathrm{ksi}$; (c) $f_{c}^{\prime}=5 \mathrm{ksi}$ and $\rho_{g} f_{y}=2 \mathrm{ksi}$; and (d) $f_{c}^{\prime}=10 \mathrm{ksi}$ and $\rho_{g} f_{y}=2 \mathrm{ksi}$

Figure A-14 Flexural deformation capacities of columns with axial load of $P=0.3 f_{c}^{\prime} A_{g}$ : (a) $f_{c}^{\prime}=5 \mathrm{ksi}$ and $\rho_{g} f_{y}=1 \mathrm{ksi}$; (b) $f_{c}^{\prime}=10 \mathrm{ksi}$ and $\rho_{g} f_{y}=1 \mathrm{ksi}$; (c) $f_{c}^{\prime}=5 \mathrm{ksi}$ and $\rho_{g} f_{y}=2 \mathrm{ksi}$; and (d) $f_{c}^{\prime}=10 \mathrm{ksi}$ and $\rho_{g} f_{y}=2 \mathrm{ksi}$

Figure A-15 Flexural deformation capacities of walls with axial load of $P=0.05 f_{c}^{\prime} A_{g}$ : (a) $f_{c}^{\prime}=5 \mathrm{ksi}$ and $\rho_{b e} f_{y}=1.5 \mathrm{ksi}$; and (b) $f_{c}^{\prime}=10 \mathrm{ksi}$ and $\rho_{b e} f_{y}=1.5 \mathrm{ksi}$

Figure A-16 Flexural deformation capacities of walls with axial load of $P=0.1 f_{c}^{\prime} A_{g}$ : (a) $f_{c}^{\prime}=5 \mathrm{ksi}$ and $\rho_{b e} f_{y}=1.5 \mathrm{ksi}$; and (b) $f_{c}^{\prime}=10 \mathrm{ksi}$ and $\rho_{b e} f_{y}=1.5 \mathrm{ksi}$

Figure B-1 Confinement scenarios used in development and splice length study B-6

Figure B-2 Ratio of Class B splice lengths for unconfined reinforcing bars in a wall, calculated by dividing the results from ACI 408R-03 Equation 4-21 (B-4) by the results from ACI 318-11 Equation 12-1 (B-1), plotted for various values of reinforcement bar specified yield strengths, $f_{y}$

Figure B-3 Ratio of Class B splice lengths for unconfined reinforcing bars in a column, calculated by dividing the results from ACI 408R03 Equation 4-21 (B-4) by the results from ACI 318-11 Equation 12-1 (B-1), plotted for various values of reinforcement bar specified yield strengths, $f_{y}$ B-8

Figure B-4 Ratio of Class B splice lengths for unconfined reinforcing bars in a beam, calculated by dividing the results from ACI 408R03 Equation 4-21 (B-4) by the results from ACI 318-11 Equation 12-1 (B-1), plotted for various values of reinforcement bar specified yield strengths, $f_{y}$

Figure B-5 Ratio of Class B splice length for unconfined, confined, and highly confined No. 8 reinforcing bars, calculated by dividing the results from ACI 408R-03 Equation 4-21 (B-4) by the results from ACI 318-11 Equation 12-1 (B-1),plotted for various values of reinforcement bar specified yield strengths, $f_{y}$ 



\section{List of Tables}

Table 2-1 Comparison of Tensile Properties of ASTM A706 Grades 60 and 80 .

Table 2-2 Comparison of A706 Grade 60 and Grade 80 Bend Test

Requirements to ACI 318-11 Stirrup/Hoop and Standard

Hook Detailing Requirements

Table 2-3 Tensile Properties of USD685 from Japan and SD685 from

Taiwan $2-12$

Table 2-4 Tensile Properties of AS/NZS 500E Reinforcement ................... 2-13

Table 2-5 Tensile Properties of ASTM A1035 Reinforcement..................... 2-15

Table 2-6 Tensile Properties of SAS 670 Reinforcement ........................... 2-16

Table 2-7 Tensile Property Requirements of ASTM A706 and A615

Grade 60 Reinforcement......................................................... 2-18

Table 2-8 Tensile Property Requirements of ASTM A706 and A615

Grade 75 and Grade 80 Reinforcement ..................................... 2-18

Table 2-9 Total Elongation Data of ASTM A706 Grade 60 and

Grade 80, and ASTM A615 Grade 60, Grade 75, and

Grade 80 Reinforcement.

Table 3-1 Properties of Test Beams with High-Strength Longitudinal

Reinforcement and Developing Plastic Hinges during

Testing

Table 3-2 Main Properties of Test Columns Built Incorporating

High-Strength Longitudinal Reinforcement and Developing

Plastic Hinges during Testing.... 3-18

Table 3-3 Specimens in Column Shear Tests Presented in Aoyama (2001)

Table 3-4 Column Shear Test Results from Aoyama (2001).

Table 4-1 Characteristics of Wall Specimens Tested with SD685

Reinforcement by Kimura and Ishikawa (2008)

Table 4-2 Load and Drift for Damage Events of Wall Specimens

Tested by Kimura and Ishikawa (2008).

Table 4-3 Characteristics of Wall Specimens Tested by

Dazio et al. (2009) 4-25 
Table 4-4 Characteristics of Wall Specimens Tested by

Lowes et al. (2012).

Table 5-1 Effective Moment of Inertia Values in ACI 318-11 ........................5-2

Table 5-2 Effective Moment of Inertia Values in FEMA 356.........................5-3

Table 5-3 Effective Moment of Inertia Values in Paulay and

Priestley (1992) ...................................................................... 5-4

Table 5-4 Effective Moment of Inertia Values in Elwood and

Eberhard (2009)...................................................................... $5-4$

Table 5-5 Effective Moment of Inertia Values Recommended in

Restrepo (2000) ......................................................................

Table 5-6 Ratio of Effective to Gross Moment of Inertia for Example

Columns

Table 5-7 Ratio of Effective to Gross Moment of Inertia for Example

Beams......

Table 5-8 Ratio of Effective to Gross Moment of Inertia for Example Walls .....

Table 5-9 Column Reinforcement Ratios in Selected Columns in Story 1, Case Study Building

Table 5-10 Beam Reinforcement Ratios in Selected Beams on Level 1, Case Study Building ............................................................. $5-12$

Table 5-11 Wall Reinforcement Ratios in Story 1, Case Study Building ....... 5-13

Table 6-1 Cost Comparison for Substituting Grade 80 for Grade 60

Reinforcement in Case Study Building One

Table 6-2 Cost Comparison for Substituting Grade 80 for Grade 60

Reinforcement in Case Study Building One

Table 7-1 Recommended Properties and Characteristics of

Reinforcement that is Grade 100 and Stronger ............................. 7-5

Table A-1 Stress-Strain Parameters for Reinforcing Steel .............................. A-2

Table A-2 Stress-Strain Parameters for Concrete.......................................... A-4

Table B-1 ACI 318-11 Section 12.2.2 Calculation Methods for

Development Lengths

Table B-2 Development and Splice Lengths and Ratios Calculated per ACI 318-11 Equation 12-1 (B-1) and ACI 408R-03

Equation 4-21 (B-4) for the Unconfined Condition:

Wall Example 
Table B-3 Development and Splice Lengths and Ratios Calculated per ACI 318-11 Equation 12-1 (B-1) and ACI 408R-03

Equation 4-21 (B-4) for the Confined Condition:

Column Example

Table B-4 Development and Splice Lengths and Ratios Calculated per ACI 318-11 Equation 12-1 (B-1) and ACI 408R-03 Equation 4-21 (B-4) for the Highly Confined Condition: Beam Example B-14 



\section{Chapter 1}

Introduction

Today, reinforced concrete buildings designed and constructed for areas with high seismic risk in the United States generally use reinforcement with a yield strength of $60 \mathrm{ksi}^{1}$ for members resisting earthquake effects. In Japan, reinforcement with yield strength as high as $100 \mathrm{ksi}$ is currently used in building members designed to resist earthquake forces. Reinforcement with a yield strength higher than $60 \mathrm{ksi}$ is currently produced in the United States and will likely become more common in the U. S. market in the near future.

There are many potential benefits to the use of high-strength reinforcement in elements resisting earthquake effects in construction in the United States. These include cost savings, reduced construction time, and reduction in reinforcement congestion.

\subsection{Report Purpose and Scope}

The purpose of this report is to document a recently completed study to evaluate whether using reinforcement with yield strength greater than $60 \mathrm{ksi}$ in structural members that resist earthquake forces is appropriate in the United States. The current standard for reinforced concrete design, ACI 318-11, Building Code Requirements for Structural Concrete and Commentary (ACI, 2011), allows the use of reinforcement with a specified yield strength of $80 \mathrm{ksi}$ for flexure and confinement, but limits the specified strength of reinforcement to $60 \mathrm{ksi}$ in special moment frame and special structural wall (shear wall) design.

This report reviews existing research to determine whether there is sufficient information to justify the use of reinforcement with specified yield strengths of $80 \mathrm{ksi}$ (or even $100 \mathrm{ksi}$ ) for special moment frames and special structural walls, and to identify performance and design issues associated with the use of reinforcement with yield strengths of $120 \mathrm{ksi}$ or more. In addition, to evaluate whether it is appropriate to use high-strength reinforcement, this report presents results of analyses exploring whether performance of a building designed with high-strength reinforcement would be equivalent to that of a building designed with conventional reinforcement in accordance with ACI 318-11. Because ACI 318-11 already allows the use of highstrength reinforcement for confinement, this report does not address this issue.

${ }^{1}$ This report refers to reinforcement strength in kips per square inch, ksi. The equivalent strengths in metric units of the reinforcements frequently referred to in this report are: $60 \mathrm{ksi}$ (420 megapascals, MPa), $80 \mathrm{ksi}(550 \mathrm{MPa})$, and $100 \mathrm{ksi}(685 \mathrm{MPa})$. 
High-strength reinforcement is defined herein as reinforcement with a yield strength of $72 \mathrm{ksi}(500 \mathrm{MPa})$ or greater. In particular, this report focuses on using highstrength reinforcement as the primary reinforcement for beams and columns resisting flexure in a special moment frame and for walls resisting flexure and shear. An evaluation of the potential cost savings and other benefits associated with using highstrength reinforcement as part of the system resisting earthquake effects is also provided.

Although using high-strength reinforcement has potential benefits, there are also numerous questions about the appropriateness of its use as part of a system to resist earthquake effects. This report seeks to identify these questions and, where possible, provide answers. The following questions, among many others, are explored:

- Do members reinforced with high-strength reinforcement for flexure have adequate ductility to resist earthquake effects under current design procedures?

- Does the use of high-strength reinforcement require deeper beam-column joints to address higher bond forces for moment frames?

- What transverse reinforcement spacing is required to prevent buckling of highstrength reinforcement?

- Will higher bond stress resulting from the use of high-strength reinforcement lead to more splitting failures of short columns and beams than those designed using 60 ksi reinforcement?

- What is the effect of the use of high-strength reinforcement on the overall stiffness and period of a structure? How does the use of high-strength reinforcement affect drift?

- Does the shear strength of beams, columns, and walls increase with the increase in shear reinforcement yield strength?

This report also provides recommendations for changes to ACI 318-11 to help implement the use of higher strength reinforcement in seismic applications. Also included are a summary of gaps in existing research and recommendations about research that could contribute to wider acceptance of the use of high-strength reinforcement in members resisting earthquake effects. These recommendations can be implemented by the ACI Committee 318 or others.

\subsection{Historical Perspective on Use of High-Strength Reinforcement}

During the last few decades, reinforced concrete construction in the United States has generally utilized reinforcement with a yield strength of $60 \mathrm{ksi}$ for most beams, girders, and columns; and less frequently reinforcement with a yield strength of 75 ksi for columns that are not a part of a special moment resisting frame. However, a number of earlier studies, including those described below, considered and evaluated 
the use of reinforcement with greater strengths for beams, girders, and columns supporting live and dead loads.

In 1934, Richart and Brown published a series of results for column tests, one of which demonstrated that longitudinal reinforcement bars with yield strengths of 72 ksi and 96 ksi were fully effective under axial compression (Richart and Brown, 1934). In 1964 Todeschini et al. published the results of tests on eccentrically loaded columns and, similar to Richart and Brown, concluded that the full yield stress was effective in resisting load for reinforcement with a yield plateau up to approximately 90 ksi (Todeschini et al., 1964).

In the late 1950s and 1960s, the Portland Cement Association (PCA) conducted a series of tests reported in eight parts that examined beams, girders, and columns (Hognestad, 1961; Hognestad, 1962; Gaston and Hognestad, 1962; Kaar and Mattock, 1963; Pfister and Mattock, 1963; Pfister and Hognestad, 1964; Kaar and Hognestad, 1965; and Kaar, 1966). The tests covered flexural strength, control of flexural cracking, compression splices in columns, and fatigue. Reinforcement strengths ranged from $55 \mathrm{ksi}$ to $120 \mathrm{ksi}$. At about the same time, Thomas and Sozen (1965) published the results of tests of beams reinforced with unstressed prestressing reinforcement with yield strength of $230 \mathrm{ksi}$. These early tests were considered in the 1971 edition of ACI 318, when the upper limit for yield strength was increased to 80 ksi, even though at the time there were no American Society for Testing and Materials (ASTM) specifications for reinforcement with yield strengths more than 75 ksi. However, the upper limit for specified reinforcement yield strength of special moment frames and special structural walls remained at $60 \mathrm{ksi}$.

The early tests of elements with high-strength reinforcement did not include cyclic tests. Cyclic tests were first performed in the early 1960s by Burns and Siess (1962) to study the performance of elements subjected to earthquake demands, i.e., forces and deformations. More tests were performed in the 1970s and 1980s. These tests demonstrated the need for more ductile reinforcement in members resisting earthquake forces. In the early 1970s, the Seismology Committee of the Structural Engineers Association of California (SEAOC) recognized the need for reinforcement with more restrictive limits on tensile properties than was specified at the time for ductile concrete moment frames. These limits on yield and tensile strength sought to improve reliability of strong-column weak-beam behavior. SEAOC also advocated the improvement of the reliability of weld splices of reinforcement, which were common at that time. Because improving the reliability of welds required controls on bar chemistry, SEAOC developed a specification for reinforcement with more restrictive tensile properties and chemistry controls (ACI, 1973; Gustafson and Felder, 1991), published as ASTM A706, Standard Specification for Low-Alloy Steel Deformed and Plain Bars for Concrete Reinforcement (ASTM, 1974), in addition to ASTM A615, Standard Specification for Deformed and Plain Carbon-Steel Bars for 
Concrete Reinforcement, which was developed as a specification for conventional reinforcement.

The 2009 versions of ASTM A615 and A706 specifications (ASTM, 2009a; ASTM, $2009 \mathrm{~b}$ ) were the first to include requirements for Grade 80 reinforcement. American Concrete Institute (ACI) Committee 318 adopted these specifications without restriction in the main body of ACI 318-11 because Grade 80 reinforcement was already allowed for use as confinement. However, Grade 80 reinforcement is not allowed for use in special moment-resisting frames and special structural walls due to the perceived lack of test data for cyclically loaded members with Grade 80 reinforcement.

\subsection{Report Scope and Development Process}

This report focuses on reinforcement with yield strengths of $80 \mathrm{ksi}, 100 \mathrm{ksi}$, and 120 ksi; however, research on reinforcement with other strengths is also discussed.

This report was prepared by a multidisciplinary team consisting of researchers, practicing engineers, and a contractor. Their work included the following activities:

- Identifying and reviewing research papers and reports on the use of high-strength reinforcement for structures and members within structures that resist earthquake forces.

- Assessing whether the research was adequate to recommend the use of highstrength reinforcement for primary members resisting earthquake effects.

- Identifying additional research needed to support a recommendation for the use of high-strength reinforcement in primary members resisting earthquake forces.

- Studying the effect of high-strength reinforcement on overall building response to earthquakes; ductility of beams, columns and walls; stiffness of members; splice and development lengths; and needed beam-column joint depths.

- Identifying provisions of ACI 318-11 that need to be changed to allow use of ASTM A706 Grade 80 high-strength reinforcement in primary members resisting earthquake effects.

- Identifying design and performance issues that need to be addressed with the use of reinforcement with yield strengths of $100 \mathrm{ksi}$ to $120 \mathrm{ksi}$ or more as flexural reinforcement for members resisting earthquake effects.

This document does not cover members with high-strength reinforcement designed to resist only dead and live loads, such as floor systems. Such members have serviceability requirements that are sensitive to the stress level in the reinforcement. Serviceability issues are discussed in several references (Tang and Lubell, 2008; ACI, 2010b; Hognestad, 1962; Kaar and Mattock, 1963; Kaar and Hognestad, 1965; 
and Kaar, 1966). However, serviceability requirements generally do not apply to, or at least do not control the design of members resisting earthquake effects.

\subsection{Report Organization}

Chapters 2 through 6 present the findings of relevant research and the results of analyses conducted for this study on a variety of aspects related to the performance of high-strength reinforcement in seismic applications.

Chapter 2 addresses the characteristics of high-strength reinforcement from a material perspective. It presents the types of high-strength reinforcement currently available, discusses the manufacture of high-strength reinforcement, and presents strength and ductility properties for different types of high-strength reinforcement.

Chapter 3 explores design and detailing considerations related to the use of highstrength reinforcement. It examines how issues such as reinforcement continuity, bond stress, bar buckling and ductility would be affected by the use of high-strength reinforcement.

Chapter 4 discusses system level impacts of the use of high-strength reinforcement. It examines how the use of high-strength reinforcement would affect moment frames and shear walls, and, to a lesser extent, diaphragms and foundations.

Chapter 5 discusses the modeling of effective stiffness of elements with high-strength reinforcement. This chapter also presents an analysis of a full-scale building model using high-strength reinforcement exposed to earthquake shaking, and compares its performance with that of the same building model using Grade 60 reinforcement.

Chapter 6 discusses issues associated with cost and constructability and presents two case studies to assess potential cost savings due to the use of high-strength reinforcement.

Chapter 7 presents the conclusions of the report and provides recommendations for material characteristics for high-strength reinforcement used to resist earthquake effects, and for needed changes to ACI 318-11 to allow the use of Grade 80 reinforcement in special moment frames and special structural walls. It also discusses issues that need further study before reinforcements with higher strength should be allowed for these purposes.

Chapter 8 identifies additional research needs for resolving important questions associated with the use of high-strength reinforcement.

Appendices A and B provide details of selected analyses conducted for this study.

A list of Symbols defining key notation and a list of References cited, as well as a list of project participants are provided at the end of this report. 



\section{Chapter 2}

\section{Material Characteristics}

This chapter identifies high-strength reinforcement types that are currently being used or are likely to be used in the United States for members resisting earthquake effects. The chapter discusses the production of high-strength reinforcement and the physical properties of currently available reinforcement in the United States and several other countries. In addition, the effect of selected material characteristics on member behavior are also discussed.

\subsection{Availability of High-Strength Reinforcement}

Reinforcement with yield strength as high as $120 \mathrm{ksi}$ is now available in the United States. In Japan, reinforcement with yield strength of $100 \mathrm{ksi}$ is currently used in buildings for members resisting earthquake effects. This report does not address stainless steel reinforcement in depth, which is available with yield strength as high as $105 \mathrm{ksi}$.

\subsubsection{High-Strength Reinforcement Available in the United States}

Grade 80 reinforcement was first included in the 2009 versions of ASTM specifications A615, Standard Specification for Deformed and Plain Carbon-Steel Bars for Concrete Reinforcement (ASTM, 2009a), and A706, Standard Specification for Low-Alloy Steel Deformed and Plain Bars for Concrete Reinforcement (ASTM, 2009b). Grade 80 reinforcing bars are being produced in the United States, but have generally been manufactured for specific project demands rather than for general use. However, its availability is expected to increase as it is specified more frequently.

ASTM A1035, Standard Specification for Deformed and Plain, Low-Carbon, Chromium, Steel Bars for Concrete Reinforcement (ASTM, 2011) which was first issued in 2004, covers Grade 100 and Grade 120 reinforcement. ACI ITG-6R-10, Design Guide for the Use of ASTM A1035/A1035M Grade 100 Steel Bars for Structural Concrete (ACI, 2010a), provides recommended design provisions in which the higher yield strength is used to increase member flexural and axial strength.

SAS 670 is a German-manufactured reinforcement intended for use as compression reinforcement in columns. An evaluation of this material for use in the United States is provided in the International Code Council (ICC) Evaluation Services (ES) report, ESR-1163 (ICC, 2011), Evaluation Subject: SAS Stressteel Grade 97 Thread Bar 
Steel Reinforcing Bars and Couplers. This reinforcement has been used for high-rise construction in New York City.

Higher strength reinforcing bars for post-tensioning applications are available for purchase in the United States from companies such as Williams and Dywidag. These bars are produced according to ASTM A722, Standard Specification for Uncoated High-Strength Steel Bars for Prestressing Concrete (ASTM, 2012b), and have a tensile strength of $150 \mathrm{ksi}$. ASTM A955, Standard Specification for Deformed and Plain Stainless-Steel Bars for Concrete Reinforcement (ASTM, 2012a), includes requirements for Grade 75 stainless-steel bar reinforcement.

\subsubsection{High-Strength Reinforcement Available in Other Countries}

There are several types of high-strength reinforcing bars available in other countries that are not generally available in the United States. In the early 1990s, Japan conducted the New RC Project, which studied high-strength reinforcement (Aoyama, 2001). Specifications for high-strength reinforcement were introduced in Japan in 1995, which coincided with a rapid increase in the number of reinforced concrete high-rise buildings constructed. Between 1995 and 2002, approximately 200 highrise reinforced concrete buildings (defined as 60 meters (197 feet) and taller) were constructed in Japan (Sugano, 2008).

The high-strength reinforcing bar types developed in Japan are the following: (1) USD685A and USD685B (both with yield strength of $100 \mathrm{ksi}$ ), intended for use as reinforcement that will yield in beams and columns; (2) USD980 (with yield strength of $142 \mathrm{ksi}$ ), intended for use in beams and columns not expected to yield; (3) USD785 (with yield strength of $114 \mathrm{ksi}$ ); and (4) USD1275 (with yield strength of $185 \mathrm{ksi}$ ), intended for use as transverse reinforcement. These new reinforcing types have not yet been accepted into the Japanese Industrial Standard (JIS), Japan's equivalent to an ASTM specification, (Nishiyama, 2009; Miyajima, 2010). However, these reinforcement types have gained acceptance through the Ministry of Construction as part of the New RC Construction Standard (Aoyama, 2001). SD685 (with yield strength of $100 \mathrm{ksi}$ ) is produced in Taiwan for research purposes, and its required mechanical properties are similar to USD685B from Japan.

New Zealand, Australia, and China produce Grade 500 (72.5 ksi) reinforcement. The Australian/New Zealand specification, AS/NZS 4671 (AS/NZS, 2001), includes Grade 500E, which is specifically intended for use in members designed to resist earthquake forces, and Grade $500 \mathrm{~N}$, which has less strict ductility requirements than those for Grade 500E. Because of Australia's low seismicity, Grade 500N reinforcement is commonly used there. New Zealand, meanwhile, uses Grade 500E reinforcement. HRB500 and HRBF500 reinforcing bars are readily available for use in China, but as of 2010 had yet to be included in Chinese building code standards 
(Li et al., 2010). A comparison of the HRB500 reinforcement available in China and the Grade $500 \mathrm{~N}$ reinforcement available in Australia and New Zealand is provided in Li et al. (2010).

\subsection{Production of High-Strength Reinforcement}

Common methods for producing high-strength reinforcement include cold working, addition of alloys, and quenching and tempering. Each of these methods is explained below.

\subsubsection{Cold Working}

Cold working or cold rolling is a long-standing method of producing high-strength reinforcement carried out below the recrystallization temperature (Caifu, 2010). The process causes dislocation generation and movements within the crystal structure. A dislocation is a crystallographic defect or irregularity within a crystal structure. The presence of these dislocations strongly affects yield strength and ductility. Cold working eliminates a yield plateau and hardens the steel. While cold working improves yield strength, it reduces both ductility and the ratio of tensile strength to yield strength, so it generally is not an appropriate means of producing high-strength reinforcement for members resisting earthquake effects.

\subsubsection{Micro-Alloying}

Higher strength steel can be obtained by adding small amounts of titanium (Ti), niobium (Nb), or vanadium (V) (Aoyama, 2001; Caifu, 2010), which is referred to as micro-alloying. Micro-alloying forms intermetallic carbides that produce fine-grain strengthening and precipitation hardening. Fine-grain strengthening occurs by the pinning of planar defects (grain boundaries) during thermo-mechanical processing (rolling), which produces a very fine grain size in the steel product. In general, the finer the grain size, the higher the yield strength (a relationship known as the HallPetch Effect). When these intermetallic carbides are dispersed through the ferrite grains, pinning line defects (dislocations) occur, which further raise the yield strength of the material. This mechanism is known as precipitation hardening.

Titanium micro-alloying contributes to precipitation hardening, but its strong tendency to combine with oxygen, sulfur, and nitrogen makes it difficult to control the strengthening effects. Niobium micro-alloying is widely used in steel sheet and strip production, in which the temperature at the end of production is relatively low and the deformation is high. Reinforcement production requires high rolling temperatures and less deformation, making niobium micro-alloying ineffective for high-strength reinforcement production.

Vanadium or vanadium-nitrogen micro-alloying is used to develop high-strength, weldable reinforcement around the world. Vanadium addition increases yield 
strength due to precipitation of carbides and nitrides. Vanadium-only micro-alloying results in $35.5 \%$ of the vanadium forming carbide and nitride precipitates, while $56.3 \%$ of the vanadium ends up as solid solution dissolved in the matrix, which does not improve the reinforcement yield strength. The amount of vanadium forming precipitates can be increased up to $70 \%$ with the addition of nitrogen. Another advantage of vanadium-nitrogen micro-alloyed reinforcement is that it eliminates the adverse effects of strain aging on properties of steel because it pins the soluble nitrogen (Caifu, 2010; Erasmus and Pussegoda, 1978; Restrepo-Posada et al., 1994).

\subsubsection{Quenching and Tempering}

Quenching is the rapid cooling of steel that has been heated to the austenitic phase (at which solid steel recrystallizes). The steel is quenched in water or oil, which results in a hard and brittle material structure. Tempering is the heating of the quenched steel, which modifies the microstructure to decrease the hardness and increase the ductility of the material. Quenching and tempering is one option for producing AS/NZS Grade 500E reinforcement and could be used to produce other types of higher strength reinforcement.

\subsection{Material Properties}

This section describes the varying ways that strength and ductility are defined for the types of high-strength reinforcement examined in this report.

Tensile properties and other requirements defining strength and ductility that might be specified include: (1) minimum or lower bound yield strength, as specified in the relevant specification; (2) maximum or upper bound yield strength, as specified in the relevant specification; (3) length of the yield plateau or strain at the end of the yield plateau; (4) tensile strength; (5) uniform elongation and total elongation; (6) ratio of tensile strength to yield strength or its inverse (referred to as the yield ratio); and (7) results of a bend test or a bend-rebend test. Some, but not all, of these properties and tests are specified for each high-strength reinforcement type and are discussed in the following sections. Several of the tensile properties are indicated on the idealized stress-strain curve shown in Figure 2-1.

\subsubsection{Yield Strength}

All reinforcement types considered specify either the yield point or yield strength, which are both referred to as $f_{y}$. However, only two of the high-strength reinforcement types previously identified (USD685 and SD685) specify the strain at the end of the yield plateau. ASTM standards do not allow the measured value of $f_{y}$ to fall below the grade of steel, whereas other standards, such as the AS/NZ Standards, use the $5 \%$ fractile concept, in which a small percentage of tests are allowed to be below the minimum strength. ASTM A370, Standard Test Methods 


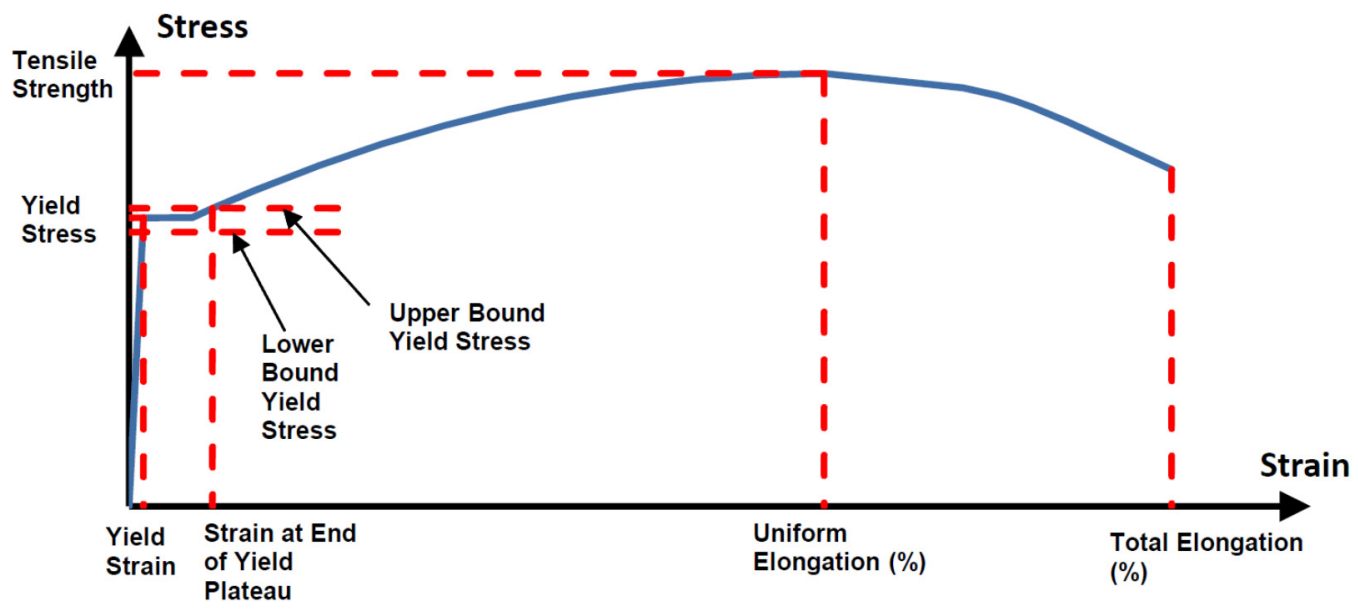

Figure 2-1 Idealized stress-strain curve indicating strength and ductility properties (not to scale).

and Definitions for Mechanical Testing of Steel Products (ASTM, 2012c), which is applicable to U.S. produced reinforcement, defines yield point as "the first stress in a material less than the maximum obtainable stress, at which an increase in strain occurs without an increase in stress." Yield point is applicable to reinforcement that exhibits an increase in strain without an increase in stress, which generally only occurs in reinforcement with lower strengths.

High-strength reinforcement typically does not have a definitive yield point, so another means of defining the yield strength is necessary. ASTM A370 defines yield strength as "the stress at which a material exhibits a specified limiting deviation from the proportionality of stress to strain." The yield strength may be determined by the 0.2\% Offset Method or the Extension Under Load (EUL) Method of ASTM A370. The $0.2 \%$ Offset Method is used for computation of the yield stress for ASTM A615, A706, and A1035 reinforcement, but an additional check using the EUL Method for a strain of 0.0035 is also required to define the minimum yield strength for ASTM A615 and A706 reinforcement. ASTM A1035 requires that the EUL Method with a strain of 0.0035 produce minimum stresses of $80 \mathrm{ksi}$ and $90 \mathrm{ksi}$ for Grade 100 and Grade 120 reinforcement, respectively. The $0.2 \%$ Offset Method is also used to define the yield strength in specifications in most other countries, including those of Japan, Australia/New Zealand, and Europe.

\subsubsection{Tensile Strength}

In the specifications, tensile strength is consistently defined as the peak stress on the stress-strain curve. In accordance with ASTM A370, tensile strength is calculated by dividing the maximum load that the specimen sustains by the nominal bar area. 


\subsubsection{Elongation}

Elongation is commonly reported as the total elongation over a prescribed gage length that extends across the fracture of a bar. Total elongation is determined in accordance with ASTM A370, which provides two methods. In one method, a bar is marked with an initial gage length of 8 inches and pulled to fracture. This method does not account for elastic elongation. For the first method, the ends of the fractured bar are fit together and the gage length is re-measured, as shown in Figure 2-2. The elongation is then reported as the percentage increase in length relative to the original gage length. In the second method, the elongation at fracture may be measured using an extensometer, in which case elastic elongation is included. Both these methods include the additional localized elongation at the necked-down region plus the elongation along the non-necked-down portions of the bar within the gage length.

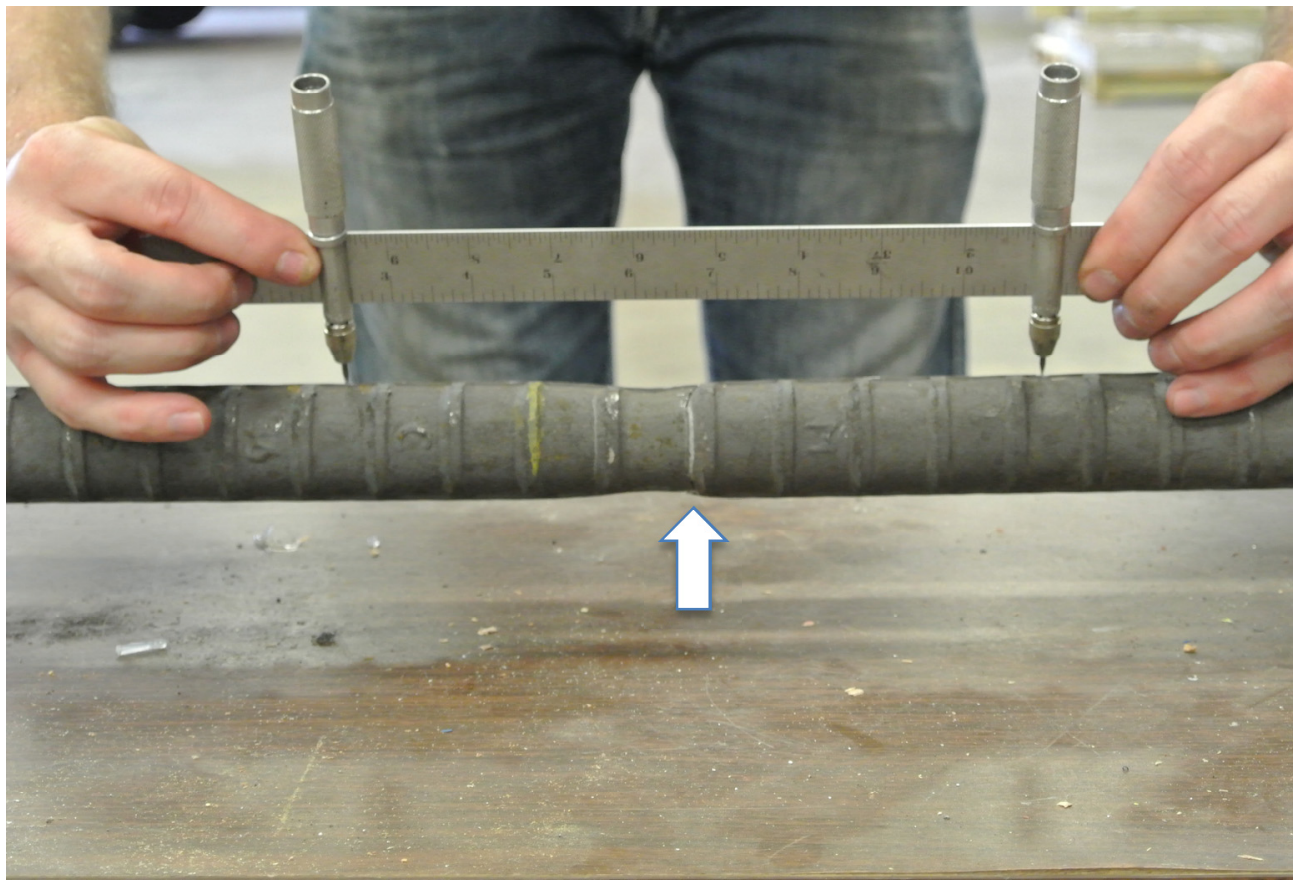

Figure 2-2 Photo of fractured bar being measured for total elongation by measuring across the 8-inch gage length. Arrow points to fracture location (photo courtesy of Wiss, Janney, Elstner Associates, Inc., Copyright 2013).

Uniform elongation is the strain that occurs as the bar reaches its peak stress (tensile strength), expressed as a percentage. Its name stems from the fact that this is the largest deformation in the test bar while the tensile strains are uniform throughout the length between the test grips. It occurs right before the onset of necking in a bar. The uniform elongation is typically measured with an extensometer while a bar specimen is being tested; it includes both plastic strain and the strain that is recovered upon unloading the bar (CSA, 2009; AS/NZS, 2001). It may also be determined by measuring the plastic elongation upon removal of the bar specimen from the test 
machine and then adding the recovered strain. In this case, plastic strain is measured away from the necked-down region, as shown in Figure 2-3, and the recovered strain is added to it to obtain the uniform elongation.

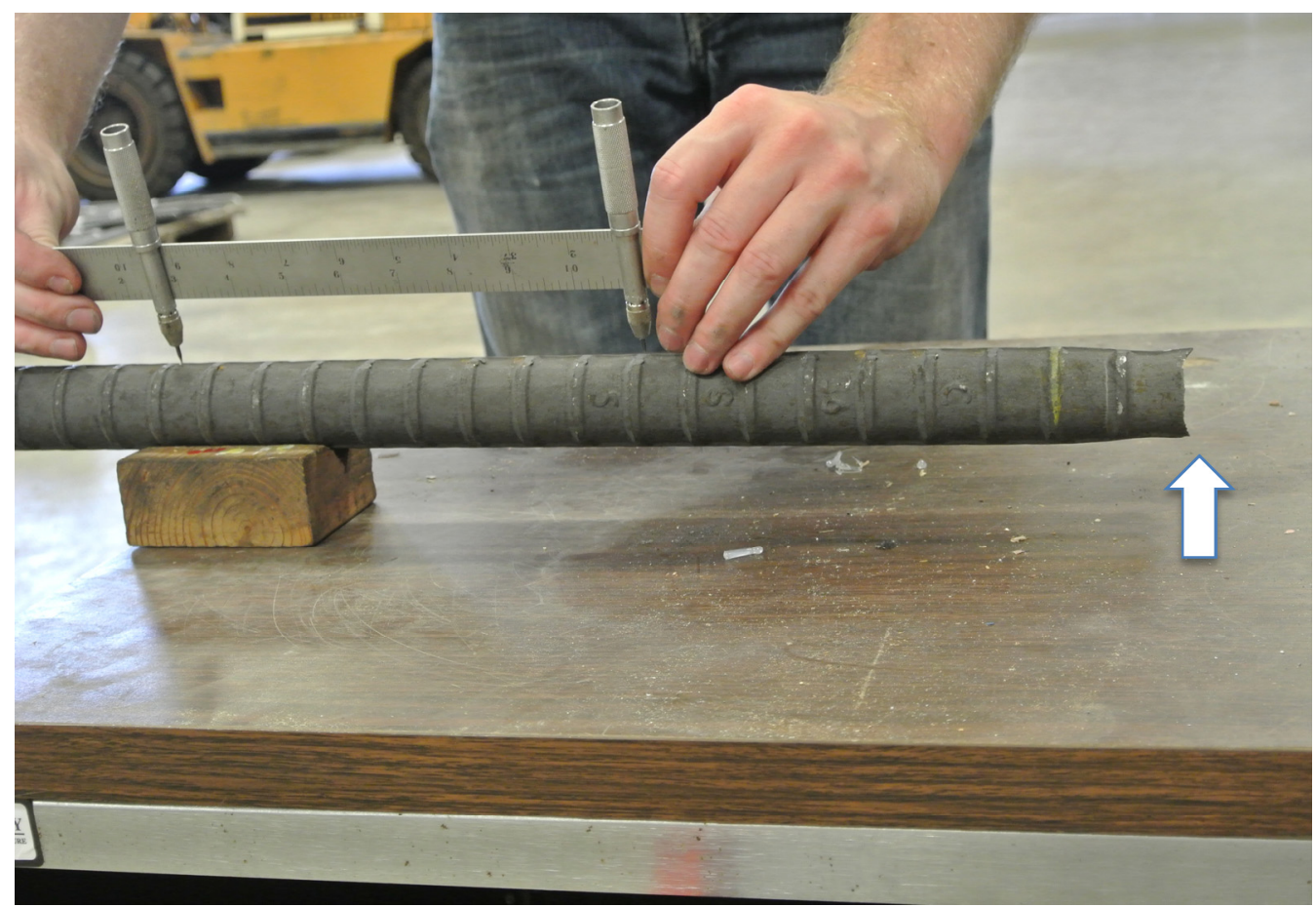

Figure 2-3 Photo of uniform elongation being measured. Arrow points to fracture location (photo courtesy of Wiss, Janney, Elstner Associates, Inc., Copyright 2013).

The uniform elongation calculated using the Canadian Associations Standard CSA G30.18 (CSA, 2009) assumes linear unloading with a modulus equal to the initial modulus of steel, $E_{s}$, of 29,000 ksi. However, test data on Grade 60 reinforcement indicate the following: (1) the unloading modulus decreases with an increase in the tensile strain; (2) the unloading curve is linear only during the initial phase of unloading; and (3) the response becomes progressively nonlinear as the bars are fully unloaded (Dodd and Restrepo-Posada, 1995). A linearization of the unloading response could result in an unloading modulus around two-thirds of the initial loading modulus. For high-strength reinforcement, the recovered strain could be as high as 1\%. The Australian/New Zealand Standard 4671 (AS/NZS, 2001) requires reporting the uniform elongation.

Although ASTM A370 and ASTM reinforcement specifications do not require reporting uniform elongation, it is a useful property for seismic design because it is more closely related to the maximum elongation (the useable elongation) that should be relied upon in a location of yielding, i.e., a plastic hinge region. Useable elongation should be taken as $75 \%$ or less of the uniform elongation, because under cyclic loading conditions, steel bars may achieve the equivalent damage state 
associated with uniform elongation at a smaller elongation. Reinforcement typically has a characteristic ratio of uniform elongation to fracture elongation, which varies by reinforcement type.

\subsubsection{Ductility}

The bend and bend-rebend tests are two ways of evaluating ductility of reinforcement. ASTM reinforcement specifications include a bend test in which bars are bent around a pin or mandrel of a specified diameter and to a specified degree of bending. The bend diameter varies with the bar diameter. The test specimen passes if no cracks appear on the outside of the bent portion of the bar.

The Australian/New Zealand Standard 4671 requires a bend-rebend test for smaller bar diameters and a bend test for larger bar diameters. For the bend-rebend test, the bar specimen must be bent around a mandrel of a specified diameter to an angle of $90^{\circ}$ at the mid-length of the specimen. Two additional $45^{\circ}$ bends are made so that the specimen is straight for a portion, v-shaped near its middle length, and straight at the other end, as shown in Figure 2-4. The specimen is then aged in oil for an hour at $100^{\circ} \mathrm{C}\left(212^{\circ} \mathrm{F}\right)$, cooled, and rebent in the reverse direction by applying a tension force to the ends of the specimen. The aging and cooling steps are necessary to simulate the detrimental effects of strain aging. When bars are bent, nitrogen may be released from the steel, which can lead to embrittlement (Erasmus and Pussegoda, 1978). Upon rebending, the embrittled steel is more likely to crack. No cracks should be evident in the rebent bar to pass the test.

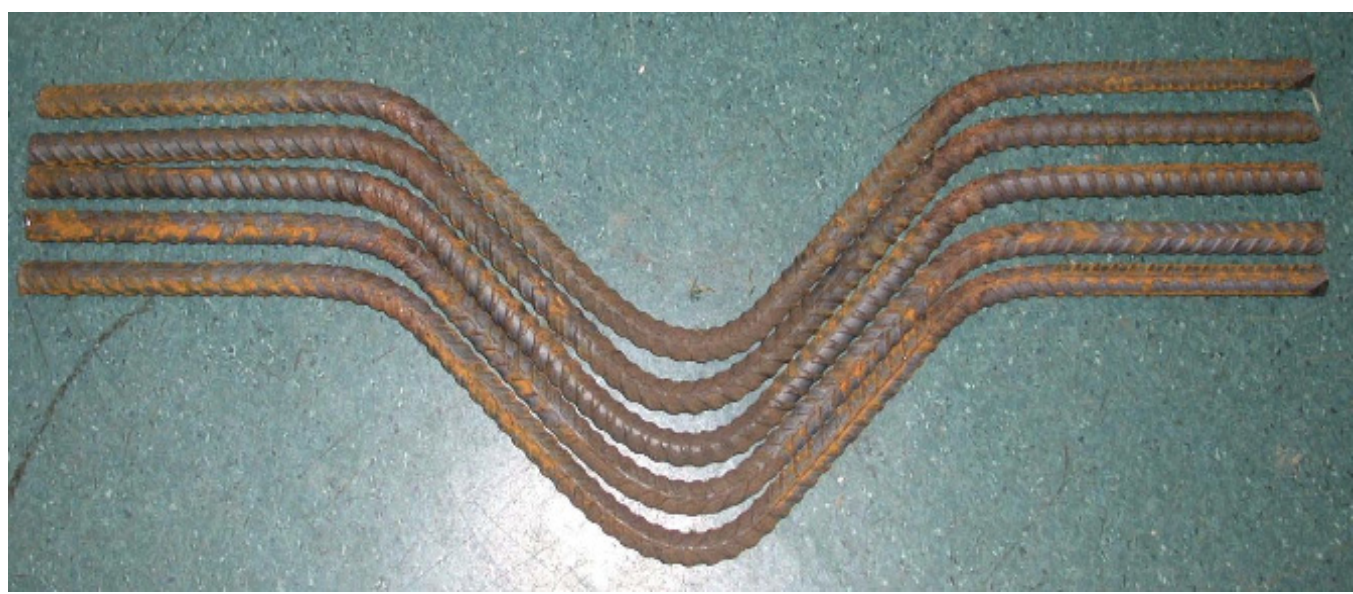

Figure 2-4 Example bend-rebend test specimens from New Zealand (Hopkins and Poole (2005), image courtesy of the New Zealand Department of Building and Housing, now part of the Ministry of Business Innovation and Employment). 


\subsection{Comparison of Material Properties}

\subsubsection{ASTM A706 Grade 60 and Grade 80 Reinforcement}

ASTM A706 Grade 80 reinforcement likely will be the first high-strength reinforcement that will be widely used within the United States in designs to resist earthquake effects. The properties of this reinforcement are similar to, but not exactly the same as ASTM A706 Grade 60 reinforcement.

\subsubsection{Properties}

Tensile strength properties of ASTM A706 Grade 60 and Grade 80 reinforcement are provided in Table 2-1. Elongation is an important measure of the suitability of reinforcement for use in members resisting earthquake effects. Although total elongation requirements for Grade 80 reinforcement are not the same as those for all sizes of Grade 60 reinforcement, the total elongation requirement is the same for bar sizes $7,8,9,10,11,14$, and 18 . These sizes are most likely to be specified for primary longitudinal reinforcement; therefore they are most likely to yield in members resisting earthquake effects. Table 2-1 notes the requirement that the tensile strength of the reinforcement be at least 1.25 times the actual yield strength. This requirement, which is the same for Grade 60 and Grade 80 reinforcement, is considered important to obtain adequate spread of plasticity in regions where yielding is expected, i.e., plastic hinges.

Table 2-1 Comparison of Tensile Properties of ASTM A706 Grades 60 and 80 (ASTM, 2009b)

\begin{tabular}{lccc}
\hline \multicolumn{1}{c}{ Property } & Grade 60 & Grade 80 \\
\cline { 1 - 1 } Tensile strength, minimum & $80^{*} \mathrm{ksi}$ & $100^{*} \mathrm{ksi}$ \\
Yield strength, minimum & $60 \mathrm{ksi}$ & $80 \mathrm{ksi}$ \\
Yield strength, maximum & $78 \mathrm{ksi}$ & $98 \mathrm{ksi}$ \\
Elongation in 8 in, minimum & & \\
$\quad$ Bar size: & & \\
$3,4,5,6$ & $14 \%$ & $12 \%$ \\
$7,8,9,10,11$ & $12 \%$ & $12 \%$ \\
14,18 & $10 \%$ & $10 \%$ \\
\hline
\end{tabular}

* Tensile strength shall not be less than 1.25 times the actual yield strength.

Example stress-strain curves for ASTM A706 Grade 60 and Grade 80 reinforcement are shown in Figures 2-5 and 2-6.

An indication of ductility is the ability to bend reinforcement about a set diameter. Table 2-2 includes the ASTM A706 bend test requirements for Grade 60 and Grade 80 reinforcement given as a multiple of the bar diameter, $d_{b}$, as well as the required 


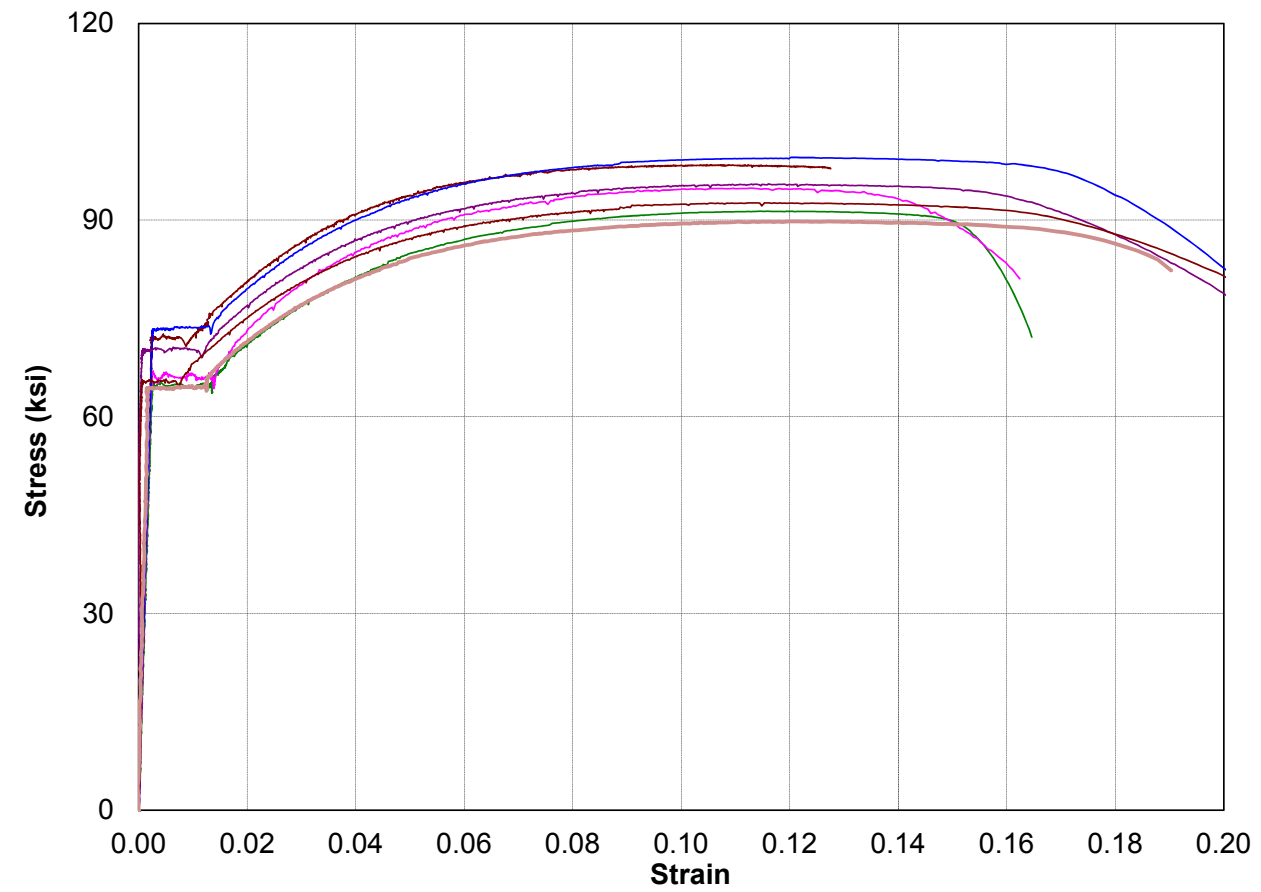

Figure 2-5 Example stress-strain curves for ASTM A706 Grade 60 reinforcement (courtesy of Wiss Janney Elstner Associates, Inc., Copyright 2012).

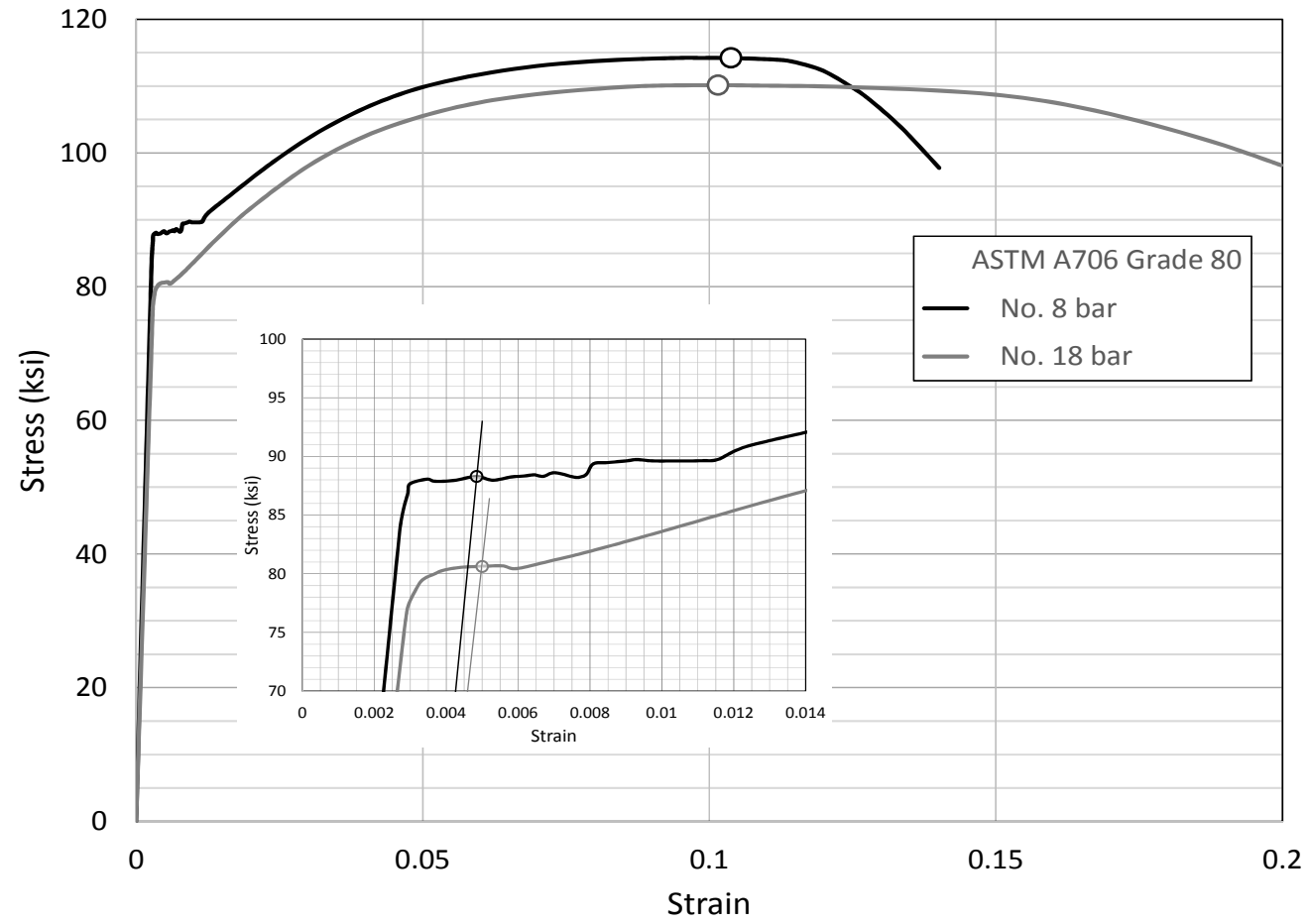

Figure 2-6 Example stress-strain curves for ASTM A706 Grade 80; dots on the curves represent the tensile strength and uniform strain. The inset image shows a larger scale view of where the $2 \%$ offset lines cross the stress-strain curves (data courtesy of Nucor Steel Seattle, Inc.). 
Table 2-2 Comparison of A706 Grade 60 and Grade 80 Bend Test Requirements to ACI 318-11 Stirrup/Hoop and Standard Hook Detailing Requirements (ASTM, 2009b; ACI, 2011)

\begin{tabular}{|c|c|c|c|c|}
\hline & $\begin{array}{c}\text { A706 Grade } 60 \\
180^{\circ} \text { Bend } \\
\text { Test }\end{array}$ & $\begin{array}{c}\text { A706 Grade } 80 \\
180^{\circ} \text { Bend } \\
\text { Test }\end{array}$ & $\begin{array}{c}\text { ACI 318-11 } \\
\text { Stirrup/Hoop } \\
\text { Bend }\end{array}$ & $\begin{array}{c}\text { ACI 318-11 } \\
\text { Standard } \\
\text { Hook Bend }\end{array}$ \\
\hline Bar Size & \multicolumn{4}{|c|}{ Inside Diameter of Bend } \\
\hline No. 3 through No. 5 & $3 d_{b}$ & $3.5 d_{b}$ & $4 d_{b}$ & $6 d_{b}$ \\
\hline No. 6 through No. 8 & $4 d_{b}$ & $5 d_{b}$ & $6 d_{b}$ & $6 d_{b}$ \\
\hline No. 9 through No. 11 & $6 d_{b}$ & $7 d_{b}$ & $8 d_{b}$ & $8 d_{b}$ \\
\hline No. 14 and No. 18 & $8 d_{b}$ & $9 d_{b}$ & $10 d_{b}$ & $10 d_{b}$ \\
\hline
\end{tabular}

bend diameter for stirrups and hoops and for standard hooks specified by ACI 318-11. This table shows that the ASTM A706 bend test requirements are less stringent for Grade 80 reinforcement than for Grade 60, even though both grades of bars are bent to the same diameter for stirrups and hoops and for standard hooks. It is important to understand that the specified bend diameters of ASTM A706 serve the purpose of quality control in manufacturing, whereas the bend diameters specified by ACI 318-11 are for purposes of reinforcement detailing. The ACI 318-11 diameters are purposely established at larger values than those of ASTM A706 in an attempt to minimize fracturing of reinforcement during bending for fabrication.

\subsubsection{Dimensions and Deformations}

ASTM A706 Grade 80 reinforcing bars are available in sizes No. 3 to 18 , the same sizes as Grade 60 reinforcement. The deformation requirements are the same for Grade 80 reinforcement as for Grade 60 reinforcement.

\subsubsection{USD685 and SD685 Reinforcement}

USD685 reinforcement has been used in Japan since the mid-1990s. Similar reinforcement, SD685, is available in Taiwan for research purposes and may be available in other Asian countries. Both types of reinforcement have a yield strength of $100 \mathrm{ksi}$. These bars are produced by micro-alloying and adjusting rolling conditions (Nishiyama, 2009).

\subsubsection{Tensile Strength Properties}

Tensile strength properties of USD685 from Japan and SD685 from Taiwan are provided in Table 2-3. An example of a stress-strain curve of USD685A reinforcement, which is also referred to as SD685 in Japan, is shown in Figure 2-7. 
There are two types of USD685 reinforcement in Japan: USD685A and USD685B. Of these, USD685B requires lower maximum yield strength and a lower ratio of yield strength to tensile strength than that required for USD685A. USD685B

Table 2-3 Tensile Properties of USD685 from Japan and SD685 from Taiwan (Aoyama, 2001; Lee, 2012)

\begin{tabular}{|c|c|c|c|}
\hline & USD685A & USD685B & SD685 \\
\hline Yield strength & $\begin{array}{c}100-114 \mathrm{ksi} \\
(685-785 \mathrm{MPa})\end{array}$ & $\begin{array}{c}100-110 \mathrm{ksi} \\
(685-755 \mathrm{MPa})\end{array}$ & $\begin{array}{c}100-114 \mathrm{ksi} \\
(685-785 \mathrm{MPa})\end{array}$ \\
\hline Tensile strength & Not specified & Not specified & $\begin{array}{c}\geq 125 \mathrm{ksi} \\
(\geq 860 \mathrm{MPa})\end{array}$ \\
\hline Strain at end of yield plateau & $\geq 1.4 \%$ & $\geq 1.4 \%$ & $\geq 1.4 \%$ \\
\hline Total elongation & $\geq 10 \%$ & $\geq 10 \%$ & $\geq 10 \%$ \\
\hline $\begin{array}{l}\text { Yield-strength-to-tensile strength } \\
\text { ratio }\left(f_{y} / f_{t u}\right)\end{array}$ & $\leq 85 \%$ & $\leq 80 \%{ }^{*}$ & $\leq 80 \%{ }^{*}$ \\
\hline Inner radius for $90^{\circ}$ bending & $2 d_{b}$ & $2 d_{b}$ & --- \\
\hline
\end{tabular}

* This is equivalent to the requirement that tensile strength be 1.25 times the actual yield strength $\left(f_{t u} / f_{y} \geq 1.25\right)$ in ASTM A706 reinforcement.

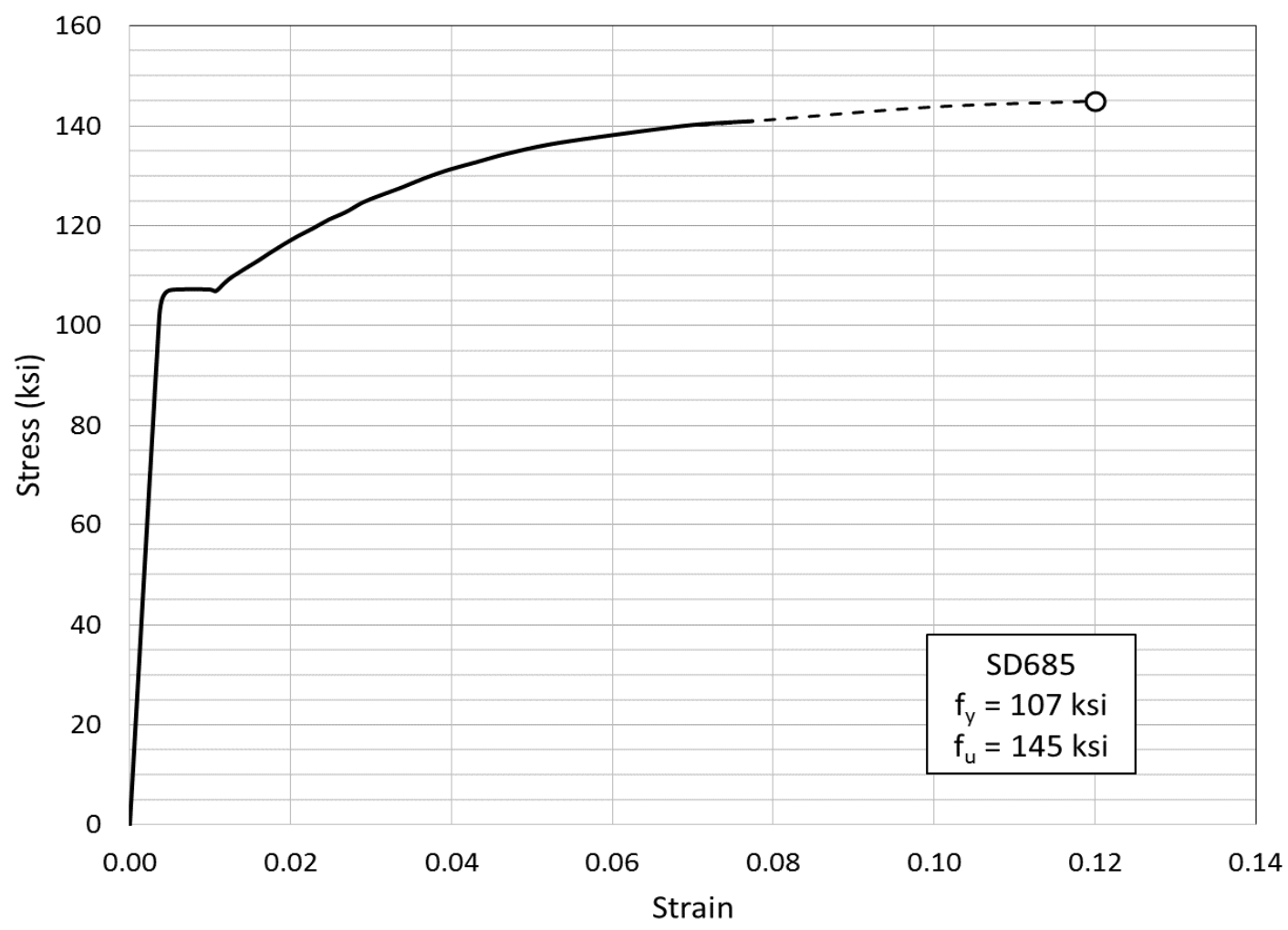

Figure 2-7 Stress-strain curve for USD685A reinforcement (note that USD685A is sometimes referred to as SD685 in Japan) (Ousalem et al., 2009). 
requires the ratio of yield strength to tensile strength to be 0.80 , which is equivalent to the ASTM A706 requirement that the tensile strength of the reinforcement be at least 1.25 times the actual yield strength. Thus, for a yield strength of $100 \mathrm{ksi}$, achieving this ratio requires treatment after rolling or other changes to the production process that increase the cost. Because this treatment is not necessary to produce USD685A, its cost is lower, and this reinforcement is more commonly used in Japan.

\subsubsection{Dimensions and Deformations}

USD685 and SD685 bars are produced in sizes D10 to D51 (deformed 10 to $51 \mathrm{~mm}$ diameter bars) and the deformations are similar to those required in the Japanese Standard JIS G3112, Steel Bars for Concrete Reinforcement (JIS, 2010). The deformations for these bars are comparable to those of ASTM A615 and A706 bars.

\subsubsection{AS/NZS 500E Reinforcement}

AS/NZS Grade 500E is used as reinforcement for members resisting earthquake effects in New Zealand. The $\mathrm{E}$ at the end of the grade designation indicates that it is intended for use in members that resist earthquake effects. Researchers have used Grade 500E reinforcement in members and joints tested cyclically, and practitioners have specified it for buildings that have already been constructed. Requirements for this reinforcement are included in Australian/New Zealand Standard 4671 (AS/NZS, 2001) (incorporating Amendment No. 1). It is produced by either micro-alloying or quenching and tempering.

\subsubsection{Tensile Properties}

Tensile strength properties of Grade 500E reinforcement are provided in Table 2-4. There are both upper and lower limits on the yield strength, $R_{e}$, and the ratio of tensile strength to yield strength $\left(R_{m} / R_{e}\right)$. Elongation is reported as uniform elongation, $A_{g t}$, measured in accordance with ISO 15630-1 or ISO 15630-2 (ISO,

Table 2-4 Tensile Properties of AS/NZS 500E Reinforcement (AS/NZS, 2001)

\begin{tabular}{|c|c|}
\hline Property & Requirement \\
\hline Yield strength, $R_{e}^{1,2}$ & $R_{e k, L}=72.5 \mathrm{ksi}(500 \mathrm{MPa}) \leq R_{e} \leq R_{e k, U}=87 \mathrm{ksi}(600 \mathrm{MPa})$ \\
\hline Tensile strength-to-yield strength ratio, $R_{m} / R_{e}$ & $1.15 \leq R_{m} / R_{e} \leq 1.40$ \\
\hline Uniform elongation, $A_{g t}$ & $\geq 10 \%$ \\
\hline Bending and rebending, $d_{b} \leq 16 \mathrm{~mm}$ (0.63 in.) & Mandrel diameter $=4 d_{b} ;$ Bend angle $=90^{\circ}$ \\
\hline Bending and rebending, $d_{b} \geq 20 \mathrm{~mm}$ (0.79 in.) & Mandrel diameter $=4 d_{b} ;$ Bend angle $=180^{\circ}$ \\
\hline \multicolumn{2}{|c|}{$\begin{array}{l}\text { The AS/NZ Standard uses the } 5 \% \text { fractile concept, in which a small percentage of tests are allowed to } \\
\text { be below the minimum strength. }\end{array}$} \\
\hline $\begin{array}{l}\text { If an obvious yield point is not present, } R_{e} \text { corr } \\
\text { or the stress for a total elongation of } 0.5 \% \text {, whi }\end{array}$ & $\begin{array}{l}\text { nds to yield strength using the } 0.2 \% \text { Offset Method } \\
\text { er is smaller. }\end{array}$ \\
\hline
\end{tabular}


2010a; ISO, 2010b), which is the elongation taken from extensometer readings corresponding to the maximum force applied to the bar during tensioning.

Alternatively, plastic elongation is measured after failure between gage marks, which are set before testing, that are spaced at intervals up to $25 \mathrm{~mm}$. If necking occurs between two gage marks, that span is not used for measuring plastic elongation. Representative stress-strain curves are provided in Figure 2-8.

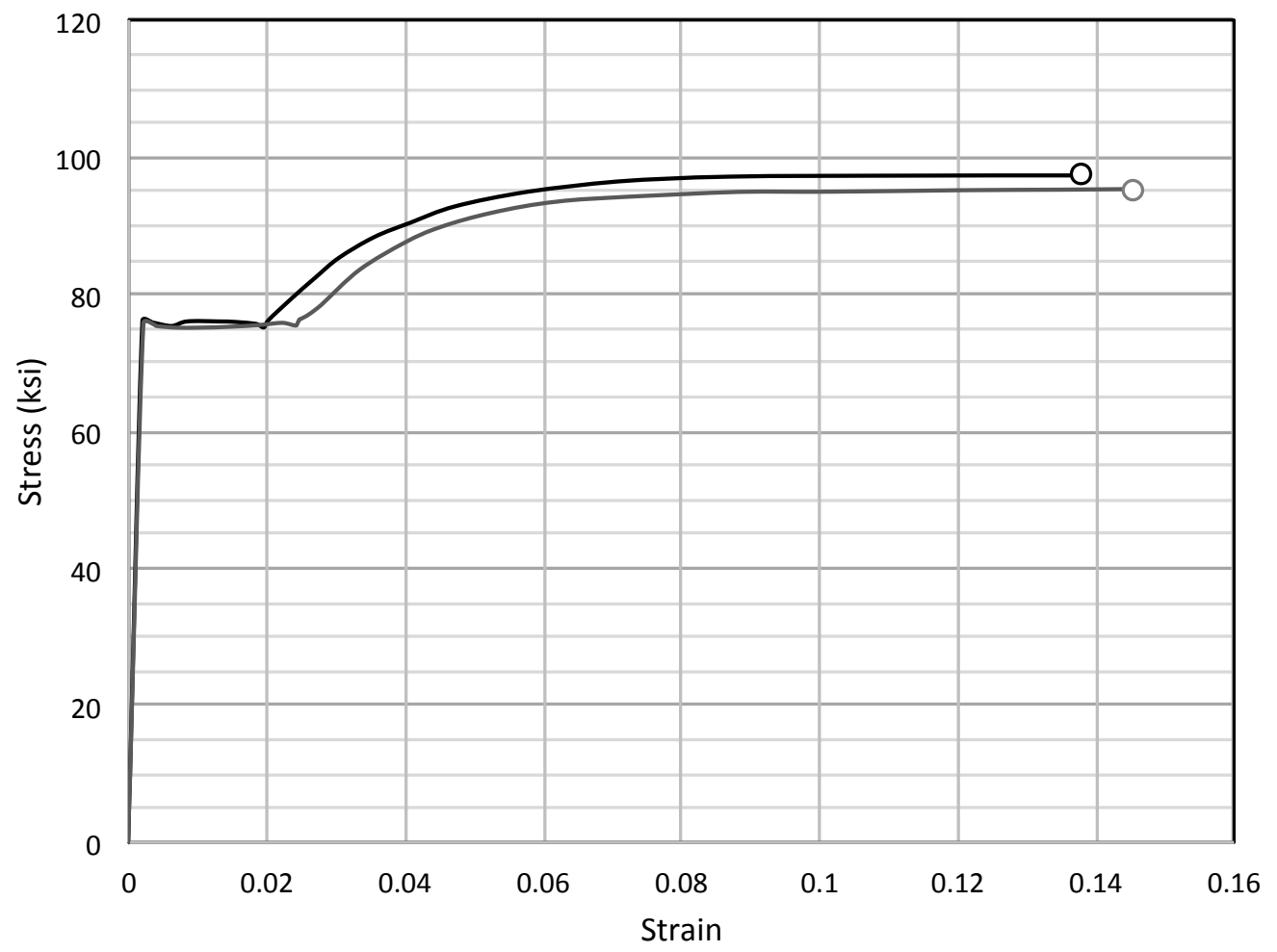

Figure 2-8 Representative stress-strain curves for AS/NZS Grade 500E (72.5 ksi) reinforcement (adapted from Lin et al., 2000).

\subsubsection{ASTM A1035 Reinforcement}

ASTM A1035 reinforcement has low carbon content and significant chromium content, resulting in high-strength bars (ACI, 2010a). It has been used primarily in bridge decks exposed to de-icing salts (Seliem et al., 2008; Shahrooz et al., 2011), and is less likely to be used for members resisting earthquake effects. However, this type of reinforcement has been used in test specimens that have been loaded cyclically and on shake tables. It is produced in Grade 100 and Grade 120.

\subsubsection{Tensile Properties}

Required tensile properties of A1035 Grade 100 and Grade 120 reinforcement are provided in Table 2-5. Bend test requirements are the same as those for ASTM A706 Grade 80 . 
Table 2-5 Tensile Properties of ASTM A1035 Reinforcement (ASTM, 2011)

\begin{tabular}{lccc}
\hline & Grade 100 & & Grade 120 \\
\cline { 2 - 2 } $\begin{array}{l}\text { Yield strength (0.2\% Offset Method), } \\
\text { minimum }\end{array}$ & $100 \mathrm{ksi}$ & $120 \mathrm{ksi}$ \\
$\begin{array}{l}\text { Tensile strength, minimum } \\
\text { Stress corresponding to an extension } \\
\text { under load of 0.0035 in./in., minimum }\end{array}$ & $150 \mathrm{ksi}$ & $150 \mathrm{ksi}$ \\
$\begin{array}{l}\text { Total elongation in } 8 \text { in., minimum } \\
\text { Bar size: }\end{array}$ & $80 \mathrm{ksi}$ & $90 \mathrm{ksi}$ \\
3 through 11 & & \\
14,18 & $6 \%$ & $7 \%$ \\
\hline
\end{tabular}

Examples of stress-strain curves are shown in Figure 2-9. The shape of the stressstrain curve does not include a yield plateau, and the elongation is less than that of ASTM A706 Grade 60 and Grade 80 reinforcement.

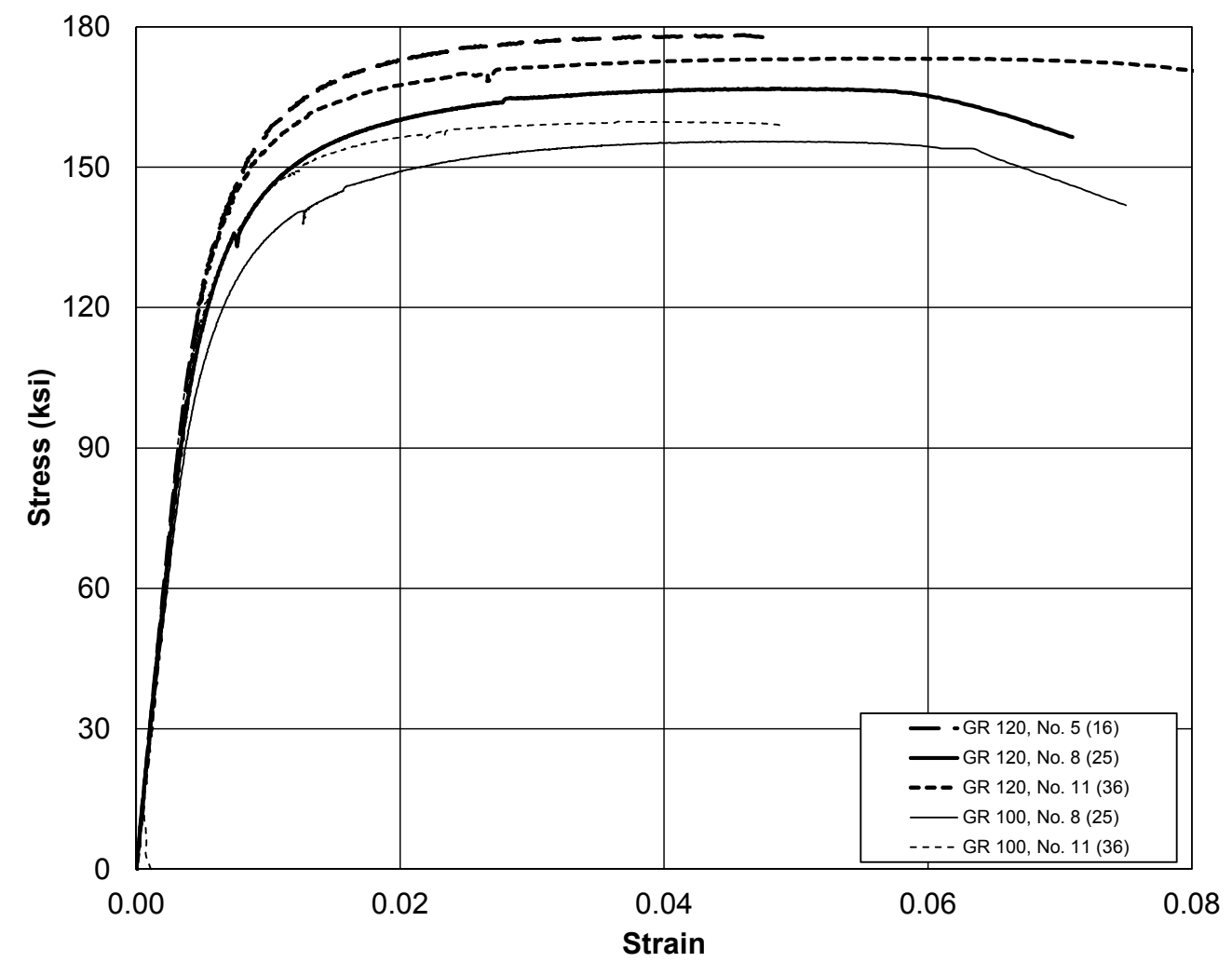

Figure 2-9 Stress-strain curve for ASTM A1035 Grade 100 and Grade 120 reinforcement (courtesy of Wiss Janney Elstner Associates, Inc., Copyright 2008). 


\subsubsection{Dimensions and Deformations}

ASTM A1035 Grade 100 and Grade 120 reinforcing bars are available in sizes No. 3 to 18 , the same as those for ASTM A706 Grade 60 reinforcement. The deformation requirements for ASTM A1035 reinforcement are the same as those for ASTM A706 Grade 60 reinforcement.

\subsubsection{SAS 670 Reinforcement}

SAS 670 is a high-strength reinforcing bar produced in Germany. Its higher strength is achieved by quenching and tempering the steel. It has been used in geotechnical applications, such as piles, soil nails, and anchors, and it has been tested for use as longitudinal reinforcement for columns (Bachmann et al., 2008). An International Code Council Evaluation Service (ICC-ES) report (ICC, 2009) has been issued for its use as column and wall longitudinal reinforcement in buildings of low seismic risk, i.e., seismic design categories A and B. Beams with SAS 670 have also been tested cyclically (Lepage et al., 2012).

\subsubsection{Tensile Properties}

The required yield strength of SAS 670 reinforcement is $97 \mathrm{ksi}$. Tensile properties are included in Table 2-6, and a representative stress strain-curve is shown in Figure 2-10. The minimum ratio of tensile strength to yield strength of 1.1 is significantly less than what is required for ASTM A706 reinforcement (a ratio of 1.25).

Table 2-6 Tensile Properties of SAS 670 Reinforcement (Falkner et al., 2008)

\begin{tabular}{|c|c|}
\hline Property & Requirement \\
\hline Characteristic yield strength ${ }^{1,2}, R_{e}$ & 97 ksi (670 MPa) \\
\hline Characteristic tensile strength ${ }^{1}, R_{m}$ & 116 ksi (800 MPa) \\
\hline Tensile-to-yield ratio, $R_{e} / R_{m}$ & $\geq 1.10$ \\
\hline $\begin{array}{l}\text { Total elongation under maximum load (uniform } \\
\text { elongation), } A_{g t}\end{array}$ & $\geq 5.0 \%$ \\
\hline Bendability & No. 6 to No. 14 (bar diameters $\leq 43 \mathrm{~mm}$ ) \\
\hline
\end{tabular}

\subsubsection{Dimensions and Deformations}

SAS 670 bars are available in diameters ranging from $18 \mathrm{~mm}$ ( 0.71 inches) to $75 \mathrm{~mm}$ (2.95 inches). Deformations are in the form of right-hand threads. 


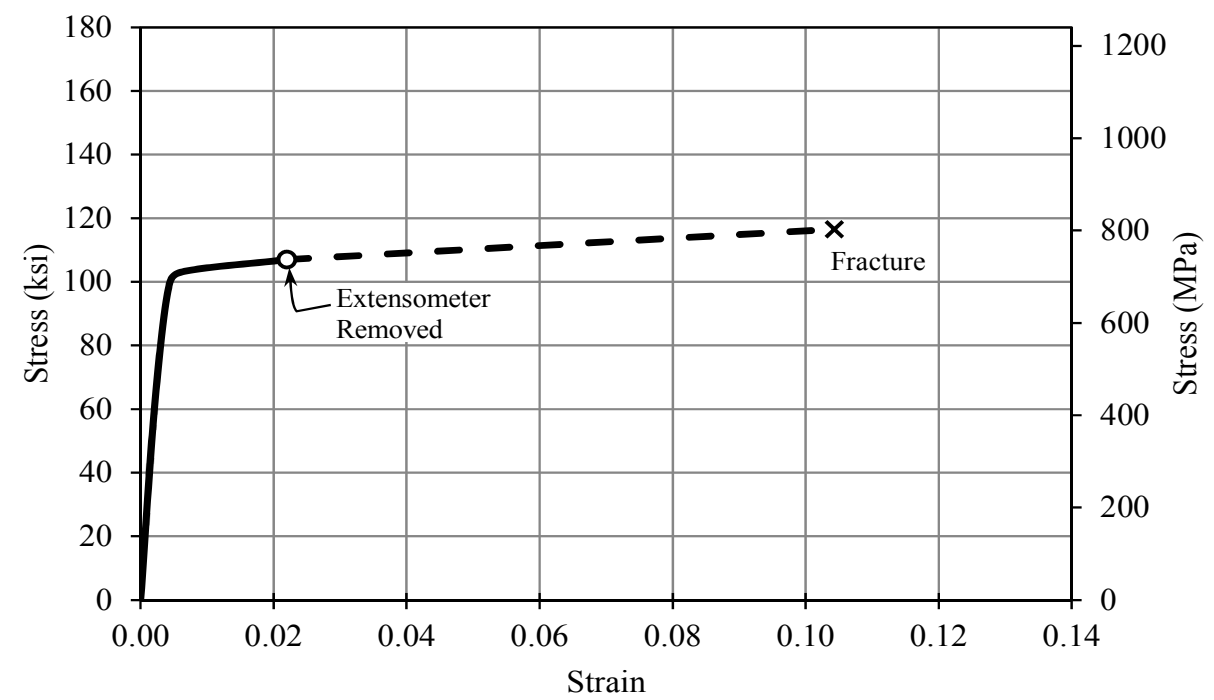

Figure 2-10 Representative stress-strain curve for SAS 670 reinforcement.

\subsection{Comparison of ASTM A615 High-Strength Reinforcement to ASTM A706 High-Strength Reinforcement}

ASTM A615 reinforcement is the most commonly used reinforcement in the United States. Although it is not specifically intended for use in members resisting earthquake effects, ACI 318-11 allows its use in special moment frames and boundary elements of special structural walls if the following strength requirements are met (these are the same strength requirements for ASTM A706 reinforcement):

- the actual yield strength based on mill tests does not exceed $f_{y}$ by more than $18,000 \mathrm{psi}$, and

- the ratio of the actual tensile strength to the actual yield strength is not less than 1.25 .

As ACI Committee 318 is currently considering approving the use of ASTM A706 Grade 80 reinforcement for special moment frames and special structural walls, it is likely that allowing the use of ASTM A615 Grade 75 and Grade 80 reinforcement will also be considered if the two requirements above are met. Therefore, this section compares the requirements and characteristics of ASTM A615 and A706 reinforcement.

Table 2-7 presents the tensile property requirements of ASTM A706 and A615 Grade 60 reinforcement. The additional ACI 318-11 requirements applicable to ASTM A615 Grade 60 reinforcement for use in seismic applications are included by footnotes. Although the minimum strength requirements are the same when the additional ACI 318-11 requirements are applied, the minimum total elongation requirements are much different. For No. 7 and 8 bars, ASTM A615 reinforcement has a required minimum total elongation of $8 \%$; for No. 9,10 , and 11 bars, it has a 
Table 2-7 Tensile Property Requirements of ASTM A706 and A615 Grade 60 Reinforcement (ASTM, 2009a; ASTM, 2009b)

\begin{tabular}{lccc}
\hline \multicolumn{1}{c}{ Property } & A706 Grade 60 & A615 Grade 60 \\
\cline { 1 - 1 } Tensile strength, minimum & $80^{1} \mathrm{ksi}$ & $90^{2} \mathrm{ksi}$ \\
Yield strength, minimum & $60 \mathrm{ksi}$ & $60 \mathrm{ksi}$ \\
Yield strength, maximum & $78 \mathrm{ksi}$ & N.A. ${ }^{3} \mathrm{ksi}$ \\
Elongation in 8 in, minimum & & \\
$\quad$ Bar size: & & \\
$3,4,5,6$ & $14 \%$ & $9 \%$ \\
7,8, & $12 \%$ & $8 \%$ \\
$9,10,11$ & $12 \%$ & $7 \%$ \\
14,18 & $10 \%$ & $7 \%$ \\
\hline
\end{tabular}

${ }^{1}$ Tensile strength shall not be less than 1.25 times the actual yield strength.

${ }^{2} \mathrm{ACl} 318-11$ requires that tensile strength shall not be less than 1.25 times the actual yield strength if used in seismic applications.

${ }^{3} \mathrm{ACl}$ 318-11 requires that the maximum yield strength be $78 \mathrm{ksi}$ if used in seismic applications.

required elongation of only 7\%. ASTM A706 reinforcement in contrast, has a required minimum total elongation of $12 \%$ for the same bar sizes.

Table 2-8 presents the tensile property requirements of ASTM A706 Grade 80 and A615 Grade 80 and Grade 75 reinforcement. The required minimum total elongation for A615 Grade 80 and Grade 75 No. 9, 10, and 11 bars is only half of what is required for A706 Grade 80 (6\% versus 12\%).

Table 2-8 Tensile Property Requirements of ASTM A706 and A615 Grade 75 and Grade 80 Reinforcement (ASTM, 2009a; ASTM, 2009b)

\begin{tabular}{|c|c|c|c|}
\hline Property & A706 Grade 80 & A615 Grade 80 & A615 Grade 75 \\
\hline Tensile strength, minimum & $100^{*} \mathrm{ksi}$ & $105^{*} \mathrm{ksi}$ & 100 ksi \\
\hline Yield strength, minimum & 80 ksi & $80 \mathrm{ksi}$ & $75 \mathrm{ksi}$ \\
\hline Yield strength, maximum & 98 ksi & N.A. & N.A. \\
\hline \multicolumn{4}{|l|}{ Elongation in 8 in, minimum } \\
\hline $3,4,5,6$ & $12 \%$ & $7 \%$ & $7 \%$ \\
\hline 7,8 & $12 \%$ & $7 \%$ & $7 \%$ \\
\hline $9,10,11$ & $12 \%$ & $6 \%$ & $6 \%$ \\
\hline 14,18 & $10 \%$ & $6 \%$ & $6 \%$ \\
\hline
\end{tabular}

"Tensile strength shall not be less than 1.25 times the actual yield strength.

In addition to differences in the required tensile properties and, notably, the total elongation, actual differences are expected in the bars that will be produced. Table 2-9 provides mean, standard deviation, and coefficient of variation of total elongation for ASTM A706 Grade 60, ASTM A615 Grade 60, and ASTM A615 Grade 75 reinforcement, as reported by Bournonville et al. (2004), based on reinforcing bars produced in the 1990s. In addition, data for ASTM A706 Grade 80 and ASTM A615 
Table 2-9 Total Elongation Data of ASTM A706 Grade 60 and Grade 80, and ASTM A615 Grade 60, Grade 75, and Grade 80 Reinforcement (Bournonville et al., 2004; CRSI, 2013)

\begin{tabular}{|c|c|c|c|c|c|}
\hline \multirow{2}{*}{$\begin{array}{l}\text { Reinforcement Type } \\
\text { Total Elongation Data }\end{array}$} & \multicolumn{5}{|c|}{ Bar Size } \\
\hline & No. 7 & No. 8 & No. 9 & No. 10 & No. 11 \\
\hline \multicolumn{6}{|l|}{ A706 Grade 60} \\
\hline Mean total elongation & $15.2 \%$ & $15.6 \%$ & $15.8 \%$ & $15.3 \%$ & $14.9 \%$ \\
\hline Standard deviation & $2.3 \%$ & $2.0 \%$ & $2.0 \%$ & $2.1 \%$ & $1.9 \%$ \\
\hline Coefficient of variation & 0.1519 & 0.1310 & 0.1273 & 0.1339 & 0.1250 \\
\hline \multicolumn{6}{|l|}{ A706 Grade 80} \\
\hline Mean total elongation & -- & $14.0 \%$ & -- & -- & $14.4 \%$ \\
\hline Standard deviation & -- & $1.6 \%$ & -- & -- & $1.1 \%$ \\
\hline Coefficient of variation & -- & 0.115 & -- & -- & 0.074 \\
\hline \multicolumn{6}{|l|}{ A615 Grade 60} \\
\hline Mean total elongation & $13.1 \%$ & $13.2 \%$ & $12.6 \%$ & $12.5 \%$ & $12.3 \%$ \\
\hline Standard deviation & $2.4 \%$ & $2.4 \%$ & $2.3 \%$ & $2.5 \%$ & $2.8 \%$ \\
\hline Coefficient of variation & 0.1826 & 0.1787 & 0.1825 & 0.2035 & 0.2292 \\
\hline \multicolumn{6}{|l|}{ A615 Grade 75} \\
\hline Mean total elongation & $12.8 \%$ & $12.2 \%$ & $12.0 \%$ & $11.0 \%$ & $10.4 \%$ \\
\hline Standard deviation & $1.8 \%$ & $1.7 \%$ & $2.4 \%$ & $1.4 \%$ & $0.9 \%$ \\
\hline Coefficient of variation & 0.1428 & 0.1397 & 0.2018 & 0.1255 & 0.0826 \\
\hline \multicolumn{6}{|l|}{ A615 Grade 80} \\
\hline Mean total elongation & -- & $11.7 \%$ & $12.8 \%$ & $13.3 \%$ & $11.2 \%$ \\
\hline Standard deviation & -- & $1.9 \%$ & $1.7 \%$ & $2.4 \%$ & $1.2 \%$ \\
\hline Coefficient of variation & -- & 0.166 & 0.131 & 0.182 & 0.105 \\
\hline
\end{tabular}

Grade 80 reinforcement were obtained from an unpublished database of certified mill test report data, maintained by the Concrete Reinforcing Steel Institute, for the production years of 2011 and 2012 (CRSI, 2013). The table only presents data for No. 7 to 11 bars because these are sizes commonly used for beams of special moment frames and for vertical wall reinforcement of special structural walls. The data show that, on average, ASTM A706 Grade 60 reinforcement has higher total elongation and less variation in total elongation than ASTM A615 Grade 60 reinforcement. The same is true for ASTM A706 Grade 80 reinforcement compared to ASTM A615 Grade 80 reinforcement. ASTM A615 Grade 75 reinforcement has lower total elongation than ASTM A615 Grade 60 and ASTM A706 Grade 60 reinforcement, with the difference being largest for the No. 10 and 11 bars. The typically smaller standard deviation and coefficient of variation of ASTM A615 Grade 75 and Grade 
80 reinforcement relative to ASTM A615 Grade 60 reinforcement is likely the result of the smaller sample size and fewer mills providing data for the ASTM A615 Grade 75 and Grade 80 bars. The sample size for ASTM A706 Grade 80 is also smaller than that used for ASTM A615 Grade 60.

\subsection{Effect of Differences in Stress-Strain Relationships and Tensile Characteristics on Member Behavior}

High-strength reinforcement can be produced with various tensile characteristics and stress-strain relationships, which affect how members constructed with the reinforcement respond to earthquakes. Studying the hysteretic behavior of cyclically loaded members provides a means of judging the benefits and detriments of tensile characteristics and the shape of stress-strain curves. Ideally, members will maintain their strength up to the level of nonlinear behavior expected from an earthquake equivalent to the design level earthquake. The loss of strength of members should ideally be less than $20 \%$ for the level of nonlinear behavior expected from an earthquake equivalent to the maximum considered earthquake, which would typically produce $50 \%$ stronger ground shaking than the design level earthquake.

The shape of a stress-strain curve is an indication of the stress-strain relationship. A change in the shape of this curve can indicate an effect on the spread of plasticity within a plastic hinge region of a member. Increased spread of ductility increases the length of the plastic hinge and reduces the maximum strains for the same plastic rotation of a member. The reinforcement stress-strain curve also affects whether sectional strength is maintained or degrades over the range of member end rotations desired for earthquake resistance. The presence of a yield plateau, the ratio of tensile strength to yield strength, and the total elongation at fracture, are considered important properties for promoting the spread of plasticity and maintaining section strength.

ASTM 706 Grade 60 reinforcement specified for flexural reinforcement of special moment frame beams, columns, and special structural walls in the United States generally has a yield plateau, a ratio of tensile strength to yield strength of at least 1.25 , and develops a total elongation of at least $12 \%$.

The presence of a yield plateau, however, is not a requirement of the ASTM A706 specification. High-strength reinforcement can be produced so that its stress-strain curve exhibits a yield plateau; examples include USD685 reinforcement produced in Japan and SD685 reinforcement produced in Taiwan. However, the typical shapes of stress-strain curves for most grades of high-strength reinforcement are rounded (such as the typical curves for ASTM A1035 Grade 100 and Grade 120 reinforcement), or they have a curve that can be described as bilinear, with a gradual increase in strength above a yield point (such as SAS 670 reinforcement). 
Reinforcement with a higher value of the ratio of tensile strength to yield strength (such as 1.25 for A706 reinforcement) is expected to spread plasticity in regions of yielding better than reinforcement with a smaller value of this ratio (such as 1.10 for SAS 670 reinforcement). The increased spread of plasticity results in longer plastic hinge lengths and, potentially, increased ductility. Another benefit of having a higher value for this ratio is maintaining or increasing the strength of a member after concrete cover spalling, which results in reduced section depth. For the hypothetical case of a perfectly elasto-plastic stress-strain curve for reinforcement, the loss of strength due to spalling is approximately equal to the reduction in depth divided by the original depth. Concrete cover is usually $11 / 2$ inches thick for beams and columns. The reduction is greater for shallower members than deeper members because the spalled cover is a larger portion of the total flexural depth prior to spalling. If the tensile strength to yield strength ratio is large enough, the flexural strength of the member will be maintained due to strain hardening after spalling.

Japan's New RC Project (Aoyama, 2001) explored the effect of the tensile strength to yield strength ratio in a series of beam tests. The tests compared the shapes of hysteresis loops for cyclically loaded beams constructed using reinforcement with various levels of this strength ratio. Performance was judged to be good if there was no loss of strength as rotations approached as much as $4 \%$ or $5 \%$. Performance was judged to be poor if the member lost substantial strength soon after yielding. Two of these tests are described in Chapter 3 of Aoyama (2001). Rather than using the term tensile strength to yield strength ratio, researchers in the New RC Project used the inverse of this ratio and refer to it as the yield ratio. Figure 2-11 shows the test specimen, and Figure 2-12 shows the difference in behavior between a beam with reinforcement with a yield ratio of 0.9 and a beam with a yield ratio of 0.75 .

Mechanical splices were included in the plastic hinge region of the beam with a yield

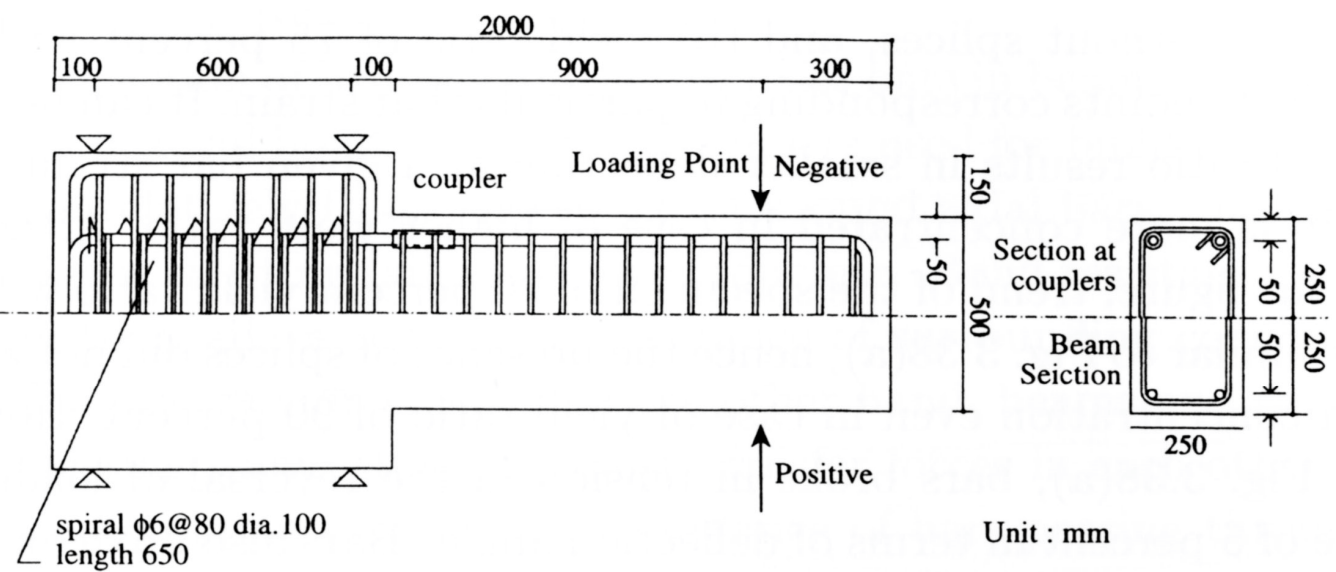

Figure 2-11 Test specimen of beams used to study the effect of the yield ratio. Yield ratio is the inverse of tensile strength to yield strength ratio. (Aoyama, 2001, Copyright 2001, Imperial College Press). 


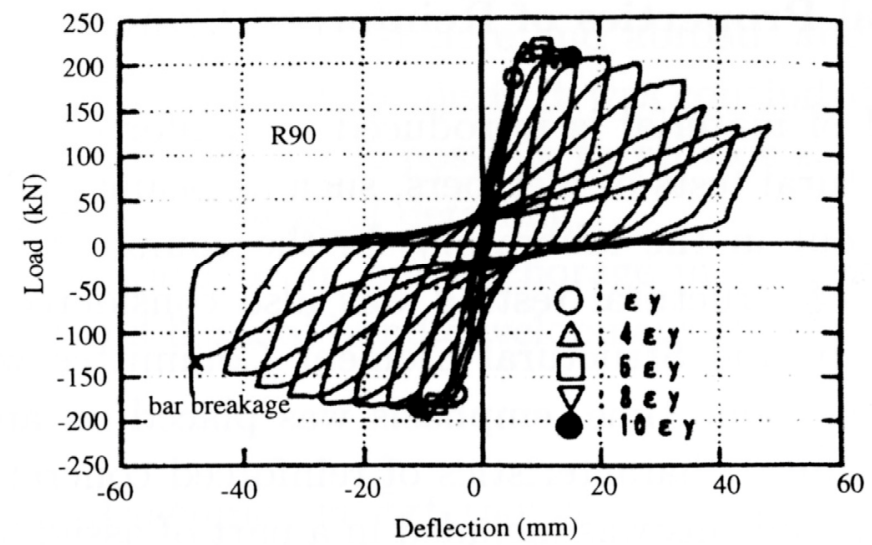

(a)

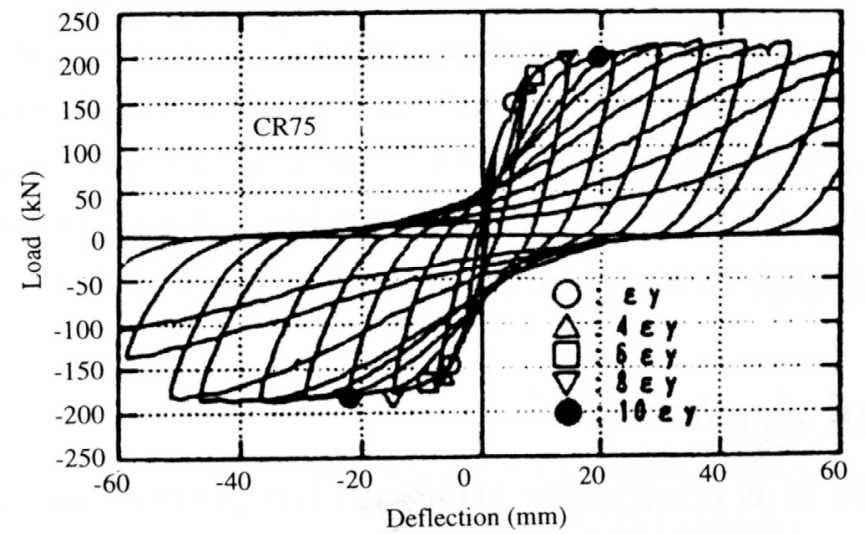

(b)

Figure 2-12 Load-deflection curves of beams with: (a) Yield ratio of 0.90 without splice; and (b) yield ratio of 0.75 with splice. Yield ratio is the inverse of the tensile strength to yield strength ratio (Aoyama, 2001, Copyright 2001, Imperial College Press).

ratio of 0.75 . The test with the yield ratio of 0.75 (tensile strength to yield strength ratio of 1.33) maintained its post yield strength to a deflection of $50 \mathrm{~mm}$, which is $5.6 \%$ rotation. In comparison, the specimen with a yield ratio of 0.90 (tensile strength to yield strength ratio of 1.11) started losing strength at a deflection of about $20 \mathrm{~mm}$ (approximately 0.8 inches), which is $2.2 \%$ rotation.

As demonstrated by the New RC Project tests, tensile characteristics and the shape of stress-strain curves affect the cyclic behavior of members. The effect of tensile characteristics and the shape of the stress-strain curve on a small number of test specimens are presented in Chapter 4, along with an analytical study presented in Appendix A. Chapter 8 discusses the need for additional research on this topic. 


\section{Chapter 3}

\section{Design and Detailing Considerations}

This chapter examines the effect of using high-strength reinforcement on design and detailing considerations, including reinforcement continuity and termination, bond stress, restraint of longitudinal bar buckling, tension-controlled strain limits, compatible strength of concrete for high-strength reinforcement, ductility, minimum reinforcing ratios, and shear strength of members reinforced with high-strength reinforcement.

\subsection{Reinforcement Continuity and Termination}

Design requirements for earthquake resistance include provisions for continuity of some reinforcing bars. Often, it is not practical to have a single bar that traverses the entire required length. Instead, bars are made continuous with lap splices, mechanical splices, or welds. Design requirements also require some bars to be terminated in a manner that allows for development of the bars' strength over a relatively short distance. These terminations are achieved with standard hooks and deformed headed reinforcement. This section examines how the use of high-strength reinforcement affects approaches to providing continuity and termination.

\subsubsection{Development and Splice Lengths for High-Strength Reinforcement}

Reinforcement strength has an effect on development length. Existing approaches to calculate development and splice lengths apply to conventional Grade 60 strength reinforcement. This section presents and assesses research examining currently used approaches for high-strength reinforcement.

Changes in stress in a deformed bar embedded in concrete require the development of bond forces between the concrete and the bar. The bond force transfer is illustrated in Figure 3-1. As bond transfer increases, a threshold is reached at which the bar slips and the surface adhesion is lost (ACI, 2003). Bearing forces at the deformations cause stresses and cracks in the surrounding concrete. The stress in concrete can cause splitting cracks between adjacent bars in a plane parallel to the bars, or between a bar and the concrete surface. 


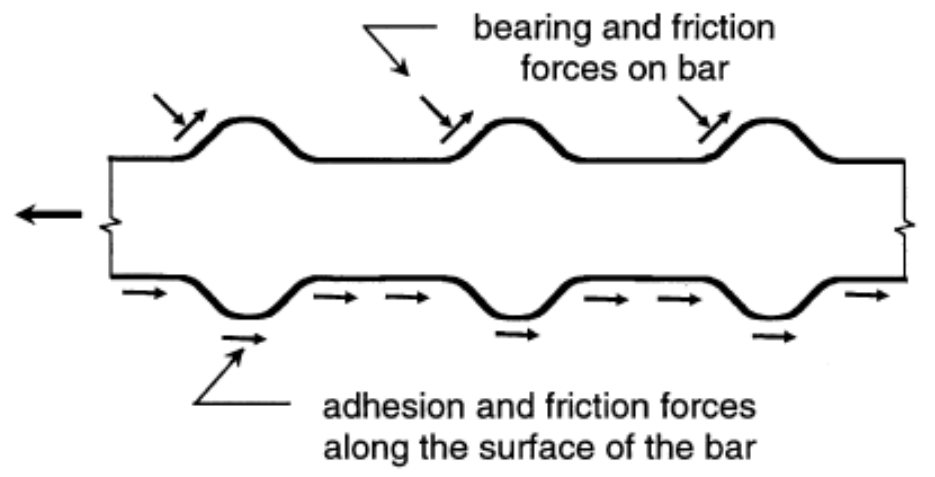

Figure 3-1 Bond force transfer mechanisms ( $\mathrm{ACl}$, 2003).

Development length is the length of bar required for the bar stress to change from zero to the specified yield strength and is a function of the mechanical bond between the concrete and the reinforcing bar and the change in the bar force. The mechanical bond depends on the size and spacing of deformations on the bar, on the concrete tensile strength, on the cover and spacing between bars, and on the presence of transverse reinforcement crossing the potential plane of splitting along the length of the bar or bars being developed. High-strength reinforcement requires longer development lengths than conventional Grade 60 reinforcement, if all other conditions are the same.

A lap splice can provide continuity by transferring stress from one bar to another. The length of a lap splice is usually determined so that the specified yield strength from one bar is transferred to another bar. Orangun et al. (1975) demonstrate that development lengths and lap splice lengths should be the same for the same conditions. By this rationale, development length equations are based primarily on findings of splice tests, although some tests intended to measure the developed stress have also been performed.

ACI 318-11 (ACI, 2011) provides development and lap splice length requirements. These requirements are design limits, and are not intended to be equations that accurately predict physical behavior of reinforcement. There are two categories of splices: Class A and Class B. For Class A splices, ACI 318-11 requires the same length as the development length. For Class B splices, a factor of 1.3 is applied to the development length. Class A splices are only allowed when the area of reinforcement is at least twice the area required by the analysis, and half or less of the total reinforcement is spliced with the required lap length.

The ACI 318-11 provisions are based on the results of splice and development tests conducted primarily with conventional strength bars (Orangun et al., 1975; Orangun et al., 1977). Orangun et al. performed a regression analysis using the results of 62 tests of unconfined splices and determined that the average bond stress developed is a function of the following: (1) the square root of the concrete strength; (2) the clear 
cover, or one-half of the clear spacing divided by the diameter of the bar; and (3) the bar diameter divided by the splice length. The average bond stress is related to the square root of the concrete compressive strength, because tensile strength is related to compressive strength in this manner. For the tests included in the regression analysis, the concrete compressive strength varied between 2,660 psi and 7,480 psi.

The bar axial stresses developed in the splice tests are not listed directly in the Orangun et al. report, but 60 of the 62 tests are included in the database summarized in the ACI 408R-03 report, Bond and Development of Straight Reinforcing Bars in Tension (ACI, 2003). The average stress developed in the spliced bars was $55 \mathrm{ksi}$; only five of the tests developed stress of more than $80 \mathrm{ksi}$ in the bars. Orangun et al. used the results of tests of splices with confining transverse reinforcement to modify the formula for unconfined development lengths. Simplifications were made to the development length equations prior to adoption into ACI 318.

Using a larger data set than Orangum, ACI Committee 408, which seeks to address bond stress between reinforcing bars and concrete, has developed an alternate procedure for calculating development lengths, presented in the ACI 408R-03 report. The ACI 408R-03 equations differ from the ACI 318-11 equations in the following ways:

- The ACI 408R-03 equations include lower sensitivity to concrete strength, a larger allowable confinement factor, and development lengths that are linear with respect to yield strength, but not proportional.

- The ACI 408R-03 equations relate development length to the fourth root of concrete compressive strength instead of its square root.

- The ACI 408R-03 equations are empirically derived based on the work of Zuo and Darwin (2000).

- The ACI 408R-03 approach does not distinguish between development lengths and splice lengths; that is, it does not include the 1.3 factor that ACI 318-11 applies to a Class B splice. The ratio of development lengths computed using the ACI 408R-03 equations relative to those computed using ACI 318 increases as bar yield strength increases.

Similar to the ACI 318-11 equations, the ACI 408R-03 equations were primarily developed considering Grade 60 reinforcement. Subsequently, the applicability of the ACI 408R-03 equations to high-strength reinforcement has also been researched. Darwin et al. (2005) and Seliem et al. (2009) compare development lengths computed using the ACI 408R-03 equations for both unconfined and confined splices to splice test results. 
The test results evaluated in Darwin et al. (2005) include some tests with highstrength bars, but the focus is on bars of conventional strength. Darwin et al. (2005) also examine splice tests for bars in concrete with compressive strengths as high as 16,000 psi.

Seliem et al. (2009) present and evaluate splice test results with developed bar stress levels varying from 68 to $157 \mathrm{ksi}$. These tests include specimens with measured concrete strengths, $f_{c}^{\prime}$, of 4,700 to 10,200 psi, as well as specimens with and without transverse reinforcement to confine the splice. Seliem et al. (2009) compare stress developed in splice tests to stress computed using the development length equations of the 2005 edition of ACI 318 and ACI 408R-03. The results of splice tests without transverse reinforcement, referred to as unconfined splices, indicate that the ACI 318 design limits for development length and Class A splices require modification for high-strength reinforcement. Although not presented in the Seliem et al. (2009) paper, applying a 1.3 factor to the development length equation to increase the length for a Class B lap splice reduces, but does not eliminate, the need for modification of unconfined splices. Seliem et al. (2009) find that ACI 408R-03 equations predict a lower stress than the stress developed in 29 of 31 tests; this indicates that the method worked relatively well.

For bars with yield strengths greater than $80 \mathrm{ksi}$, the results of tests with transverse reinforcement to confine the splice also indicate the need for modification of ACI 318 design limits for development lengths and Class A splice lengths. This is illustrated in Figure 3-2, in which the ratio of stress developed in the splice test to the stress calculated using bar development equations is shown on the vertical axis, and

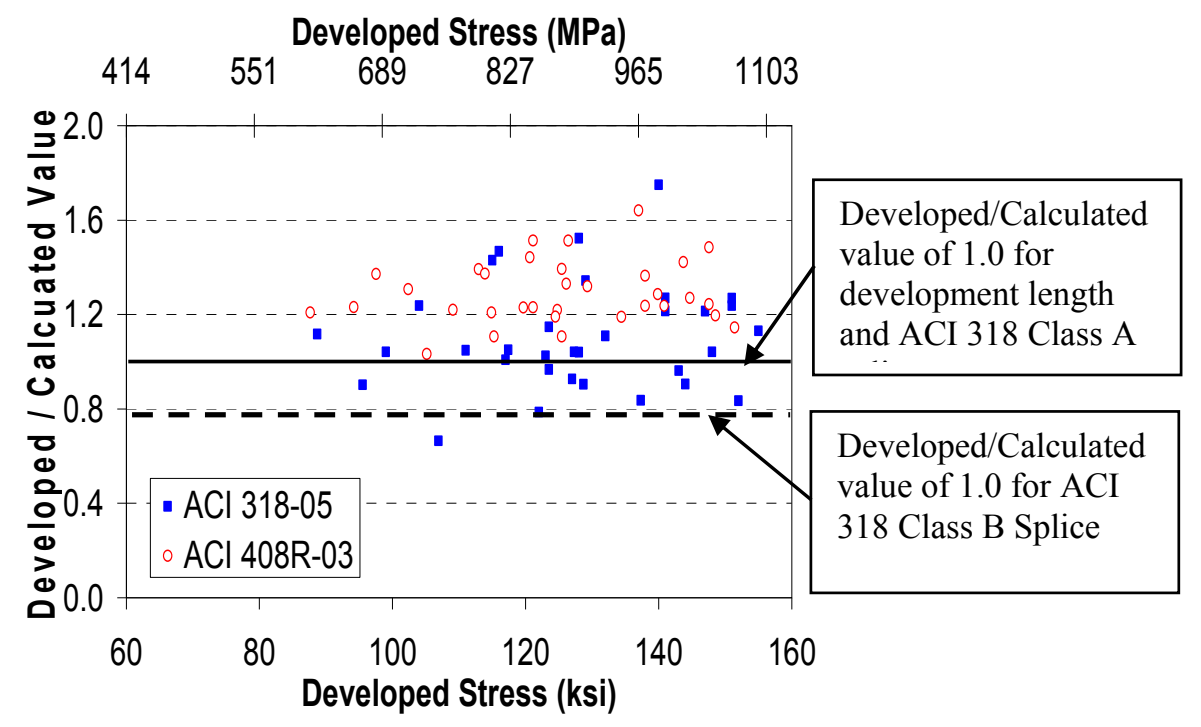

Figure 3-2 Distribution of developed to calculated values of spliced bars with yield strengths greater than $80 \mathrm{ksi}$ for confined splice tests (adapted from Seliem et al,, 2009). 
developed stress is plotted on the horizontal axis. In this figure, the dashed line at the value of about 0.8 on the vertical axis represents the developed/calculated value of 1.0 for the Class B splice (by applying the 1.3 factor in accordance with ACI 318-11), indicating that use of the factor for a Class B splice comes close to eliminating the need for modification to ACI 318. Only one test result, which is from a specimen with a low amount of confining reinforcement, is below this line.

The test results reported by Seliem et al. (2009) show a clear trend of higher developed stress with an increase in the amount of confinement reinforcement provided.

ACI 318 includes a transverse reinforcement index, $K_{t r}$, in its confinement term in the development equation, calculated as follows:

$$
K_{t r}=\frac{40 A_{t r}}{s n}
$$

where:

$$
\begin{aligned}
& A_{t r}=\quad \begin{array}{l}
\text { total area of transverse reinforcement within spacing, } s, \text { that crosses the } \\
\text { potential plane of splitting, in square inches }
\end{array} \\
& s=\text { spacing of transverse reinforcement, in inches } \\
& n=\text { number of bars being spliced }
\end{aligned}
$$

The developed-to-calculated values using ACI 318 for the confined tests are plotted against the transverse reinforcement index, $K_{t r}$, in Figure 3-3. The results suggest that a minimum transverse reinforcement index of 1.3 is appropriate for Grade 80 reinforcement.

Seliem et al. (2009) also compare the data to development lengths computed in accordance with ACI 408R-03, which indicates that it is applicable to reinforcement strengths between 80 and 150 ksi.

Appendix B includes a comparison of development and splice lengths computed using the ACI 318 and ACI 408R-03 approaches. The comparisons are made both for lap splices that are not confined by transverse reinforcement and for those that are confined by transverse reinforcement.

The ACI 408R-03 computed lengths provide an indication of how splice lengths should vary at grades above 80 , relative to those that would be calculated using the current approach of ACI 318. Since the ACI 318 procedure was not calibrated to a large number of splice tests that developed axial bar stress of $80 \mathrm{ksi}$ or higher, it should not be expected to be applicable to Grade 100 or higher reinforcement. 


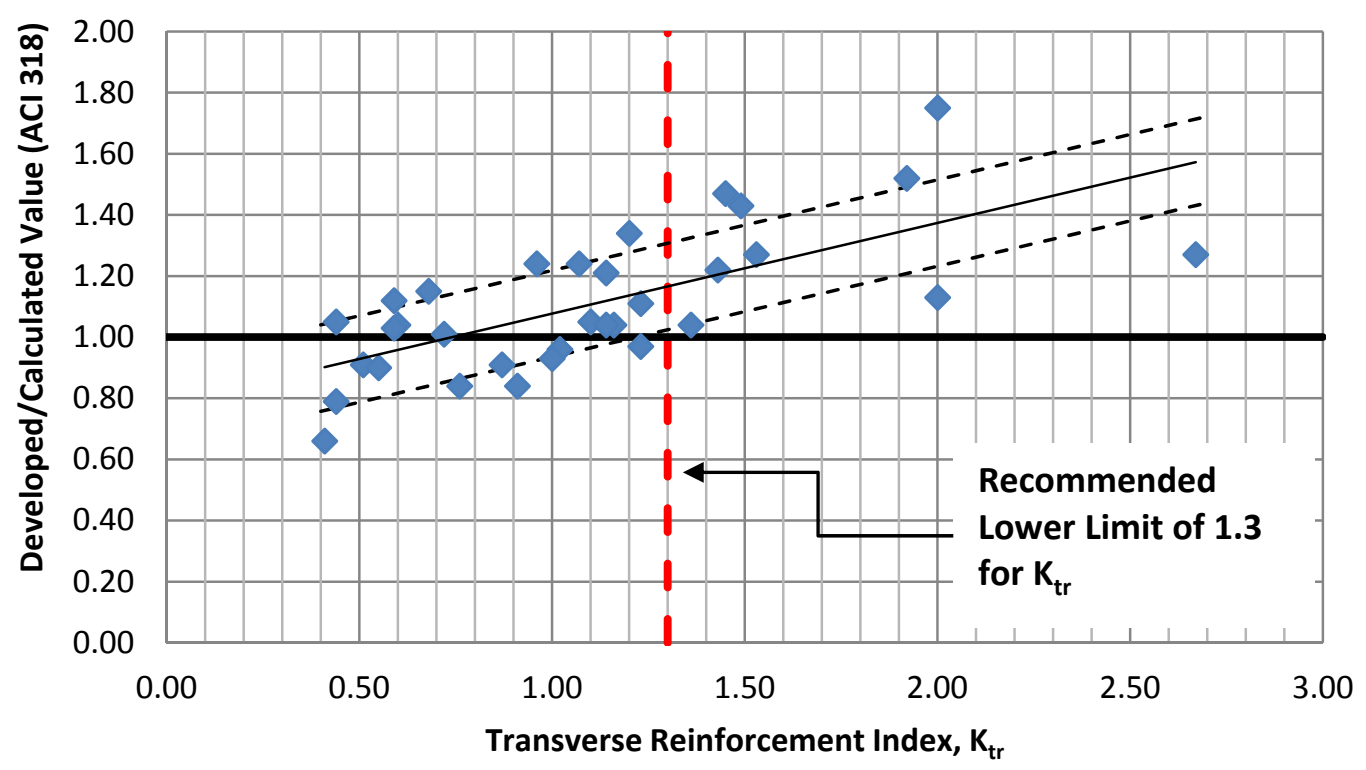

Figure 3-3 Developed-to-calculated stress values versus transverse reinforcement index, $K_{t r}$ (based on data from Seliem et al., 2009).

For splices of Grade 80 and higher reinforcement, it is recommended that ACI Committee 318 study available test results and make appropriate modifications, if necessary, to the provisions of ACI 318, or create new provisions to replace them. The procedures of ACI 408R-03 or those of Canbay and Frosch (2005) could serve as starting points or as references for revised or new provisions. As suggested above, one possible approach to minimize changes to the ACI 318 approach could be to require a minimum amount of transverse reinforcement when using high-strength reinforcement.

\subsubsection{Lap Splice Lengths in Members Resisting Earthquake Effects}

Lap splice lengths are computed based on minimum specified yield strengths. For certain splices in members resisting earthquake effects, the stress transferred could be as high as the stress at the actual yield strength of the bar, or even higher if strain hardening occurs. This stress is typically significantly higher than the nominal strength of the bar. For example, ASTM A706 allows Grade 80 reinforcement to have a measured yield strength as high as $98 \mathrm{ksi}$ and requires that the measured tensile strength be at least 1.25 times the measured yield strength. In the extreme case, the combination of measured yield strength and actual tensile strength may result in bar stresses at the start or end of a splice that could be as much as $50 \%$ higher than the minimum specified yield stress.

Bar continuity using lap splices is also an important consideration. Five conditions are considered below: 
1. Special moment frame beam and column longitudinal bars. Lap splices of these bars will be confined by transverse reinforcement and are located away from plastic hinges. For beams, the splice must be located at least twice the beam depth from the face of the joint. For columns, the splice must be located within the center half of the column. Given these restrictions on locations of splices, it is unnecessary to account for higher than minimum specified yield strength for these splices.

2. Structural wall special boundary elements. These splices will be confined by transverse reinforcement. Lap splice locations are not restricted in structural walls, so lap splices may be located in regions of a special boundary element, where yielding may occur. At these locations, longitudinal bars may yield and strain harden adjacent to a splice. For these splices, stress being transferred that is more than the minimum specified yield stress, $f_{y}$, should be accounted for. Options for addressing this issue could be to eliminate splices where yielding of longitudinal boundary element bars may occur or to use mechanical splices instead.

3. Inner layer of structural wall typical reinforcement. Lap splices of the inner layer of typical wall reinforcing bars will be confined by the outer layer of bars. Structural walls may be constructed with either the typical vertical or horizontal wall reinforcement as the inner layer. Both vertical and horizontal bars may yield when subjected to earthquake effects, so stress transferred at these splices may exceed the minimum specified yield strength, $f_{y}$. Mechanical splices could be used instead.

4. Outer layer of structural wall web reinforcement. Splices of the outer layer of typical wall reinforcing bars will be unconfined. Structural walls may be constructed with either the typical vertical or horizontal wall reinforcement as the outer layer. Both vertical and horizontal bars may yield when subjected to earthquake effects, so stress transferred at these splices may exceed the minimum specified yield strength, $f_{y}$. Mechanical splices could be used instead.

5. Columns that are not part of the special moment frame. ACI 318-11 currently requires that these lap splices be located in the center half of the column, but ACI Committee 318 is reconsidering this requirement. Typical construction practice is to locate these splices directly above floor slabs so that the upper column bar cages do not need to be supported by a crane while they are tied into place. Although these columns could experience earthquake effects that cause the bars to yield at the floor line, the presence of transverse reinforcement will minimize reductions in compressive strength of the column, should the bars slip along the splice. The stresses transferred at these splices do not need to include higher than minimum yield strength and strain hardening. 
Using the development and splice length equations of ACI 318-11 is considered to be adequate for Class B splices of Grade 80 bars confined by transverse reinforcement. However, the minimum amount of transverse reinforcement remains to be established. Based on the data shown in Figure 3-3, it is recommended that transverse reinforcement confining splices should result in a transverse reinforcement index, $K_{t r}$, of 1.3 or greater. Such an approach may also work for splices of Grade 100 and Grade 120 bars. Although not currently required by ACI 318-11, ACI Committee 318 should consider whether higher-than-minimum-specified yield strength should be used for determining certain splice lengths, or whether additional restrictions on splice locations are required.

Finally, although ACI 318 equations for splice lengths are currently applicable to Grade 80 bars, the results of tests indicate that splices without transverse reinforcement to confine them may not develop the specified yield strength. For Grade 80 or higher reinforcement, therefore, lap splices should be confined by transverse reinforcement; if this is not possible, mechanical splices could be used.

\subsubsection{High Relative Rib Area Reinforcement}

One option for reducing development and splice lengths required for high-strength reinforcement is to use reinforcing bars with a high relative rib area. The relative rib area, $R_{r}$, is the ratio of the bearing area of the ribs to the shearing area of the concrete, as illustrated in Figure 3-4. It is a useful parameter for quantifying the effectiveness of the deformations in transferring bond forces. The relative rib area of reinforcing bars commonly available in the United States is approximately 0.09 . High relative rib area bars have relative rib area values between 0.10 and 0.14 , and ultra-high relative rib area bars have values more than 0.14 (ACI, 2009).

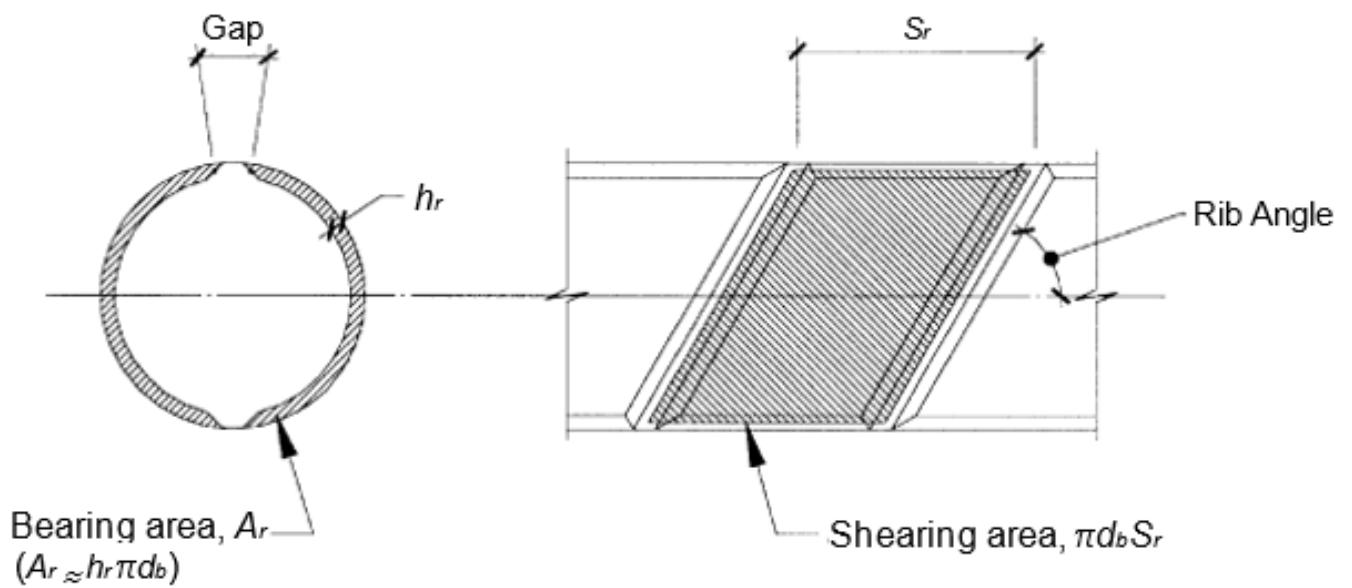
$\left(A_{r} \approx h_{r} \pi d_{b}\right)$

$$
R_{r}=\frac{\text { Bearing area }}{\text { Shearing area }} \approx \frac{h_{r}}{S_{r}}
$$

(Actual $R_{r}$ values range from 0.8 to $0.9^{\frac{h_{r}}{s_{r}}}$ )

Figure 3-4 Definition of relative rib area, $R_{r}(\mathrm{ACl}, 2009)$. 
Increased relative rib area allows for increased bond stress transfer for a unit length of bar, if confined. Confining reinforcement transverse to the splice is critical because bars with higher $R_{r}$ values are more likely to split the concrete.

Mills that produce conventional reinforcing bars have not embraced production of high relative rib area bars. There has been concern that complete filling of higher ribs will not occur during the rolling process, causing increased wear on the tools for rolling the bar. Another concern is that producers will need to stock both normal and high relative rib area bars. Rolling technology has been improving, however, and at least one specialty reinforcement producer is considering producing high-strength reinforcement with high relative rib area.

Development lengths of confined splices of bars with high relative rib area reinforcement should be investigated further. There could be some benefit to using these bars for transfer of bond stresses in beam-column joints. These bars should not be used for unconfined splices of bars in members resisting earthquake effects.

\subsubsection{Column or Beam Bond Splitting}

Short columns or beams subjected to earthquake effects are susceptible to splitting along the length of longitudinal bars. The susceptibility increases with increased bar strength. Flexural yielding causes inelastic strain in longitudinal bars. As the direction of loading is reversed, the inelastic strain of the reinforcement results in higher splitting stresses forming in the concrete as the concrete pushes on the reinforcement to yield it in the reverse direction. The resulting splits can extend the length of the clear story height (Ichinose, 1995). This splitting reduces ductility and energy dissipation. ACI 318-11 does not require a check for this splitting.

The recommendation to avoid splitting along the clear length of a column is given in the following equation (Ichinose, 1995):

$$
\ell_{d} \geq \ell_{n} / 2-0.7 d
$$

where:

$$
\begin{aligned}
\ell_{d}= & \text { the development length in tension of a deformed bar in inches } \\
\ell_{n}= & \text { length of the column clear span, measured face-to-face from joints above } \\
& \text { and below in inches } \\
d= & \text { the distance from the extreme compression fiber to the centroid of } \\
& \text { longitudinal tension reinforcement in inches }
\end{aligned}
$$

Japan's New RC Project studied bond splitting of short columns and beams with high-strength longitudinal reinforcement (Aoyama, 2001). Six beam specimens were tested with USD685 (100 ksi) longitudinal reinforcement. The specimens were 
designed to test the effects of different areas of lateral reinforcement, span to depth ratios, and double layers of reinforcement. Specimens were tested cyclically using two cycles to drifts of $0.5 \%, 1 \%, 2 \%, 3 \%$, and $5 \%$. After cyclic loading, each specimen was then loaded to failure. The critical deflection was taken as the deflection for which the resisting shear force was only $80 \%$ of the maximum shear resisted. The tests showed that increased area of transverse reinforcement increased the critical deformation. The double layer of reinforcement decreased the critical deformation. The beam depth did not affect the critical deformation.

The New RC Project gives a recommendation for computing the design bond stress, which assumes compression yield near one end of the member and tension yield near the other end, distributed uniformly over a length less than the clear length. The bond index is then computed as the ratio of the design bond divided by the ultimate bond strength. A graph that plots bond index on the vertical axis versus limiting deflection (\% drift) on the horizontal axis, reproduced as Figure 3-5, determines the required bond index.

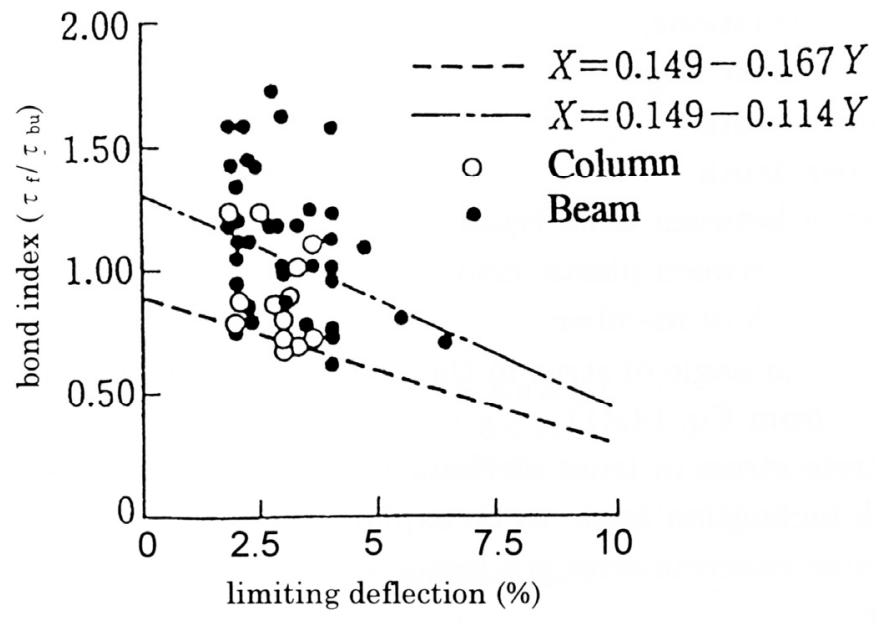

Figure 3-5 Bond index and limiting deflection (\% drift) (Aoyama, 2001).

Bond stress will increase for high-strength reinforcement relative to the same configuration of Grade 60 reinforcement. ACI Committee 318 should consider including a check for bond splitting for the design of short columns or beams using high-strength reinforcing bars and, perhaps, for all grades of reinforcement.

\subsubsection{Mechanical Splices}

Lap splice lengths are often impractically long for high-strength longitudinal reinforcement in columns of moment frames or boundary elements of structural walls. Lap splicing can also cause congestion, making construction difficult. 
In situations where lap splices become too long from a constructability standpoint or when lap splices are not allowed, such as in plastic hinge regions of beams and columns of moment frames, mechanical splices may be used.

ACI 318-11 Section 12.14 specifies two types of mechanical splices: Type 1 and Type 2. Type 1 mechanical splices develop at least 1.25 times the specified yield strength of the bar being spliced, which can be substantially less than the actual tensile strength of a bar. Consequently Type 1 splices may not be used where yielding is expected in special moment frames and shears walls. Type 2 mechanical splices are required to develop the specified tensile strength of the bar and are allowed to be used in any location, including plastic hinge regions of beams and columns. Because Type 2 mechanical splice is only required to develop the specified tensile strength rather than the actual tensile strength of a bar, it may not develop adequate strain when the splice is located in a plastic hinge region.

Type 2 mechanical splices may not be adequate for bars with a very rounded stressstrain curve or with tensile strengths that are higher than the specified tensile strength. Both of these conditions can exist for some high-strength reinforcement. Introduction of a "Type 3" mechanical splice required to develop the actual tensile strength of the bar, could resolve this issue. Alternatively, requirements for a Type 3 mechanical splice could be strain-based instead of stress-based (Type 1 and Type 2 splices are stress-based) to ensure adequate bar elongation. The required elongation in the splice test specimen away from the splice could be specified as the uniform elongation associated with the maximum actual tensile strength of a bar, or an elongation of $8 \%$ for ASTM A706 reinforcement. A Type 3 splice should be applicable to all grades of reinforcement.

\subsubsection{Standard Hooks and Headed Deformed Bars}

Japan's New RC Project did not perform development length tests for high-strength hooked reinforcement. However, the project included tests that represent hooked beam bars of Grade 100, anchored into an exterior beam-column joint (Aoyama, 2001). The force developed in the bars depend on concrete strength, side concrete cover, spacing of beam bars, embedment length, lateral reinforcement, and bend radius. The required development lengths for hooks in the Japanese study were similar, but not the same, as those obtained using the ACI provisions (ACI 318 Sections 12.5 and 21.7.5).

Heads at the ends of bars in tension can provide anchorage with less congestion than hooked bars. In accordance with ASTM A970, Standard Specification for Headed Steel Bars for Concrete Reinforcement (ASTM, 2013), heads may be forged-formed, machined from bar stock, or cut from plate. Heads may be integrally hot-forged at the end of a bar, attached by welding, or a threaded bar end may be screwed into 
internal threads in the head. Other means are also allowed by the specification. Heads specified as Class A are required to develop the minimum specified tensile strength of the bar. Class B heads are required to develop the minimum specified tensile strength of the bar and the minimum specified elongation for the bar. Class B heads should be specified in beams and columns resisting earthquake effects.

In accordance with ACI 318-11 Section 12.6, standard heads can be used with development lengths slightly shorter than the development length for a standard hook. This development length relies upon transfer of force through the bar deformations and the head. Heads must conform to size and cover requirements and are only allowed in normal weight concrete for bars with yield strength up to $60 \mathrm{ksi}$. ACI 318-11 requires that the heads have a net bearing area of at least 4 times the area of the bar $\left(4 A_{b}\right)$, but heads with a net bearing area of up to 9 times the area of the bar are available $\left(9 A_{b}\right)$. For example, the California Department of Transportation (Caltrans) categorizes heads as either "full size" $\left(9 A_{b}\right)$ or "reduced size" $\left(4 A_{b}\right)$.

In fact, Caltrans has additional requirements for headed bars (Caltrans, 2010) and qualifies headed bars through tension and cyclic testing. For instance, the head must be able to develop the full bar strength to the point of rupture during testing. This results in a more reliable headed connection. Although ACI 318-11 does not require a head connection that develops the tensile strength and elongation of the bar (Class B) for bars of special moment frame beams, such a requirement would be a logical improvement for bars of all strengths. This is because bar slip, as described in Chapter 4 of this report, likely occurs in joints of moment frames loaded by a design level earthquake. If the slip extends deep in a joint in which only one beam frames into the column in a given direction, the portion of the bar strength development from the deformations on the bar may no longer be effective, so heads with larger than the minimum net area should be used. High stresses develop at the heads, so confinement reinforcement may also be necessary.

It is anticipated that there will be a demand for headed high-strength deformed reinforcement. It is recommended that heads be required to develop the actual tensile strength of the bar and cause the bar to fail away from the head. Alternatively, the head could be required to develop the specified elongation of the bar (Class B).

At the time this report was written, testing of standard hooks and headed deformed bars of high-strength reinforcement was underway by Darwin et al. at the University of Kansas. The program includes testing of Grade 60, 80, 100, and 120 reinforcing bars that are hooked or have heads. The targeted concrete strengths for the tests are $5,000,8,000,10,000$, and 12,000 psi. Each test specimen generally has two hooked or headed bars, but some specimens have three bars, which are more closely spaced and probably more similar to the spacing of bars used in moment frames. The test program will likely include testing of bars in specimens that are confined, and a 
limited number of cyclic tests may be performed. At the time this report was written, results to date were not available for review.

\subsection{Bar Buckling Restraint}

ACI 318-11 limits the spacing of transverse reinforcement in potential plastic hinge areas of beams and columns and in boundary elements of walls to six times the diameter of the longitudinal bar. This requirement aims to restrain the longitudinal reinforcement and thus delays buckling when the reinforcement undergoes reversed cycles where yielding and hardening occur in tension and compression in a plastic hinge area. In addition, both the spacing and stiffness of the transverse reinforcement restraining a longitudinal bar and the absolute strain affect the buckling of longitudinal reinforcement (Tanaka, 1990; Restrepo-Posada, 1992; Rodriguez et al., 1999; Wang and Restrepo, 2001; Moyer and Kowalsky, 2003). Absolute strain is the difference between the maximum tensile and compressive strains during the strain history of a longitudinal bar. Premature buckling of the longitudinal reinforcement can hamper the ductility and energy dissipation capacity of the member. It can eventually result in cracking around the transverse deformations in the compressed region of the buckled bar, as well as in bar fracture, as shown in Figure 3-6.

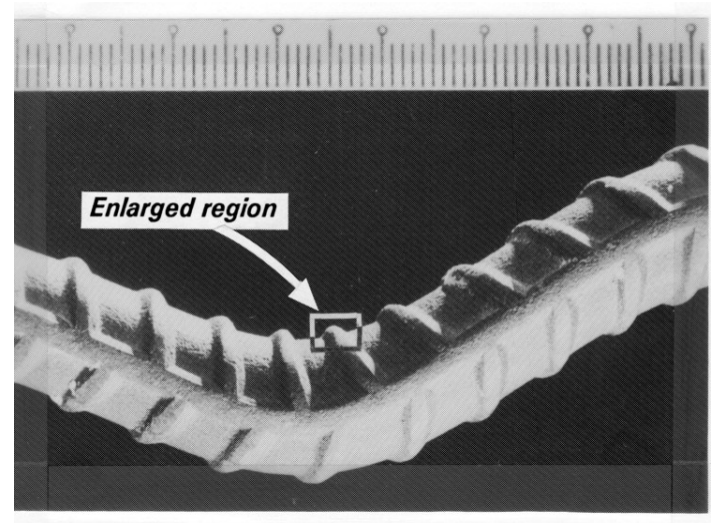

(a)

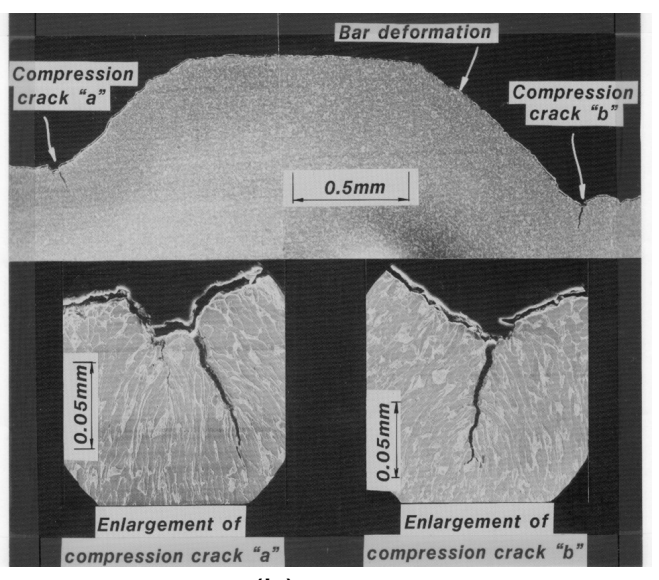

(b)

Figure 3-6 Cracking along the root of the deformation in the compressed side a buckled reinforcing bar (Restrepo-Posada, 1992): (a) overall view of buckled reinforcing bar; (b) electron microscope view of cracking.

For this report, analyses of bars were performed to determine, in relative terms, the maximum spacing of transverse reinforcement for restraining longitudinal bars. The recommendations that follow intend to provide restraint of high-strength reinforcing bars, comparable to the restraint ACI 318-11 currently requires for Grade 60 longitudinal reinforcement.

Figure 3-7 shows theoretical compressive stress-strain relationships for Grade 60, 80, and 100 reinforcing bars for three $s / d_{b}$ aspect ratios, where $s$ is the distance between the bar ends in which fully fixed conditions are assumed, and $d_{b}$ is the bar diameter. 


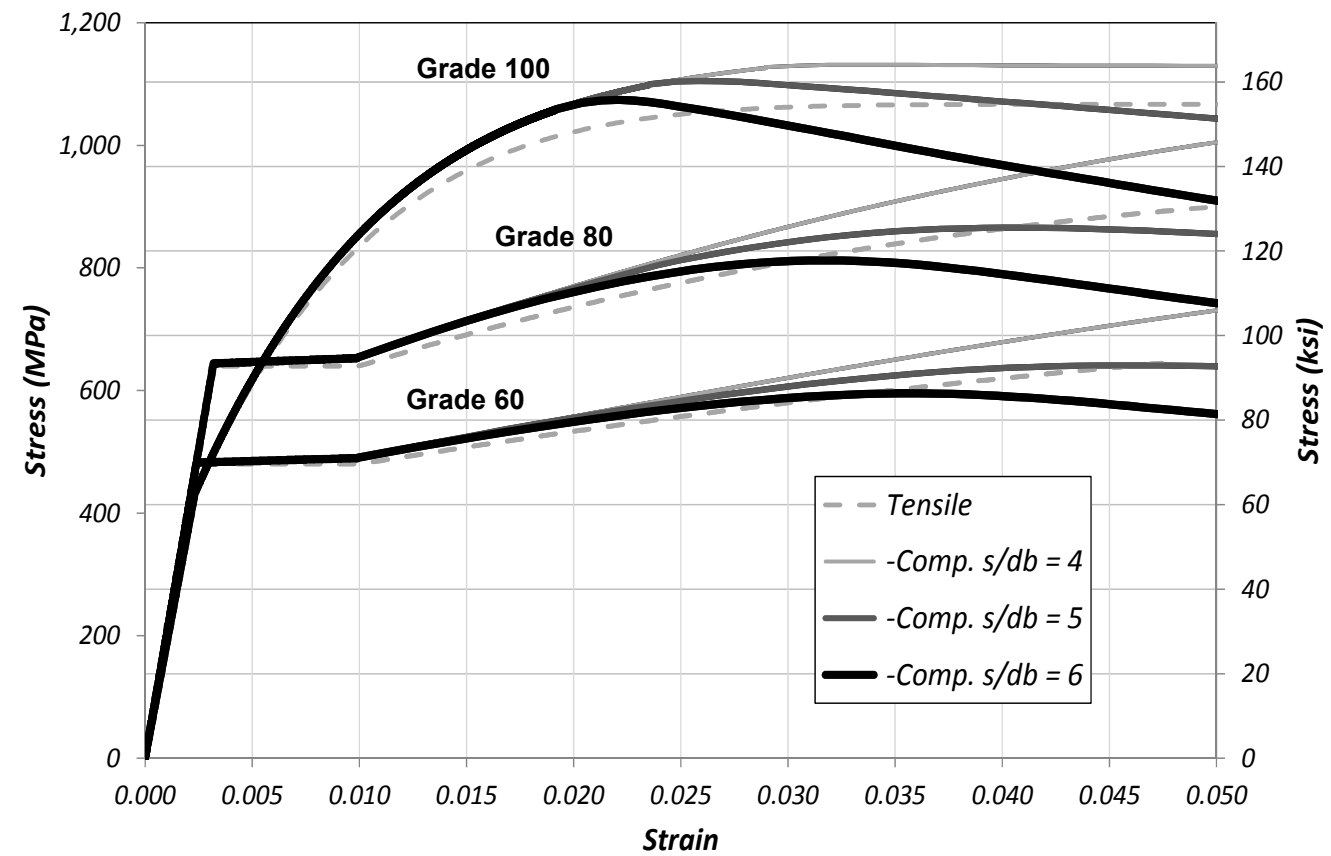

Figure 3-7 Compressive stress-strain responses of reinforcing bars of different grades and three $s / d_{b}$ ratios and comparison with the mirrored tensile stress-strain response (courtesy of M. Schoettler).

The analyses were performed with expected material properties. The onset of strain hardening for Grade 60 and 80 reinforcement was assumed to be 0.01 . The Poisson ratio of 0.5 was assumed in calculating the compressive stress-strain relationships from known tensile stress-strain relationships (Dodd and Restrepo-Posada, 1995). To obtain the compressive stress-strain relationships, the cross sections of the bars were discretized into a number of fibers to capture the geometric nonlinearity and strain reversal that develop upon buckling.

In the analyses, the bars were assumed to be fully fixed at their ends. That is, bars were analyzed under ideal conditions; the effects of the stiffness of the transverse reinforcement, the longitudinal bar concrete cover, and core longitudinal bar interaction were not investigated. The compressive strain shown in Figure 3-7 is equal to the change in length of the bar divided by the initial length. This differs from the local bar compressive strain that develops at the critical section in the plastic hinges once buckling occurs. Figure 3-7 also shows the mirrored tensile stress-strain relationships for the bars for comparison.

In Figure 3-7, it can be seen that the compressive stress-strain responses of the Grade 60 and Grade 80 bars closely follow the mirrored tensile stress-strain relationships up to a strain of approximately 0.025 , when the effect of buckling becomes evident. Furthermore, Grade 60 and Grade 80 bars show similar compressive stresses relative to the tensile stress at a given strain for the three different ratios of transverse bar 
spacing to longitudinal bar diameter, or $s / d_{b}$ ratios. This suggests that current provisions for transverse spacing of six times the diameter of the longitudinal bar in ACI 318-11 could be directly applicable to Grade 80 reinforcing bars. Figure 3-7 shows that when the ratio $s / d_{b}$ equals 6 , buckling begins to affect the response of Grade 100 reinforcement at a strain that is smaller than that observed for Grade 60 and Grade 80 reinforcement and that the stress-strain response past this strain rapidly softens. However, when the aspect ratio $s / d_{b}$ equals 5 , the effect of buckling is observed at a compressive strain of 0.025 ; softening of the response beyond this strain is comparable with the softening of Grade 60 and 80 reinforcement with an aspect ratio, $s / d_{b}$, equal to 6 . Based on this information, a ratio of 6 for the spacing of the hoops or stirrups and cross-ties to the longitudinal bar diameter could be recommended for Grades 60 through 80, and a ratio of 5 could be recommended for Grades above 80.

However, such recommendations should accompany tighter construction tolerances for the spacing of the transverse reinforcement, particularly in potential plastic hinge regions; otherwise, the recommended ratios should be reduced. For example, ACI 117-10, Specification for Tolerances for Concrete Construction and Materials and Commentary (ACI, 2010b), allows the spacing of stirrups to be the lesser of \pm 3 inches or \pm 1 inch per foot of beam depth and of column ties, and the lesser of \pm 3 inches or \pm 1 inch per foot of the least column section dimension. Under these accepted tolerances, it would be acceptable to place the transverse reinforcement within 3 inches of the specified spacing in a 36-inch deep or deeper element. For a Grade 60 or 80 No. 8 bar, this means that, in practice, a spacing of 9 inches, or $9 d_{b}$, between sets of hoops or stirrups and cross-ties would be acceptable, because the maximum specified spacing in design is $6 d_{b}$. Likewise, a spacing of 8 inches, or $8 d_{b}$, would also be acceptable for the transverse reinforcement tying a Grade 100 or Grade 120 No. 8 bar whose spacing in design is $5 d_{b}$. Such allowable spacing of the transverse reinforcement is clearly unsuitable for high-strength longitudinal reinforcement in potential plastic hinge regions of beams and columns, and also in potential plastic hinge regions of walls.

Buckling of longitudinal bars can take place over several hoops or cross ties when the stiffness, strength, or detailing of a single hoop or cross tie cannot constrain the buckling to within the distance between two consecutive hoops or cross ties. Tanaka (1990) carried out a comprehensive analytical and experimental study on column longitudinal bar buckling to validate, or make modifications to, the design provisions in the New Zealand Code of Practice for the Design of Concrete Structures (NZS, 1982) for the detailing of transverse reinforcement in the potential plastic hinges of columns. Tanaka modeled the hoops and cross-ties with nonlinear Winkler springs and discretized the longitudinal bar into nonlinear fibers, as shown in Figure 3-8. 

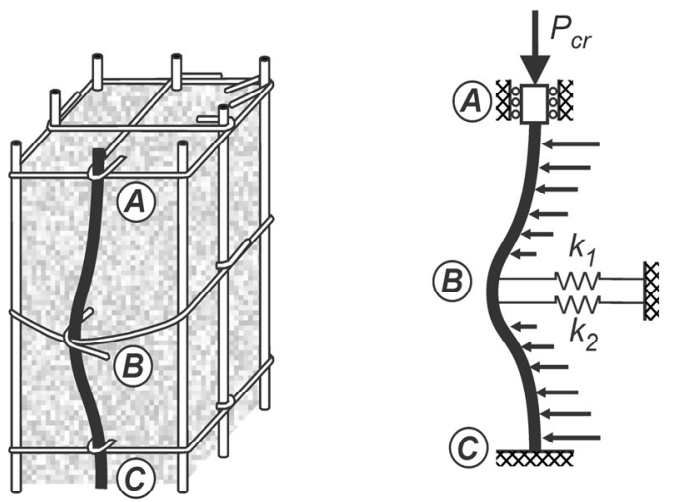

$$
\begin{aligned}
w= & \text { Lateral pressure } \\
& \text { from core concrete } \\
k_{1}= & \text { Nonlinear spring of } \\
& \text { tie with } 90^{\circ} \text { hook } \\
k_{2}= & \text { Nonlinear spring of } \\
& \text { perimeter hoop }
\end{aligned}
$$

(A) (C): $135^{\circ}$ or $180^{\circ}$ hook

(B) : $90^{\circ}$ hook

Figure 3-8 Buckling of bars between hoops and cross ties (adapted from Tanaka, 1990).

It is worth noting that the 1982 New Zealand Code of Practice included provisions to confine the concrete core of columns and boundary elements of walls and to delay the buckling of the longitudinal reinforcement in beams with the transverse reinforcement. In addition, the New Zealand Code of Practice prohibited the use of cross ties with 90-degree hooks. Based on analytical and experimental work, Tanaka (1990) concluded that the effectiveness of cross ties with a 90-degree hook at one end and a 135- or 180-degree hook at the other end, alternating along longitudinal reinforcement, was generally as satisfactory as that of conventional cross ties with 135- or 180-degree hooks at both ends. This is because the 90-degree hooks have sufficient flexural stiffness to maintain the confining effect of the cross ties. Tanaka also pointed out that early opening of the 90 -degree hooks in cross ties could be the result of construction tolerances that are too liberal. It should be noted that for Grade 80 or higher strength longitudinal bars restrained by Grade 80 or higher strength cross ties, the flexural stiffness of 90 -degree end hooks is bound to be smaller than that studied by Tanaka. Therefore, further investigation of the acceptability of this detail with Grade 80 and higher strength reinforcement is recommended.

In Japan, it has been recommended that the spacing of transverse reinforcement restraining buckling of Grade 100 longitudinal reinforcement be no more than six bar diameters (Aoyama, 2001). This recommendation was validated through monotonic testing of prisms. Under cyclic conditions, buckling of the reinforcement can occur at smaller compressive strains, or even in the tensile strain domain as a result of a previous large tensile strain excursion. For this reason, the Japanese recommendations should be interpreted with caution. To date, there have been limited tests conducted on beams and columns incorporating high-strength reinforcement that are detailed to ensure the development of a plastic hinge at the end 
of the element. Table 3-1 lists the main properties and the ultimate drift ratio, $\theta_{u}$, for test beams, and Table 3-2 lists the properties and ultimate drift ratio for test columns.

Table 3-1 Properties of Test Beams with High-Strength Longitudinal Reinforcement and Developing Plastic Hinges during Testing

\begin{tabular}{|c|c|c|c|c|c|c|c|c|}
\hline Reference & Unit & $\begin{array}{c}d_{b} \\
\text { (\# or in.) }\end{array}$ & $\begin{array}{c}f_{y}{ }^{*} \\
(\mathrm{ksi})\end{array}$ & $\begin{array}{l}f_{y t}{ }^{*} \\
(\mathrm{ksi})\end{array}$ & $s / d_{b}$ & $\begin{array}{c}\rho_{v} \\
(\%)\end{array}$ & $\begin{array}{c}\text { All bars } \\
\text { tied? }\end{array}$ & $\begin{array}{c}\theta_{u} \\
(\%)\end{array}$ \\
\hline Chang et al., 2008 & Sp. \#3 & $\# 10$ & 130 & 133 & 3.2 & 1.1 & Yes & 5.5 \\
\hline Chang et al., 2008 & Sp. \#4 & $1-3 / 8$ & 142 & 77 & 3.2 & 1.1 & Yes & $>7.1$ \\
\hline Tavallali, 2011 & UC4-X & 0.7 & 97 & 60 & 2.9 & 0.69 & No & $>5$ \\
\hline Chen et al., 2013 & $\begin{array}{l}\text { BNCS- } \\
\text { Beam }\end{array}$ & $\# 7$ & 131 & $\begin{array}{c}68 \\
\text { (ave) }\end{array}$ & 4.6 & 0.83 & Yes & $>5$ \\
\hline
\end{tabular}

* Based on $0.2 \%$ Offset Method in reinforcement, without a well-defined yield plateau.

Table 3-2 Main Properties of Test Columns Built Incorporating High-Strength Longitudinal Reinforcement and Developing Plastic Hinges during Testing

\begin{tabular}{|c|c|c|c|c|c|c|c|c|c|}
\hline Reference & Unit & $\begin{array}{r}P_{u} / \\
A_{g} f_{c}^{\prime} \\
\end{array}$ & $\begin{array}{c}d_{b} \\
\text { (\# or in.) } \\
\end{array}$ & $\begin{array}{r}f_{y}^{2} \\
(\mathrm{ksi}) \\
\end{array}$ & $\begin{array}{r}f_{y t}{ }^{2} \\
(\mathrm{ksi}) \\
\end{array}$ & $s / d_{b}$ & $\begin{array}{c}\rho_{v} \\
(\%) \\
\end{array}$ & $\begin{array}{c}\text { All bars } \\
\text { tied? }\end{array}$ & $\begin{array}{c}\theta_{u} \\
(\%) \\
\end{array}$ \\
\hline \multirow{2}{*}{$\begin{array}{l}\text { Satyarno et } \\
\text { al., } 1993\end{array}$} & Unit 11 & 0.6 & 0.87 & 144 & 145 & 3.6 & 0.46 & Yes & 3.9 \\
\hline & Unit $2^{1}$ & 0.6 & 0.87 & 144 & 145 & 3.6 & 0.46 & Yes & 3.1 \\
\hline \multirow{4}{*}{$\begin{array}{l}\text { Sato et al., } \\
1993\end{array}$} & Unit $2^{1}$ & 0.3 & 0.87 & 150 & 198 & 3.6 & 0.71 & Yes & 5 \\
\hline & Unit 31 & 0.3 & 0.87 & 150 & 198 & 3.6 & 0.71 & Yes & 5 \\
\hline & Unit $5^{1}$ & 0.6 & 0.87 & 150 & 198 & 3.6 & 0.71 & Yes & $>2$ \\
\hline & Unit 61 & 0.6 & 0.87 & 150 & 198 & 3.6 & 0.71 & Yes & 3 \\
\hline \multirow{4}{*}{$\begin{array}{l}\text { Chen et al., } \\
2013\end{array}$} & BNCS N Col. ${ }^{1}$ & Variable & $\# 7$ & 131 & Gr. 75 & 4.6 & 0.83 & Yes & 3.5 to -2.4 \\
\hline & BNCS NE Col. ${ }^{1}$ & Variable & $\# 7$ & 131 & Gr. 75 & 4.6 & 0.83 & Yes & 4.6 to -2.0 \\
\hline & BNCS S Col. ${ }^{1}$ & Variable & $\# 7$ & 131 & Gr. 75 & 4.6 & 0.83 & Yes & 3.5 to -2.1 \\
\hline & BNCS SE Col. ${ }^{1}$ & Variable & $\# 7$ & 131 & Gr. 75 & 4.6 & 0.83 & Yes & 4.9 to -1.8 \\
\hline \multirow{5}{*}{$\begin{array}{l}\text { Rautenberg } \\
\text { et al., } 2013\end{array}$} & HC-2.2-10 & 0.1 & $\# 7$ & 83 & 62 & 2.9 & 1.0 & Yes & $>5$ \\
\hline & UC-1.6-10 & 0.1 & $\# 6$ & 133 & 68 & 3.3 & 1.0 & Yes & $>5$ \\
\hline & HC-2.2-20 & 0.2 & $\# 7$ & 83 & 62 & 2.9 & 1.0 & Yes & $>3$ \\
\hline & UC-1.6-20 & 0.2 & \#6 & 133 & 63 & 3.3 & 1.0 & Yes & $>4$ \\
\hline & UC-1.1-20 & 0.2 & $\# 5$ & 134 & 62 & 4.0 & 1.0 & Yes & $>4$ \\
\hline
\end{tabular}

${ }_{1}^{1}$ Columns with mixed grade (Grade 60 and ultra-high strength (greater than $\left.135 \mathrm{ksi}\right)$ ) longitudinal reinforcement.

${ }^{2}$ Based on $0.2 \%$ Offset Method in reinforcement, without a well-defined yield plateau. The reinforcement grade is listed where test data have not been reported.

All beams reported in Table 3-1 show excellent deformation capacity, i.e., drift ratios in excess of $5 \%$ were attained in all the tests. The ratio of the spacing of the transverse reinforcement to the longitudinal bar diameter, $s / d_{b}$, in these beams was equal to or less than 4.6. In all tests but one, all of the longitudinal reinforcement 
was tied to the corner of a stirrup or to a cross-tie with alternating 90- and 135-degree hooks.

Columns reinforced partially or totally with high-strength longitudinal reinforcement have also shown excellent performance overall. With one exception, tests have attained a drift ratio equal to or greater than $3 \%$. The columns tested with high axial load ratios exhibited smaller deformation capacity than those with smaller axial load ratios. All of the column tests reported had all of the longitudinal bars tied to the corner of a hoop or to the corner of a diamond hoop, and the transverse reinforcement to longitudinal bar diameter ratio, $s / d_{b}$, in the columns was equal to or less than 4.6.

\subsection{Strain Limit for a Tension-Controlled Section}

ACI 318-11 defines a tension-controlled section as one in which the net tensile strain in the extreme tension reinforcement is equal to or greater than 0.005 . For Grade 60 reinforcement, this strain limit is approximately 2.5 times the yield strain. This limiting strain is applicable to all reinforcement allowed by ACI 318-11, which includes reinforcement with yield strengths as high as $80 \mathrm{ksi}$, even though this limit represents a strain that is only 1.8 times the yield strain for Grade 80 reinforcement. Applying the intent of ACI 318-11 for a tension-controlled section to members constructed with Grade 100 reinforcement requires the strain limit defining a tensioncontrolled section to be approximately 0.009 (ACI, 2010a). A way to achieve this is to set the tension-controlled strain limit to 2.5 times the yield strain, instead of using a single value of 0.005 . For Grade 80 reinforcement, the limit would be approximately 0.007 .

The commentary of ACI 318-11 states that a higher strain limit is sometimes required, and it also provides the example of moment redistribution requiring the net tensile strain to be 0.0075 . Consideration should be given to increasing the net tensile strain of beams in special moment frames to provide improved ductility. Such an increase in the net tensile strain for beams of special moment frames would include all grades of reinforcement, including Grade 60. An appropriate limit might be 3.5 times the yield strain, which would be a strain of 0.0075 for Grade 60 reinforcement and 0.010 for Grade 80 reinforcement.

\subsection{High-Strength Concrete}

It is advantageous to use high-strength concrete in members that contain highstrength reinforcement. High concrete strength reduces the required development and splice lengths of reinforcement, increases the shear strength of joints of special moment frames, and has the potential to increase the shear strength of structural walls. Existing literature includes tests combining high-strength concrete with highstrength reinforcement (e.g., Aoyama, 2001; Okamoto et al., 2004; Nishiyama, 2009; Restrepo et al., 2006). 
For members of the same dimensions and reinforcement, use of high-strength concrete improves the deformation capacity of flexural members. Consider two beams deformed to their ultimate deformation capacity with the only difference being that one has higher strength concrete than the other. The beam with the higher strength concrete will have a shallower neutral axis depth, slightly increased peak moment strength, higher curvature, higher bar tensile strain, and higher hinge rotation. However, the benefit of improved deformation capacity may be somewhat negated if higher concrete strength is used to reduce the dimensions of the member.

\subsection{Ductility}

It is important to understand the expected range of ductility demands on members when evaluating the acceptability of the use of high-strength reinforcement for members with ductile hinges. Changes in inelastic deformation demands are explored in Chapter 5 of this report. In general, when high-strength reinforcement is incorporated in a member, the stiffness of the member is reduced so that increased elastic deformation occurs before the onset of yielding. As a result, the net inelastic deformation demands are less, but for Grade 80 reinforcement, these demands are not substantially less than those for Grade 60 reinforcement. The ductility or deformation capacities of members constructed with high-strength reinforcement are discussed further in Chapter 4.

\subsection{Minimum Reinforcing Ratios}

A limitation on the benefit of using high-strength reinforcement is that minimum reinforcement ratios are more likely to control than when Grade 60 reinforcement is used. For example, the minimum column reinforcement ratio of $1 \%$ often controls columns in the upper levels of a building. Unless the minimum reinforcement ratio requirement is reduced, smaller column sizes would have to be specified to take advantage of the high-strength reinforcement in the upper levels.

The minimum wall reinforcing ratio of 0.0025 is another limitation that can often control in the upper levels of a building. As further discussed in Chapter 4, minimum reinforcing ratios for walls may need to increase to avoid formation of a single, wide crack. High-strength reinforcement could be advantageous if the design moment strength provided by the minimum reinforcement is required to exceed the cracking moment strength of the wall section, as has been suggested.

Future studies should consider the merits and detriments of reducing minimum reinforcing ratio requirements.

\subsection{Strength Provided by High-Strength Shear Reinforcement}

ACI 318-11 Section 11.4.2 requires that the yield strength assumed for design of shear reinforcement shall not exceed $60 \mathrm{ksi}$, but the yield strength for design may be 
increased to as much as $80 \mathrm{ksi}$ for welded deformed wire reinforcement. Transverse reinforcement with yield strength as high as $100 \mathrm{ksi}$ may be used for confinement of columns for special moment frames and special boundary elements of structural walls. The assumed yield strength, however, cannot exceed $60 \mathrm{ksi}$ for calculation of shear strength (ACI 318-11 Sections 21.1.5.4 and 21.1.5.5). The Commentary Section R11.4.2 to ACI 318-11 states, "Limiting the values of $f_{y}$ and $f_{y t}$ used in design of shear reinforcement to 60,000 psi provides a control on diagonal crack width." The New Zealand Concrete Structures Standard - The Design of Concrete Structures (NZS, 2006) requires that the design yield strength of shear reinforcement not exceed $72 \mathrm{ksi}(500 \mathrm{MPa})$. Park (1996) states, "A limitation of $500 \mathrm{MPa}$ on that stress is imposed for shear calculations to restrict the width of diagonal tension cracks at services loads."

If cracks wider than those accepted for Grade 60 reinforcement are tolerable, smaller bars with higher yield strength could potentially be used to obtain the required shear strength. However, when computing the contribution of reinforcing steel to shear strength, $V_{s}$, the increase in yield strength would result in wider cracks that would reduce the concrete contribution to shear strength. At the end regions of beams of special moment-resisting frames, the concrete contribution to shear strength, $V_{c}$, is assumed to be zero, so the reduction in concrete contribution would not appear to be an important consideration. However, wider cracks could lead to earlier degradation of the end regions of the beams due to the effects of an earthquake.

Several test programs have been completed in which the effectiveness of highstrength reinforcement as shear reinforcement has been considered. Summaries and select conclusions of several of these test programs are provided below.

Ou et al. (2012) tested column shear specimens with high-strength reinforcement and axial load ratios of 0.10 and 0.20 . The axial load ratio is defined as:

$$
n=\frac{N}{A_{g} f_{c}}
$$

where:

$$
\begin{aligned}
& n=\text { axial load ratio } \\
& N=\text { axial load in kips } \\
& A_{g}=\text { gross cross sectional area in inches }{ }^{2} \\
& f_{c}^{\prime}=\text { concrete compressive strength at time of testing in ksi }
\end{aligned}
$$

The specified yield strength for the longitudinal bars was $100 \mathrm{ksi}$, and the specified yield strength for the transverse bars was $115 \mathrm{ksi}$. The columns were reinforced with relatively light amounts of shear reinforcement to induce shear failure before flexural yielding. Transverse reinforcing ratios were $0.14 \%$ to $0.24 \%$. Specimens were 
loaded cyclically up to $4 \%$ drift. Peak shear strengths were reached at drifts of $0.50 \%$ to $0.79 \%$. As stated by Ou et al.:

"Test results showed that all of the specimens had shear failure mechanism indicated by the development of diagonal shear cracks during the testing. The maximum strength did not occur at the same time with the yielding of the transverse reinforcement. Thus, the maximum stress of shear reinforcement in design should be limited."

Ou et al. recommended the limit for stress of shear reinforcement be $600 \mathrm{MPa}$ (87 ksi). This is consistent with the conclusion reached by Sumpter et al. (2009), who tested nine beams and concluded, "Current design codes can conservatively be used for the design of HP [high performance] steel using a yield strength of $80 \mathrm{ksi}$."

Munikrishna (2008) performed 18 tests on nine beams in which shear failures were obtained. Regarding crack width, he concluded, "Shear crack widths measured for all tested beams reinforced with MMFX steel designed with yield strength of $80 \mathrm{ksi}$ and $100 \mathrm{ksi}$ were within the allowable limit specified by the ACI Code." ACI 318 does not specify an allowable crack width; however, the comparison is to a crack width of 0.016 inches, which was the target crack width for flexure that last appeared in the 1995 edition of ACI 318.

For the development of the National Cooperative Highway Research Program (NCHRP) Report, Design of Concrete Structures Using High-Strength Steel Reinforcement (Shahrooz, et al., 2011), nine shear specimens were tested. For shear reinforcement, eight of the specimens had ASTM A615 Grade 60 bars for one half of the specimen and ASTM A1035 Grade 100 bars for the other half. The size of bars and spacing of stirrups were adjusted to provide equivalent design strengths. Tests showed small differences in crack widths between the portions reinforced with A615 Grade 60 stirrups versus those reinforced with A1035 Grade 100 stirrups.

Munikrishna's (2008) research and the NCHRP Report point to an increase in the design yield strength used for shear computations. However, this work is not directly applicable to seismic-force resisting members that are loaded cyclically and whose strength is reduced by degradation due to repeated yielding due to flexure.

As part of the New RC Project in Japan (Aoyama, 2001) columns and beams were tested to determine shear strength for earthquake resistance. Chapter 4 of Aoyama (2001) states:

"For members in which yield hinges are not expected to occur, premature shear failure must be prevented. For this purpose it only suffices to equate the shear force associated with the formation of yield mechanism to the shear strength of the member in the elastic range, i.e., shear strength at the pre-yield shear 
failure, which may be referred to as 'elastic' shear strength. On the other hand, for members in which yield hinges are expected to occur, hinge rotation corresponding to the maximum anticipated deformation must be ensured."

Based on this approach, columns were treated as developing the "elastic" shear strength because, in Japan, it is common practice not to allow the columns to yield. Beams are thus required to maintain shear strength for the maximum anticipated deformation, i.e., "inelastic" shear strength.

The test columns (Aoyama, 2001) were 11.8 square inches $\left(300 \mathrm{~mm}^{2}\right)$ large with a clear height of 35.4 inches $(900 \mathrm{~mm})$. Transverse reinforcement was spaced at 3.1 inches $(80 \mathrm{~mm})$ on center, and the transverse reinforcing ratio was $0.53 \%$ to $1.19 \%$. Concrete strength was $10,700 \mathrm{psi}$ at the testing age. The transverse reinforcement yield strength varied from $58 \mathrm{ksi}$ to $158 \mathrm{ksi}$. The axial load ratio for four specimens was approximately $1 / 6$, and for the other four tests the axial load ratio was approximately $1 / 3$.

Information about the specimens is listed in Table 3-3. Table 3-4 shows the computed and measured shear strengths. Calculated flexural strengths and bond strengths are not included in Table 3-4, which were reported as being stronger than the computed shear strengths and the shear strengths from the tests.

Table 3-3 Specimens in Column Shear Tests Presented in Aoyama (2001)

\begin{tabular}{|c|c|c|c|c|c|}
\hline Specimen & $\begin{array}{c}\text { Axial Load } \\
\text { Ratio } \\
\end{array}$ & $\begin{array}{c}\text { Transverse Bar } \\
\text { Size }^{1} \\
\end{array}$ & $\rho_{w}{ }^{2}(\%)$ & $f_{y t}(\mathrm{ksi})$ & $\rho_{w} f_{y t}(\mathrm{ksi})$ \\
\hline $6-1$ & $1 / 6$ & D6 & 0.53 & 58.3 & 0.309 \\
\hline $6-2$ & $1 / 6$ & D10 & 1.19 & 59.3 & 0.706 \\
\hline $6-3$ & $1 / 6$ & D6 & 0.53 & 135 & 0.715 \\
\hline $6-4$ & $1 / 6$ & D10 & 1.19 & 158 & 1.882 \\
\hline $3-1$ & $1 / 3$ & D6 & 0.53 & 58.3 & 0.309 \\
\hline $3-2$ & $1 / 3$ & D10 & 1.19 & 59.3 & 0.706 \\
\hline $3-3$ & $1 / 3$ & D6 & 0.53 & 135 & 0.715 \\
\hline $3-4$ & $1 / 3$ & D10 & 1.19 & 158 & 1.882 \\
\hline
\end{tabular}

${ }^{1}$ Area of D6 is 0.049 inches $^{2}$ and area of D10 is 0.11 inches $^{2}$. Four legs are provided in each direction.

${ }^{2} \rho_{w}=A_{w t} /(s d)$ where $A_{w t}$ is the area of shear reinforcement, $s$ is the spacing of the shear reinforcement, and $d$ is the flexural depth of the column.

Comparing Specimens 6-2 and 6-3, which have essentially equivalent $\rho_{w} f_{y t}$ values (meaning they should have equivalent strength provided by the shear reinforcement if the yield strength of the transverse reinforcement is fully effective at resisting shear), 
it is noted that the measured strength of Specimen 6-2 is $150 \mathrm{kips}$, compared to a measured strength of 128 kips for Specimen 6-3.

Table 3-4 Column Shear Test Results from Aoyama (2001)

\begin{tabular}{|c|c|c|c|c|}
\hline Specimen & $\begin{array}{c}\text { Measured } \\
\text { Shear Strength } \\
\text { (kips) }\end{array}$ & $\begin{array}{c}V_{c}(\text { Eq. 11-4) } \\
\text { (kips) }\end{array}$ & $\begin{array}{c}V_{s}(\text { Eq. } 11-15)^{2} \\
(\text { kips })\end{array}$ & $\begin{array}{c}V_{n}=V_{c}+V_{s} \\
\quad \text { (kips) }\end{array}$ \\
\hline $6-1$ & 104 & 47 & 37 & 84 \\
\hline $6-2$ & 150 & 47 & 85 & 132 \\
\hline $6-3$ & 128 & 47 & 86 & 133 \\
\hline $6-4$ & 158 & 47 & 228 & 275 \\
\hline $3-1$ & 120 & 65 & 37 & 102 \\
\hline $3-2$ & 159 & 65 & 85 & 150 \\
\hline $3-3$ & 132 & 65 & 86 & 151 \\
\hline $3-4$ & 167 & 65 & 228 & 293 \\
\hline
\end{tabular}

${ }^{1}$ According to Equation 11-4 of $\mathrm{ACl} 318-11$.

${ }^{2}$ According to Equation 11-15 of $\mathrm{ACl} 318-11$, ignoring the 60 ksi limit for yield strength.

It is observed that higher strength, smaller bars are less effective at resisting shear than lower strength, larger bars. Specimens 3-2 and 3-3 can be compared in a similar manner. The measured strength of Specimen 3-2 is $159 \mathrm{kips}$, compared to a measured strength of 132 kips for Specimen 3-3.

Specimens 6-4 and 3-4 appear to show that high-strength reinforcement is ineffective at resisting shear, but these specimens contained large amounts of shear reinforcement. If the reinforcement were fully effective up to its yield strength, it would have had more than twice the allowable design limit of shear strength that can be assigned to shear reinforcement, as defined by $V_{s} \leq 8 \sqrt{f^{\prime}{ }_{c} b d}$, from ACI 318-11 Section 11.4.7.9.

Four beam specimens were also tested so that shear strength could be monitored from the elastic to inelastic range. Each specimen had the same shear reinforcement, concrete, and cross sectional dimensions. Only the yield strength and amount of axial reinforcement varied. Although the longitudinal reinforcement of these specimens had yield strengths of $142 \mathrm{ksi}, 95 \mathrm{ksi}$, and $60 \mathrm{ksi}$, the yield strength of the shear reinforcement was only $49 \mathrm{ksi}$, so the results are not presented here.

The New RC Project in Japan makes recommendations for computing the shear strength in plastic hinge regions that allow the use of high-strength shear reinforcement. The approach is more complex than shear strength computations customarily performed in the United States, and the method does not appear to be based on a large database of test results. Therefore, the approach is not presented here. The approach does not allow the full yield strength of the shear reinforcement 
to be used. The effectiveness of this approach could be studied once more test data are available. Some simplification of the approach is likely warranted.

Budek et al. (2002) tested round bridge piers with high-strength transverse reinforcement. Prestressing strand and wire with tensile strengths of $250 \mathrm{ksi}$ and 270 ksi were continuously wound around the longitudinal bars as transverse reinforcement. Budek et al. performed companion tests with conventional strength Grade 60 spiral reinforcement. Longitudinal reinforcement was also conventional strength. A constant axial load was applied to each specimen. The axial load ratios, $N / f_{c}^{\prime} A_{g}$, were 0.12 to 0.30 . Most specimens were designed to have lower predicted shear strength than flexural strength. Budek et al. concluded:

"The observed response of the tested columns indicate that using a conservative value of $0.6 f_{p u}$ for maximum allowable tensile stress in the transverse reinforcement provided adequate strength for the steel truss shearresisting mechanism while significantly reducing steel congestion. Crack widths resulting from elastic deformation of the transverse reinforcement were not large enough to significantly degrade the concrete shear-resisting response.

The transverse reinforcement in the plastic hinge regions remained, in general, within the elastic range; the strains recorded would have caused yielding in conventional reinforcement."

In regards to the concrete contribution to shear strength, Budek et al. stated, "A degrading strength model can successfully predict the behavior of columns reinforced with high-strength transverse reinforcement."

Based on the research reviewed, the usable stress for shear strength could be increased to $80 \mathrm{ksi}$ for design of members resisting earthquake effects. In addition, stress-strain curves with a rounded shape and without a yield plateau are preferred. This is because members loaded cyclically during an earthquake cause tension in the shear reinforcement, regardless of the direction in which the member is being loaded. Once the shear reinforcement yields, the cracks will remain open. For members with shear reinforcement with a yield plateau, cracks will open wider relative to cracks in members with shear reinforcement that does not have a yield plateau. Additional research is needed, including tests of cyclically loaded members, before design shear stress higher than $80 \mathrm{ksi}$ is used. 


\section{Chapter 4 \\ Structural System Considerations}

This chapter examines the systems that make up a reinforced concrete building, i.e., special moment frames, special structural walls, diaphragms, foundations, and members that are not part of the system to resist seismic forces, presents available information for use of high-strength reinforcement in these systems, and discusses how design and performance of these elements might be affected by the use of highstrength reinforcement.

\subsection{Special Moment Frames}

Special moment frames are made up of beams, columns, and joints. This section reviews test data for each element of a special moment frame (beams, columns, and joints), and assesses the implications for the use of high-strength reinforcement. The data were obtained from experimental studies conducted primarily to study the deformation capacity of beams and columns subjected to large displacement reversals. This section focuses on the response of frame members controlled by flexural yielding.

\subsubsection{Beams}

In recent decades, a number of tests with cyclic loading have been conducted on beams constructed with high-strength reinforcement. Japanese researchers undertook a major effort in the 1980s and 1990s to study the use of ductile reinforcing bars, including members with specified yield strength in excess of $80 \mathrm{ksi}$ for transverse and longitudinal reinforcement. A summary of these efforts, which are limited to rectangular beam specimens having the same amount of top and bottom longitudinal reinforcement, is presented by Otani et al. (1996). The data for the 105 beams identified by Otani et al. include measured load-deformation curves under reversed cyclic loading. In addition, Aoyama (2001) presents a summary of the major findings of the Japanese New RC Project.

Otani et al. (1996) made reference to more than 25 laboratory reports. Most of these reports are in Japanese without any available translation. Among the research papers available in English are works by Sugano et al. (1990) and Kimura et al. (1993), both of which focus on the cyclic response of concrete beams constructed with highstrength reinforcement. Two of the eight beams (part of beam-column subassemblages) tested by Sugano et al. were reinforced with longitudinal and transverse reinforcement having a yield strength of $85 \mathrm{ksi}$ and $125 \mathrm{ksi}$, respectively. 
The compressive strength of concrete was $12 \mathrm{ksi}$, and the beam cross section was 12 inches wide by 16 inches deep, with a shear span to effective depth ratio of about 3.5. Kimura et al. tested 14 cantilever beams, seven of which were reinforced with longitudinal and transverse reinforcement having a yield strength of $115 \mathrm{ksi}$. The compressive strength of concrete was either $5.5 \mathrm{ksi}$ or $11 \mathrm{ksi}$, and the beam cross section was 8 inches wide by 12 inches deep, with a shear span to effective depth ratio of 4.7. The measured deformation capacities of all of the beams with highstrength reinforcement, as reported by Sugano et al. and Kimura et al., reached drift ratios in excess of $5 \%$.

Tavallali (2011) presents a more recent example of tests of the cyclic response of concrete beams reinforced with high-strength steel bars. Figure 4-1 shows the stressstrain curve representative of the longitudinal reinforcement that was used in the test specimens. The tensile strength and total elongation of the steel bars were $98 \mathrm{ksi}$ and $16 \%$ for the Grade 60 bars, and $117 \mathrm{ksi}$ and $10 \%$ for the Grade 97 bars. This section reviews experimental data for two of Tavallali's beam specimens, CC4-X and UC4-X.

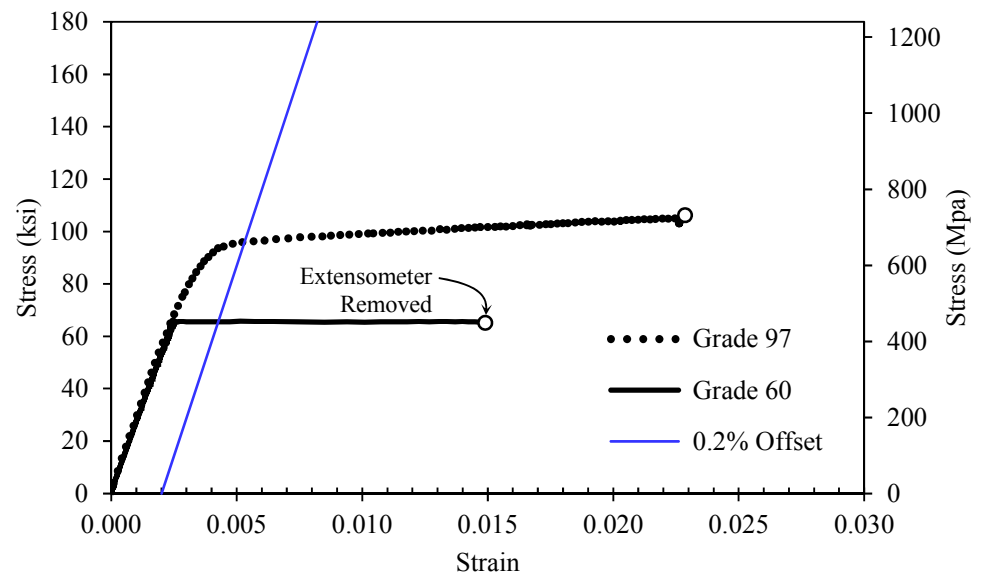

Figure 4-1 Measured stress-strain relationship for longitudinal reinforcement in beam specimens (adapted from Tavallali, 2011).

Specimen CC4-X was reinforced with conventional longitudinal reinforcement (ASTM A706 Grade 60) and specimen UC4-X was reinforced with high-strength reinforcement (SAS 670 Grade 97). The typical geometry and reinforcement details of the test specimens are shown in Figure 4-2. The specimens consisted of two identical beams connected to a central stub through which load was applied, subjecting the specimens to single curvature bending. All transverse reinforcing bars were Grade 60, and the nominal compressive strength of concrete was 6 ksi. The layout of the longitudinal reinforcement was symmetrical, with identical top and bottom layers. The amount of longitudinal reinforcement was chosen so that both specimens reached nearly identical flexural strength while limiting the shear stress, $V / b d$, to values approaching $6 \sqrt{f^{\prime}{ }_{c}}(\mathrm{psi})$. Both specimens had nearly identical $\rho f_{y}$. 


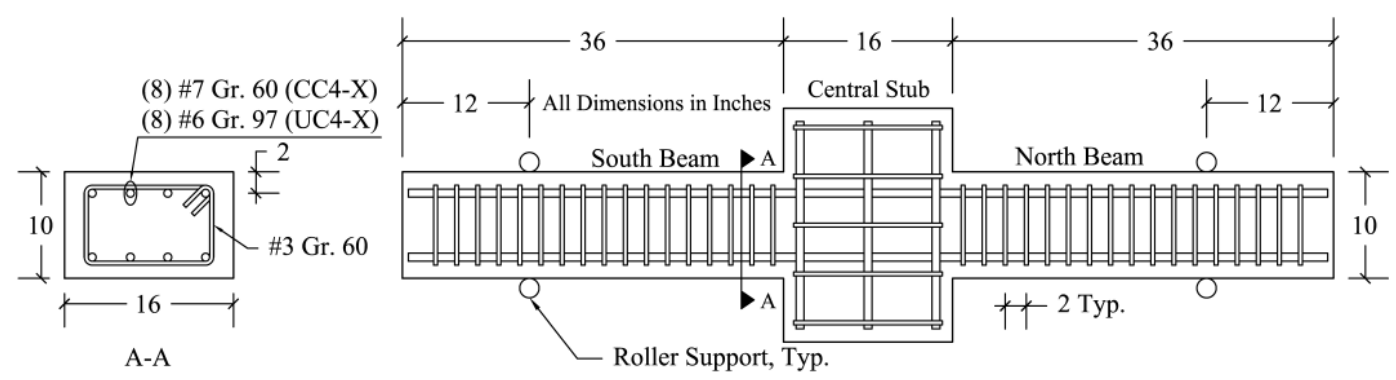

Figure 4-2 Reinforcement details for beam specimens (adapted from Tavallali, 2011).

The drift ratio history applied to each specimen followed the protocol of FEMA 461, Interim Testing Protocols for Determining the Seismic Performance Characteristics of Structural and Nonstructural Components (FEMA, 2007). The drift ratio was defined as the transverse displacement of the central stub divided by the shear span, corrected for the rotation of the central stub.

Specimen CC4-X was designed with $60 \mathrm{ksi}$ steel bars according to the requirements in the 2008 edition of ACI 318, Building Code Requirements for Structural Concrete and Commentary, for special moment frame beams. The measured shear-drift response for $\mathrm{CC} 4-\mathrm{X}$ is shown in Figure 4-3a, excluding the final monotonic loading event. The north beam tolerated two cycles of 5\% drift while maintaining a loadcarrying capacity similar to the peak load resisted in previous cycles.

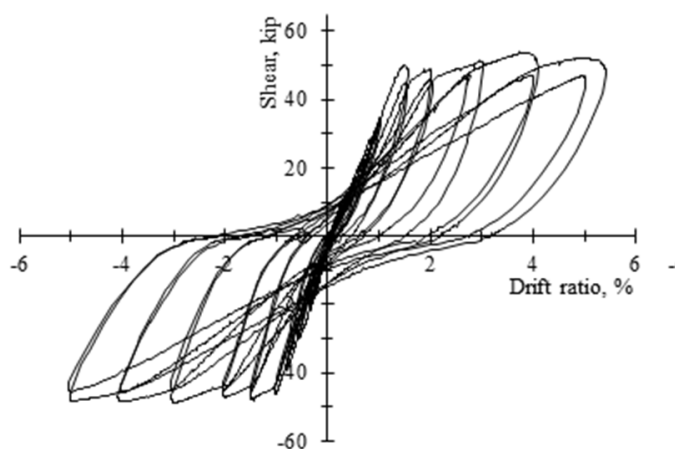

(a)

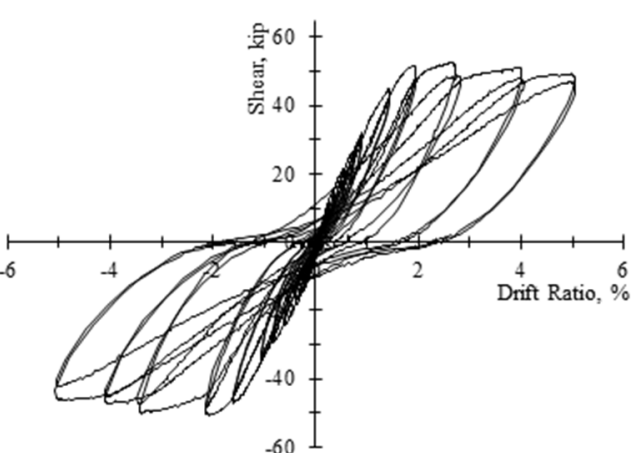

(b)

Figure 4-3 Measured shear versus drift ratio in testing of beams (Tavallali, 2011): (a) Specimen CC4-X, with Grade 60 reinforcement; and (b) Specimen UC4-X, with Grade 97 reinforcement.

Specimen UC4-X had similar properties to Specimen CC4-X, with the exception that it was reinforced longitudinally with Grade 97 (SAS 670) steel bars. Figure 4-3b shows its measured shear-drift response.

Compared with Specimen CC4-X, Specimen UC4-X demonstrated reduced postcracking stiffness and increased yield deformation. The south beam of specimen UC4-X controlled the loading protocol and tolerated two cycles of 5\% drift while 
maintaining a load-carrying capacity similar to the peak load resisted in previous cycles.

Both beam specimens, CC4-X and UC4-X, had similar behavior. Specimen CC4-X showed a small increase in shear after yielding, while specimen UC4-X had a nearly flat post-yield shear-drift curve, which resembled the stress-strain curve of the Grade 97 bars (Figure 4-1). The Grade 60 bars were characterized by a tensile strength to yield strength ratio $\left(f_{u} / f_{y}\right)$ of 1.5 , while the Grade 97 bars had a ratio of 1.2. This difference did not severely affect the load-carrying capacity of specimen UC4-X through large drift ratios.

The above test data indicate that replacing Grade 60 longitudinal reinforcement with Grade 97 reinforcement, reduced in proportion to the yield strength of the reinforcement, leads to comparable flexural strength and deformation capacity. These findings were corroborated by Pfund (2012) using similar beam specimens with ASTM A1035 Grade 120 reinforcement. These observations suggest that concrete beams reinforced with high-strength reinforcement are a viable option in earthquake-resistant construction, if designed and detailed to allow flexural yielding to dominate the nonlinear cyclic response while avoiding brittle failures due to bond, shear, bar buckling, or beam-column joint distress.

\subsubsection{Columns}

In recent years, cyclic tests have been conducted for columns constructed with highstrength reinforcement. In Japan and New Zealand, there has also been research on columns with mixed-grade reinforcement (a combination of high and normal grade longitudinal reinforcement) and columns with ultra-high-strength fiber-reinforced concrete combined with high-strength longitudinal reinforcement.

\subsubsection{Columns with High-Strength Reinforcement}

This section presents results from two recent test programs conducted in the United States on columns reinforced with high-strength bars.

Restrepo et al. (2006) report the testing of two circular columns that were scale models for the Oakland approach of the new San Francisco-Oakland Bay Bridge. One of the columns (referred to as Unit 1) was built with ASTM A706 Grade 60 longitudinal and transverse reinforcement, while the second column (referred to as Unit 2) incorporated ASTM A1035 Grade 100 longitudinal and transverse reinforcement. The columns were built at 35\% scale: 3 feet in diameter, and 9-feet 6-inches tall.

Unit 1, with Grade 60 reinforcement, was a scale model of the original design. It consisted of two cages, each containing 42 No. 5 bars tied to No. 3 fuse-welded hoops spaced at 1.56 inches on center. The longitudinal reinforcement ratio for the column of 
this unit was $\rho_{\ell}=2.54 \%$, and the volumetric transverse reinforcement ratio was $\rho_{s}=$ $1.74 \%$.

Unit 2, with Grade 100 reinforcement, incorporated a single cage with 42 No. 5 longitudinal bars tied to No. 3 fuse-welded hoops spaced at 1.56 inches on center. Therefore, the longitudinal and volumetric transverse reinforcement ratios for this unit were half of those of Unit 1. The use of high-strength reinforcement in this column allowed the elimination of the inner column cage, leading to significant savings in labor and construction time, while matching the capacity of the column in Unit 1.

The columns were made with self-consolidating concrete with a compressive 28-day strength of $8 \mathrm{ksi}$. The measured compressive strength of the concrete cast in the column of Unit 1 was $9.3 \mathrm{ksi}$; that of Unit 2 was $8.2 \mathrm{ksi}$. The ASTM A1035 Grade 100 No. 5 bars used to reinforce the column in Unit 2 had a yield strength of $94 \mathrm{ksi}$, calculated using the $0.2 \%$ Offset Method, a tensile strength of $155 \mathrm{ksi}$, and a uniform elongation of $5.1 \%$. Both units were tested with a small axial load of about $0.07 f_{c}^{\prime} A_{g}$ (applied axial load was 600 kips), representing the axial load scaled down from the prototype bridge column.

The test units were subjected to reversed cyclic loading by applying lateral displacements at the column tops. The test units showed very similar cracking patterns and crack widths. The concrete cover spalled in Unit 1 at $2 \%$ drift. Spalling of the concrete occurred in Unit 2 at a drift ratio of 2.9\%. At this drift ratio, Unit 2 also showed a number of very fine vertical bond-splitting cracks. Unit 1 was cycled to large drift ratios, in excess of $6 \%$, when extensive yielding of the hoops led to longitudinal bar buckling followed by fracture. Unit 2 was tested through three complete cycles with a drift ratio of $3.9 \%$, with only cosmetic damage in the column resulting from spalling of the concrete cover. The hoops effectively restrained the longitudinal bars from buckling up to this drift level. Degradation in the response began with the fracture of a hoop at 5 inches above the base of the column. This hoop fractured at $3.1 \%$ drift on the first cycle to a target drift of $6 \%$. The hoop fractured in the heataffected region adjacent to the fuse weld.

Figure 4-4 shows the hysteretic response of the two test units. Unit 2 showed lower strength than Unit 1 at drift ratios between $0.5 \%$ and $1.5 \%$. At drift ratios between $1.8 \%$ and $3.9 \%$, the two units showed similar strengths. Unit 1 showed fatter hysteresis loops and a higher effective stiffness to the yield point than Unit 2. However, Unit 2 showed significantly smaller residual displacements than Unit 1 after being displaced to the same drift ratio.

In summary, the testing reported by Restrepo et al. (2006) gives a positive indication that high-strength reinforcement can be successfully used up to the drift levels to which Unit 2 was tested (3.9\%). Fracture of a fuse-welded hoop precluded the evaluation of 


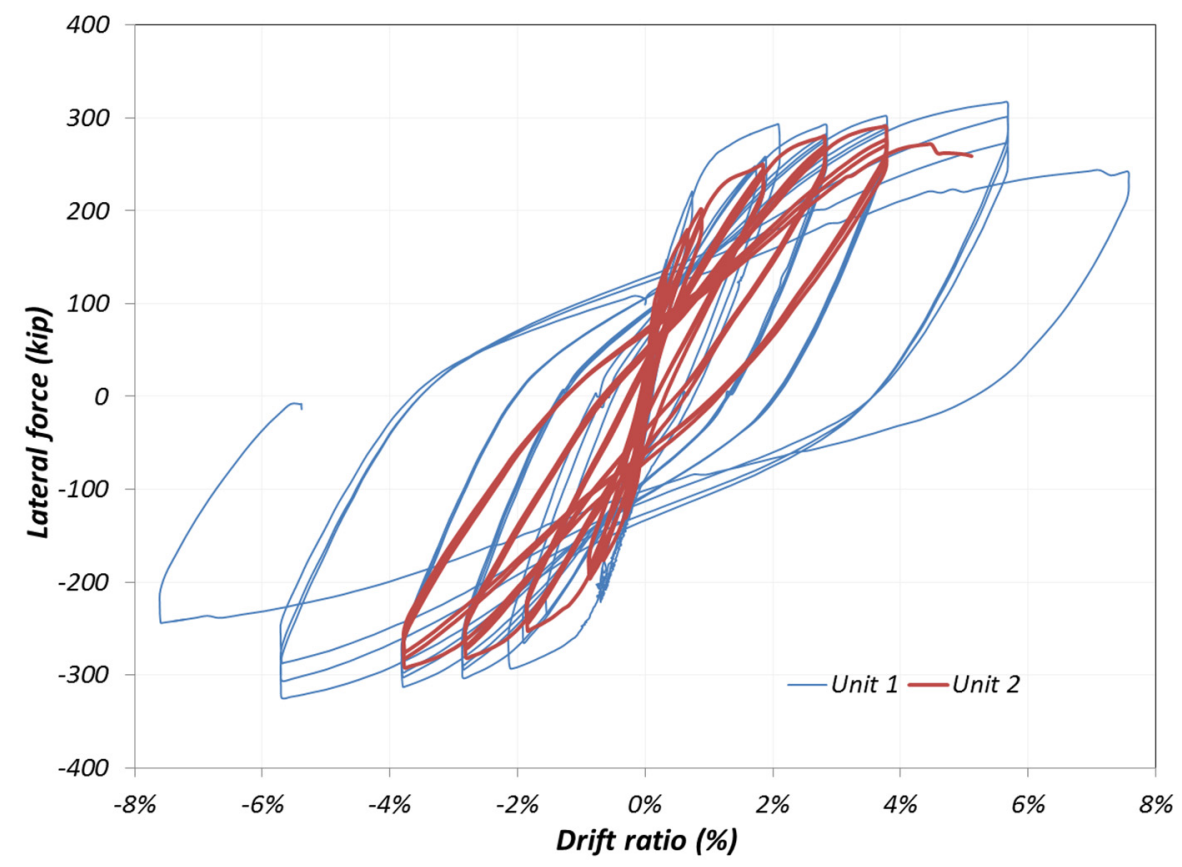

Figure 4-4 Hysteretic response of circular columns tested by Restrepo et al. (2006) (image courtesy of J. Restrepo). Unit 1 uses Grade 60 reinforcement and Unit 2 uses Grade 100 reinforcement.

the performance of this unit at larger drift ratios and the subsequent observation of the mode of failure that otherwise would have occurred.

Rautenberg (2011) also tested concrete columns reinforced with high-strength steel bars. Experimental data are presented for two column specimens, CC-3.3-20 and UC-1.6-20. Specimen CC-3.3-20 was designed with $60 \mathrm{ksi}$ reinforcement according to ACI 318-08 requirements for special moment frame columns. Specimen UC-1.6-20 had properties that were similar to Specimen CC-3.3-20, with the exception that UC-1.6-20 was reinforced longitudinally with ASTM A1035 Grade 120 steel bars, using nearly half the amount of longitudinal reinforcement as the Grade 60 specimen (i.e., $\rho_{\ell} f_{y}$ was nearly identical in both specimens).

Figure 4-5 shows the typical stress-strain curve for the longitudinal reinforcement used in the column specimens. The tensile strength and total elongation were $92 \mathrm{ksi}$ and $20 \%$ for the Grade 60 bars, and $168 \mathrm{ksi}$ and $8.6 \%$ for the Grade 120 bars, respectively. The test setup and loading protocol were similar to those used by Tavallali (2011) in the beam specimens presented earlier in this chapter. The typical geometry and reinforcement details of the test specimens are shown in Figure 4-6. Both specimens were subjected to large displacement reversals while carrying a constant axial load of $0.2 f_{c}^{\prime} A_{g}$. The nominal compressive strength of concrete, $f_{c}^{\prime}$, was 6 ksi.

The layout of the longitudinal reinforcement was symmetrical, with identical top and bottom layers. The amount of longitudinal reinforcement was chosen so that the 


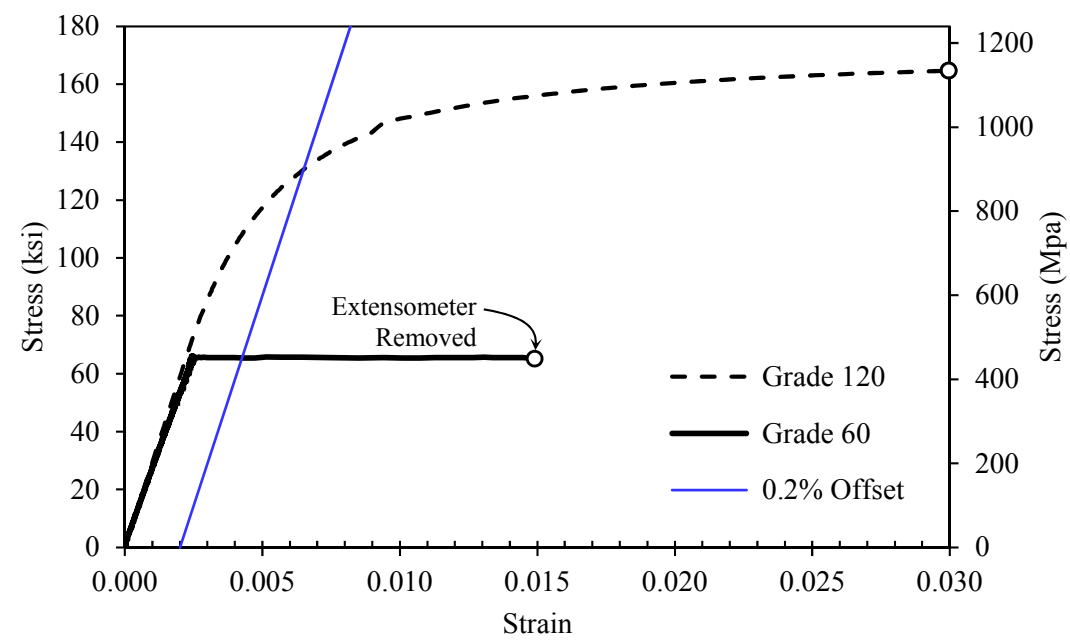

Figure 4-5 Measured stress-strain relationship for longitudinal reinforcement in column specimens (adapted from Rautenberg, 2011).

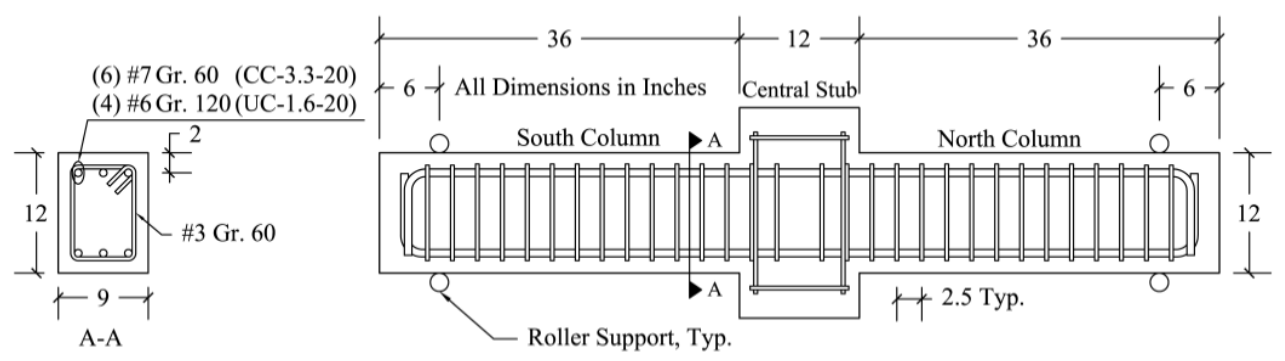

Figure 4-6 Reinforcement details for column specimens (adapted from Rautenberg, 2011).

columns reached nearly identical flexural strength while limiting the shear stress, $V / b d$, to values approaching $8 \sqrt{f^{\prime}}$ (psi). All transverse reinforcement was Grade 60 .

The measured shear drift response for CC-3.3-20 is shown in Figure 4-7a. The controlling column completed the first cycle to $5 \%$ drift, but the longitudinal bars buckled during the second cycle at that drift ratio. A plausible explanation for the specimen failing at a drift ratio near zero is that the cracks on both sides (tension and compression) of the critical section were open, and the axial load was carried predominantly by the longitudinal reinforcement, which led to buckling.

Figure 4-7b shows the measured shear-drift response for the specimen with Grade 120 reinforcement, UC-1.6-20. This specimen showed reduced post-cracking stiffness and increased yield deformation, compared to the specimen with Grade 60 reinforcement, Specimen CC-3.3-20. The controlling column of Specimen UC-1.6-20 completed the first half-cycle to 5\% drift, but the longitudinal bars buckled during the second half-cycle at that drift ratio. Upon continued testing, the remaining longitudinal bars buckled at a small drift ratio (approximately $2 \%$ ) during the second cycle to 5\% drift. Again, a plausible explanation is that the longitudinal 


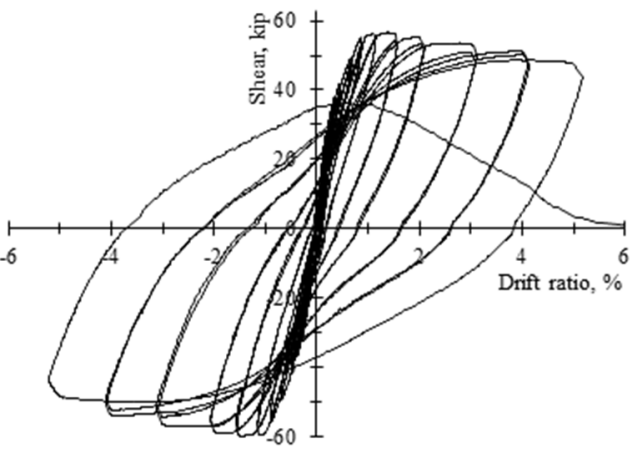

(a)

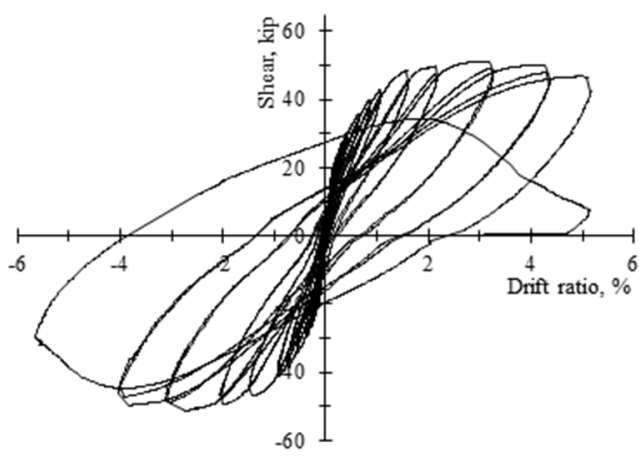

(b)

Figure 4-7 Measured shear versus drift ratio in testing of columns (Rautenberg, 2011): (a) Specimen CC-3.3-20, with Grade 60 reinforcement; and (b) Specimen UC-1.6-20, with Grade 120 reinforcement.

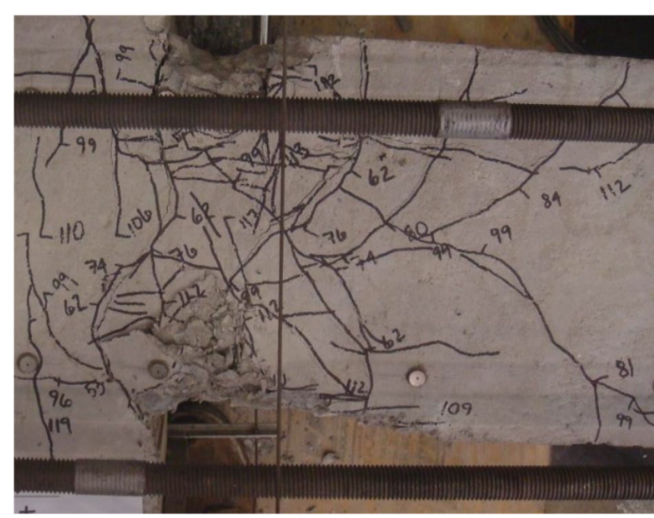

(a)

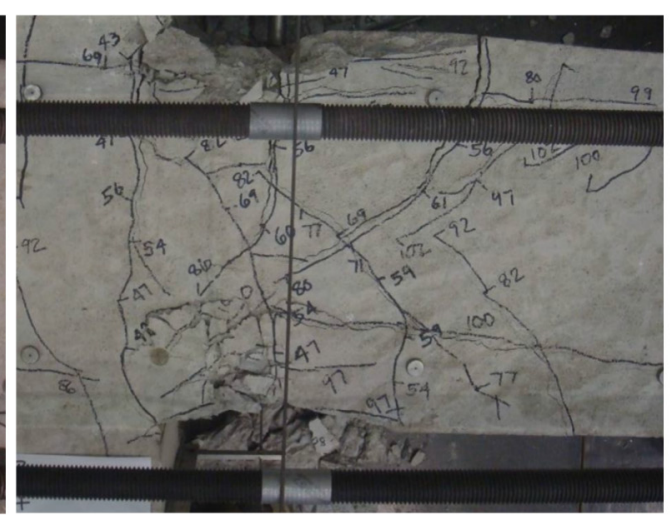

(b)

Figure 4-8 Column specimens at first excursion to drift ratio of 4\% (Rautenberg, 2011): (a) Specimen CC-3.3-20, with Grade 60 reinforcement; and (b) Specimen UC-1.6-20, with Grade 120 reinforcement.

bars were required to carry a larger fraction of the axial load when the concrete cracked. Figure 4-8 shows photographs of the plastic hinge region of each specimen. It is important to emphasize that both column specimens reached drift ratios of $5 \%$ or greater, which exceeds what would be expected for a modern building structure subjected to a design level earthquake. The above test data indicate that replacing Grade 60 longitudinal reinforcement with reduced amounts of ASTM A1035 Grade 120 reinforcement (reduced in proportion to the yield strength of the reinforcement) leads to comparable flexural strength and deformation capacity. Similar findings were obtained by Tretiakova (2013) on cyclic tests of concrete columns reinforced with SAS 670 Grade 97 steel bars. The column specimens tested by Tretiakova were nearly identical to the ones tested by Rautenberg (2011).

In addition to the tests discussed here, many tests have been conducted in Japan on columns with the yield strength of the longitudinal and transverse reinforcement reaching $174 \mathrm{ksi}$ and with the concrete compressive strength ranging from $8 \mathrm{ksi}$ to 30 
ksi. A large database of 115 columns has been used to calibrate statistical models for predicting the ultimate deformation capacity of a column (Ishikawa et al., 2008).

\subsubsection{Columns with Mixed-Grade Reinforcement}

Mixed-grade reinforcement is the combination of different grades of reinforcement in the same column, intended to improve the ductility and post-yield strength gain of the member. Typically, mixed-grade columns combine conventional strength reinforcement, $58 \mathrm{ksi}$ to $73 \mathrm{ksi}$, with ultra-high-strength reinforcement $135 \mathrm{ksi}$ or greater. A number of research projects have identified the benefits of using mixedgrade reinforcement (Watanabe et al., 1990; Sato et al., 1993; Satyarno, 1993; Watanabe et al., 1995; Park, 1996; Xiao et al., 2008). Park (1996) states:

"The flexural ductility of reinforced concrete columns when undergoing plastic hinge rotation can be improved by using mixed grades of normal strength and ultra-high-strength longitudinal reinforcement. Yielding of such columns when loaded into the inelastic range commences in the normal strength steel and then at higher curvatures in the high strength steel, thus delaying the degradation of the flexural strength of the column.

... a positive stiffness of the column is maintained at higher inelastic displacements when mixed ultra-high-strength and normal strength longitudinal steel is used."

Watanabe et al. (1995) identify practical problems that must be addressed, "such as the possible splitting bond failure along, and possible elasto-plastic buckling of, very high-strength longitudinal reinforcement."

Qazi et al. (2008) analytically studied six- and ten-story buildings for the effect of replacing $20 \%$ and $50 \%$ of the conventional strength reinforcement (58 ksi) in columns with ultra-high-strength reinforcement ( $270 \mathrm{ksi})$. Replacement of all of the column longitudinal reinforcement with the ultra-high-strength reinforcement in the bottom two stories was also evaluated. The total area of column reinforcement was not reduced in the substitutions. The study found that residual lateral displacement was reduced with the substitution, and formation of a failure mechanism was delayed.

Using mixed-grade longitudinal reinforcement in columns appears to be beneficial, but practical issues must be overcome before using this approach in U.S. practice. ACI 318-11 does not have specific provisions to address splitting along the length of a column or inelastic buckling of ultra-high-strength longitudinal reinforcement. Additionally, reinforcement of this strength is not readily available in the United States. 


\subsubsection{Columns with Ultra-High-Strength Fiber Reinforced Concrete and High-Strength Reinforcement}

Codes have limited the use of high- and ultra-high-strength concrete in the construction of buildings in seismic regions, because these types of concrete are inherently brittle. These types of concrete do not exhibit the dilation properties of conventional strength concrete, which permits the efficient use of confinement reinforcement as a way to increase ductility.

Ousalem et al. (2009) report the results of an experimental program where three 11 -inch square columns were built using ultra-high-strength concrete with $f_{c}^{\prime}$ of 25 ksi and SD685 and SD980 high-strength longitudinal reinforcement, with specified yield strengths of $100 \mathrm{ksi}$ and $140 \mathrm{ksi}$, respectively. To control possible bond-split cracking and sudden spalling of the concrete cover, and to increase ductility and lateral deformation capacity, Ousalem et al. incorporated high-strength steel fibers into the concrete mix at a $1 \%$ volumetric ratio. These columns were tested under constant and variable axial load conditions, including high compressive and high tensile axial load ratios. The critical section of the test columns maintained their capacity, allowing the columns to reach drift ratios in excess of $3.5 \%$. Although it is unlikely this technology will be adopted by codes in the United States in the near future, it indicates that some particular applications could make use of columns that incorporate ultra-high-strength materials and steel fibers.

\subsubsection{Beam-Column Joints}

Joints are one of the most complex structural elements in special moment frames. Joints have to transfer shear forces that generally are more than twice those carried by the columns framing into them. Furthermore, plastic hinges are generally expected to develop in the beams at the joint faces, requiring the beam longitudinal reinforcement to repeatedly yield in tension and harden, and also develop large compressive forces.

Large tensile and compressive forces develop concurrently in the beam longitudinal reinforcement at opposite ends of interior joints, as shown in Figure 4-9. The tensile forces are associated with the development of strains well past the yield strain, most likely within the strain hardening region. The compressive forces depend on the detailing of the top and bottom reinforcement in the section, which are often expected to be stressed to near the yield strength. Concurrent tensile and compressive forces can only develop in the longitudinal bars at the opposite sides of an interior joint if the bars are developed over a relatively short length in the joint core. As a result, large bond stresses are expected to develop in the joint core (ACI, 2002). Cycles of repeated tensile and compressive forces associated with high tensile strain demands gradually degrade the bond conditions in interior joints and, in some cases, result in bond failure. 


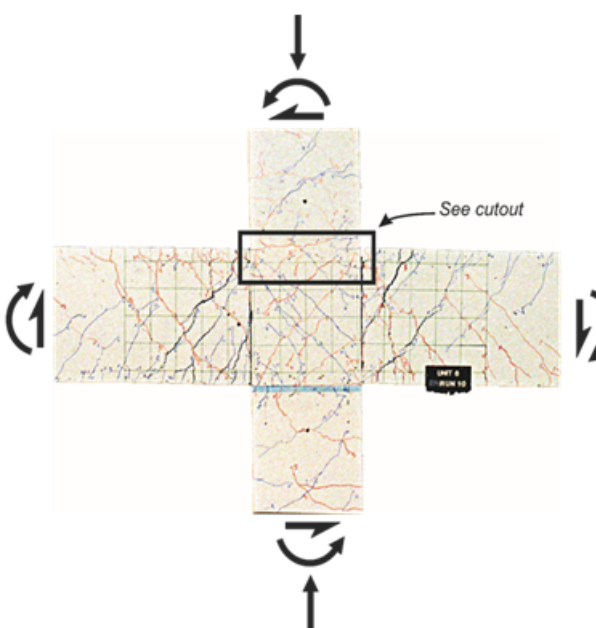

(a)

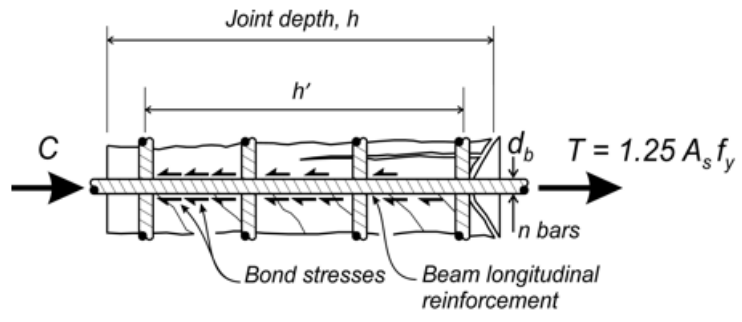

Average bond stress: $u_{b}=(T+C) /\left(n \pi d_{b} h^{\prime}\right)$

(b)

Figure 4-9 Bond stress in interior joints of moment frames with beams developing plastic hinges at the joint faces showing: (a) Interior joint with beam plastic hinges at the joint faces; and (b) cutout depicting forces required for equilibrium in the beam longitudinal reinforcement and bond stresses around the reinforcement anchored in the joint core.

Bond failure causes permanent degradation in the stiffness of the frame. The bond conditions in the joint cannot be restored through any nondestructive repair method due to the volumetric expansion of the concrete crushed around the perimeter of the longitudinal bars.

To delay the development of bond failure, codes provide requirements to calculate the minimum ratio of the column depth to the bar diameter of the beam longitudinal reinforcement. Such requirements recognize that the bond conditions in wellconfined interior joints are substantially better than in less well-confined joints or in other conditions where bars are being developed. Thus, the required joint depths are much shorter than combined tension and compression development lengths.

The main challenge in the incorporation of high-strength longitudinal reinforcement in beams of special moment frames is finding suitable ways to anchor the reinforcement in the joints. The following sections discuss research looking at joints with high-strength reinforcement, and present analyses that indicate changes that may be needed to enable the use of high-strength reinforcement in the beam-column joints of moment frames.

\subsubsection{Development of Straight Beam Longitudinal Reinforcement in Interior Joints}

The use of high-strength reinforcement brings some challenges when it comes to developing longitudinal bars of special moment frames, particularly in interior joints. Zhu and Jirsa (1983) and Lin et al. (2000) present an extensive summary of past 
research work on interior joints, with emphasis on the depth of these joints to ensure suitable bar bond performance. Additionally, Aoyama (2001) reports the results of a test program that assessed the bond strength of reinforcement of Grade 60 to Grade 100. These tests were used to develop recommendations for calculating the minimum joint depth in moment frames in Japan.

Current recommendations in ACI 318-11 for the depth of interior joints (equal to twenty times the diameter of the beam longitudinal reinforcement in normal weight concrete) grew out of the work of Zhu and Jirsa (1983). These researchers examined the performance of a number of component tests built using Grade 60 reinforcement, with concrete strengths in the 4 ksi to 5 ksi range.

Lin et al. (2000) investigated the performance of special moment frame joints incorporating Grade 75 reinforcement, which was to supersede Grade 60 reinforcement in New Zealand. They also report the results of eight quasi-static reversed cyclic tests on interior beam-column joint units. The ratio of the column depth to beam longitudinal reinforcement was equal to 32.5 , and the strength of the concrete was $4.5 \mathrm{ksi}$.

The main variables investigated by Lin et al. were the amount of joint reinforcement, the axial load level, and the ratio of top to bottom areas of beam longitudinal reinforcement. The test units incorporated precast beam-joint elements, and the beam-columns were connected in order to emulate cast-in-place construction. All elements were cast in the upright position and used normal weight concrete. The beams in this test series were 22 inches deep. Consequently, all the beam top longitudinal reinforcement was cast with over 12 inches of fresh concrete below. The depth and construction of the beams in these units provided a way to observe whether the top bar effect also affected the bond conditions in the joint.

Unit 2 was reinforced with eight $12 \mathrm{~mm}$ (nominally No. 4) top and bottom longitudinal bars, in two layers of four bars each. The performance of this test unit illustrates the findings of Lin et al. The column in this unit was tested under constant axial force equal to $0.4 f_{c}^{\prime} A_{g}$. This test unit was able to sustain two cycles to a drift ratio of $2.6 \%$. When loading towards the first cycle to a drift ratio of $4 \%$, the top longitudinal reinforcement slipped through the joint, causing pinching in the hysteretic response that persisted for the rest of the test (see the mark "bf" in Figure 4-10).

Bar slip through the joint is a damage state that is reached when the peak to peak slip of the longitudinal reinforcement relative to the surrounding concrete at the joint mid-depth exceeds the clear spacing between bar deformations. Once bar slip through the joint occurs the longitudinal reinforcement is expected to move as a rigid body inside the joint until the beam joint interface crack closes. This enables these 


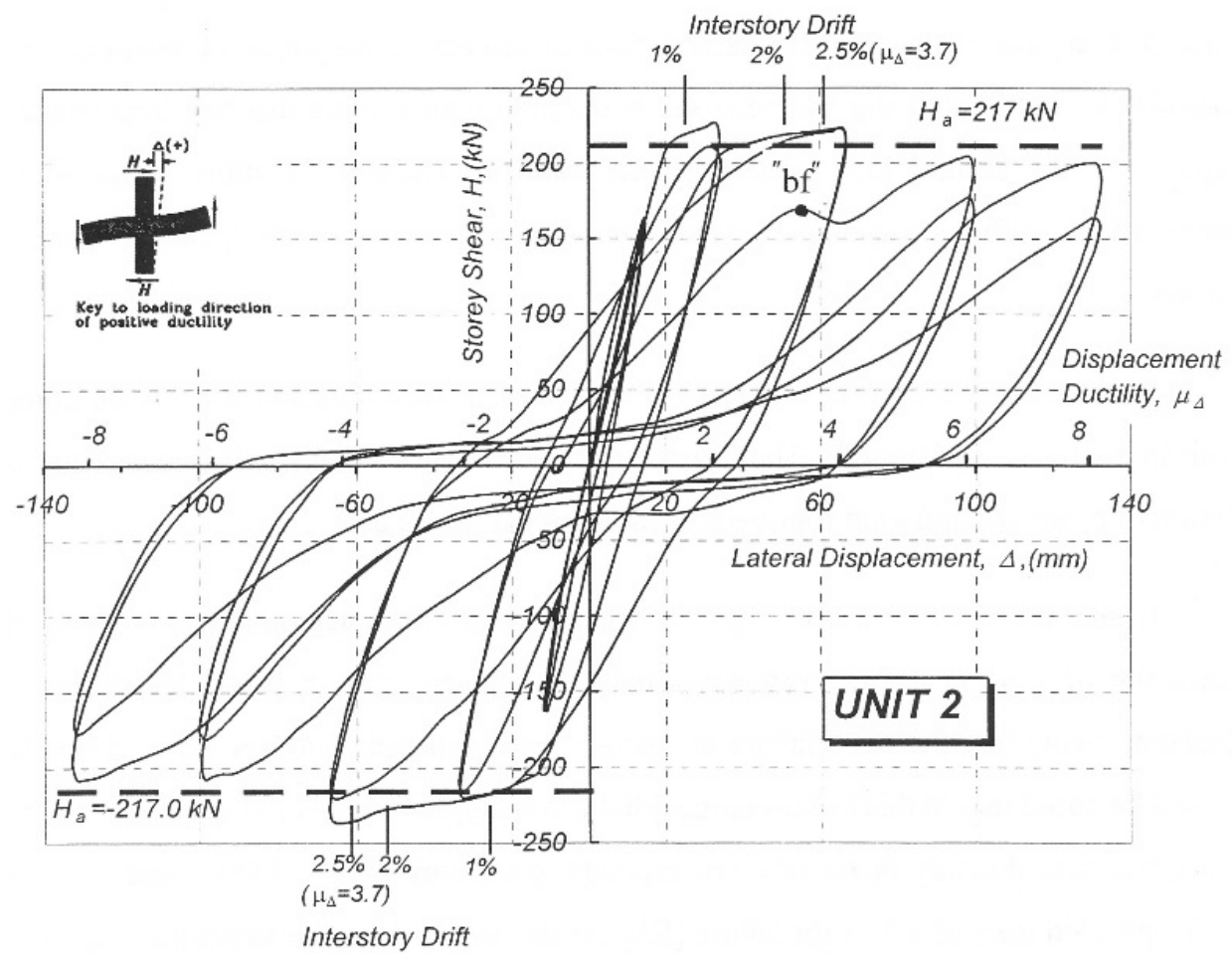

Figure 4-10 Hysteretic lateral-force lateral-displacement response of joint Unit 2 with Grade 75 reinforcement tested by Lin et al. (2000).

bars to be anchored in the beam at the opposite side of the joint, where the bars would typically be expected to be subjected to compression (Zhu and Jirsa, 1983). This could increase the beam neutral axis depth and reduce the rotation capacity of the plastic hinge that forms in the beam at the opposite side of the joint.

Lin et al. reported longitudinal reinforcement slipping at the top and bottom of the beam relative to the concrete surface at the center of the joint and at the joint faces in the test units. Figure 4-11 plots the recorded history of bar slip for the top and bottom beam longitudinal reinforcement of Unit 2. When the test unit was subjected to a drift ratio of $1.3 \%$, bar slip at the top recorded at the joint mid-depth reached 0.024 inches, which is about $12 \%$ of the clear spacing of 0.2 inches between bar deformations. The bar slip at the joint faces at this drift level was about 0.08 inches, with $80 \%$ of it caused by tensile strain penetration of the longitudinal bars into the joint. The rigid body slippage of the bar contributed to the remaining $20 \%$. At the second cycle at a drift ratio of $2.6 \%$, the slippage of the bar at the joint mid-depth increased to 0.16 inches, or $80 \%$ of the clear spacing between bar deformations. The contribution of this slippage to the bar slip, recorded at the joint faces, increased to about $50 \%$. The effect of bar slip through the joint was recorded in the overall hysteretic response of the test unit when peak-to-peak slippage was 1.7 times the clear distance between the bar deformations (see the "bf" marks in Figures 4-10 and 4-11). Beyond this point, the rigid body slippage of the bar had a pronounced 
contribution toward the slippage at the joint faces, until the bars were able to be developed in the beam on the side where they were meant to be in compression.

The recorded bar slip in the top and bottom bars, as shown in Figure 4-11, provides evidence that the so-called top bar effect in the longitudinal reinforcement also affects the bond conditions in interior joints. While significant mid-depth joint slippage was observed for the top bars, less slippage was recorded for the bottom bars.

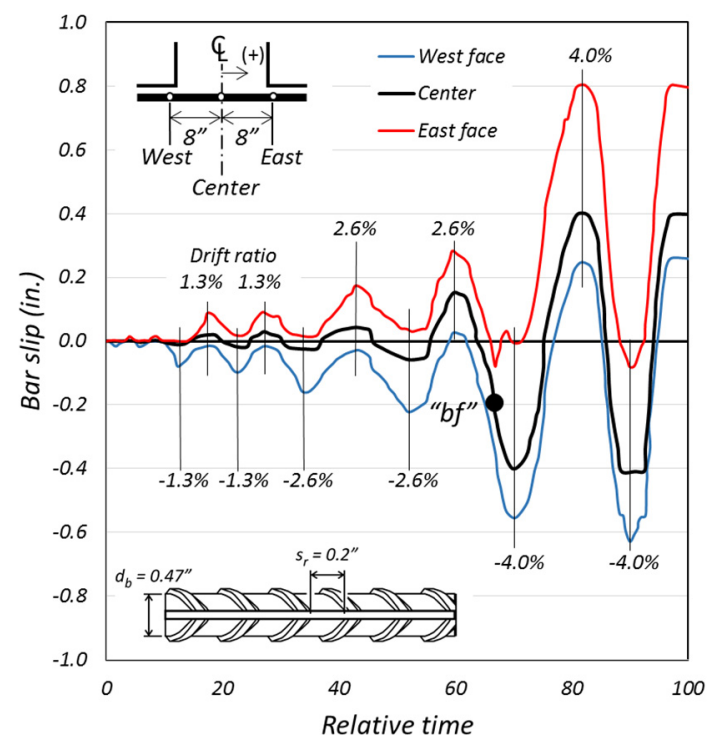

(a)

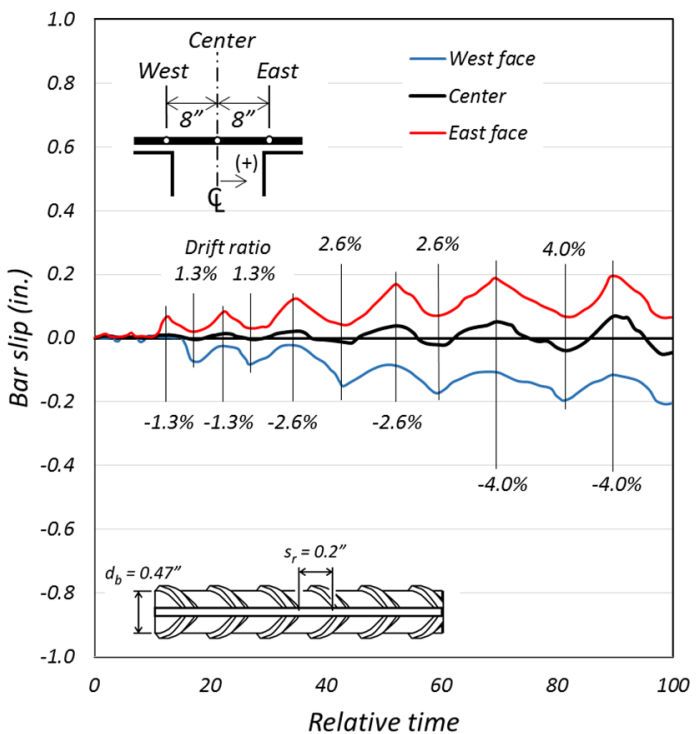

(b)

Figure 4-11 Recorded slip for longitudinal Grade 75 bars inside an interior joint relative to the concrete surface (adapted from Lin et al., 2000): (a) Top bars; (b) bottom bars.

\subsubsection{Calculation of Joint Depths}

Upon studying bar slip response of Grade 40, Grade 60, and Grade 75 beam longitudinal reinforcement anchored in interior beam-column joints, Lin et al. (2000) observed that bond degrades at a greater rate as the grade of the reinforcement increases. This is most likely due to the damage caused by local bond-slip, itself a result of the elastic deformation of the bars (Eligehausen et al., 1983). Lin et al. recommended an equation to calculate the joint depth in interior joints of normal weight concrete with plastic hinges developing at the joint faces. This includes the detrimental effect of casting significant concrete below the longitudinal reinforcement (top bar effect), as well as the enhancement of the bond conditions caused by axial load. The recommendation, with some minor variables omitted, and in notation compatible with usage in ACI, is:

$$
h=\frac{\psi_{t}}{1250 \psi_{p}} \frac{f_{y}^{1.3}}{\sqrt{f_{c}^{\prime}}} d_{b}
$$


where $\Psi_{t}$ is the modification factor for the column axial load passing through the joint, 1.2 for bars cast with 12 inches of fresh concrete below the bar, and 1 in all other cases and $\Psi_{p}$ is a modification factor for the top bar effect, defined in Equation 4-2.

$$
\psi_{p}=1+\frac{1}{1.8} \frac{P_{u}}{A_{g} f_{c}^{\prime}} \text { and } \psi_{p} \geq 1
$$

The equation suggested by Lin et al. reflects the approach to reinforced concrete design in New Zealand. This approach aims to minimize the probability of bar bond failure and improve the likelihood of post-earthquake repairability. However, tests have shown that bond failure of the beam longitudinal reinforcement often occurs at drift levels comparable to those expected for the maximum considered earthquake, or greater (Zhu and Jirsa, 1983; Lin et al., 2000), where repairability may no longer be an issue. Hence, relaxation of the maximum bar diameter allowed under Equation 4-1 could be made with the rationale of minimizing bar bond failure for the design level earthquake, as intended in ACI 318 (Zhu and Jirsa, 1983), rather than for the maximum considered earthquake. To this end, the coefficient of 1,250 in Equation 4-1 could be increased. Moreover, the top bar modification factor could be made compatible with that currently recommended in ACI 318-11, $\Psi_{t}=1.3$; the modification factor could be slightly adjusted to unity at $P_{u} /\left(A_{g} f_{c}^{\prime}\right)=0.1$. These modifications, which translate the Lin et al. approach into something closer to the current approach in the United States, result in the following equation for the joint depth:

$$
h=\frac{\psi_{t}}{1500 \psi_{p}} \frac{f_{y}^{1.3}}{\sqrt{f_{c}^{\prime}}} d_{b}
$$

where $\Psi_{t}$ is 1.3 for bars cast with 12 inches of fresh concrete below the bar, and 1 in all other cases and $\Psi_{p}$ is defined in Equation 4-4.

$$
\psi_{p}=0.95+\frac{1}{2} \frac{P_{u}}{A_{g} f_{c}^{\prime}} \text { and } \psi_{p} \geq 1
$$

Equation 4-3 can result in a joint depth less than $20 d_{b}$, which is below the depth currently allowed in ACI 318. For this reason, it is recommended that joint depths should not be permitted below the current limit.

The general equation for the joint depth given by Equation 4-3 can be simplified by making $\Psi_{t}=1.3$ and $\Psi_{p}=1$, thus obtaining an expression suitable for simplified design:

$$
h=\frac{1}{1200} \frac{f_{y}^{1.3}}{\sqrt{f_{c}^{\prime}}} d_{b}
$$

where $h$ shall not be taken smaller than $20 d_{b}$. 
Equation 4-3 can be simplified even further to develop a design equation for the joint depth that is a function of the bar diameter alone, as is the current equation in ACI 318-11. If it is assumed that $\Psi_{t}=1.3, \Psi_{p}=1$, and $f_{c}^{\prime}=6,000 \mathrm{psi}$, Equation 4-3 simplifies to the following for Grade 80 reinforcement $\left(f_{y}=80,000 \mathrm{psi}\right)$ :

$$
h=26 d_{b}
$$

For Grade 100, Equation 4-3 simplifies to:

$$
h=35 d_{b}
$$

The Lin et al. approach, as adjusted to reflect U.S. practice, can be compared to the Japanese approach to calculate joint depth. Thirteen tests were performed on bars embedded in a well-confined column to develop design provisions for the joint depth in Japan (Aoyama, 2001). In this test series, the main variables were the concrete strength, which varied from $5.8 \mathrm{ksi}$ to $20 \mathrm{ksi}$; the joint depth, which was either 16 or 24 inches; the bar diameter, which ranged from $3 / 4$ inch to 13/8 inches; and the column axial load ratio, whose range is not reported. Analysis of the test data led to an equation for the joint depth, which, written in ACI notation, is the following:

$$
h=\frac{1}{7\left(1+\frac{P_{u}}{A_{g} f_{c}^{\prime}}\right)} \frac{f_{y}}{\left(f_{c}^{\prime}\right)^{2 / 3}} d_{b}
$$

A comparison of Equations 4-3 and 4-8 shows that relative to the equation by Lin et al., the Japanese joint depth equation gives less weight to the yield strength of the reinforcement and more weight to the concrete strength and axial load ratio. The joint depth calculated by these two equations, normalized by the bar diameter, are compared graphically in Figure 4-12. The equations have been plotted for concrete strengths ranging between $3 \mathrm{ksi}$ to $8 \mathrm{ksi}$ for Lin et al. and from $5.5 \mathrm{ksi}$ to $14 \mathrm{ksi}$ for the Japanese equation. Figure 4-12a depicts the joint depth to bar diameter ratio versus the concrete strength for Grade 60, Grade 80, and Grade 100 beam longitudinal reinforcement calculated with Equation 4-3 evaluated with $\Psi_{t}=1.3$ and $P_{u} /\left(A_{g} f_{c}^{\prime}\right)=0.1$ and Equation 4-8 evaluated for the same axial load ratio. Figure 4-12b compares these two equations for an axial load ratio of $P_{u} /\left(A_{g} f_{c}^{\prime}\right)=0.4$.

In Figures 4-12a and 4-12b, it is evident that bond conditions in interior joints are enhanced when using high-strength or ultra-high-strength concrete. Some projects have used construction strategies of casting the columns and joints with high-strength concrete and the beams with normal strength concrete. A comparison of the two equations in the common range of concrete strengths indicates that the Japanese equation is more stringent than the modified Lin et al. equation when the column axial load is low, as shown in Figure 4-12a. Nonetheless, both equations lead to similar joint depths when the axial load ratio is $P_{u} /\left(A_{g} f_{c}^{\prime}\right)=0.4$, as shown in Figure 4-12b. 


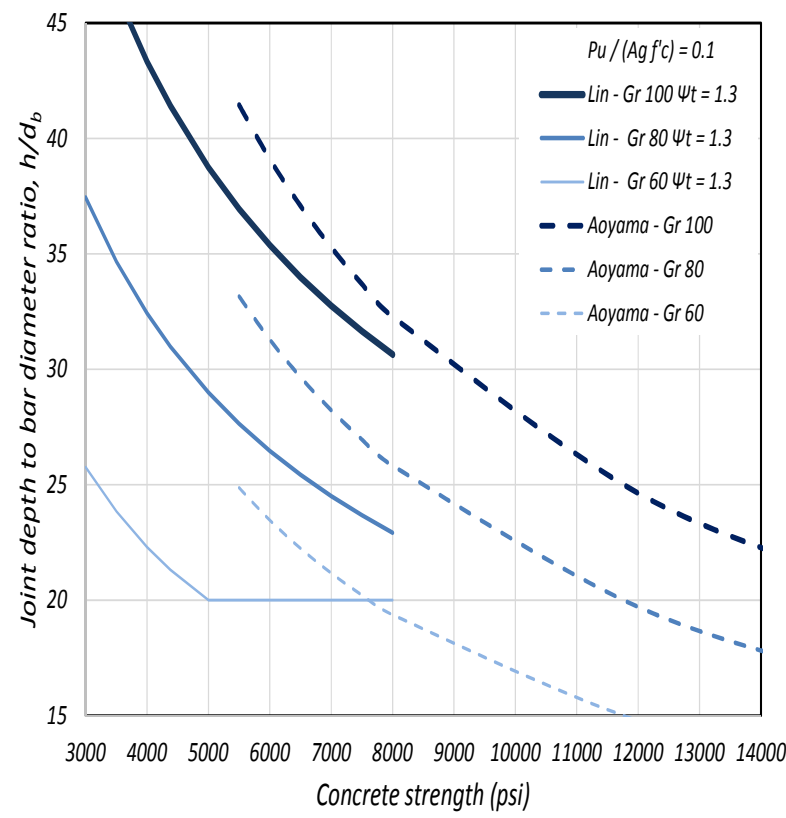

(a)

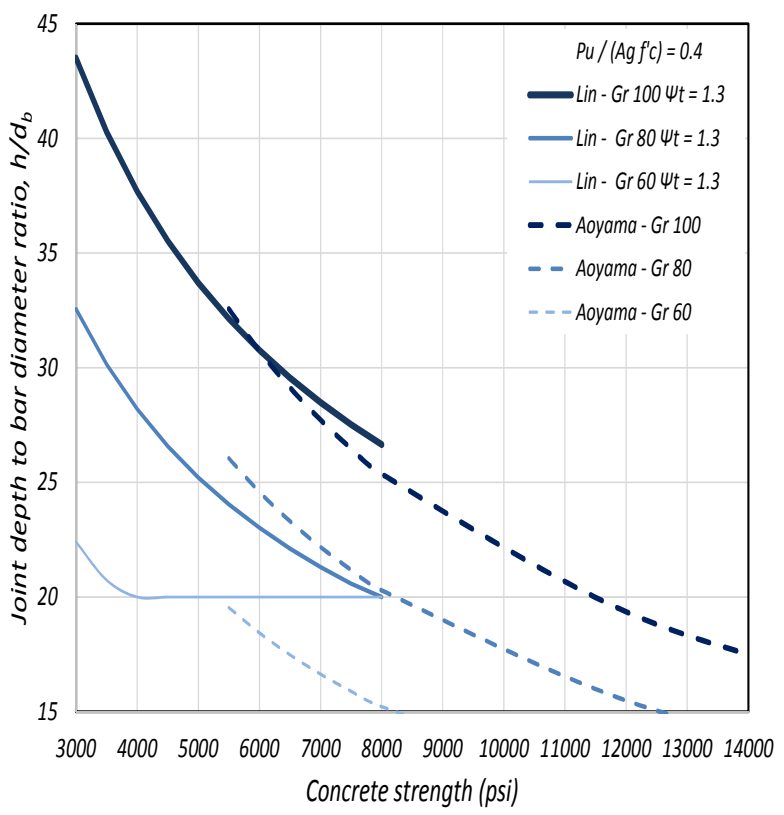

(b)

Figure 4-12 Comparison of joint depth to bar diameter ratio, $h / d_{b}$, calculated using modified Lin et al. (2000) (Eq. 4-3 with $\Psi_{t}=h$ ) approach and Aoyama (2001) approach, for various grades of reinforcement: (a) with Axial load ratio $P_{u} /\left(A_{g} f_{c}^{\prime}\right)=0.1$; and (b) Axial load ratio $P_{u} /\left(A_{g} f_{c}^{\prime}\right)$ $=0.4$.

Figure 4-12 indicates that deep joints or, conversely, very small bar diameters relative to the joint size, are needed when Grade 100 reinforcement is used in interior joints of special moment frames with normal weight concrete and a compressive strength of concrete below 6 ksi.

\subsubsection{Alternative Mechanisms for Developing Beam Longitudinal Reinforcement in Interior Joints}

If an increase in the concrete strength or the joint depth is not feasible, a possible alternative for developing large diameter, high-strength longitudinal reinforcement in interior joints is to connect the reinforcement to proprietary mechanical devices. Such devices are specifically designed to reduce the bar slip and provide adequate development of the bars in the joint. Two tests have been reported in the literature, and the tests exhibited satisfactory hysteretic performance and drift capacity.

Chang et al. (2008) report the test results of two interior beam-column specimens whose beams incorporated ASTM A722 and A1035 beam longitudinal reinforcement. These test specimens are referred to as Specimen 3 and Specimen 4. In these, the beam longitudinal reinforcement was mechanically spliced or connected to proprietary devices that were anchored in the joint, as shown in Figure 4-13. The beams in these units were 22 inches wide by 36 inches deep, and the columns were 30 inches wide by 36 inches deep. 


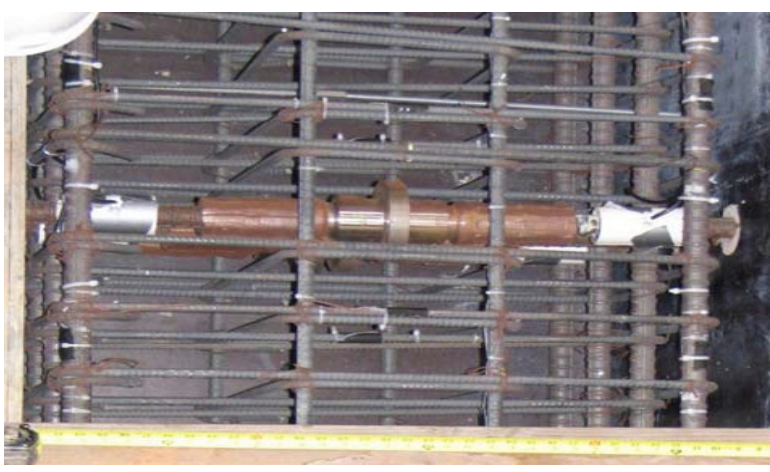

(a)

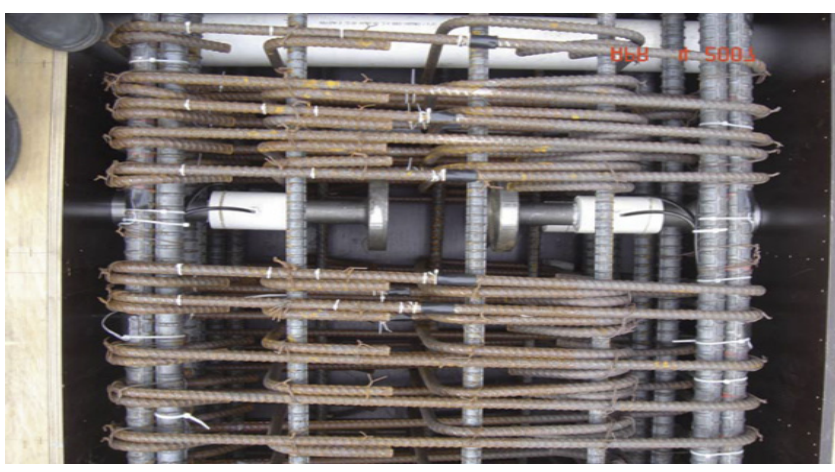

(b)

Figure 4-13 View of mechanical connectors used in the joint region in Chang et al. (2008) tests: (a) Specimen 3 with ASTM A1035 reinforcement; and (b) Specimen 4 with ASTM A722 threaded bars.

The beam in Specimen 3 had three No. 10 ASTM A1035 Grade 120 longitudinal reinforcing bars with yield and ultimate tensile strengths of $130 \mathrm{ksi}$ and $167 \mathrm{ksi}$, respectively. These bars were spliced at the joint faces to a mechanical connector. The connector had a single ring at the joint mid-depth, shown in Figure 4-13a. In this specimen, the columns and joint were cast prior to the beam. This allowed these two elements to incorporate higher strength concrete in the columns than in the beams. The concrete strengths measured on the day of testing were $5 \mathrm{ksi}$ for the beams and $6.7 \mathrm{ksi}$ for the column and joint.

Specimen 3 was tested under constant axial force equal to $0.02 A_{g} f_{c}^{\prime}$. Given the joint concrete strength and column axial force, Equations 4-3 and 4-8 would have required joint depths of 54 inches and 60 inches, respectively, to provide adequate development of the ASTM A1035 No. 10 bars. Conversely, for the joint geometry, joint concrete strength, and column axial force, Equations 4-3 and 4-8 would have restricted the beam longitudinal reinforcement to No. 6 bars. Nevertheless, the hysteretic response of this unit, shown in Figure 4-14a, is stable and satisfactory, indicating the effectiveness of the mechanical device used. This specimen reached two cycles to a drift ratio of $3.2 \%$, and was then subjected to a drift ratio of $5.5 \%$, when the beam longitudinal reinforcement fractured.

The beams in Specimen 4 were reinforced with ASTM A722 $13 / 8$ inch threaded bars with measured yield and ultimate tensile strengths of $142 \mathrm{ksi}$ and $167 \mathrm{ksi}$, respectively. These bars were threaded to headed connectors at the joint faces, as shown in Figure 4-13b. Sufficient transverse reinforcement was provided in the column and the joint adjacent to the mechanical device to transfer the tie force to the back end of the joint. As in Specimen 3, the column and the joint in this unit were cast prior to the beam. The concrete strengths measured on the day of testing for Specimen 4 were $5.7 \mathrm{ksi}$ for the beams and $9.6 \mathrm{ksi}$ for the column and joint. 
Specimen 4 was tested under constant axial force equal to $0.02 A_{g} f_{c}^{\prime}$. For a given specified yield strength of $120,000 \mathrm{psi}$, and using the joint concrete strength and column axial force, Equation 4-3 would have required a joint depth of 53 inches to provide adequate development to the ASTM A722 13/8-inch bars. Conversely, for the joint geometry, joint concrete strength, and column axial force, Equation 4-8 would have restricted the beam longitudinal reinforcement to No. 7 bars. Specimen 4 exhibited excellent hysteretic performance overall, as shown in Figure 4-14b, again indicating that the proprietary bar device effectively anchored the beam longitudinal reinforcement in the joint. Limited slackness was observed in the hysteretic response at a shear force reversal, as shown in Figure 4-14b. Chang et al. reported that, at large drift ratios, the mechanical device gradually pulled out of the face of the joint, indicating possible crushing of the concrete surrounding the headed anchor. It is notable that Specimen 4 was loaded through cycles to a $7.2 \%$ drift ratio, and only then was buckling of the beam longitudinal reinforcement noticeable at the connection with the mechanical device.

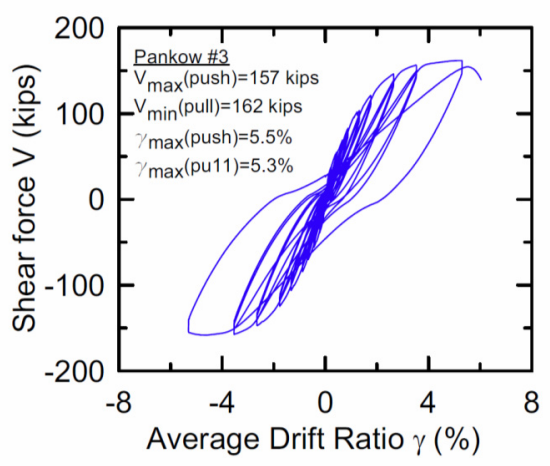

(a)

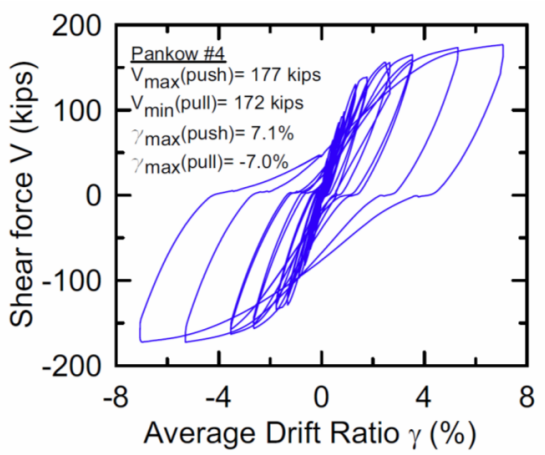

(b)

Figure 4-14 Hysteretic response of cruciform test units anchored with mechanical connectors in Chang et al. (2008) tests: (a) Specimen 3 with ASTM A1035 reinforcement; and (b) Specimen 4 with ASTM A722 threaded bars.

The force transfer mechanism through the joint for Specimen 4 relies upon placement of numerous additional hoops at the joint top and bottom and at the column ends to transfer force from the head to the back of the joint. The joint would need to be specifically designed for this force transfer. Without accounting for the force transfer, a vertical crack could form in the center of the joint between the mechanical anchorage devices. Therefore, horizontal transverse reinforcing bars oriented parallel to the longitudinal bars are needed both near the perimeter and the center of the joint. Strut and tie modeling would be an appropriate means of determining the magnitude of forces being transferred. 


\subsubsection{Development of Hooked Bars in Exterior Joints}

Beam longitudinal reinforcement is generally terminated with standard 90-degree hooks in exterior joints, for which ACI 318-11 has a series of requirements. These provisions aim to ensure that bars can be developed in tension and that a strut can develop diagonally through the joint to carry the joint shear. The main issues of concern associated with ending high-strength bars with standard 90-degree hooks in exterior joints are the following: (1) the potential for increased bar slip as a result of crushing of the concrete, due to the larger local contact stresses around the bend in the hooked bars; and (2) the potential for developing a splitting failure in the joint (Marques and Jirsa, 1975). In Japan, the use of USD685 high-strength reinforcement terminated with a hook inside an exterior joint is highly restricted (Aoyama, 2001). Hooked bars can only be used in joints that include transverse reinforcement in which the strength of the concrete is greater than $11 \mathrm{ksi}$. This recommendation is based on the results of tests that used rectangular hoops around the perimeter of the beamcolumn joint, which is noncompliant with ACI 318 requirements. For this reason, the results of the tests performed in Japan cannot be used to draw conclusions for use in the United States.

Chen et al. $(2012,2013)$ document a shake table test of a five-story building built at full-scale that was conducted in the United States. This building incorporated highstrength reinforcement bars. At the exterior beam-column joints, the high-strength bars had 90 degree hooks at their ends. Special moment frames, consisting of 12inch wide by 30 -inch deep beams and 18 -inch wide by 26 -inch deep columns, provided the lateral resistance in this building. The beams in the lower two floors were reinforced with ASTM A1035 Grade 120 steel bars, consisting of two No. 7 bars, top and bottom. The measured yield and ultimate tensile strength of these bars were $130 \mathrm{ksi}$ and $160 \mathrm{ksi}$, respectively. The compressive strength of the concrete averaged $7.5 \mathrm{ksi}$ on the day of testing. The hooked bars were extended to near the back of the joint, and the joint had transverse reinforcement compliant with ACI 318 using $\ell_{d h}$ equal to 20 inches. The embedment length, 21.5 inches, provided for the No. 7 bars slightly exceeded that required by ACI 318. The building was subjected to input ground motions that caused rotation demand on the beams exceeding 0.06 radians and caused fracture in some of the No. 7 top and bottom bars. Inspections indicated no distress in the beam-column joints in the building.

\subsubsection{Joint Transverse Reinforcement}

Beam-column joints anchoring high-strength beam and column reinforcement have an increased potential for splitting in exterior joints as a result of increased forces for a bar with a standard hook. However, inspection of the exterior joints in the shake table test reported by Chen et al. (2012) showed that the use of ASTM A1035 Grade 120 longitudinal reinforcement did not cause splitting in the joint. Further research 
may indicate whether a change in the amount of joint transverse reinforcement is required.

\subsubsection{Strong Column-Weak Beams}

A fundamental principle that has been adopted in ACI 318 for the design of concrete moment frames is the strong column-weak beam concept. This principle holds that the ratio of the sum of the flexural strengths of the columns framing into a joint divided by the sum of the flexural strengths of the beams framing into the joint should be $6 / 5$ or more. This is intended to promote yielding and formation of plastic hinges in beams before yielding and hinging takes place in columns. Hinging of beams spreads story drifts more uniformly throughout the building height than hinging of columns; moreover, hinging of columns can create story collapse mechanisms. A story collapse mechanism would not arise if plastic hinges formed at the ends of all beams at the top and bottom of the same story.

In ACI 318-11, the strong column-weak beam concept is enforced in the design of special moment frames through the so-called sixth-fifths rule in Section 21.6.2.2. The required ratio of column strength to beam strength, $6 / 5$, was originally determined largely through engineering judgment, at a time when the yield strength of flexural reinforcement used in concrete moment frames ranged from $40 \mathrm{ksi}$ to 60 ksi. A characteristic of Grade 40 and Grade 60 ASTM A615 and Grade 60 A706 reinforcement is the presence of a yield plateau in the stress-strain curve. This yield plateau typically has a strain length of 0.005 to 0.015 . Reinforcement with yield strengths of $100 \mathrm{ksi}$ or higher may not have a yield plateau, but may exhibit a rounded or bilinear stress-strain curve. They may also have tensile strength to yield strength ratios that deviate from the 1.25 required minimum ratio of ASTM A706 reinforcement, potentially requiring more than a $6 / 5$ ratio of column-to-beam strength to inhibit column hinging.

The effect of high-strength reinforcement on the strong column-weak beam provisions in ACI 318-11 should be investigated further. It is important to develop analytical models calibrated with the measured response of full-scale beam-column joints and full-scale multi-story moment frames that incorporate high-strength flexural reinforcement and reflect typical U.S. design codes and practice.

\subsection{Special Structural Walls}

This section discusses the characteristics of special structural walls used on the West Coast of the United States and the results of tests of structural walls that include highstrength reinforcement. 


\subsubsection{Characteristics of Special Structural Walls in the United States}

In the United States, special structural walls are either rectangular in shape, part of a core wall system with coupling beams and piers, or various shapes at isolated banks of elevators or stairs. Lowes et al. (2012) provides results of a survey of structural wall properties for modern buildings on the West Coast of the United States. The average, minimum, and maximum longitudinal reinforcement ratios for boundary elements in the survey are $2.89 \%, 1.54 \%$, and $3.97 \%$, respectively; the average, minimum, and maximum reinforcement ratios for distributed longitudinal reinforcement are $0.46 \%, 0.24 \%$, and $0.99 \%$, respectively.

Results of a review of damage to structural walls on the West Coast of the United States (Birely, 2011) found that the primary failure mode was compressive damage and bar fracture of previously buckled bars, which occurred in about $50 \%$ of the damage incidents. The second most common type of damage was a horizontal failure plane that extended the length of the wall, which typically occurred at locations with changes in geometry or at construction joints.

\subsubsection{Structural Wall Tests Conducted in Japan with Grade 100 or Stronger Bars}

There are a number of Japanese tests that studied the use of high-strength reinforcement in structural walls. Kimura and Ishikawa (2008) tested three 1/5-scale slender wall specimens. These walls were reinforced with SD685 bars (nominal yield strength of $100 \mathrm{ksi}$ ) in the boundary elements and the horizontal and vertical web reinforcement. The shear span ratio of the tests was 2.0. Characteristics of the wall specimens are listed in Table 4-1. Although the transverse reinforcement area did not comply with the requirements of ACI 318 for special boundary elements, the details did. The transverse reinforcement spacing to longitudinal bar diameter ratio, $s / d_{b}$, was 5 .

Load displacement curves for the wall specimens are shown in Kimura and Ishikawa (2008), and Table 4-2 provides the applied shear and drift for damage events during the tests. Hysteresis loops showed no degradation in strength up to the ultimate drift. The ultimate drift was $1.5 \%$ for the wall with an axial stress ratio of 0.15 , and $2 \%$ for the walls with an axial stress ratio of 0.10. All walls exhibited a flexural compression failure mode in which the concrete crushed and the bars buckled. The plastic hinge zone at the base of the specimens was about half the wall length.

As a second example, wall specimens with high-strength reinforcement were tested as part of Japan's New RC Project (Aoyama, 2001; Kabeyasawa and Ishikawa, 1998). Three series of tests were performed to study the following: (1) the strength of walls that first yield in flexure but fail in shear-compression (web crushing) mode; (2) the impact of bi-directional loading of walls; and (3) the shear strength of walls. 
Table 4-1 Characteristics of Wall Specimens Tested with SD685

Reinforcement by Kimura and Ishikawa (2008)

\begin{tabular}{|c|c|c|c|}
\hline Characteristics & $\begin{array}{l}\text { Specimen } \\
07 \mathrm{~N} 10 \\
\end{array}$ & $\begin{array}{l}\text { Specimen } \\
07 \mathrm{~N} 15 \\
\end{array}$ & $\begin{array}{c}\text { Specimen } \\
10 \mathrm{~N} 10 \\
\end{array}$ \\
\hline Measured concrete strength, $f_{c}^{\prime}$ & $10.9 \mathrm{ksi}$ & 10.9 ksi & 15.8 ksi \\
\hline Axial stress ratio & 0.10 & 0.15 & 0.10 \\
\hline Wall thickness, $t_{w}$ & 5.9 in & 5.9 in & 5.9 in \\
\hline Wall length, $\ell_{w}$ & 59 in & 59 in & 59 in \\
\hline Length of boundary element & 11.8 in & 11.8 in & 11.8 in \\
\hline Shear span ratio, $M /\left(V \ell_{w}\right)$ & 2.00 & 2.00 & 2.00 \\
\hline Longitudinal bars at boundary element & \multicolumn{3}{|c|}{$\begin{array}{l}\left.14-\mathrm{D} 13^{1} \text { (SD685 with measured } f_{y}=102 \mathrm{ksi}\right) \\
\rho_{b e}=3.94 \%\end{array}$} \\
\hline $\begin{array}{l}\text { Transverse reinforcement at boundary } \\
\text { elements }\end{array}$ & \multicolumn{3}{|c|}{$\begin{array}{c}\left.\text { 6-D62 @ } 2.6 \text { in (SD685 with measured } f_{y}=109 \mathrm{ksi}\right) \\
\rho_{\mathrm{vol}}=1.39 \%\end{array}$} \\
\hline Vertical and horizontal reinforcement & \multicolumn{3}{|c|}{$\begin{array}{c}\left.18-\mathrm{D} 10^{3} @ 3.9 \text { in (SD685 with measured } f_{y}=114 \mathrm{ksi}\right) \\
\rho_{t}=\rho_{t}=0.95 \%\end{array}$} \\
\hline
\end{tabular}

${ }^{1}$ Area of a $13 \mathrm{~mm}$ deformed bar (D13) is $0.196 \mathrm{in}^{2}$

2 Area of a $10 \mathrm{~mm}$ deformed bar (D10) is $0.11 \mathrm{in}^{2}$

${ }^{3}$ Area of a $6 \mathrm{~mm}$ deformed bar (D6) is $0.049 \mathrm{in}^{2}$

Table 4-2 Load and Drift for Damage Events of Wall Specimens Tested by Kimura and Ishikawa (2008)

\begin{tabular}{|c|c|c|c|c|}
\hline \multicolumn{2}{|l|}{ Event } & $\begin{array}{c}\text { Specimen } \\
07 N 10\end{array}$ & $\begin{array}{c}\text { Specimen } \\
07 N 15\end{array}$ & $\begin{array}{c}\text { Specimen } \\
10 \mathrm{~N} 10\end{array}$ \\
\hline \multirow[t]{2}{*}{ Flexural crack } & V & 54 kips & 86 kips & 83 kips \\
\hline & Drift & $0.03 \%$ & $0.05 \%$ & $0.04 \%$ \\
\hline \multirow[t]{2}{*}{ Yield of boundary element bars } & V & 200 kips & 233 kips & 226 kips \\
\hline & Drift & $0.46 \%$ & $0.50 \%$ & $0.48 \%$ \\
\hline \multirow[t]{2}{*}{ Maximum strength } & $V_{\max }$ & 259 kips & 274 kips & 285 kips \\
\hline & Drift & $1.0 \%$ & $1.4 \%$ & $1.45 \%$ \\
\hline $\begin{array}{l}\text { Lateral load for calculated flexural } \\
\text { strength }\end{array}$ & $V_{\text {flex. cal. }}$ & 226 kips & 264 kips & 264 kips \\
\hline Ultimate Drift (\%) & & $2.0 \%$ & $1.5 \%$ & $2.0 \%$ \\
\hline
\end{tabular}

Twenty-one 1/4-scale specimens with boundary member widths at their ends that were wider than the walls were tested. The specimens were 5 feet 6 inches long with a 3.1-inch-thick web and 7.9-inch by 7.9-inch boundary elements. Bar yield strengths varied from $100 \mathrm{ksi}$ to $210 \mathrm{ksi}$. Shear spans for the specimens varied between 0.67 and 2.0. These specimens do not represent the types of structural walls commonly constructed in the United States, so the tests results are only briefly summarized. 
Twenty of the wall specimens failed in a brittle manner due to web crushing, with one failing due to bar fracture of the vertical bars in the boundary element. Drifts achieved before the lateral strength was reduced by more than $20 \%$ varied between $0.5 \%$ and $2.0 \%$. Bi-directionally loaded specimens failed at drifts of about $1.5 \%$, compared to $1.8 \%$ for the equivalent specimen loaded only in-plane. For the test results of walls expected to be limited by shear strength, the horizontal web reinforcement yielded when the reinforcement ratio, $\rho_{t}$, was less than or equal to $0.53 \%$ and the yield strength was $117 \mathrm{ksi}$ or less.

The horizontal web reinforcement did not yield for the following combinations of reinforcement ratio, $\rho_{t}$, and yield strength: $0.62 \%$ and $185 \mathrm{ksi}, 1.00 \%$ and $117 \mathrm{ksi}$, and $1.45 \%$ and $117 \mathrm{ksi}$.

Wallace (1998) reports that the maximum shear obtained for the twenty-one New RC Project tests described above exceeded the nominal shear strength for a structural wall computed in accordance with Chapter 21 of ACI 318 . He also reports that the maximum shear exceeded $7 \sqrt{f^{\prime}{ }_{c}}$ (psi) for all tests, which is more that the recommendations of Wood (1990).

\subsubsection{Structural Wall Tests Conducted with Bars of Approximately Grade 80}

Two sets of tests have been conducted that had reinforcement with yield strength close to $80 \mathrm{ksi}$ (Dazio et al., 2009; Lowes et al., 2012). The results provide insight as to how walls with Grade 80 reinforcement will perform.

Dazio et al. tested six wall specimens that, in comparison to the averages found in the survey of shear walls from the West Coast (Lowes et al., 2012), had low reinforcing ratios in the boundary elements and low-to-moderate reinforcement ratios of distributed longitudinal reinforcement. The axial load, quantity of reinforcing steel, steel elongation, and transverse reinforcement at the ends of the walls varied. The transverse reinforcement for the boundary elements did not comply with the ACI 318 requirements of special boundary elements, but the test results of four specimens demonstrate trends in behavior.

The specimens were 5.9 inches wide by 79 inches long. The shear span ratios were approximately 2.3. Yield strengths of the bars varied but were close to $80 \mathrm{ksi}$. The uniform strains, $A_{g t}$, developed by the bars also varied. Characteristics of the tests are included in Table 4-3. Lateral load versus drift and top displacement are shown in Figure 4-15 for Specimens WSH1, WSH2, WSH3, and WSH6.

Differences in the response of WSH1 and WSH2 highlight the need for ductile reinforcement with strain hardening. These two specimens had the same quantity of reinforcement and reinforcement details, but the reinforcement for WSH1 was much 


\begin{tabular}{|c|c|c|c|c|c|c|}
\hline Specimen & $\begin{array}{l}\text { Axial } \\
\text { Load } \\
\text { Ratio } \\
P / A_{g} f_{c}^{\prime} \\
\end{array}$ & $\begin{array}{l}\text { Compressive } \\
\text { Strength, } f_{c}^{\prime}\end{array}$ & $\begin{array}{c}\text { Boundary } \\
\text { Element } \\
\text { Reinforcement } \\
\text { Ratio, } \rho_{b e} \\
\end{array}$ & $\begin{array}{c}\text { Distributed } \\
\text { Longitudinal } \\
\text { Reinforcement } \\
\text { Ratio, } \rho_{\ell} \\
\end{array}$ & $\begin{array}{c}\text { Distributed } \\
\text { Horizontal } \\
\text { Reinforcement } \\
\text { Ratio, } \rho_{t} \\
\end{array}$ & $\begin{array}{c}\text { Ratio of } \\
\text { Transverse } \\
\text { Reinforcement } \\
\text { Spacing to } \\
\text { Diameter of } \\
\text { Longitudinal } \\
\text { Bar, } s / d_{b} \\
\end{array}$ \\
\hline WSH1 & 0.051 & $6.5 \mathrm{ksi}$ & $1.32 \%$ & $0.30 \%$ & $0.25 \%$ & 7.5 \\
\hline WSH2 & 0.057 & $5.9 \mathrm{ksi}$ & $1.32 \%$ & $0.30 \%$ & $0.25 \%$ & 7.5 \\
\hline WSH3 & 0.058 & $5.7 \mathrm{ksi}$ & $1.54 \%$ & $0.54 \%$ & $0.25 \%$ & 6.3 \\
\hline WSH6 & 0.108 & $6.6 \mathrm{ksi}$ & $1.54 \%$ & $0.54 \%$ & $0.25 \%$ & 4.2 \\
\hline
\end{tabular}

a

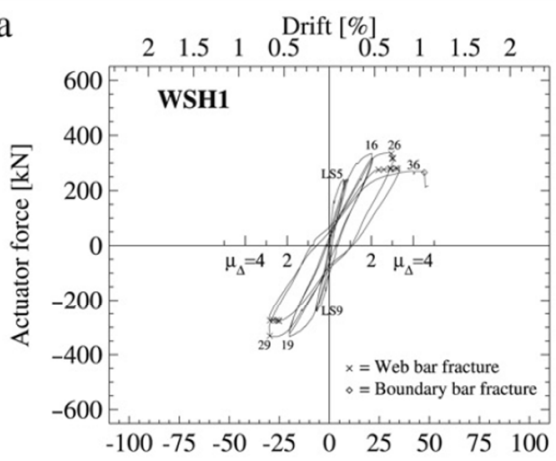

d

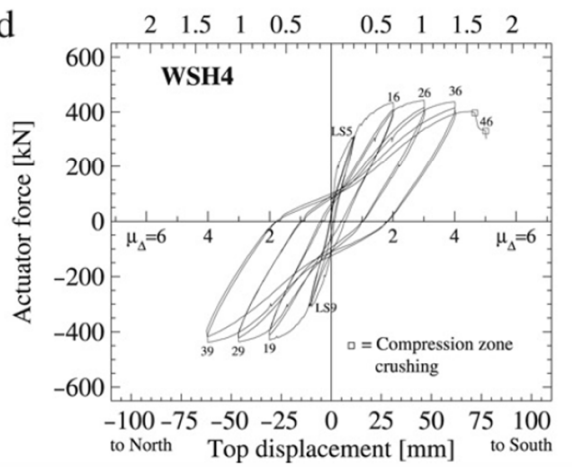

b

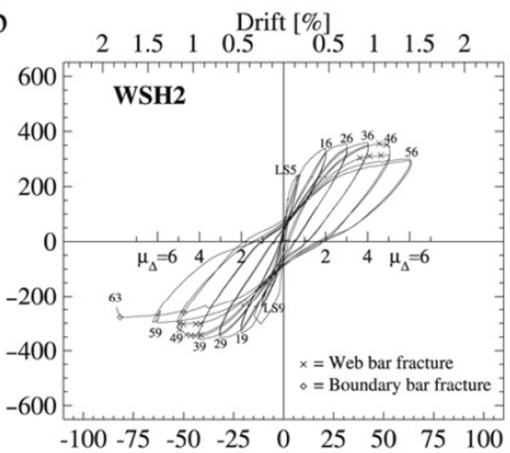

e

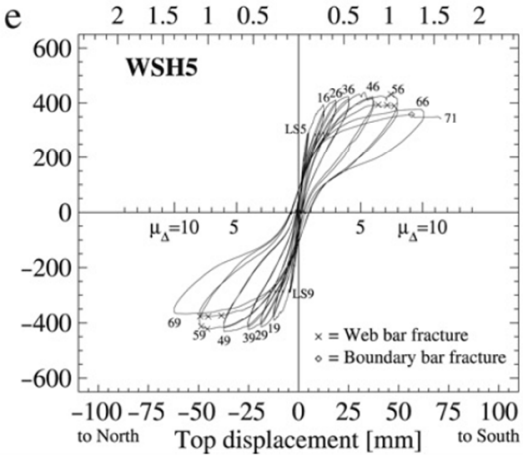

$\mathrm{c}$

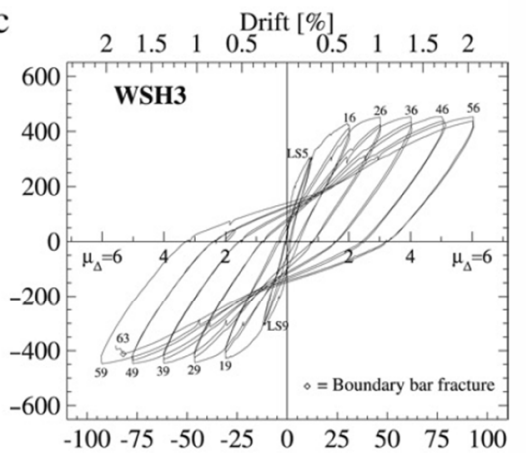

$\mathrm{f}$
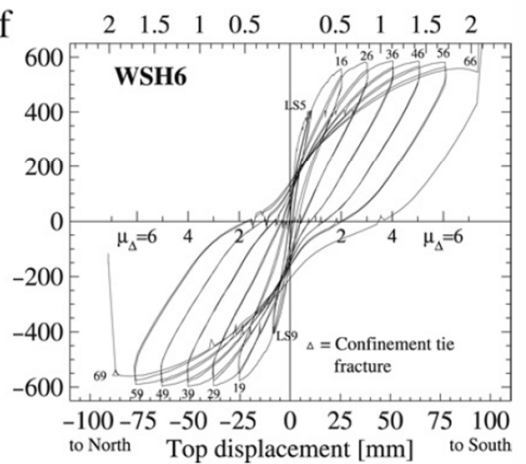

Figure 4-15 Lateral load versus drift for wall test specimens with reinforcement yield strength close to 80 ksi (Dazio et al., 2009).

less ductile than that of WSH2. For WSH1, the vertical distributed reinforcement, which had a measured uniform elongation of only $2.3 \%$, started to rupture at a drift of $0.68 \%$. At a drift of $1.04 \%$, several longitudinal bars in the boundary element, which had uniform elongations of $4.6 \%$, ruptured.

For WSH2, distributed vertical bars, which had uniform elongations of 5.8\%, started to rupture at a drift of $1.2 \%$, and the longitudinal boundary elements corner bars buckled. The longitudinal boundary element bars were supported by transverse reinforcement with a ratio of transverse bar spacing to longitudinal bar diameter of 7.5. All six longitudinal bars in a boundary element buckled at a drift of $1.4 \%$ and 
fractured while loading in the reverse direction. The results show the need for closer spacing of transverse reinforcement to delay the onset of longitudinal bar buckling. Specimens WSH1 and WSH2 had low reinforcement ratios, and the failure of each wall included a wide horizontal crack where the bars fractured. Similar behavior of walls was observed following the Christchurch, New Zealand, earthquake in 2011. The performance of these walls demonstrates that shear walls require a minimum amount of vertical reinforcement to avoid formation of a single wide crack.

The improvement in deformation capacity when transverse bars are more closely spaced is demonstrated by comparing the results of WSH3 to those of WSH2. WSH3 had about twice the longitudinal web reinforcement, $17 \%$ more boundary element longitudinal reinforcement, and closer transverse reinforcement spacing than WSH2. The ratio of transverse bar spacing to longitudinal bar diameter was 6.3 for WSH3. The first sign of buckling of boundary element bars occurred at a drift of $1.7 \%$, a corner bar ruptured at $1.8 \% \mathrm{drift}$, and the maximum drift was $2.0 \%$.

WSH6 had twice the axial load of WSH1 and WSH3. It had a similar reinforcement ratio to WSH3, but had a ratio of transverse reinforcement spacing to longitudinal bar diameter, $s / d_{b}$, of 4.2 . The onset of buckling occurred at a drift of $1.7 \%$, and the maximum drift reached was $2.1 \%$. The result demonstrates the improvement of performance with closer spacing of transverse reinforcement.

In a second example, Lowes et al. (2012) tested four walls, two of which had longitudinal boundary element reinforcement with a yield strength of about $85 \mathrm{ksi}$. The boundary elements were detailed to comply with the requirements ACI 318. The distributed horizontal reinforcement was placed as the outer layer. The base of the two walls with boundary element reinforcement with yield strengths of $84 \mathrm{ksi}$ included splices of the longitudinal boundary element bars and vertical distributed reinforcement.

Characteristics of the two walls, PW1 and PW2, are included in Table 4-4 and the layout of reinforcement is shown in Figure 4-16.

For PW1, cover spalled at the bottom of the wall at a drift of $0.56 \%$, cover spalled above the boundary element longitudinal bar splices at a drift of $0.75 \%$, boundary element longitudinal bar buckling began during the second cycle to $1 \% \mathrm{drift}$, and longitudinal bars fractured below the splice during the second cycle to $1.5 \%$ drift.

For PW2, cover spalled above the boundary element longitudinal bar splices at a drift of $0.75 \%$, boundary element longitudinal bar buckling occurred during the third cycle to $0.75 \%$ drift, core damage was observed above the splices at $1.5 \% \mathrm{drift}$, and the concrete crushed extensively and bars buckled above the splice at $1.05 \%$ drift during the loading cycle to $1.5 \%$ drift. The results of these tests show that the yielding of 
Table 4-4 Characteristics of Wall Specimens Tested by Lowes et al. (2012)

\begin{tabular}{|c|c|c|}
\hline Characteristics & $\begin{array}{c}\text { Specimen } \\
\text { PW1 }\end{array}$ & $\begin{array}{c}\text { Specimen } \\
\text { PW2 }\end{array}$ \\
\hline Measured concrete strength, $f_{c}^{\prime}$ & $5.23 \mathrm{ksi}$ & $5.84 \mathrm{ksi}$ \\
\hline Axial stress ratio & 0.095 & 0.13 \\
\hline Wall thickness, $t_{w}$ & 6 in & 6 in \\
\hline Wall length, $\ell_{w}$ & 120 in & 120 in \\
\hline Length of boundary element, $\ell_{b e}$ & $20 \mathrm{in}$ & 20 in \\
\hline Shear span ratio $M /\left(V \ell_{w}\right)^{*}$ & 2.84 & 2.00 \\
\hline Longitudinal bars at boundary element & \multicolumn{2}{|c|}{$\begin{array}{l}\text { 21-No. } 4 @ 3 \text { in. }\left(\text { A615 with measured } f_{y}=84 \mathrm{ksi} \text {, }\right. \\
\left.f_{u}=101 \mathrm{ksi} \text {, and } f_{u} / f_{y}=1.20\right) ; \rho_{b e}=3.5 \%\end{array}$} \\
\hline $\begin{array}{l}\text { Transverse reinforcement at boundary } \\
\text { elements (ties and hoops) }\end{array}$ & \multicolumn{2}{|c|}{$\begin{array}{l}\text { No. } 2 @ 2 \text { in. (A615 with measured } f_{y}=76 \mathrm{ksi}, f_{u}=85 \mathrm{ksi} \text {, } \\
\text { and } f_{u} / f_{y}=1.12 \text { ); transverse reinforcement complies with } \\
\text { special boundary element provisions; } s / d_{b}=4\end{array}$} \\
\hline Vertical and horizontal reinforcement & \multicolumn{2}{|c|}{$\begin{array}{l}\text { No. } 2 @ 6 \text { in. ea. way ea. face (A615 with measured } \\
\left.f_{y}=76 \mathrm{ksi}, f_{u}=85 \mathrm{ksi} \text {, and } f_{u} / f_{y}=1.12\right) ; \rho_{t}=\rho_{\ell}=0.27 \%\end{array}$} \\
\hline
\end{tabular}

*Achieved by introducing moment at the top of the specimen.

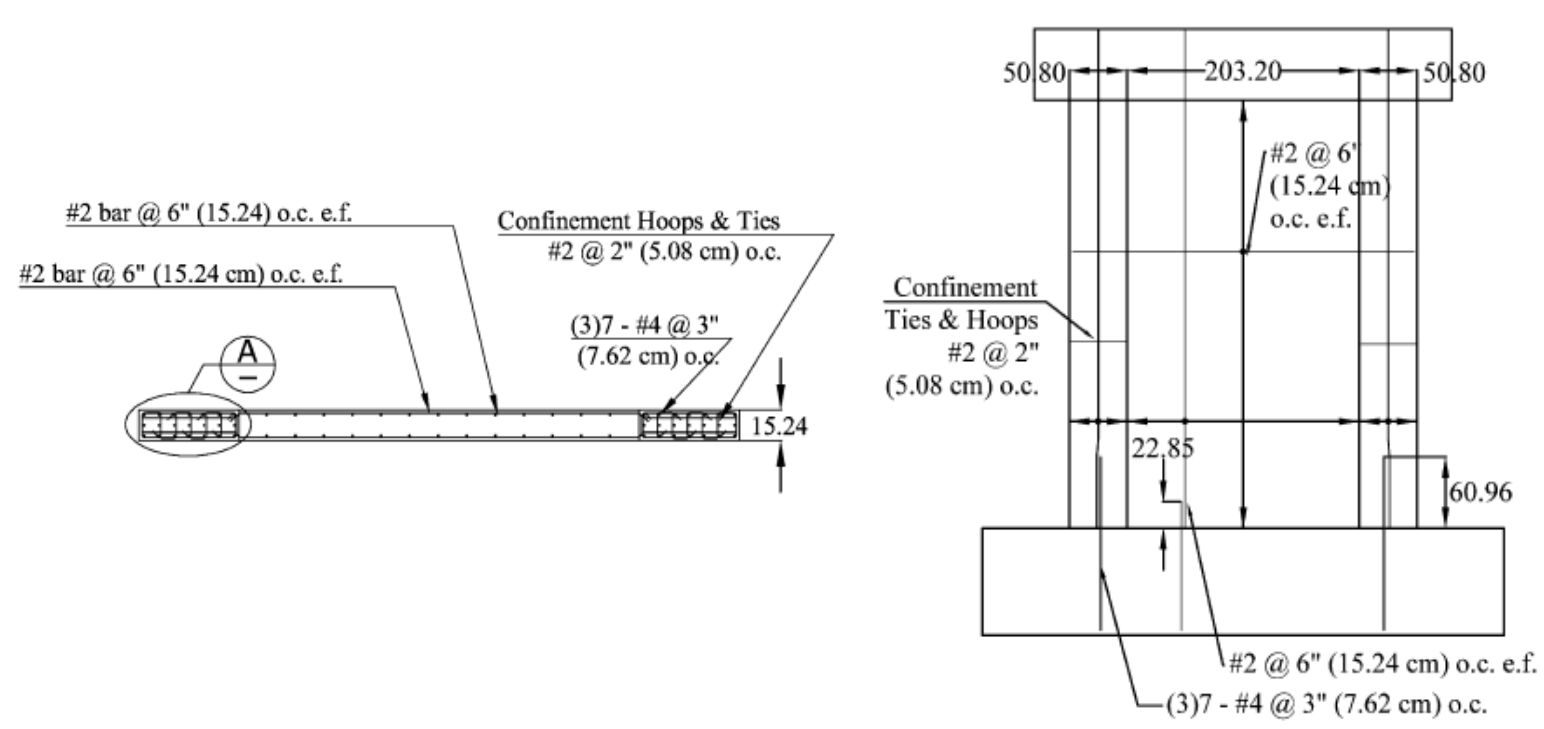

Figure 4-16 Details of Walls PW1 and PW2 tested by Lowes et al. (2012).

bars can occur at both the top and bottom of the splice and that strain can be concentrated at the base of the wall, resulting in bar fracture.

\subsection{Members Not Designated as Part of a System Resisting Seismic Forces}

According to the seismic requirements of ACI 318, members not designated as part of a system resisting seismic forces need to have sufficient strength to resist the 
additional forces induced by the expected seismic deformations. Alternatively, these members may be provided with ductile reinforcing details to allow yielding when subjected to the expected seismic deformations.

When using high-strength reinforcement in a system resisting seismic forces, the expected displacement demand is slightly higher than in systems that use normal strength reinforcement, as indicated in Chapter 5. The increased displacement demand will likely not induce higher forces in the elements not participating in seismic resistance, because these members will have reduced stiffness (assuming they are also reinforced with high-strength steel bars). When a designer chooses to provide ductile reinforcing details because yielding is expected to occur, it is reasonable to assume that the member deformation capacity will exceed the deformation demands, as long as the building drifts are in compliance with the governing code for earthquake-resistant design. It is important to note that the reinforcement detailing requirements in members with high-strength reinforcement should be more restrictive than those in members with normal strength reinforcement, as recommended in Chapter 3 (e.g., a reduced spacing of transverse reinforcement may be required to prevent bar buckling). In addition, where the design provisions of ACI 318 trigger the need for calculating the probable moment strength, $M_{p r}$, values greater than 1.25 times the specified yield strength of reinforcement may be required for those members using high-strength reinforcement.

\subsection{Diaphragms}

High stress in the reinforcement of diaphragm collectors and chords can lead to excessive cracking of the diaphragm. In accordance with NIST (2010):

"ACI 318 Section 21.11.7.2 limits the stress from design earthquake forces to 60,000 psi for bonded tendons. Although stress in other collector and chord reinforcement is not limited, consideration should be given to deformation compatibility between tension chords, collectors, and the floor slab. High tensile stress and strains in collectors and chords can result in excessive cracking that will migrate into the slab."

There are no tests that directly address this issue. Given the current state of knowledge of diaphragm behavior, caution should be employed when bars with yield strength greater than $60 \mathrm{ksi}$ are used for the design of chords and collectors. Elongations of bars at the anticipated stress levels should be computed and assessed considering deformation compatibility.

The use of slab bars with yield strength greater than $60 \mathrm{ksi}$ for the design of diaphragms is similar to using higher strength reinforcement for shear walls. At this time, there is evidence that some increase in shear strength could be used for shear walls, so it should be acceptable for shear reinforcement of diaphragms. It is 
recommended that such an increase should be limited to using a maximum design yield strength of $80 \mathrm{ksi}$ until more research results are available that demonstrate that strengths higher than $80 \mathrm{ksi}$ are effective.

\subsection{Foundations}

Mat slabs, pile caps, and footings are good candidates for the use of high-strength reinforcement as flexural reinforcement. Earthquake effects on foundation elements often control some aspects of their design. An issue to consider in the design of these members is whether a reduction in shear strength occurs if high-strength reinforcement is used for the flexural design. Mat slabs, pile caps, and footings are often sized so that steel reinforcement to resist shear is not required. This results in relatively thick (deep) members with a low reinforcing ratio for flexure.

Several factors influence the shear strength of members without shear reinforcement. These include the stress level or strain in the longitudinal bars; the depth of the member; the reinforcement ratio; and the aggregate size (Commentary to ACI 318-11; Angelakos et al., 2001; Lubell et al., 2004; Brown et al., 2006). Higher stress levels in longitudinal bars and lower reinforcing ratios result in higher bar strains, which permit wider opening of shear cracks. The wider cracks result in reduced aggregate interlock, which in turn reduces the shear strength. Increase in the depth of a member results in a reduction in shear strength for a unit depth of beam because cracks open wider between the compression block in the concrete and the tension in the reinforcing steel, allowing less force transfer across the crack. Tests indicate that thick (deep) members without shear reinforcement and with low reinforcing ratios for flexure may have shear strengths that are lower than those computed with ACI 318 (Lubell et al., 2004).

If high-strength flexural reinforcement is used in place of Grade 60 reinforcement for mat slabs, pile caps, and footings, the reinforcing ratio will be reduced and the stress level in the reinforcement will increase, which will contribute to a reduction in shear strength (Collins and Kuchma, 1999; Reineck et al., 2003; Lubell et al., 2004). If minimum shear reinforcement is used, this reduction in shear strength is minimized. If shear reinforcement is not used, alternative means should be used to check the adequacy of shear strength, such as using modified compression field theory or designing these members with the strut-and-tie method (Garay-Moran and Lubell, 2008). 



\section{Chapter 5}

\section{Analysis of Buildings}

This chapter examines the effect of the use of high-strength reinforcement on the performance of buildings by presenting a study on how high-strength reinforcement affects calculations of effective stiffness of elements and a comparison of nonlinear analyses of a building using Grade 60 and higher grades of reinforcement.

\subsection{Modeling Effective Stiffness of Elements for Linear Analysis}

Currently, most reinforced concrete buildings in the United States are designed using a force-based procedure in which members are determined from a linear responsespectrum analysis or an equivalent static procedure. An effective stiffness value is required to account for the development of cracking in concrete to find the correct design point for linear analysis and, in particular, to develop a good approximation of the deflections. Effective stiffness is a function of several parameters, such as the modulus of elasticity, moment of inertia, length, and support conditions, but is most affected by the change in the moment of inertia as the concrete cracks. Although effective stiffness and effective moment of inertia are technically different concepts, they can sometimes be used interchangeably. Typically, in analysis, the effective moment of inertia, $I_{e}$, is given as a fraction of the moment of inertia of the grosssection, $I_{g}$.

Existing recommendations provide a variety of procedures for calculating the effective stiffness of an element. Many existing effective stiffness recommendations have been calibrated for use with Grade 60 longitudinal reinforcement. Members with high-strength reinforcement can achieve the same design strength as members with Grade 60 reinforcement, while using less longitudinal reinforcement. The reduction in the total area of longitudinal reinforcement can cause a reduction in the post-cracking stiffness in a section, as illustrated in Figure 5-1; this can occur particularly in beams and in walls and columns where axial load level in the section is low. The reduction in the post-cracking stiffness has an impact on the effective flexural rigidity of the section, $E_{c} I_{e}$, which would be used in a conventional linear model. As the grade of the longitudinal reinforcement is increased, the values calculated according to existing recommendations may no longer be appropriate. The following sections provide a review and comparison of selected methods for determining the effective stiffness. 


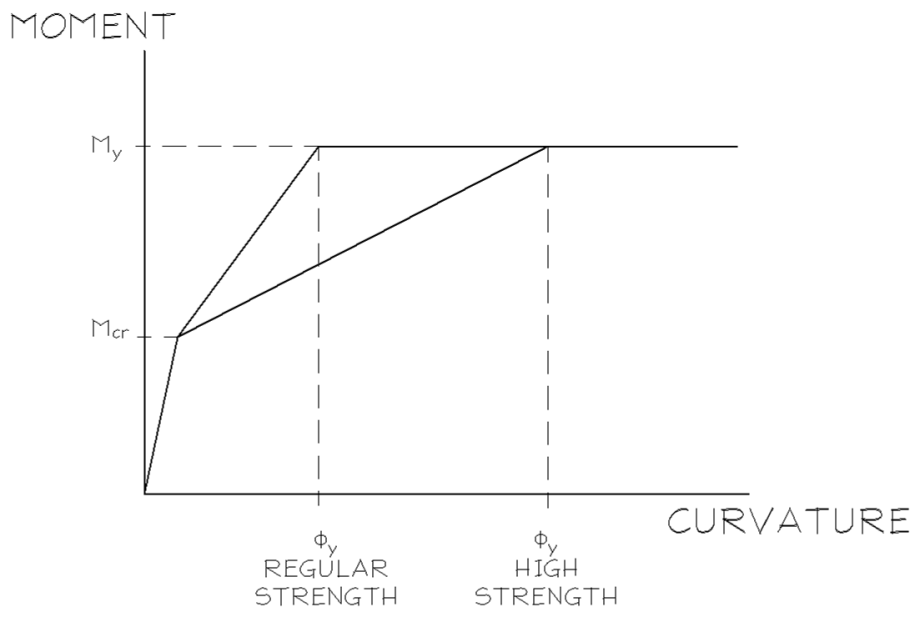

Figure 5-1 Moment-curvature sketch of members with the same yield strength built with conventional and high-strength bars.

\subsubsection{ACI 318-11}

ACI 318-11 Section 8.8.2 allows the effective moment of inertia, $I_{e}$, to be taken equal to $0.5 I_{g}$, where $I_{g}$ is the gross moment of inertia, or calculated according to ACI 318-11 Section 10.10.4.1. Table 5-1 summarizes the formulations for $I_{e}$ in ACI $318-11$

\section{Table 5-1 Effective Moment of Inertia Values in ACI 318-11}

\begin{tabular}{|c|c|c|}
\hline Member & $\begin{array}{c}\text { Effective Moment of Inertia } \\
\text { per Section 10.10.4.1 }\end{array}$ & $\begin{array}{c}\text { Effective Moment of Inertia } \\
\text { per Section 8.8.2(b) }\end{array}$ \\
\hline Columns & $0.70 \mathrm{lg}$ & $0.50 / g$ \\
\hline Beams & $0.35 / g$ & $0.50 / g$ \\
\hline Walls & $\begin{array}{l}\text { Uncracked: } 0.70 / g \\
\text { Cracked: } 0.35 / g\end{array}$ & $\begin{array}{l}\text { Uncracked: } 0.50 \mathrm{lg} \\
\text { Cracked: } 0.50 \mathrm{~g}\end{array}$ \\
\hline
\end{tabular}

As an alternative, ACI 318-11 also includes two equations for calculating $I_{e}$ that take the amount of reinforcing steel into account. ACI 318-11 Equation 10-8, repeated below, is for compression members (columns and walls):

$$
I_{e}=\left(0.8+\frac{25 A_{s t}}{A_{g}}\right)\left(1-\frac{M_{u}}{P_{u} h}-\frac{0.5 P_{u}}{P_{o}}\right) I_{g} \leq 0.875 I_{g}
$$

where:

$$
\begin{aligned}
& A_{s t}=\text { area of longitudinal reinforcement } \\
& A_{g}=\text { gross section area } \\
& M_{u}=\text { factored moment for the load combination under consideration } \\
& P_{u}=\text { factored axial compression for the load combination under consideration } \\
& h=\text { member depth } \\
& P_{o}=\text { nominal axial strength at zero eccentricity }
\end{aligned}
$$


$I_{g}=$ gross moment of inertia

$I_{e}$ need not be taken less than $0.35 I_{g}$

ACI 318-11 Equation 10-9 for flexural members (beams) is as follows:

$$
I_{e}=(0.10+25 \rho)\left(1.2-\frac{0.2 b_{w}}{d}\right) I_{g} \leq 0.5 I_{g}
$$

where:

$$
\begin{aligned}
& \rho=\text { reinforcement ratio } \\
& b_{w}=\text { web width (equivalent to member width for this study) } \\
& I_{e} \text { need not be taken less that } 0.25 I_{g}
\end{aligned}
$$

Per the commentary in ACI 318-11 Section 10.10.4.1, moment of inertia of T-beams should be based on the effective flange width, per ACI 318-11 Section 8.12.

\subsubsection{FEMA 356}

Table 5-2 summarizes the formulations for effective moment of inertia in FEMA 356,

\begin{tabular}{|c|c|}
\hline Member & Effective moment of inertia \\
\hline Columns ${ }^{1}$ & $\begin{array}{l}P_{u} \geq 0.5 A_{g} f_{c}^{\prime}: 0.70 l_{g} \\
P_{u} \leq 0.3 A_{g} f_{c}^{\prime}: 0.50 l_{g} \\
\text { (linearly interpolate between) }\end{array}$ \\
\hline Beams $^{2}$ & $\begin{array}{l}\text { Nonprestressed: } 0.5 / g \\
\text { Prestressed: } / g\end{array}$ \\
\hline Walls & $\begin{array}{l}\text { Uncracked: } 0.8 / \mathrm{g} \\
\text { Cracked: } 0.5 / \mathrm{g}\end{array}$ \\
\hline
\end{tabular}
Prestandard and Commentary for the Seismic Rehabilitation of Buildings (FEMA, 2000).

Table 5-2 Effective Moment of Inertia Values in FEMA 356

${ }^{1} P_{u}$ is defined as the axial load from gravity loads only.

${ }^{2} I_{g}$ for T-beams may be taken as twice the value of $I_{g}$ for the web alone.

\subsubsection{Paulay and Priestley (1992)}

Table 5-3 summarizes the formulations for effective moment of inertia in Paulay and Priestley (1992).

\subsubsection{Elwood and Eberhard (2009)}

Elwood and Eberhard (2009) compared the values of $I_{e}$ calculated from FEMA 356 to test data and found that FEMA 356 overestimated these values for columns with low axial loads. Table 5-4 summarizes the proposed formulations for effective moment of inertia in Elwood and Eberhard (2009). 
Table 5-3 Effective Moment of Inertia Values in Paulay and Priestley (1992)

\begin{tabular}{ll}
\hline \multicolumn{1}{c}{ Member } & \multicolumn{1}{c}{ Effective Moment of Inertia } \\
\cline { 2 - 3 } Columns & $P_{u}>0.5 A_{g} f_{c}^{\prime}: 0.80 I_{g}$ \\
& $P_{u}=0.2 A_{g} f_{c}^{\prime}: 0.60 I_{g}$ \\
& $P_{u}=-0.05 A_{g} f_{c}^{\prime}: 0.40 I_{g}$ \\
& (For this report, assume linear interpolation between specified \\
& values, though this is not specified in the textbook) \\
Beams & Rectangular sections: $0.40 I_{g}$ \\
& $T$ and $L$ sections: $0.35 I_{g}$ \\
Walls & $\left\{14.5 / f_{y}+P_{u} /\left(f_{c}^{\prime} A_{g}\right)\right\} I_{g}$ \\
\hline
\end{tabular}

Table 5-4 Effective Moment of Inertia Values in Elwood and Eberhard (2009)

\begin{tabular}{lll}
\hline \multicolumn{1}{c}{ Member } & & \multicolumn{1}{c}{ Effective Moment of Inertia } \\
\cline { 3 - 3 } Columns & $P_{u}>0.5 A_{g} f_{c}^{\prime}: 0.70 l_{g}$ \\
& $P_{u} \leq 0.2 A_{g} f_{c}^{\prime}: 0.20 l_{g}$ \\
& (linearly interpolate between) \\
\hline
\end{tabular}

\subsubsection{Restrepo (2000)}

Restrepo (2000) investigated the impact of the reinforcement ratio on the stiffness of beams, columns, and walls. Restrepo presents equations for calculating $I_{e}$ that correspond to the secant response to the yield point in the critical section of the members. These equations were based on moment-curvature studies. Table 5-5 summarizes the formulations for effective moment of inertia in Restrepo (2000).

Table 5-5 Effective Moment of Inertia Values Recommended in Restrepo (2000)

\begin{tabular}{ll}
\hline \multicolumn{1}{c}{ Member } & $\frac{1}{\text { Effective Moment of Inertia* }}$ \\
Columns & $\left\{0.08+14 \rho_{l}+2 P_{u} /\left(A_{g} f_{c}^{\prime}\right)\left(0.6-8.3 \rho_{l}\right)\right\} I_{g} \leq I_{g}$ \\
Beams & $\{36(\rho+\rho)+0.07\} l_{g}$ \\
Walls & $\left(29 \rho_{l}+0.03\right) l_{g} \leq l_{g}$ \\
\hline
\end{tabular}

"For the examples, the reinforcement ratio reduces with the grade of reinforcement.

\subsubsection{Comparison of Methods for Calculating Effective Moment of Inertia}

This section compares the methods presented above, using the example members from the National Earthquake Hazards Reduction Program (NEHRP) reinforced concrete frame-wall building design example presented in FEMA 451, NEHRP Recommended Provisions: Design Examples (FEMA, 2006). Members are varied to include $5 \mathrm{ksi}$ and $10 \mathrm{ksi}$ concrete and $60 \mathrm{ksi}, 80 \mathrm{ksi}$, and $100 \mathrm{ksi}$ longitudinal reinforcement. Member dimensions and reinforcement layout for Grade 60 bars 
remain unchanged from FEMA 451. For strengths other than Grade 60, member dimensions and reinforcement layout are selected to maintain equivalent strength (i.e., $A_{s} f_{y}$ stays approximately constant). This results in the member designs shown in Figures 5-2, 5-3, and 5-4. Note that some of the methods studied include reinforcement ratio or reinforcing area but do not include yield strength. Results for these methods vary because the reinforcement ratio was reduced for high-strength bars.

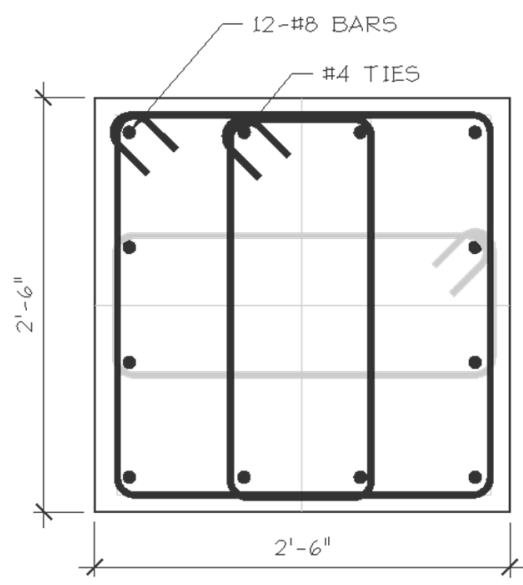

60 KSI COLUMN As $=9.48$ in $^{2}$
As $* f y=569 K$

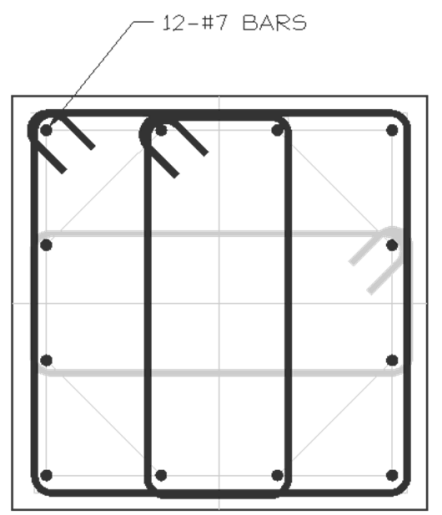

80 KSI COLUMN $\mathrm{As}=7.2 \mathrm{in}^{2}$ $A s * f y=576 K$

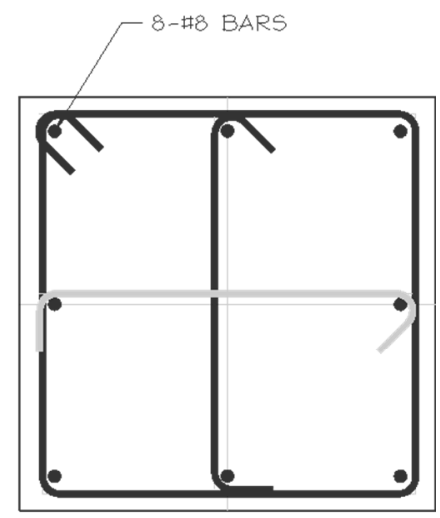

100 KSI COLUMN

$A s=6.32 \mathrm{in}^{2}$ $A s * f y=632 K$

Figure 5-2 Example column sections utilized when comparing effective moment of inertia calculation methods.

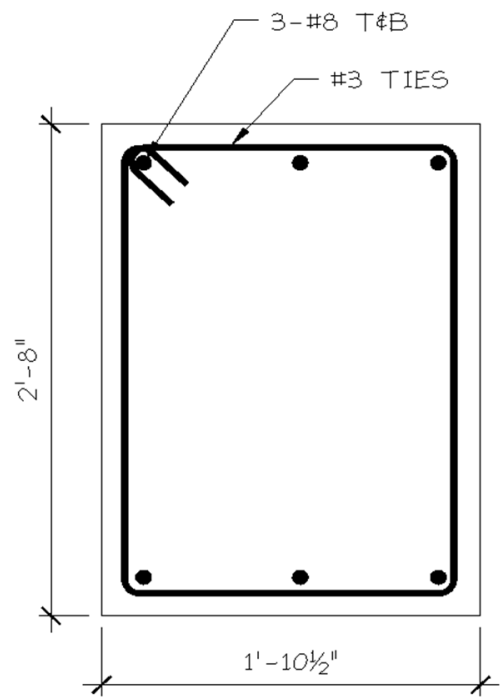

$60 \mathrm{KSI}$ BEAM

$A s=2.37 \mathrm{in}^{2}$

As F $_{\mathrm{f}} \mathrm{y}=142 \mathrm{~K}$

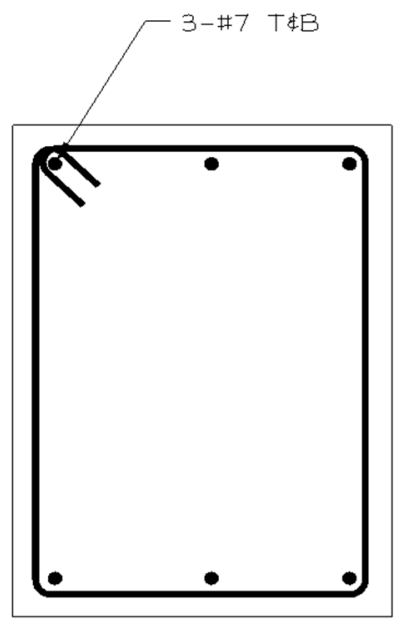

80 KSI BEAM

$A_{S}=1 . \sin ^{2}$

As $* f y=144 k$

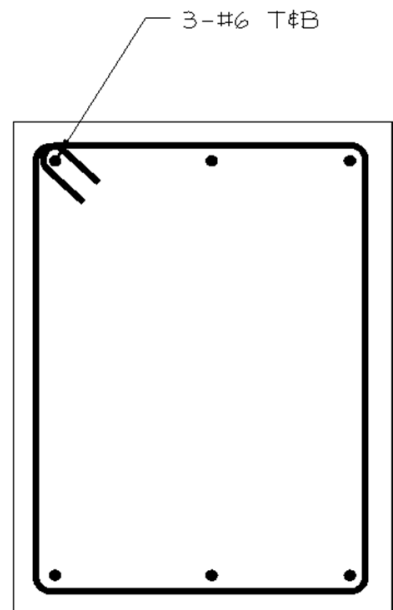

100 KSI BEAM

$A s=1.32 \mathrm{in}^{2}$

As $* F Y=132 K$

Figure 5-3 Example beam sections utilized when comparing effective moment of inertia calculation methods. 

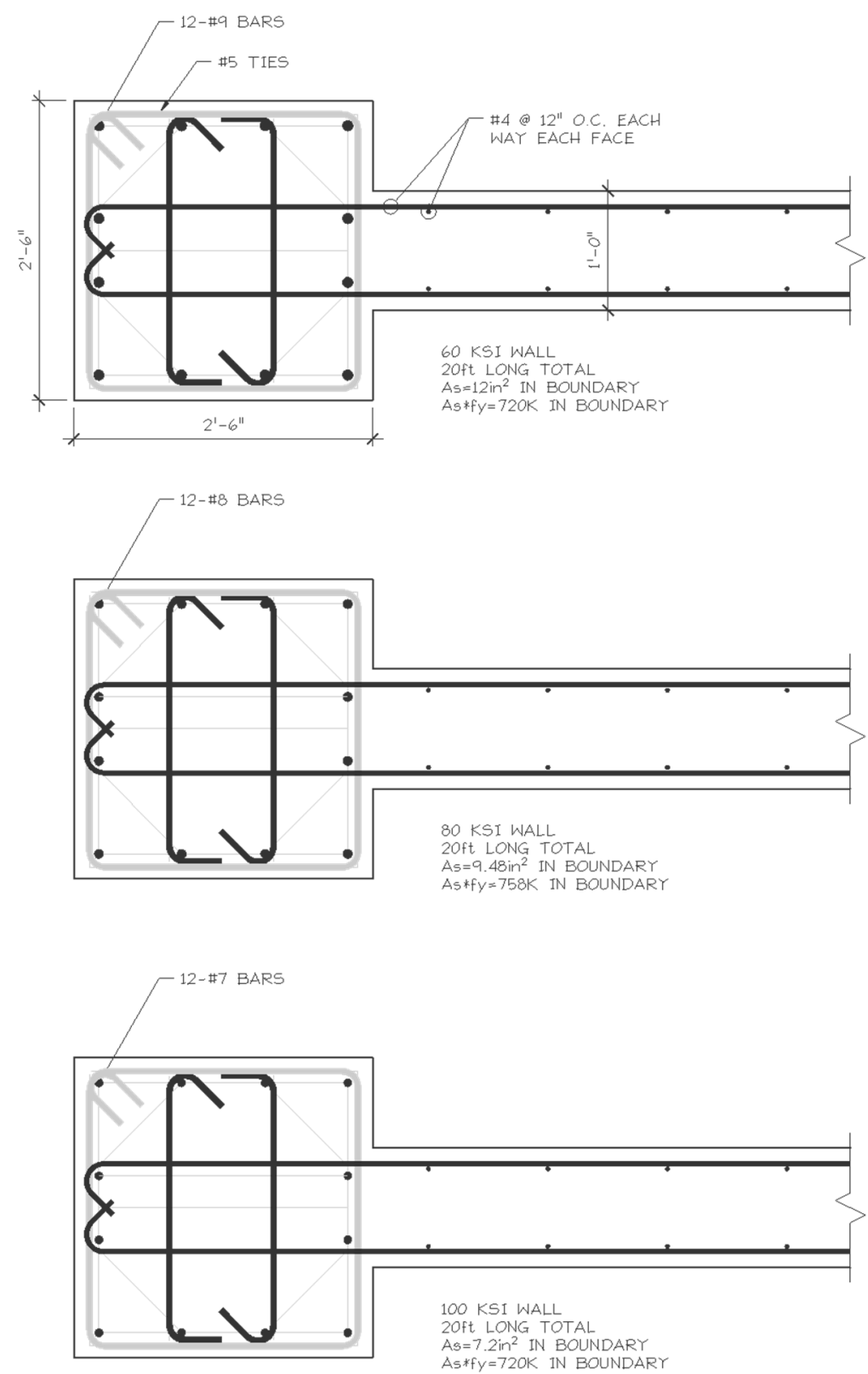

Figure 5-4 Example wall sections utilized when comparing effective moment of inertia calculation methods.

Additional assumptions were necessary to evaluate several of the equations. These assumptions were based on the FEMA 451 design example. Specifically:

- Members are not prestressed.

- Members are assumed to be cracked.

- Columns are based on a typical interior column of the frame on gridline 1 for the case study building (presented in Section 5.2).

- Walls are based on a typical frame-wall on gridline 3 for the base of the case study building. 
- Low axial members are assumed to have $P_{u}=0.1 A_{g} f_{c}^{\prime}$.

- High axial members are assumed to have $P_{u}=0.3 A_{g} f^{\prime}$.

Ratio of effective to gross moment of inertia for each member type was calculated according to each of the existing methods. The results are presented in Table 5-6 for columns, Table 5-7 for beams, and Table 5-8 for walls. Note that only some of the methods described above included $I_{e}$ estimates for beams and walls. In many cases, Tables 5-6, 5-7, and 5-8 suggest that $I_{e}$ should not vary with changes in either concrete or steel strengths or with changes in the longitudinal reinforcement ratio. However, there are large variations among the different methods in the values calculated for $I_{e}$. For columns, the ratio of the maximum and minimum values calculated for $I_{e}$ is 3.5 when the axial load is low, and is nearly 2 when the axial load is high. The variation is also very large for beams. For these, the ratio between the maximum and minimum value calculated for $I_{e}$ by the different methods is 2.8 for Grade 60 reinforcement and 3.6 when the reinforcement ratio is reduced as a result of the substitution of Grade 100 reinforcement for Grade 60 reinforcement. Finally, the variation in the $I_{e}$ values predicted for walls is even larger than for beams and columns. In walls, the ratio between the maximum and minimum value calculated for $I_{e}$ by the different methods is 3.3 for Grade 60 reinforcement and 5.6 when the reinforcement ratio is reduced as a result of the substitution of Grade 100 reinforcement for Grade 60 reinforcement.

Table 5-6 Ratio of Effective to Gross Moment of Inertia for Example Columns

\begin{tabular}{|c|c|c|c|c|c|c|c|c|c|}
\hline $\begin{array}{c}\text { Column } \\
\text { type }^{1}\end{array}$ & $\begin{array}{c}f_{c}^{\prime} \\
(\mathrm{ksi}) \\
\end{array}$ & $\begin{array}{c}f_{y} \\
(\mathrm{ksi}) \\
\end{array}$ & $\begin{array}{c}\mathrm{ACl} 318-11 \\
\text { Section } \\
8.8 .2(\mathrm{~b}) \\
\end{array}$ & $\begin{array}{c}\mathrm{ACl} 318-11 \\
\text { Section } \\
10.10 .4 .1 \\
\end{array}$ & $\begin{array}{c}\text { ACI } 318-11 \\
\text { Eq. } 10-8 \\
\end{array}$ & $\begin{array}{c}\text { FEMA } \\
356 \\
\end{array}$ & $\begin{array}{c}\text { Paulay } \\
\text { and } \\
\text { Priestley } \\
(1992) \\
\end{array}$ & $\begin{array}{c}\text { Elwood } \\
\text { and } \\
\text { Eberhard } \\
(2009) \\
\end{array}$ & $\begin{array}{c}\text { Restrepo } \\
(2000)\end{array}$ \\
\hline High & 5 & 60 & 0.50 & 0.70 & 0.80 & 0.50 & 0.67 & 0.37 & 0.56 \\
\hline High & 5 & 80 & 0.50 & 0.70 & 0.75 & 0.50 & 0.67 & 0.37 & 0.54 \\
\hline High & 5 & 100 & 0.50 & 0.70 & 0.68 & 0.50 & 0.67 & 0.37 & 0.50 \\
\hline High & 10 & 60 & 0.50 & 0.70 & 0.88 & 0.50 & 0.67 & 0.37 & 0.56 \\
\hline High & 10 & 80 & 0.50 & 0.70 & 0.83 & 0.50 & 0.67 & 0.37 & 0.54 \\
\hline High & 10 & 100 & 0.50 & 0.70 & 0.75 & 0.50 & 0.67 & 0.37 & 0.50 \\
\hline Low & 5 & 60 & 0.50 & 0.70 & 0.52 & 0.50 & 0.52 & 0.20 & 0.36 \\
\hline Low & 5 & 80 & 0.50 & 0.70 & 0.49 & 0.50 & 0.52 & 0.20 & 0.33 \\
\hline Low & 5 & 100 & 0.50 & 0.70 & 0.44 & 0.50 & 0.52 & 0.20 & 0.28 \\
\hline Low & 10 & 60 & 0.50 & 0.70 & 0.80 & 0.50 & 0.52 & 0.20 & 0.36 \\
\hline Low & 10 & 80 & 0.50 & 0.70 & 0.75 & 0.50 & 0.52 & 0.20 & 0.33 \\
\hline Low & 10 & 100 & 0.50 & 0.70 & 0.68 & 0.50 & 0.52 & 0.20 & 0.28 \\
\hline
\end{tabular}

${ }^{1}$ Column type is defined in terms of axial load level (High or Low). 
Table 5-7 Ratio of Effective to Gross Moment of Inertia for Example Beams

\begin{tabular}{|c|c|c|c|c|c|c|c|}
\hline $\begin{array}{r}f_{c}^{\prime} \\
(\mathrm{ksi}) \\
\end{array}$ & $\begin{array}{r}f_{y} \\
(\mathrm{ksi}) \\
\end{array}$ & $\begin{array}{c}\text { ACI 318-11 } \\
\text { Sec. 8.8.2 } \\
\end{array}$ & $\begin{array}{c}\text { ACI 318-11 } \\
\text { Sec. 10.10.4.1 } \\
\end{array}$ & $\begin{array}{c}\text { ACI } 318-11 \\
\text { Eq 10-9 } \\
\end{array}$ & $\begin{array}{c}\text { FEMA } \\
356 \\
\end{array}$ & $\begin{array}{c}\text { Paulay } \\
\text { and } \\
\text { Priestley } \\
(1992) \\
\end{array}$ & $\begin{array}{c}\text { Restrepo } \\
(2000) \\
\end{array}$ \\
\hline 5 & 60 & 0.50 & 0.35 & 0.25 & 0.50 & 0.40 & 0.18 \\
\hline 5 & 80 & 0.50 & 0.35 & 0.25 & 0.50 & 0.40 & 0.16 \\
\hline 5 & 100 & 0.50 & 0.35 & 0.25 & 0.50 & 0.40 & 0.14 \\
\hline 10 & 60 & 0.50 & 0.35 & 0.25 & 0.50 & 0.40 & 0.18 \\
\hline 10 & 80 & 0.50 & 0.35 & 0.25 & 0.50 & 0.40 & 0.16 \\
\hline 10 & 100 & 0.50 & 0.35 & 0.25 & 0.50 & 0.40 & 0.14 \\
\hline
\end{tabular}

Table 5-8 Ratio of Effective to Gross Moment of Inertia for Example Walls

\begin{tabular}{|c|c|c|c|c|c|c|c|c|}
\hline $\begin{array}{l}\text { Wall } \\
\text { type }^{1} \\
\end{array}$ & $\begin{array}{r}f_{c}^{\prime} \\
\text { (ksi) } \\
\end{array}$ & $\begin{array}{c}f_{y}(\mathrm{ksi}) \\
\text { boundary } \\
\end{array}$ & $\begin{array}{c}\text { ACI } 318-11 \\
\text { section } \\
8.8 .2 \\
\end{array}$ & $\begin{array}{c}\text { ACI } 318-11 \\
\text { section } \\
10.10 .4 .1 \\
\end{array}$ & $\begin{array}{c}\text { ACI 318-11 } \\
\text { Eq 10-8 } \\
\end{array}$ & $\begin{array}{c}\text { FEMA } \\
356 \\
\end{array}$ & $\begin{array}{c}\text { Paulay } \\
\text { and } \\
\text { Priestley } \\
(1992) \\
\end{array}$ & $\begin{array}{c}\text { Restrepo } \\
(2000) \\
\end{array}$ \\
\hline High & 5 & 60 & 0.50 & 0.35 & 0.70 & 0.50 & 0.54 & 0.24 \\
\hline High & 5 & 80 & 0.50 & 0.35 & 0.67 & 0.50 & 0.54 & 0.19 \\
\hline High & 5 & 100 & 0.50 & 0.35 & 0.64 & 0.50 & 0.54 & 0.13 \\
\hline High & 10 & 60 & 0.50 & 0.35 & 0.79 & 0.50 & 0.54 & 0.24 \\
\hline High & 10 & 80 & 0.50 & 0.35 & 0.75 & 0.50 & 0.54 & 0.19 \\
\hline High & 10 & 100 & 0.50 & 0.35 & 0.73 & 0.50 & 0.54 & 0.13 \\
\hline Low & 5 & 60 & 0.50 & 0.35 & 0.41 & 0.50 & 0.34 & 0.24 \\
\hline Low & 5 & 80 & 0.50 & 0.35 & 0.39 & 0.50 & 0.34 & 0.19 \\
\hline Low & 5 & 100 & 0.50 & 0.35 & 0.37 & 0.50 & 0.34 & 0.13 \\
\hline Low & 10 & 60 & 0.50 & 0.35 & 0.70 & 0.50 & 0.34 & 0.24 \\
\hline Low & 10 & 80 & 0.50 & 0.35 & 0.66 & 0.50 & 0.34 & 0.19 \\
\hline Low & 10 & 100 & 0.50 & 0.35 & 0.64 & 0.50 & 0.34 & 0.13 \\
\hline
\end{tabular}

${ }^{1}$ Wall type is defined in terms of axial load level (High or Low).

\subsubsection{Calibration to Test Results}

A study calibrating effective moment of inertia values was performed by Schotanus and Maffei (2007) using shake table test results for a full-scale, seven-story reinforced concrete bearing wall building (Panagiotou and Restrepo, 2011; Panagiotou et al., 2011). The building had a rectangular wall subjected to low axial load. The longitudinal reinforcement ratio, $\rho_{\ell}$, at the wall base was $0.66 \%$, which is similar to the ratio used to compute $I_{e} / I_{g}$ in Table 5-8. In this test, all of the reinforcement was ASTM A615 Grade 60 with $f_{y}=66 \mathrm{ksi}$ and $f_{c}^{\prime}=5.5 \mathrm{ksi}$. The fullscale test structure included walls, slabs, and gravity columns, making it more 
comprehensive than test specimens based on components or specimens that exclude gravity framing. However, architectural finishes were not included in the test structure or model; such components are expected to make a building stiffer.

Schotanus and Maffei modeled the building using ETABS (2006) structural analysis software and varied the values of $I_{e}$ for the wall and the slabs. Modeling results were compared with shake table results at the point when the building was excited to about $40 \%$ of the design level earthquake with a fairly linear response, despite strains in the wall longitudinal reinforcement reaching $1.8 \%$. The roof drift ratio peaked at $0.73 \%$.

The study found that a model using $I_{e}$ of $0.13 I_{g}$ in the first level of the wall and $0.3 I_{g}$ in the remaining levels, as well as $0.1 I_{g}$ for the slabs, provided the best match with shake table results when the damping ratio was set at $5 \%$ in the first mode of response. These factors are lower than those typically used for elastic analysis and they are at the low range of values recommended by various available methods. Of the methods evaluated, Restrepo (2000) and Paulay and Priestley (1992) come closest to matching the values of $I_{e} / I_{g}$ reported by Schotanus and Maffei during the calibration study.

The following are observed from the results presented above: (1) most methods for calculating effective moment of inertia do not vary with changing steel area and changing steel yield strength, which conflicts with theory; and (2) the spread between the $I_{e}$ values calculated using various methods is extremely large, especially for beams and columns. Even for methods that modify $I_{e}$ based on steel yield strength or steel area, the changes caused by these properties are small compared to variation between methods. Some differences between models may reflect differences in intent, such as those between computing the yield point of a particular member, and modeling a larger structure. Consequently, there appears to be wide disagreement regarding the methods for calculation of $I_{e}$ that overshadows the impact of using high-strength steel.

\subsection{Nonlinear Analysis of a Building with Conventional and High- Strength Reinforcement}

The efficient way to observe the effects that high-strength reinforcement have on the overall and interstory drift demands is through parametric analyses of the nonlinear dynamic response of buildings because conclusions based on the observation that sections reinforced with high-strength reinforcement have reduced effective moment of inertia, and that such reduction causes an increase in the drift demands, ignore the effect that significant portions of the elements remain uncracked, and that those that crack can maintain significant flexural stiffness due to the tension-stiffening phenomena. 
This section uses nonlinear analyses to compare the performance of a building when constructed with Grade 60 reinforcement to when it is constructed with various grades of high-strength reinforcement. The results provide insights into how highstrength reinforcement affects building stiffness, drift, and strain.

\subsubsection{Building Description}

A parametric analysis was conducted on a 13-story building to evaluate the sensitivity of the stiffness of a building to the reinforcement grade. The building structure was based on the NEHRP reinforced concrete frame-wall building design example in FEMA 451 (FEMA, 2006).

The building is assumed to be located in Berkeley, California, with an office occupancy. The site is on Soil Class C, with site-specific spectral values, $S_{D S}$ and $S_{D 1}$, of 1.17 and 0.65, respectively, as defined in ASCE/SEI 7-10, Minimum Design Loads for Buildings and Other Structures (ASCE, 2010). The building has one basement level and twelve stories above grade, as shown in Figures 5-5 and 5-6. Typical bays

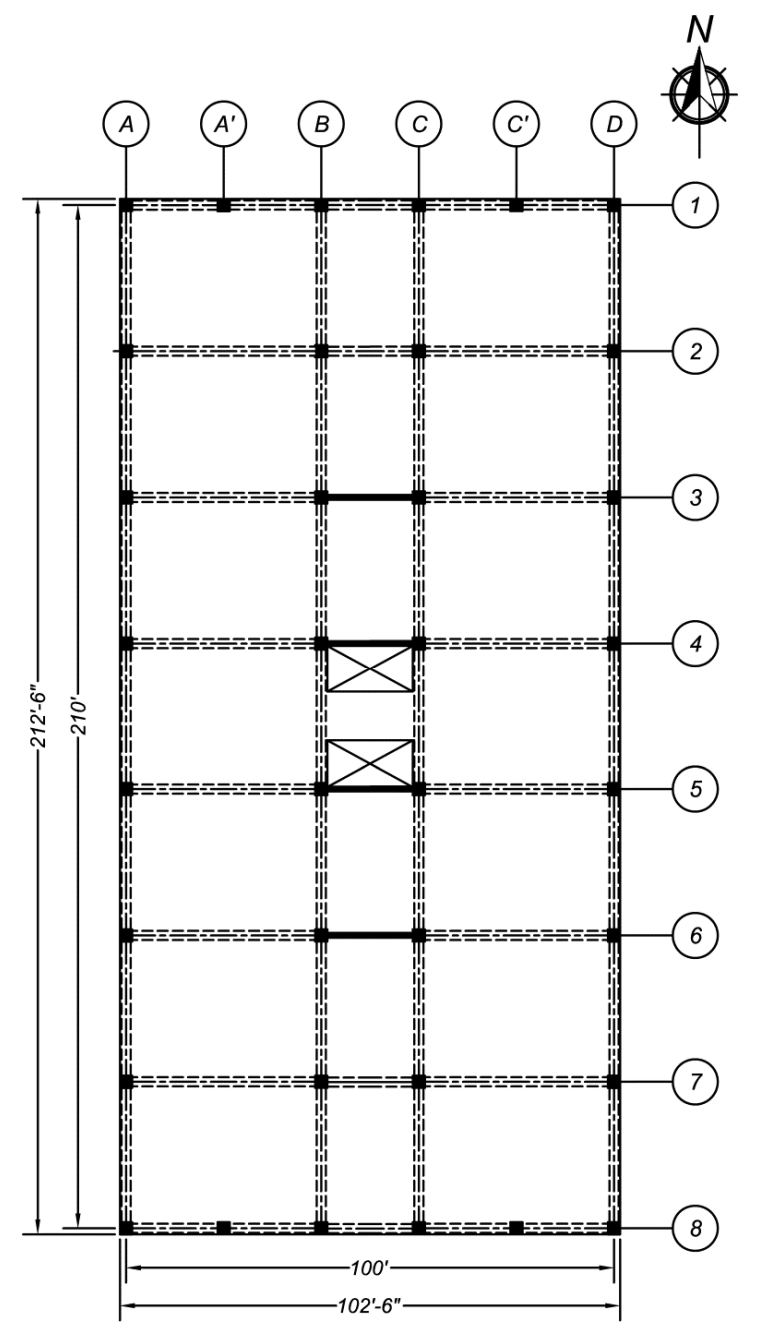

Figure 5-5 Plan view of case study building (Barbosa, 2011). 


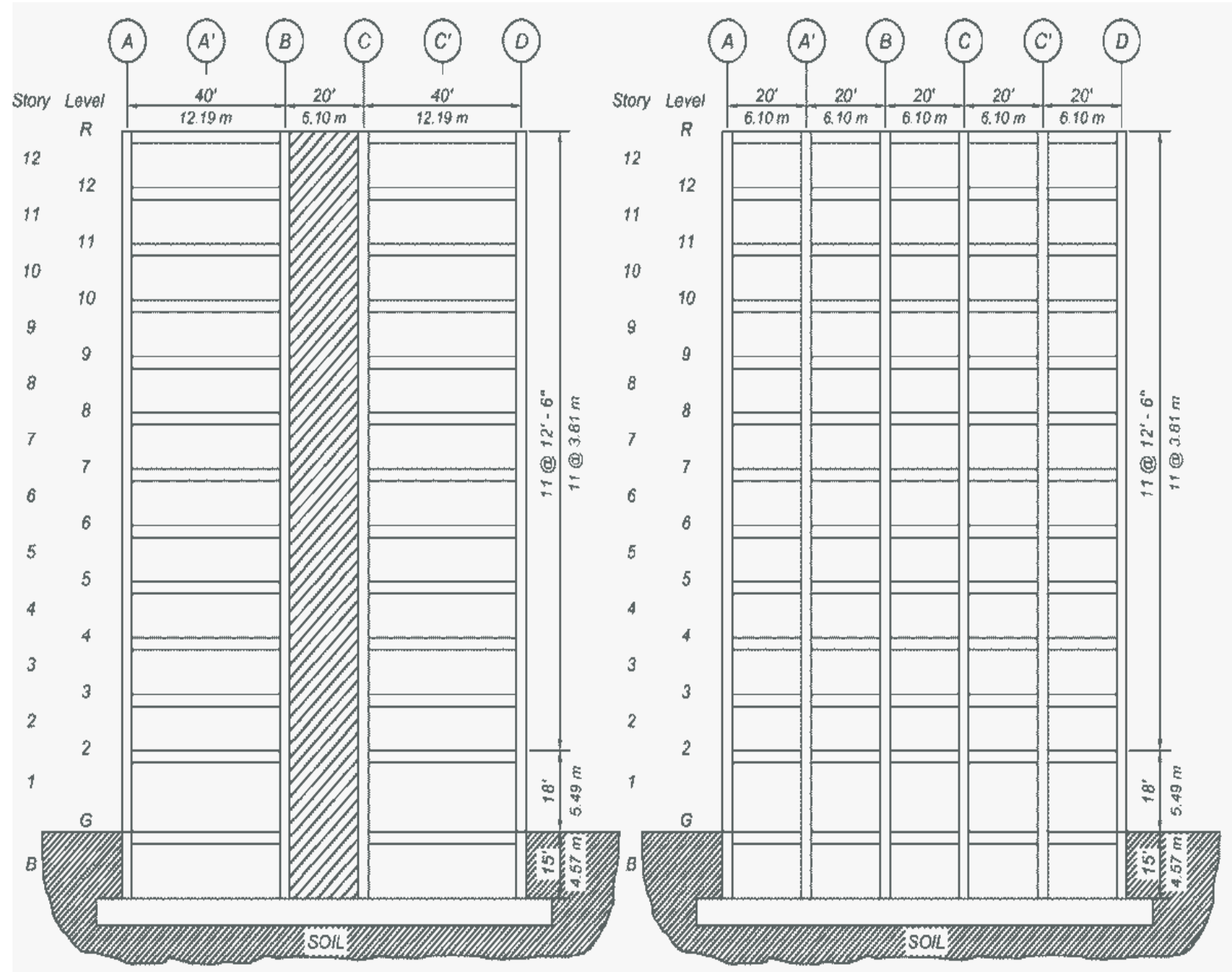

Figure 5-6 Elevation of case study building through Gridlines 3 and 8 (Barbosa, 2011).

are 30 feet long in the north-south direction and either 40 feet or 20 feet long in the east-west direction. The floor consists of a two-way, post-tensioned, 8-inch thick cast-in-place slab. As shown in Figure 5-5, along gridlines 2 through 7, slabs are supported by beams spanning 40 feet in the exterior bays and 20 feet in the interior bays. These beams are 32 inches deep by 22.5 inches wide. On exterior gridlines 1 and 8 , the 40 -feet spans have been divided into two equal parts and, therefore, these frames have a total of five 20 -feet spans with the same dimensions. The beams along all spans between gridlines A through D also are 32 inches deep by 22.5 inches wide. The lateral force-resisting system in the north-south direction consists of four 7-bay special moment-resisting frames. In the east-west direction, the lateral-forceresisting system is a dual system composed of four special moment frames and four special structural walls with outrigger beams on gridlines 3, 4, 5, and 6. All columns are 30 inches square; structural walls are 22.5 feet long and have 30 -inch square boundary elements at both ends and a 12-inch thick web. 


\subsubsection{Building Designs}

For this study, the following four designs were analyzed: (1) using ASTM A706 Grade 60 reinforcement for beams, columns, and walls; (2) using ASTM A706 Grade 80 longitudinal reinforcement for beams, columns, and walls; (3) using a combination of ASTM A706 Grade 80 reinforcement for beams and ASTM A706 Grade 100 reinforcement for columns and walls; and (4) using Grade 100 reinforcement for beams, columns, and walls.

The building was first designed according to ACI 318-11 and ASCE/SEI 7-10 requirements, using Grade 60 reinforcement throughout and a specified concrete strength, $f_{c}^{\prime}$, of $5 \mathrm{ksi}$ (Barbosa, 2011). According to ASCE/SEI 7-10, the building is classified as Seismic Design Category D. The building has an importance factor, $I$, of 1 . The response modification coefficient, $R$, is 8 for the Special Reinforced Concrete Moment Frame system and 7 for the dual system incorporating Special Reinforced Concrete Shear Walls and Special Moment Frames. The design base shear coefficients are $4.1 \%$ in the north-south (special moment frames) direction and $7.6 \%$ in the east-west direction (dual system). All drift requirements in ASCE/SEI 710 are fulfilled.

Typical reinforcement ratios in key column, beam, and wall elements are listed in Tables 5-9 through 5-11, respectively. The gravity, unfactored axial load in the perimeter columns range approximately from $0.15 f^{\prime} A_{g}$ to $0.35 f_{c}^{\prime} A_{g}$. Column $\mathrm{A}^{\prime}-1$, has a gravity load of $0.3 f^{\prime} A_{g}$. The gravity load on the walls was $0.12 f_{c}^{\prime} A_{g}$.

Table 5-9 Column Reinforcement Ratios in Selected Columns in Story 1, Case Study Building

\begin{tabular}{lc}
\hline \multicolumn{1}{c}{ Location } & Ratio $\rho$ \\
\hline Corners & $1.7 \%$ \\
Line B/C; Line $1 / 8$ & $2.1 \%$ \\
Line A/D; Line $2 / 7$ & $2.1 \%$ \\
Line A'/C'; Line $1 / 8$ & $2.1 \%$ \\
Line B/C; Line $2 / 7$ & $2.8 \%$ \\
\hline
\end{tabular}

Table 5-10 Beam Reinforcement Ratios in Selected Beams on Level 1, Case Study Building

\begin{tabular}{lccc}
\hline \multicolumn{1}{c}{ Location } & Ratio $\rho^{\prime}$ & & Ratio $\rho$ \\
\cline { 1 - 1 } Outrigger beam lines 3-6 & $1.5 \%$ & $0.7 \%$ \\
Lines B8-C8 & $0.77 \%$ & $0.55 \%$ \\
Lines A8-A7 and A5-A4 & $0.64 \%$ & $0.55 \%$ \\
\hline
\end{tabular}


Table 5-11 Wall Reinforcement Ratios in Story 1, Case Study Building

\begin{tabular}{lc}
\hline \multicolumn{1}{c}{ Location } & Ratio $\rho_{\ell}$ \\
Boundary elements & $1.3 \%$ \\
Web & $0.3 \%$ \\
Total web and boundary elements & $0.73 \%$ \\
\hline
\end{tabular}

In this design with Grade 60 reinforcement, beam reinforcement anchored in all beam-column joints were designed to be No. 9 or smaller. Therefore, the joint depth to bar diameter ratio is at least 26.7 , which is greater than the limit of 20 prescribed by ACI 318-11.

Designs with reinforcement other than Grade 60 were completed by reducing the area of longitudinal reinforcement detailed for the Grade 60 design by the ratio of the yield strengths of the reinforcement grades used. The longitudinal reinforcement ratio in the columns in the designs was not allowed to be less than $1 \%$. Using Equation 4-5, the diameter of the beam longitudinal bars were limited to 1 inch for Grade 80 reinforcement and to 0.77 inches for Grade 100 reinforcement, when anchored in 30-inch deep joints with $f_{c}^{\prime}$ equal to $5 \mathrm{ksi}$. Therefore, beams reinforced with Grade 80 longitudinal reinforcement were reinforced with No. 8 or smaller bars. Accordingly, beams reinforced with Grade 100 longitudinal reinforcement would use No. 6 or smaller bars. However, this was not considered effective, as it would have resulted in a replacement of the Grade 60 No. 9 bars with Grade 100 No. 6 bars, for which the spacing between stirrups sets would have been smaller. Instead, the beams in the design with Grade 100 reinforcement used No. 9 bars that were assumed to be mechanically spliced with a proprietary device similar to one of the devices described in Chapter 4. Therefore, the beam longitudinal reinforcement in all of the alternative designs was assumed to be appropriately anchored in the beam-column joints.

\subsubsection{Analytical Models}

The nonlinear dynamic response of the building to bidirectional seismic base excitation was analyzed using the Open System for Earthquake Engineering Simulations (OpenSees, 2011). A finite element model of the building shown in Figure 5-7 was developed within this program. Beams and columns were modeled using a force-based fiber discretization, whereas a 3-D nonlinear truss modeling approach was used to model the reinforced-concrete walls (Barbosa, 2011; Panagiotou et al., 2011; Lu and Panagiotou, 2013). All component models were calibrated and validated with the response reported for various subassembly tests. The phenomenological approach employed in this study for modeling reinforced concrete diaphragms, developed by Barbosa (2011), was validated against test data. The diaphragm model allowed for beam elongation caused by the axial lengthening of the plastic hinges, which is unrealistically constrained when using the typical rigid 


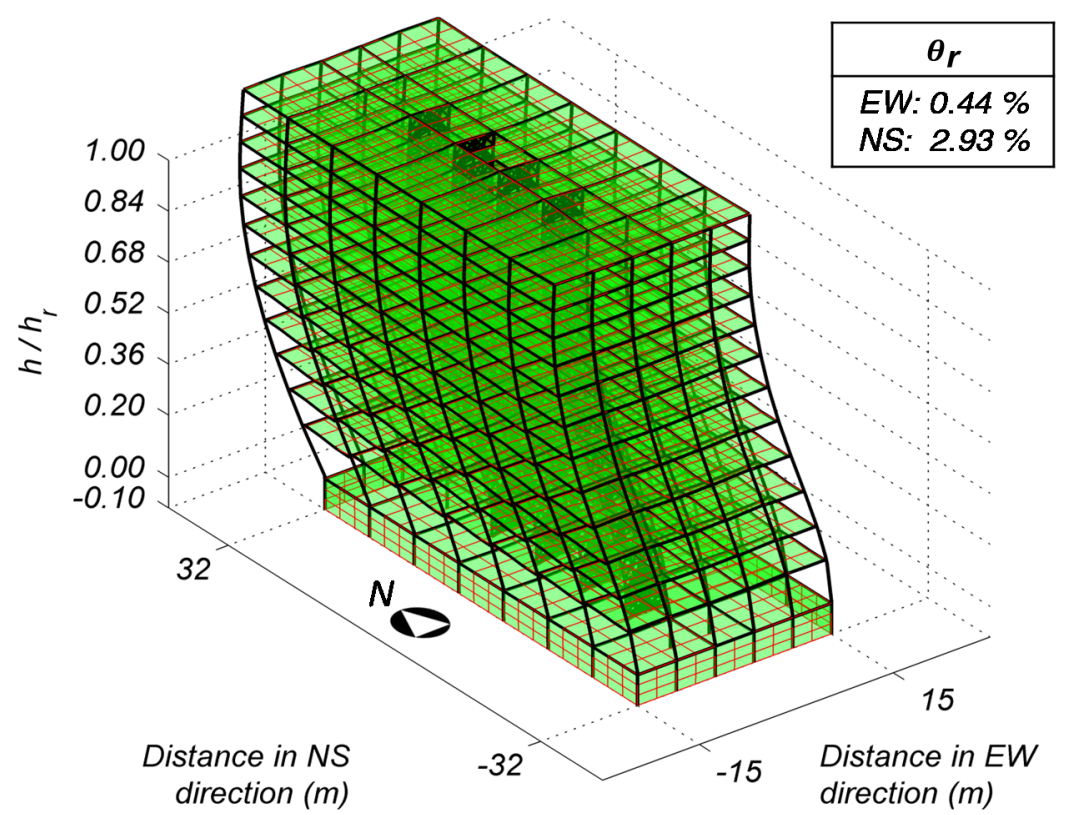

Figure 5-7 Rendering of the finite element model of the nonlinear analysis case study building (Barbosa, 2011).

diaphragm assumption. The nonlinear analysis solution strategy is explained elsewhere (Barbosa, 2011).

The Giufree-Menegotto-Pinto Steel02 hysteretic model for steel, available in OpenSees, was used to model the three grades of reinforcement. Analyses were performed assuming expected material properties; for the steel reinforcement, an expected to specified yield strength ratio of 1.15 was assumed. The post-elastic to elastic modulus was taken equal to $1 \%$ for all three grades of reinforcement. Concrete was modeled with expected material properties. The unconfined concrete strength was assumed to be $6.8 \mathrm{ksi}$, that is, 1.36 times the specified strength. The expected strength for the core concrete, well confined by hoops in columns and boundary elements of walls, was calculated at $9.4 \mathrm{ksi}$. The Concrete 02 model with the linear tension stiffening material model, available in OpenSees, was used to model unconfined and confined regions in the structure. A complete description of the material models and their parameters is given in the OpenSees Command Language Manual (Mazzoni et al., 2009).

Four models of the building were developed, each representing one of the four designs:

- Case (i): Grade 60 reinforcement throughout in the beams, columns, and walls;

- Case (ii): Grade 80 longitudinal reinforcement in the beams, columns, and walls;

- Case (iii): Grade 80 longitudinal reinforcement in the beams and Grade 100 longitudinal reinforcement in the columns and walls; and 
- Case (iv): Grade 100 longitudinal reinforcement in the beams, columns, and walls.

The model developed for each of the case studies did not capture bond slip of the beam longitudinal reinforcement anchored in the beam-column joints, or the wall longitudinal bars anchored below the critical region of the walls where plasticity developed. Under this limitation, the model is unable to capture any bond failure of longitudinal bars anchored in beam-column joints. However, because the design of the beams with longitudinal Grade 60 and Grade 80 reinforcement was compliant with Equation 4-5, and Grade 100 reinforcement was assumed to be anchored with mechanical devices through the joints, bond-slip was assumed to play a minor role in the response, with bar slip through the joint considered unlikely to occur in all cases (see Chapter 4 for more discussion).

A modal analysis of each of the four models indicated that, as expected, the periods of natural vibration of the longitudinal and transverse directions of the building in its uncracked condition, using uncracked transformed section properties, are practically insensitive to the amount of longitudinal reinforcement in the elements. The first translational mode natural period in the north-south direction (direction of the frames) varied narrowly near 1.7 seconds, with the shorter period corresponding, as expected, to the model for Grade 60 reinforcement (Case (i)) and the longest period corresponding to the model with Grade 100 reinforcement (Case (iv)). The first mode translational natural periods in the east-west direction (direction of the dual system) also varied narrowly near 1.2 seconds.

All models incorporated Rayleigh damping proportional to stiffness after the application of gravity loads. Damping coefficients of $2 \%$ were set at $0.56 \mathrm{~Hz}(1.77$ seconds) and $6.25 \mathrm{~Hz}$ (0.16 seconds), meaning that all the higher modes of significance were underdamped. At the highest frequency of $6.25 \mathrm{~Hz}$, the cumulative modal mass was nearly $100 \%$ of the total mass in the direction of the frames and $95 \%$ in the direction of the walls.

All analyses were staged. Prior to the earthquake base excitation, a nonlinear analysis for gravity loads was performed, and cracking developed in some members. All the nonlinear analyses were carried out accounting for nonlinear geometry (PDelta effects).

\subsubsection{Input Ground Motions}

In order to perform the nonlinear time-history analyses, seven historical ground motion pairs were selected for the analyses from the 2010 PEER strong motion database (PEER, 2010). All seven ground motions had near-fault characteristics. Figure 5-8a and 5-8b show the spectra for ground motions in the Fault Normal and Fault Parallel directions, respectively. A comparison of the arithmetic mean spectra 


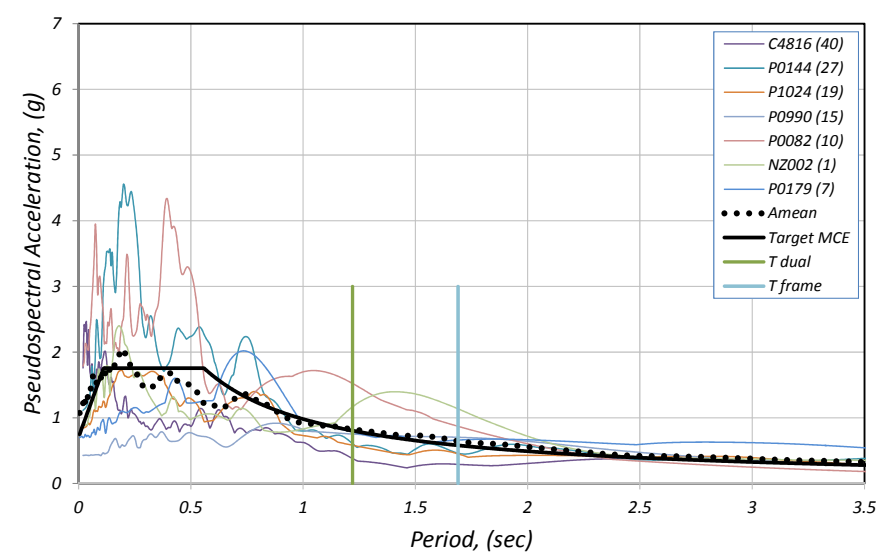

(a)

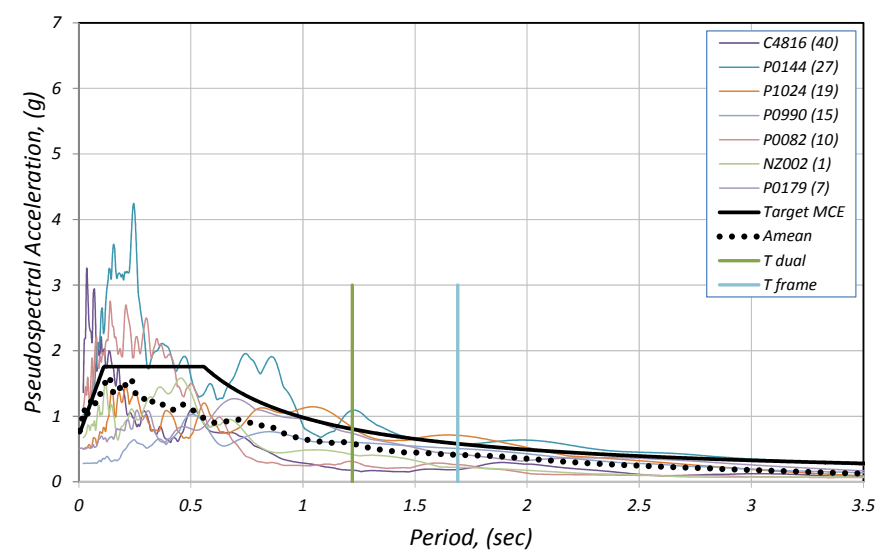

(b)

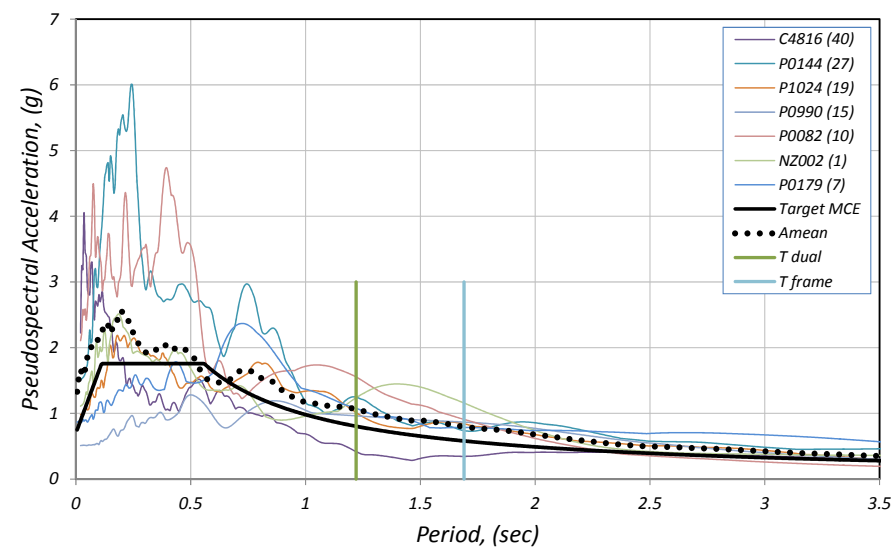

(c)

Figure 5-8 Response Spectra for 5\% damping of records scaled at MCE (maximum considered earthquake), Mean and Target Spectra (Peer, 2010): (a) Spectra of Fault Normal (FN) component of ground motions; (b) Spectra of Fault Parallel (FP) component of ground motions; (c) Spectra of square root sum of the squares of FN and FP ground motion spectral ordinates. 
for the Fault Normal and Fault Parallel ground motions reveals that the Fault Normal component of the ground motions has stronger intensity than the Fault Parallel component over the entire period range. The ground motion records were scaled to ensure that the arithmetic mean spectra calculated for 5\% damping of the square root sum of the squares of the Fault Normal and Fault Parallel components were greater than the response spectra determined from ASCE/SEI 7-10 for the maximum considered earthquake. This objective was attained up to a period of 5.8 seconds, except for a small range at around a period of 0.6 seconds, as shown in Figure 5-8c. Figure 5-8a shows that, beyond a period of 0.75 seconds, the mean spectrum corresponds very closely to the ASCE/SEI 7-10 spectrum.

\subsubsection{Results}

Nonlinear history dynamic analyses were carried out for the four case studies. Analyses were performed for the design level earthquake (with an intensity defined as 2/3 of the maximum considered earthquake, in accordance with ASCE/SEI 7-10), and for the maximum considered earthquake.

This section discusses key results of the nonlinear response of the building to the seven input ground motions scaled at the design earthquake and at the maximum considered earthquake. Fault Normal and Fault Parallel ground motions were applied concurrently in each analysis.

A first set of analyses was performed with the Fault Normal component applied in the north-south direction, and another set of analyses was performed with the Fault Normal component of the ground motions in the east-west direction. That is, fourteen analyses were carried out to observe the building's response at the design level earthquake, and fourteen analyses were carried out to observe the building's response at the maximum considered earthquake.

The Fault Normal component of the ground motion had stronger mean spectral intensity than the Fault Parallel component. As a result, the mean response parameters in the special moment frames were greater when the Fault Normal component was applied in the north-south direction (the same direction as the orientation of the moment frames) than when applied in the east-west direction. Likewise, the mean response parameters obtained for the dual system were greater when the Fault Normal component was applied in the east-west direction (that is, the same direction as the orientation of the dual system) than applied in the north-south direction.

\subsubsection{Drift Ratios}

Figures 5-9 and 5-10 depict the mean maxima roof drift ratios and mean maxima interstory drift ratios obtained for the special moment frames at intensities 


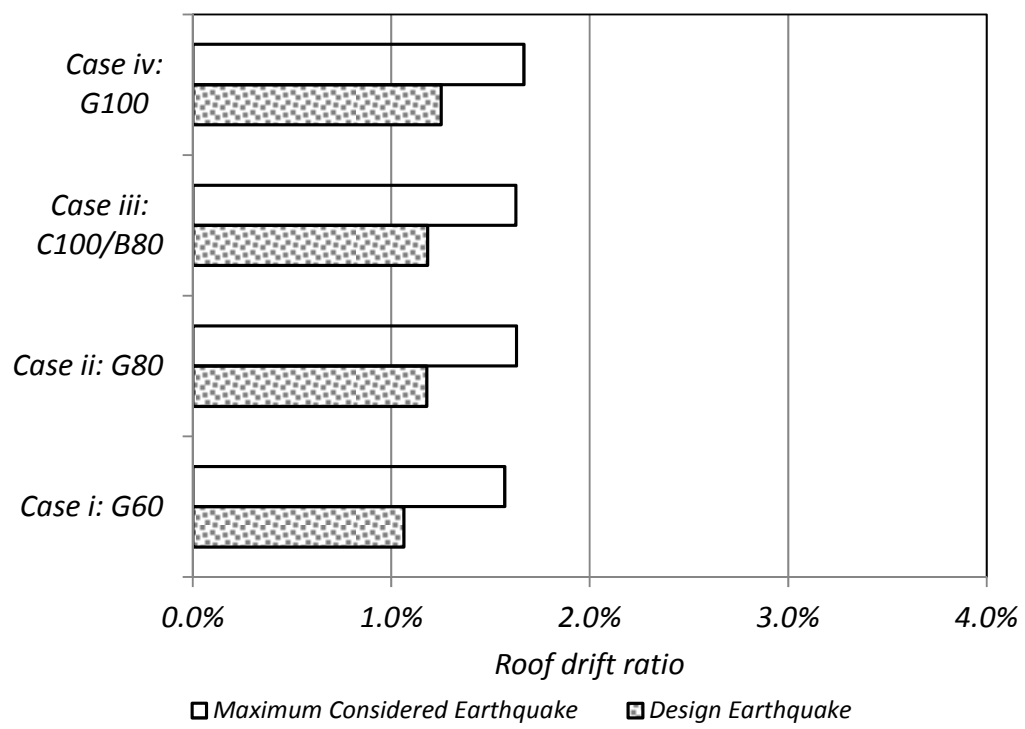

Figure 5-9 Mean maxima roof drift ratios in special moment frames in building with varying grades of reinforcement (Fault Normal component applied in the north-south direction).

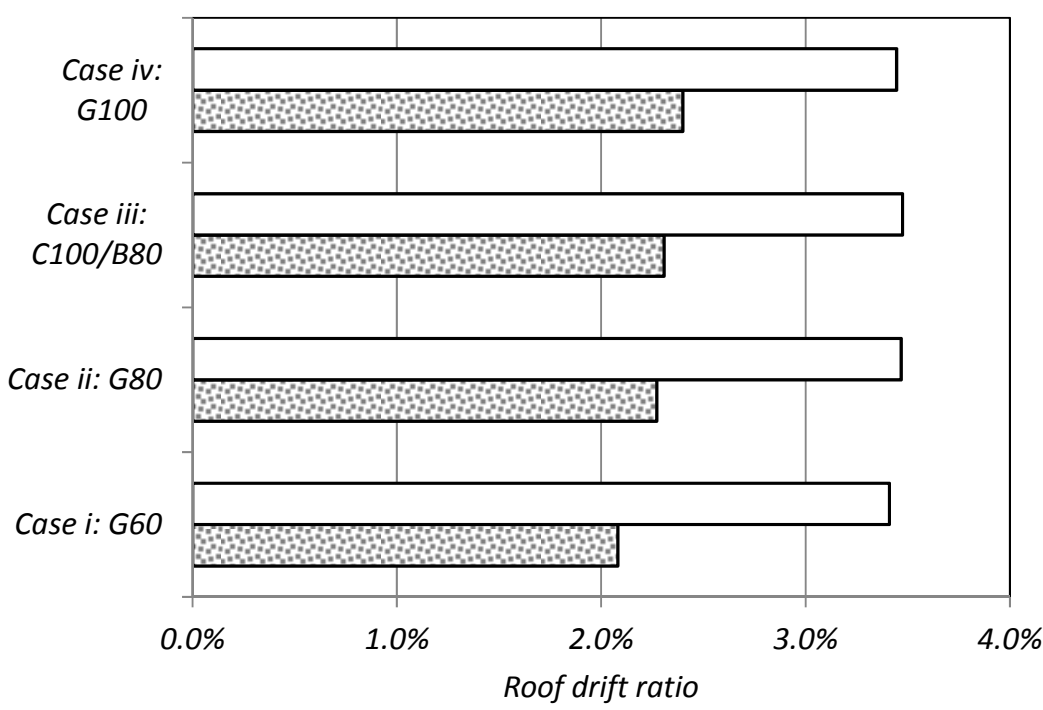

口Maximum Considered Earthquake 田Design Earthquake

Figure 5-10 Mean maxima interstory drift ratios in special moment frames in building with varying grades of reinforcement (Fault Normal component applied in the north-south direction).

corresponding to the design level earthquake and the maximum considered earthquake. Roof drift ratios and interstory drift ratios were calculated at the building geometric center and therefore do not include any magnification induced by torsional response (which was small in this building). Furthermore, the interstory drift ratio, as presented here, is equal to the interstory drift divided by the story height. 
At the design level earthquake, mean maxima roof drift ratios for the moment frame system varied from $1.06 \%$ to $1.25 \%$, with the smallest drift ratio found for the model of the building containing Grade 60 reinforcement (Case (i)) and the largest for the building containing Grade 100 longitudinal reinforcement in beams and columns (Case (iv)). The variation from the midpoint of these calculated values $(1.16 \%)$ to the smallest and largest roof drift ratios was $8 \%$.

For the maximum considered earthquake, Case (i) and Case (iv) exhibited the smallest and largest mean maxima roof drift ratios of $1.57 \%$ and $1.66 \%$, respectively. The variation from the midpoint of these values to the largest and smallest roof drift ratios was $3 \%$.

Mean maxima interstory drift ratios for the special moment frame showed similar trends. Case (i) displayed the smallest interstory drift ratios of $2.08 \%$ at the design level earthquake and $3.40 \%$ at the maximum considered earthquake. Case (iv) exhibited the largest maximum interstory drift ratios of $2.40 \%$ at the design level earthquake and $3.45 \%$ at the maximum considered earthquake.

The trends observed for the response of the special moment frame systems at the design level earthquake and the maximum considered earthquake show direct correlation with the reinforcement grade, but the variations at the midpoint are small to moderate. At the design level earthquake, the variation from the midpoint for the interstory drift ratios computed for Grade 100 and Grade 60 reinforcement was 7\%, and at the maximum considered earthquake the variation decreased to $1 \%$. The smaller variation for the maximum considered earthquake may have been influenced by the transient fundamental period of the building response encroaching into the constant displacement portion of the mean response spectrum of the input ground motions used, which began at about 5.8 seconds.

Figures 5-11 and 5-12 depict the mean maxima roof and mean maxima interstory drift ratios obtained for the dual system at the design level earthquake and at the maximum considered earthquake. Similar to the drift ratios described above for the moment frames acting in the north-south direction, roof drift ratios and interstory drift ratios were calculated at the building geometric center and therefore did not include any magnification induced by torsional response.

At the design level earthquake, mean maxima roof drift ratios for the dual system varied from $0.88 \%$ to $0.97 \%$, with the smallest drift ratio found for the model of the building with Grade 60 reinforcement (Case (i)) and the largest for the building with Grade 100 reinforcement (Case (iv)). The variation from the midpoint of these calculated values $(0.93 \%)$ to the smallest and largest roof drift ratios was approximately $5 \%$. 


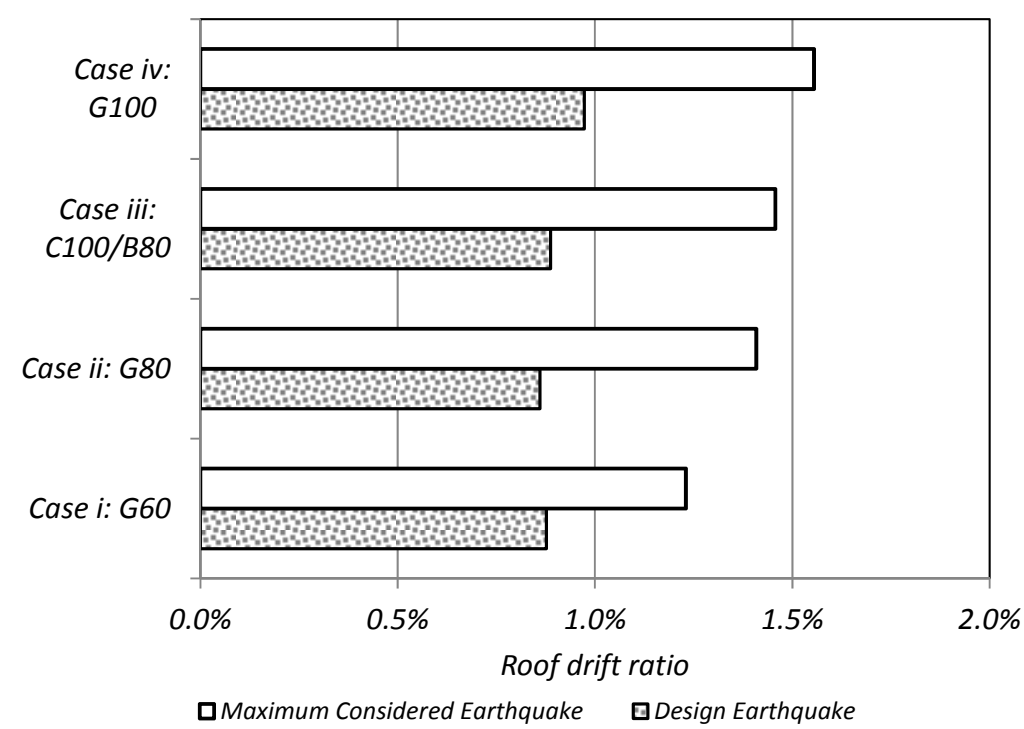

Figure 5-11 Mean maxima roof drift ratios in dual system in building with varying grades of reinforcement (Fault Normal component applied in the eastwest direction).

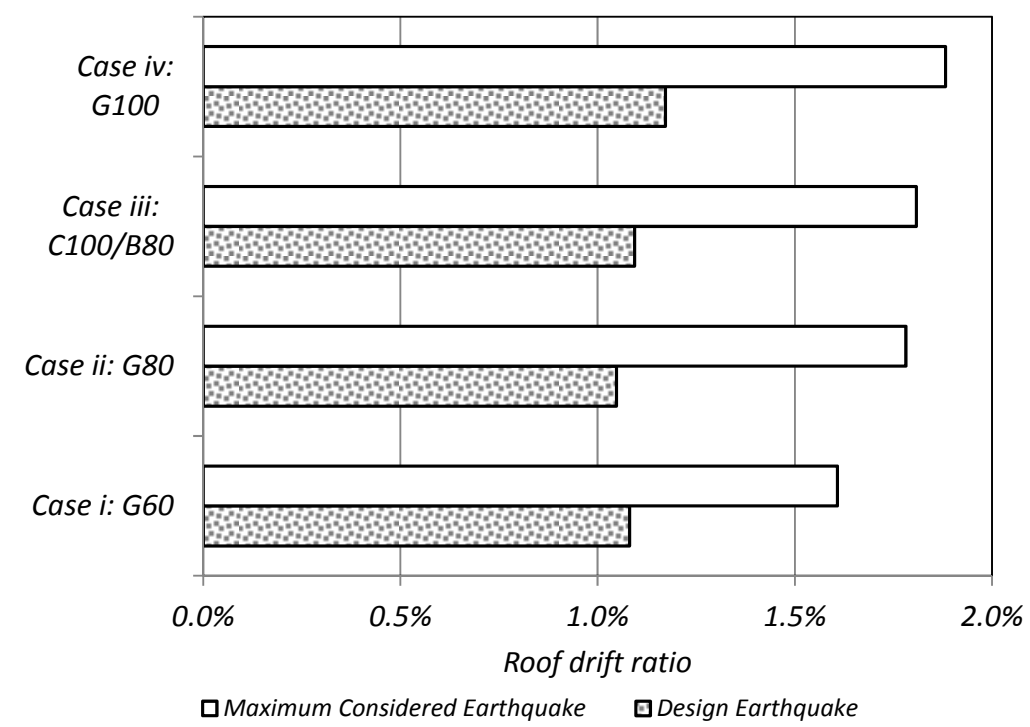

Figure 5-12 Mean maxima interstory drift ratios in dual system in building with varying grades of reinforcement (Fault Normal component applied in the east-west direction).

For the maximum considered earthquake, Case (i) and Case (iv) exhibited the smallest and largest mean maxima roof drift ratios of $1.23 \%$ and $1.55 \%$, respectively. The variation from the midpoint of these values to the largest and smallest roof drift ratios was approximately $12 \%$.

Mean maxima interstory drift ratios showed similar trends. Case (i) displayed the smallest interstory drift ratios of $1.08 \%$ at the design level earthquake and $1.60 \%$ at the maximum considered earthquake. Case (iv) exhibited the largest maximum 
interstory drift ratios of $1.17 \%$ at the design level earthquake and $1.88 \%$ at the maximum considered earthquake.

At the design level earthquake for the dual system, the variation from the midpoint for the interstory drift ratios computed for Grade 100 and Grade 60 reinforcement was $4 \%$, and at the maximum considered earthquake it increased to $8 \%$. The trends observed for the response of the dual system at the design level earthquake and the maximum considered earthquake are indeed correlated with the grade of reinforcement, but as in the case of the special moment frames, roof and interstory drift ratios vary within a small range.

\subsubsection{System Lateral Stiffness}

Mean maxima interstory drift ratios obtained in both directions of the building during the design level earthquake analysis were found to be moderate. Given this response, it is possible to assume that the mode shapes and the modal masses remained unchanged. Hence, the predominant system stiffness can be determined based on the predominant period of response, which can be determined using the response spectral ratios (Rosenblueth and Arciniega, 1992). In the context of a building, the ratio of the spectral ordinate at the roof and the ground is computed, and a spectrum of the ratio is obtained for each excitation. The predominant period of response is the period that is greater than the fundamental period obtained from a modal analysis using uncracked section properties where a peak is observed. Predominant periods were determined for each of the responses of the building in the north-south and eastwest directions. The reduction in the system stiffness was determined as the square root of the ratio of the fundamental period of the building in the direction of interest and the predominant period in the same direction.

Figure 5-13(a) shows the reduction in the system lateral stiffness calculated for the special moment frames at the design level earthquake for each of the case studies. Figure 5-13(b) shows the same calculation in the direction of the dual system. The reduction in stiffness calculated in the north-south direction, where the special moment frames provide most of the lateral stiffness, is rather insensitive to the grade of reinforcement used. The reduced stiffness is about $31 \%$ of the initial stiffness.

In the east-west direction, where the dual system acted, the walls provide a greater share of the lateral stiffness. Because of the intertwined combination of walls, frames, and outrigger beams, however, it is difficult to make good comparisons with values recommended and described in Section 5.1. At the design level earthquake, the lateral stiffness in this direction of the building was reduced to $42 \%$ for Case (i), and was reduced to the range of $31 \%$ to $36 \%$ for Cases (ii) through (iv). 


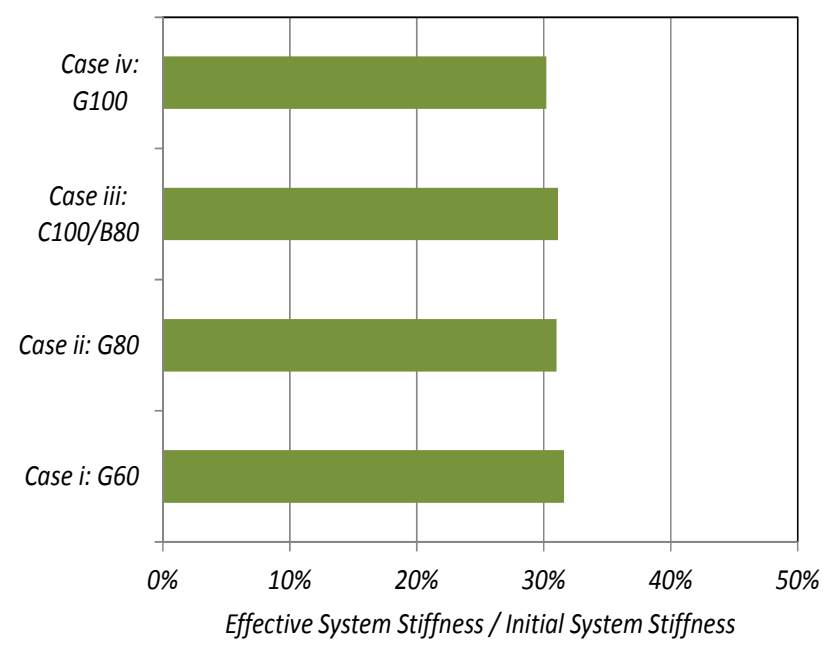

(a)

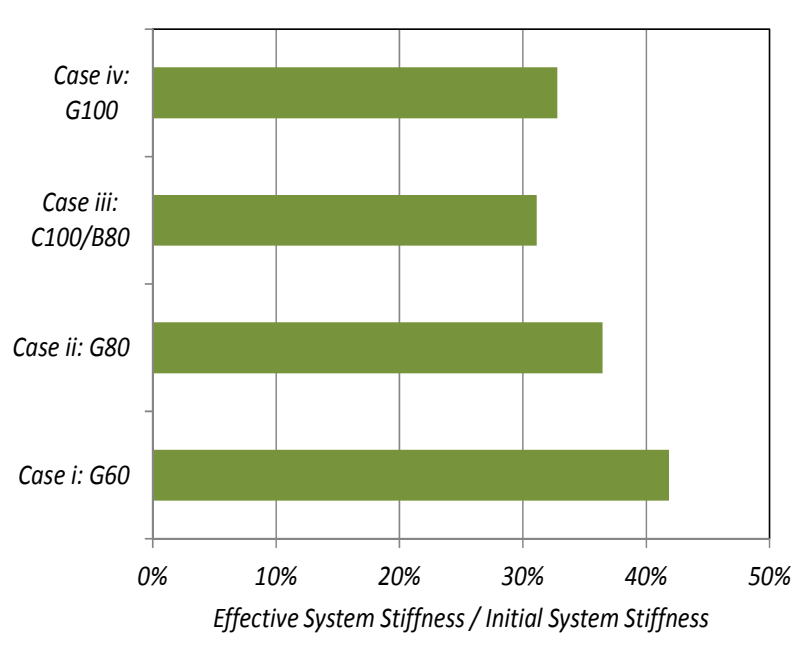

(b)

Figure 5-13 Reduction in lateral system stiffness at the predominant period of response during the design level earthquake for case study building: (a) Moment frame system; (b) dual system.

\subsubsection{Bar Strains}

Longitudinal bar strains were recorded at critical locations in a north-south perimeter beam, a perimeter column, and a wall of the building for each of the case studies for the design level earthquake and the maximum considered earthquake. Maximum and minimum mean strains are depicted in Figure 5-14. Overall, strain demands at the design level earthquake and the maximum considered earthquake were found to be relatively unaffected by the grade of reinforcement used.

The bars on the north-south perimeter beam sustained tensile strains on the order of $2.5 \%$ at the design level earthquake and $4.3 \%$ at the maximum considered earthquake, as shown in Figure 5-14(a). The strains at the maximum considered earthquake are moderately large and about one-half of the uniform elongation (discussed in Chapter 2). These strains are consistent with the larger interstory drift demands observed for the building in the north-south direction in the moment frames, which are more flexible than the dual system. These beams sustained very small compressive strains. The column investigated sustained smaller tensile strain demands than the beam but larger compressive strain demands. The strain ranged from about $-0.2 \%$ compressive strain to $1.1 \%$ tensile strain at the design level earthquake and from $-0.6 \%$ compressive strain to $2 \%$ tensile strain at the maximum considered earthquake.

The wall boundary element bar shown in Figure 5-14(c) sustained relatively even compressive and tensile strains at the design level earthquake and the maximum considered earthquake. At the design level earthquake, strains ranged from approximately $-0.5 \%$ to $0.7 \%$; at the maximum considered earthquake, the strains 


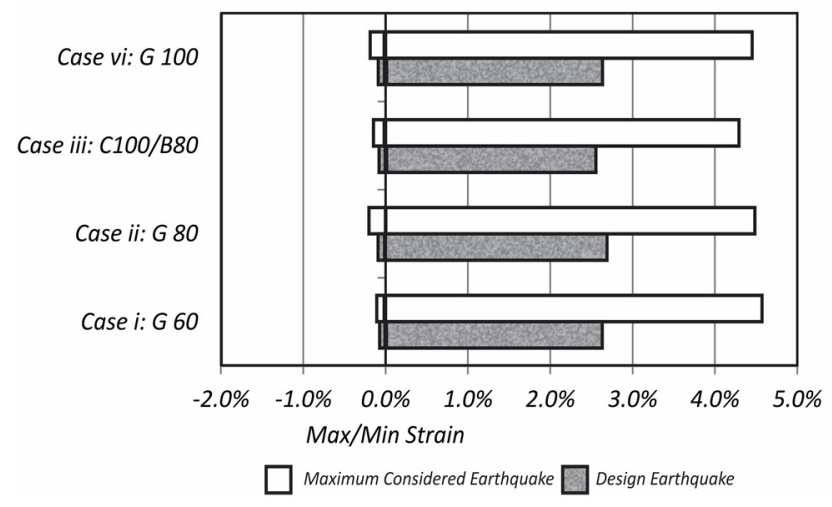

(a)

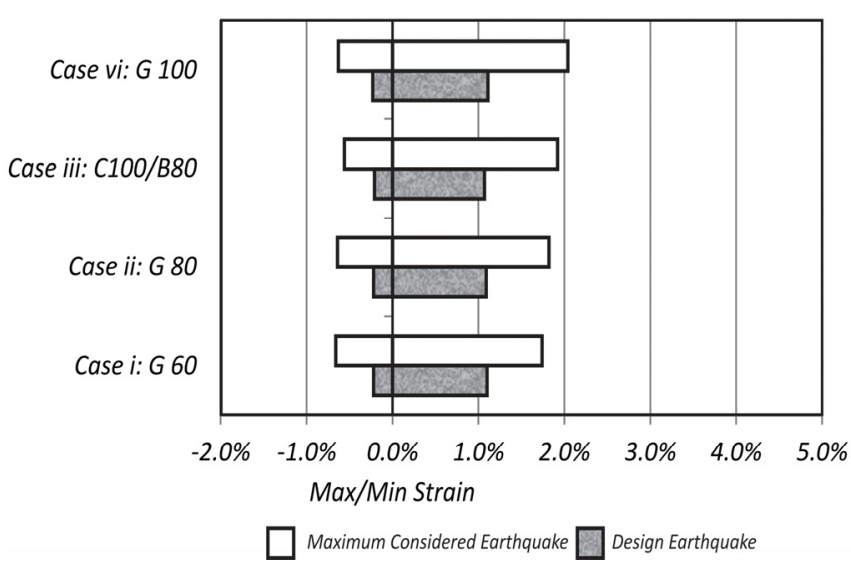

(b)

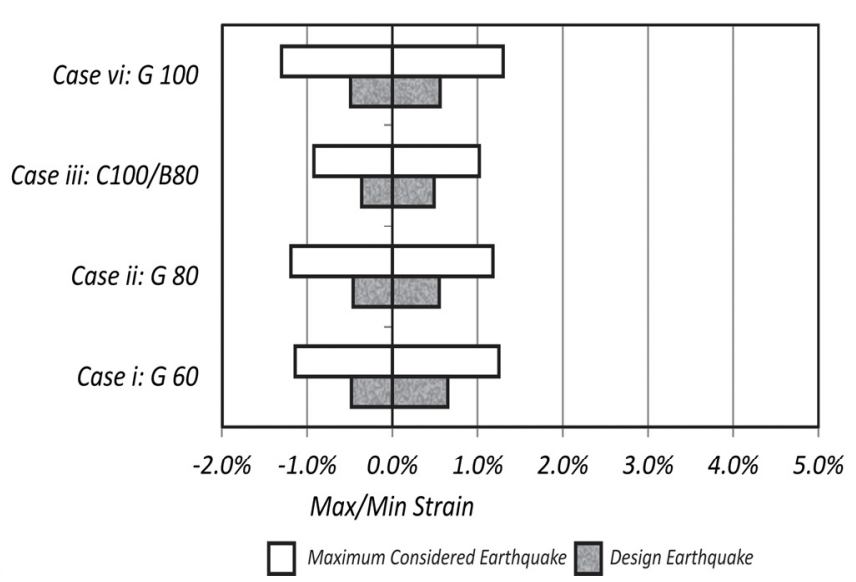

(c)

Figure 5-14 Mean strains on longitudinal bars observed at critical sections of elements in the case study building: (a) Perimeter beam (Level 3, Line 1 between Lines 4-5 at face of column on Lines 1-5); (b) interior column (base of Story 1, Lines $A^{\prime}-1$ ); (c) wall boundary element (base of Story 1, Lines B-4).

ranged between $-1.3 \%$ to $1.3 \%$. At first glance, the similarity between the tensile and compressive mean strain demands in a bar of the boundary element of a wall seems odd. This effect occurs because the axial load acting on the wall and the longitudinal reinforcement ratio in the walls are moderate, and compressive strains of such magnitude would not be expected when using first principles of flexure theory. However, a look into the strain histories of the corner bars in the boundary elements of one of the walls reveals that the large compressive strains were caused by bidirectional bending wall response.

Figure 5-15 shows the wall boundary element bar strain time histories for Case (ii) (Grade 80 reinforcement) during the building response to the Newhall-West Pico Canyon Road input ground motion of the 1994 Northridge, California, earthquake, with the Fault Normal component applied in the direction of the dual system. At the beginning of the time history, all four bars were subjected to small compressive 


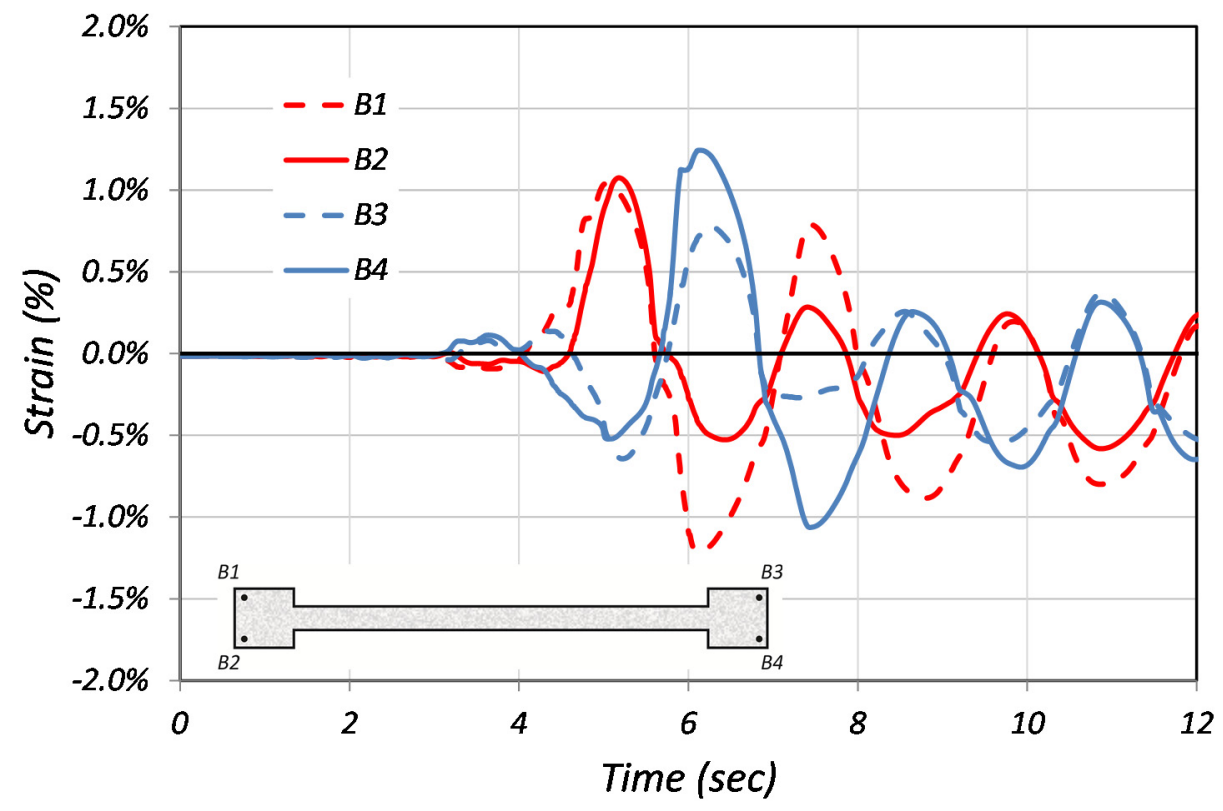

Figure 5-15 Strain time-history recorded for wall corner bars during the building response to the Newhall-West Pico Canyon Road input ground motion of the 1994 Northridge Earthquake (base of Story 1, Lines B-4).

strains that were caused entirely by gravity load. Large strain oscillations began at 3 seconds, and peak responses occurred at 3.7 seconds and 5.2 seconds. Bars B1 and $\mathrm{B} 2$, which are corner bars on one boundary element, underwent similar strains. Bars B3 and B4, which are corner bars in the opposite boundary element, also underwent similar strains. This similitude in strains indicates predominant wall in-plane bending during these two peaks. Furthermore, at 5.2 seconds, when bars B1 and B2 yielded in tension, the tensile strains in these bars were about twice the compressive strains in bars B3 and B4. The neutral axis depth derived from the bar strains at 5.2 seconds, and from the location of the bars in the boundary elements of the wall, was about one-third of the wall length. This depth is in the range of that calculated from in-plane flexure theory.

Bars B1 and B4 reached their peak compressive and tensile strains at 6.3 seconds. The compressive strain of bar B1 was 1.2\%, a strain value considered large for the surrounding concrete core. The strains in bars B1 and B2 and in bars B3 and B4 were strikingly different. This difference in strains is due to a combination of inplane and out-of-plane wall bending. That is, the three-dimensional nature of the nonlinear analysis allows one to gauge the extent at which thin elements, like the walls in this building, are subjected to in-plane and out-of plane bending, something that is not currently considered in the design of planar walls. In this particular example, the large compressive strains near the corners of the boundary elements have been accentuated by the fact that the building lateral resistance in the northsouth direction is provided by rather flexible special moment frames. 


\subsubsection{Summary of Key Findings}

The nonlinear response of a 13-story reinforced concrete building subjected to earthquake excitation was evaluated for different reinforcement options:

- Case (i): Grade 60 reinforcement throughout in the beams, columns, and walls;

- Case (ii): Grade 80 longitudinal reinforcement in the beams, columns, and walls;

- Case (iii): Grade 80 longitudinal reinforcement in the beams and Grade 100

longitudinal reinforcement in the columns and walls; and

- Case (iv): Grade 100 longitudinal reinforcement in the beams, columns, and walls.

The lateral force resistance in this building consisted of special moment frames in one direction and a dual system consisting of special moment frames and shear walls in the other direction.

Drift ratios were correlated to the grade of reinforcement for both the moment frames and the dual system in the building, with higher grade reinforcement leading to larger drift ratios. However, for both systems, the roof and interstory drift ratios varied within a small to moderate range.

For both the design level earthquake and the maximum considered earthquake, the computed building responses found the maximum longitudinal bar strains in a beam and column of the north-south perimeter frames and in a wall of the east-west dual system, to be relatively unaffected by the grade of reinforcement used.

All of these results indicate that, for this building model, the use of different grades of reinforcement, ranging from conventional strength to high-strength, provided comparable performance in design level and maximum considered earthquake shaking. 



\section{Chapter 6}

\section{Cost and Constructability}

This chapter examines the effects of the use of high-strength reinforcement on the structural and total project cost of a building and ease of constructability. This chapter also presents case studies evaluating the potential cost savings of substituting Grade 80 reinforcement for Grade 60 reinforcement in two recently constructed buildings.

This section only examines impacts associated with the use of Grade 80 reinforcement. Other strengths of reinforcement are not examined because cost and constructability factors are heavily dependent on the availability of reinforcement. Although ASTM A1035 Grade 100 and Grade 120 reinforcement are available in the United States, their suitability for use in elements resisting seismic forces is not yet clear, as discussed in other chapters; furthermore, these types of reinforcement are expensive because of their corrosion-resistant properties.

\subsection{Cost and Constructability Considerations}

In the past 15 years, a significant number of high-rise concrete buildings, mostly residential towers that are 20 stories or more in height, have been constructed in major cities along the West Coast of the United States. Reinforcing bars are a significant component of the cost of high-rise concrete construction, generally equating to about $30 \%$ of the overall cost of the structure, which is typically between $15 \%$ to $20 \%$ of the overall project cost of a high-rise building (depending on the quality of the architectural finishes). Reducing the cost of the reinforcement will thus reduce the overall cost of a building.

The construction of a building structure involves the placement of quantities of reinforcement and concrete into a final configuration. Reducing the amount (tonnage) of reinforcement in a project will reduce the cost of the completed building, and the ease of constructability will reduce the time necessary for construction. Reducing the quantity of reinforcement reduces the following costaffecting factors:

- quantities of material;

- labor for placing the materials;

- duration of time to place materials;

- costs of ancillary equipment (e.g., cranes, hoists) to place materials; 
- congestion and impact on other trades that interface with the structural members, such as setting sleeves or embedding items;

- overall time for the construction of the building; and

- project overhead costs.

A key advantage of the use of high-strength reinforcement is the reduction of the tonnage of required reinforcement. Fewer bars would be needed in concrete elements constructed with high-strength reinforcement compared to elements of the same size constructed with Grade 60 reinforcement, while resisting the same level of forces. Alternatively, the number of bars may remain the same, but smaller sized bars may be used.

In some instances, it may also be possible to reduce element sizes, such as with the use of high-strength concrete. Typically, however, the size of columns that are part of the earthquake-resisting system cannot be reduced due to minimum joint depth requirements.

\subsubsection{Supply Chain}

In regions of higher seismic risk within the United States, such as California, nearly all buildings are currently designed and constructed using Grade 60 reinforcement for both the seismic- and non-seismic force-resisting elements of the buildings. The manufacture, fabrication, and installation supply chain for Grade 60 reinforcement has been well established for nearly 50 years. As with the introduction of any new construction material, the supply chain for Grade 80 reinforcement must be developed to meet the scheduling and cost needs of the construction industry. Over time, assuming increased use, the supply chain for Grade 80 reinforcement could develop to be as robust as the current supply chain for Grade 60 reinforcement. However, in the early stages of increased use of Grade 80 reinforcement, many of the participants in the supply chain may see their revenue reduced because they will be manufacturing, fabricating, and installing less material for a given amount of construction. In the long term, it is expected that the increase in overall construction activity due to lower overall construction cost will benefit all participants, including those in the supply chain.

For buildings located in the Western United States, ASTM A706 reinforcement may be purchased at little or no cost increase compared to ASTM A615 reinforcement. In the Midwest and Eastern United States, ASTM A706 reinforcement is less readily available, although several transportation departments now require its use. Many of the mills in the Midwest and Eastern United States are capable of producing ASTM A706 reinforcement; however, insisting on its use will have a cost premium (Gustafson, 2007). 
ACI 318-11 contains an exception that allows the use of ASTM A615 reinforcement that meets the strengths requirements of ASTM A706 reinforcement in elements designed to resist earthquake effects. Note that Chapter 7 of this report recommends changes to this exception.

\subsubsection{Rolling Mills}

Grade 60 bars are commonly stocked by both mills and fabricators and are readily available for construction use. The use of Grade 80 reinforcement for buildings is currently limited.

Grade 80 reinforcement accounts for less than $0.5 \%$ of reinforcement shipments on the West Coast. Because engineers currently specify Grade 80 reinforcement infrequently, mills currently roll it infrequently. Likewise, because it is not commonly stocked, engineers default to specifying Grade 60 reinforcement. Once code obstacles are removed and economic benefits become apparent, it is expected that mills will start to regularly produce Grade 80 reinforcement.

Rolling mills today generally do not stock Grade 80 bars and only roll it to order on a monthly basis if there is a need. This limits the application of Grade 80 bars to those elements of buildings where a long lead time is acceptable. In addition to lead time considerations, mills require minimum quantities in orders of Grade 80 . It is expected that as the use of Grade 80 reinforcement increases, these lead times should be shortened, and procurement challenges will decrease.

Rolling mills can produce Grade 80 reinforcement of standard sizes up to and including No. 18 bars to meet ASTM A615 and A706 requirements. Other than using refined metallurgical processes, the method used to produce Grade 80 reinforcement is similar to that used for Grade 60 reinforcement. Mills can achieve the higher strength using these similar processes by varying the alloy content only slightly. Because the process modification is relatively minor, the additional material cost premium for Grade 80 bar over Grade 60 bar is currently only about $10 \%$. It is expected that this cost premium will be reduced if the use of Grade 80 bar increases. Since the material cost is slightly less than half of the installed price of rebar, the price premium for installing Grade 80 bars is expected to be slightly less than $5 \%$.

\subsubsection{Fabrication}

Grade 80 bars can be cut, bent, and fabricated with the same equipment that are used for Grade 60 bars. The strength of the bar will cause only slightly more wear on the fabricating equipment than Grade 60 bar. Initially, fabricators may have to stock inventories of both grades of reinforcement in all bar sizes, which could increase storage space demands. The fabricator will also have to exercise heightened attention to prevent Grade 60 reinforcement from being inadvertently used in place of Grade 
80 reinforcement. Nonetheless, as the use of Grade 80 becomes more prevalent, especially in entire building projects, these storage and segregation issues will be minimized.

\subsubsection{Installation}

The use of less reinforcement has many positive impacts on the construction schedule of a project, including shortened construction duration for the floor-to-floor cycle. From a bar-placer perspective, the grade of a bar is not a factor in the time and cost of its placement, so reduced reinforcement quantity leads directly to savings in time and cost of placement.

The installation of reinforcement on a jobsite is a highly sequenced activity that will benefit from a reduction in the quantity of reinforcement to be installed. If less reinforcement is required to construct a building, the allotted time on the schedule to install it will also be reduced. In the case of columns, reinforcement can be installed prior to formwork installation, in the case of slabs, after formwork installation, or, in the case of walls, integral with formwork installation. In each of the cases, the amount of time involved in the installation of the reinforcement, compared to the total cycle time of the activity, is significant. Regardless of whether the reinforcement is placed prior to, after, or integral with the forms, installing the reinforcement is on the critical path of the activity. Reducing the critical path time frames, by reducing the quantity of reinforcement to be installed, would reduce the schedule and, thus, the cost of the job. This effect will be most pronounced in the walls and beams of a project, as significant parts of these elements are usually handbuilt in position. A reduction in the labor requirement translates into a smaller number of workers on a project or a shorter duration for its installation, depending on the needs of the project.

Shortened construction durations reduce the cost of construction. Ten to $15 \%$ of the construction cost of a building is for management, supervision, and time-dependent overhead for contractors and sub-contractors. Making the building process more efficient reduces the amount of overhead necessary to manage the process.

Additionally, reducing the time required on equipment associated with the construction of the project, especially cranes and personnel lifts, will lower the total cost of the project.

The reduced construction schedule due to less steel congestion has other benefits that are less easily quantified but equal to, if not more than, the savings from reduced labor and material costs. The reduction in length of construction results in reduced interest paid during construction and it gets occupants into the building sooner, so the owner generates revenue sooner. 


\subsubsection{Impacts on Other Trades}

Reducing congestion of reinforcement in the building elements will have additional benefits on other trades, as follows:

- Reduced reinforcement congestion in the walls will enable easier installation of embedded items, sleeves, and reinforcing dowels.

- Electrical conduits and boxes will be run easier and terminate in the desired location without as much interference from bars.

- Concrete placement will be easier due to the reduced congestion and may allow for the use of less expensive mixes.

\subsubsection{Other Considerations}

For Grade 60 reinforcement, conventions have evolved over time with regard to commonly used sizes and spacing of bars in columns, walls, beams, and slabs of typical sizes. It is expected that similar conventions will develop for Grade 80 bars, such as common sizes of bar for the ease of inventorying, handling, cutting, and placing of bars. Over time, a whole building approach using Grade 80 reinforcement will likely arise after an initial substitution and comparison approach. Also over time, the design of elements containing Grade 80 reinforcement will be optimized with the use of high-strength concrete, thereby maximizing the utility of both the reinforcement and concrete.

\subsection{Case Studies for Cost Savings}

Two case studies are presented in this section to provide insight into the order of magnitude of cost savings achievable through the use of Grade 80 reinforcement. Both of these case studies show savings of approximately $3 \%$ to the structure cost and approximately $0.6 \%$ to the cost of the project. The savings can be achieved without any significant loss of quality in the building structure. These savings do not include other possible reductions in cost due to time saved in the floor-to-floor cycle of the project and less complexity in the delivery process.

Two 20-story high-rise buildings designed and built in Los Angeles in the past five years were chosen as the basis of this study. Each building underwent a reinforcement quantity survey that tabulated the reinforcement quantities for the foundations, walls, columns, beams, and slabs. A replacement analysis was performed for the substitution of Grade 80 reinforcement for Grade 60 reinforcement in the foundations, walls, columns, and beams. This replacement analysis was based on a straight strength-to-strength substitution, which provided the ratio of 0.75 when substituting Grade 60 reinforcement with Grade 80 reinforcement by weight. It was assumed that the most economical arrangement of Grade 80 reinforcement could be obtained without violating other applicable code provisions through bar sizing and 
placement. Horizontal slabs were not included in this replacement analysis, since it was assumed that a more thorough analysis would be needed to determine if a straight strength-to-strength substitution could be implemented or if other design factors would govern the potential substitution.

For both buildings, the column and wall bars include vertical splices at each floor level because using cages taller than one story can be more expensive and disruptive to the construction process than splicing the bars. In addition, for bars smaller than No. 14, a splice at each floor level was considered to be more economical than use of mechanical splices.

This analysis considered the impact of different development lengths negligible because a No. 9 Grade 80 bar and No. 11 Grade 60 bar have similar strengths and similar development lengths in compression and tension.

In the comparisons, costs are based on construction in 2013. A 5\% price premium was assumed for use of Grade 80 reinforcement when compared to the cost of Grade 60 reinforcement.

\subsubsection{Shear Wall Building}

Case Study Building One is a 20 -story concrete shear wall building approximately 200 feet in height, located in downtown Los Angeles. The building is an apartment tower with fairly regular 15,000 square foot rectangular floor plates above four garage levels of 30,000 square feet each. Floor-to-floor heights are 16 feet for the first two levels and 9 feet 8 inches, typically, above level two. The comparison in Table 6-1 shows that replacing Grade 60 reinforcement with Grade 80 reinforcement in the foundations, vertical walls and columns would result in savings of $3.4 \%$ to the structure cost and $0.66 \%$ to the total project cost, with a total savings of $\$ 528,000$.

\subsubsection{Moment Frame Building}

Case Study Building Two is a 21-story concrete moment frame building approximately 298 feet in height, located on the west side of Los Angeles, about ten miles west of the downtown area. This building is a high-end luxury condominium tower with a nearly square 9,200 square-foot floor plate. Floor-to-floor heights are 20 feet from level one to level two, 12 feet from level two to level fifteen, and 13 feet from level fifteen through the penthouse level. There are no transfers in the columns from the base to the roof. The comparison presented in Table 6-2 shows that replacing Grade 60 reinforcement with Grade 80 reinforcement in the foundations and moment frame columns and beams would result in savings of $3.8 \%$ to the structure cost and $0.63 \%$ to the total project cost, with an overall savings of $\$ 756,800$. 
Table 6-1 Cost Comparison for Substituting Grade 80 for Grade 60 Reinforcement in Case Study Building One

\begin{tabular}{|c|c|}
\hline Item Being Calculated & Results \\
\hline Total project cost & $\$ 80,100,000$ \\
\hline Structure cost & $\begin{array}{l}\$ 15,500,000 \\
\text { (approximately } 19 \% \text { of total project cost) }\end{array}$ \\
\hline Building area & 420,000 square feet \\
\hline Reinforcement quantity for all elements & $4,800,000 \mathrm{lbs}$ \\
\hline Reinforcement quantity breakdown & $\begin{array}{l}\text { Foundation: } 13 \% \\
\text { Vertical columns and walls: } 42 \% \\
\text { Horizontal slabs: } 45 \%\end{array}$ \\
\hline $\begin{array}{l}\text { Reinforcement quantity in foundation and } \\
\text { vertical columns and walls }\end{array}$ & $\begin{array}{l}(13 \%+42 \%) \times 4,800,000 \mathrm{lbs}= \\
2,640,000 \mathrm{lbs}\end{array}$ \\
\hline Average price for Grade 60 reinforcement & $\$ 0.95 / \mathrm{lb}$ \\
\hline Cost of Grade 60 reinforcement & $2,640,000 \mathrm{lbs} \times \$ 0.95 / \mathrm{lb}=\$ 2,508,000$ \\
\hline $\begin{array}{l}\text { Ratio of Grade } 80 \text { to Grade } 60 \text { required } \\
\text { reinforcement weight: }\end{array}$ & 0.75 \\
\hline $\begin{array}{l}\text { Grade } 80 \text { reinforcement weight in foundation } \\
\text { and vertical columns and walls }\end{array}$ & $2,640,000 \mathrm{lbs} \times 0.75=1,980,000 \mathrm{lbs}$ \\
\hline $\begin{array}{l}\text { Cost of Grade } 80 \text { reinforcement, including } \\
5 \% \text { premium }\end{array}$ & $\begin{array}{l}1,980,000 \mathrm{lbs} \times(\$ 0.95+\$ 0.05) / \mathrm{lb}= \\
\$ 1,980,000\end{array}$ \\
\hline $\begin{array}{l}\text { Savings by substituting Grade } 80 \\
\text { reinforcement for Grade } 60 \text { in the foundation } \\
\text { and vertical elements: }\end{array}$ & $\$ 528,000$ \\
\hline Percent savings in cost of structure: & $\$ 528,000 / \$ 15,500,000=3.4 \%$ \\
\hline Percent savings in total project cost: & $\$ 528,000 / \$ 80,100,000=0.66 \%$ \\
\hline
\end{tabular}


Table 6-2 Cost Comparison for Substituting Grade 80 for Grade 60 Reinforcement in Case Study Building One

\begin{tabular}{|c|c|}
\hline Item Being Calculated & Results \\
\hline Total project cost & $\$ 120,000,000$ \\
\hline Structure cost & $\begin{array}{l}\$ 19,800,000 \\
(16.5 \% \text { of total project cost) }\end{array}$ \\
\hline Building area & 292,000 square feet \\
\hline Reinforcement quantity for all elements & $5,330,000 \mathrm{lbs}$ \\
\hline \multirow[t]{3}{*}{ Reinforcement quantity breakdown } & Foundation: $18 \%$ \\
\hline & $\begin{array}{l}\text { Vertical columns, walls, and moment frame } \\
\text { beams: } 53 \%\end{array}$ \\
\hline & Horizontal slabs: $29 \%$ \\
\hline $\begin{array}{l}\text { Reinforcement quantity in foundation and } \\
\text { moment frame beams and columns }\end{array}$ & $\begin{array}{l}(18 \%+53 \%) \times 5,330,000 \mathrm{lbs}= \\
3,784,300 \mathrm{lbs}\end{array}$ \\
\hline Average price of Grade 60 reinforcement & $\$ 0.95 / \mathrm{lb}$ \\
\hline Cost of Grade 60 reinforcement & $3,784,300 \mathrm{lbs} \times \$ 0.95 / \mathrm{lb}=\$ 3,595,085$ \\
\hline $\begin{array}{l}\text { Ratio of Grade } 80 \text { to Grade } 60 \text { required } \\
\text { reinforcement weight }\end{array}$ & 0.75 \\
\hline $\begin{array}{l}\text { Grade } 80 \text { reinforcement weight in foundation } \\
\text { and moment frame beams and columns }\end{array}$ & $3,784,300 \mathrm{lbs} \times 0.75=2,838,225 \mathrm{lbs}$ \\
\hline Cost of Grade 80 bar, including 5\% premium & $\begin{array}{l}2,838,225 \mathrm{lbs} \times(\$ 0.95+\$ 0.05) / \mathrm{lb}= \\
\$ 2,838,225\end{array}$ \\
\hline $\begin{array}{l}\text { Savings for substituting Grade } 80 \\
\text { reinforcement for Grade } 60 \text { in the foundation } \\
\text { and moment frame beams and columns }\end{array}$ & $\$ 756,860$ \\
\hline Percent savings in cost of structure & $\$ 756,800 / \$ 19,800,000=3.8 \%$ \\
\hline Percent savings in total project cost & $\$ 756,800 / \$ 120,000,000=0.63 \%$ \\
\hline
\end{tabular}




\section{Chapter 7 \\ Conclusions and Recommendations}

This chapter presents the conclusions of the review of available research and studies presented on the use of high-strength reinforcement to resist earthquake effects. In addition, recommendations for material characteristics of high-strength reinforcement, and recommendations for changes to ACI 318-11 to help implement the use of Grade 80 reinforcement in seismic applications are also presented. This chapter also includes a brief discussion of code provisions that might need to be altered if Grade 100 and stronger reinforcement were permitted as flexural reinforcement in special moment frames and special structural walls.

\subsection{Conclusions}

Based on the research reviewed and the studies performed, it was observed that concrete members reinforced with reduced amounts of high-strength reinforcement (with yield strengths of $80 \mathrm{ksi}$ or stronger) are capable of reaching comparable strength and deformation capacity to those achieved by members reinforced with conventional strength reinforcement. This observation applies to members having reinforcement details that provide concrete confinement and inhibit brittle failures related to shear, bond stress, and bar buckling.

Use of high-strength reinforcement can result in cost reductions and improved constructability. Benefits include reduced reinforcement quantity, reduced reinforcement congestion, improved placement of concrete, and accelerated reduced construction schedule. The cost benefits will not be fully achieved in the United States without the associated increase in production, however, until there is increased demand for high-strength reinforcement.

\subsection{Recommended Reinforcement Material Characteristics}

This section includes recommendations for material characteristics of high-strength reinforcement, including elongation and strength requirements. These recommended properties for high-strength reinforcement could be incorporated into a new specification for reinforcement intended for use in earthquake-resistant members, to which future editions of ACI 318 could refer.

In the United States, ASTM A706 reinforcement is currently commonly specified for earthquake resisting members. ASTM A706 has requirements for both Grade 60 and Grade 80 bars, although ACI 318-11 does not allow the use of Grade 80 
reinforcement in special moment frames and special structural walls. In this chapter, the requirements of ASTM A706 are used as the starting point for consideration of desirable properties for Grade 80 reinforcement. For Grade 100 reinforcement and reinforcement with higher strengths, this chapter considers the requirements of other available high-strength reinforcement, with an emphasis placed on the requirements of USD685A and USD685B reinforcement produced in Japan.

\subsubsection{Recommended Revisions to ASTM A706 Grade 80 Requirements}

The requirements for ASTM A706 Grade 80 reinforcement are similar to those of ASTM A706 Grade 60 reinforcement. They differ, however, in their relaxed bend diameter requirements. The reason for the difference is related to bending requirements for other reinforcement of similar strength, rather than a limitation of the material. It is recommended that ASTM A706 be revised to apply the bend diameter required for Grade 60 reinforcement to Grade 80 reinforcement.

It is observed that the total elongation requirement for No. 3, 4, 5, and 6 bars are lower for Grade 80 reinforcement (12\%) compared to Grade 60 reinforcement (14\%). However, it is not necessary to increase the total elongation requirement of Grade 80 reinforcement for these smaller bar sizes; the current requirements for Grade 80 bars appear acceptable.

\subsubsection{Recommended Requirements for Grade 100 and Higher Strength Reinforcement}

This section presents recommended limiting values for those material characteristics deemed essential for application in members subjected to earthquake effects. These limiting values are based on the test data and analytical studies that were available at the time this report was written. As additional research is performed, limiting values may require adjustments.

\subsubsection{Minimum Yield Strength}

Minimum yield strength is an essential property that must be specified. Its value should match the reinforcement grade; for example, it should be $100 \mathrm{ksi}$ for Grade 100 reinforcement. The measured yield strength should equal or exceed the specified yield strength rather than using the 5\% fractile value that would allow some bars to have measured yield strengths less than the specified yield strength. For reinforcement with a yield point, yield strength should be defined as the stress associated with the sharp knee in the stress-strain curve. For other reinforcement, the value of yield strength could be defined as the stress obtained from the $0.2 \%$ Offset Method of ASTM A370 (ASTM, 2012c). 


\subsubsection{Maximum Yield Strength}

Assigning maximum yield strength is necessary to obtain reliability similar to that provided by ACI 318-11 for provisions based on relative strength, such as strongcolumn weak-beam provisions or provisions that compare shear limited by flexural strength to the design shear strength. The maximum yield strength for higher strength reinforcement should be set to $115 \%$ of the minimum specified yield stress. Thus, a value of $115 \mathrm{ksi}$ is proposed for the maximum yield strength of Grade 100 reinforcement.

\subsubsection{Yield Plateau}

It was observed that in quasi-static cyclic reversed load testing and shake table tests, the presence or lack of a yield plateau in the longitudinal reinforcement where plastic hinges develop made little difference in the element and system response. Accordingly, it is recommended that presence of a yield plateau not be required for primary reinforcement of earthquake-resisting elements.

ACI 318-11 assumes reinforcement has a yield plateau, and use of high-strength reinforcement without a yield plateau could require changes to the flexural design approach. ACI ITG-6R-10 (ACI, 2010a) provides revised approaches for computing flexural strength of members reinforced with ASTM A1035 Grade 100 reinforcement, which do not have a yield plateau. Similar provisions could be considered for inclusion into ACI 318; however, the analyses presented in Appendix A of this report demonstrate that such revisions may be unnecessary.

\subsubsection{Strain at End of Yield Plateau}

If a yield plateau is not required, then specifying the strain at the end of the yield plateau is not necessary. Current ASTM specifications do not include any requirement related to yield plateau.

If the presence of a yield plateau is found necessary, a value for minimum strain at the end of the yield plateau could be considered, similar to the $1.4 \%$ that is required for Japan's USD685 reinforcement.

\subsubsection{Tensile-to-Yield Strength Ratio}

Specifying a minimum measured tensile strength to measured yield strength ratio is essential because it has an impact on the following:

- the relative strength of members, such as the beams and columns of moment frames,

- how well plasticity spreads at plastic hinges, and

- how well strength is maintained after initial yielding. 
Based on the Japanese experience, achieving a ratio of 1.25 for the minimum measured tensile to measured yield strength ratio may be difficult or costly for Grade 100 and stronger reinforcement. A minimum value of 1.18 is more realistic.

Relative to current reinforcement used in the United States, such a reduced value, is not problematic as long as members whose relative strengths are compared to one another in the design process employ the same type of reinforcement. For example, designing columns with Grade 100 reinforcement that has a lower tensile to yield strength ratio and designing beams with either Grade 60 or Grade 80 reinforcement that has a higher tensile to yield strength ratio would make strong-column weakbeam provisions less effective, because the overall strength comparison would be less reliable.

\subsubsection{Uniform Elongation}

Requiring uniform elongation to be reported on reinforcement mill certifications is desirable because it is a better gage of strain than total elongation. Currently, uniform elongation is not required to be reported in the United States and Japan. On the other hand, producers in Europe, Australia, and New Zealand routinely report uniform elongation.

A minimum uniform elongation of $8 \%$ for Grade 100 and stronger reinforcement is recommended. This is approximately what ASTM A706 reinforcement would provide for uniform elongation (12\% is set as the requirement for total elongation). This value is higher than the maximum useable strain of $6 \%$ used in Appendix A.

\subsubsection{Total Elongation}

If uniform elongation is reported, total elongation, as measured over an 8-inch gage length including the necked-down region as the test specimen fractures, is not necessary to be specified. However, in the event that producers resist reporting uniform elongation, a total elongation of $12 \%$ would be appropriate to match the elongation requirement of ASTM A706 Grade 80 reinforcement. This value is more than the $10 \%$ total elongation required for Japan's USD685 reinforcement, but it is expected to be achievable.

\subsubsection{Bend Test}

Bend tests should match those required for ASTM A706 Grade 60 bars. In development of new reinforcement, a bend-rebend test similar to or the same as that used to develop AS/NZS 500E (72 ksi) reinforcement should be used.

\subsubsection{Deformations}

The deformations on Grade 100 and higher reinforcement should be the same as those required for ASTM A706 and A615 reinforcement in order not to require 
retooling for producing the bar deformations. However, the option of rolling bars with a high relative rib area for bar deformations should be considered for inclusion into any new specification. Reinforcement with high relative rib area would reduce the lengths required to transfer bond stresses and to develop and splice bars.

Previously there have been concerns that ribs with high deformations will not fully fill during the production process and that the tools will wear out more quickly. However, rolling procedures have since become more efficient, leading to new interest in this option. The use of a high relative rib area would require additional changes to design requirements for development and splice lengths, as well as for transverse reinforcement, to prevent splitting cracks where bond stresses are high. It would also require additional testing to confirm that high relative rib area bars do not reduce the spread of plasticity in regions of members intended to yield.

\subsubsection{Summary of Recommendations for Grade 100 and Higher Reinforcement}

The recommended characteristics of Grade 100 and stronger reinforcement are summarized in Table 7-1.

Table 7-1 Recommended Properties and Characteristics of Reinforcement that is Grade 100 and Stronger

\begin{tabular}{lll}
\hline \multicolumn{1}{c}{ Property or Characteristic } & & \multicolumn{1}{c}{ Recommendation } \\
\cline { 1 - 1 } Minimum yield strength & & $\begin{array}{l}\text { Minimum threshold equal to the grade rather } \\
\text { than } 5 \% \text { fractile value }\end{array}$ \\
Maximum yield strength & & $115 \%$ of specified minimum yield strength \\
Yield plateau & Not required \\
Strain at end of yield plateau & Not required \\
Minimum measured tensile to measured & 1.18 \\
yield strength ratio & \\
Uniform elongation & $8 \%$ \\
Total elongation ${ }^{1}$ & $12 \%$ \\
Bend test & Match ASTM A706 Grade 60 \\
Bend-rebend test ${ }^{2}$ & Match requirements in AS/NZ 500E \\
Deformations & Match requirements in ASTM A706 \\
\hline 1 Total elongation is not required if uniform elongation is reported. \\
${ }^{2}$ Bend-rebend testing is only required for producers when they are producing new types of bars.
\end{tabular}

\subsection{Recommended Changes to $\mathrm{ACl} 318-11$ for Use of Grade 80 Reinforcement}

The current version of the structural building code that governs the design of reinforced concrete buildings in the United States, ACI 318-11, does not permit the use of flexural reinforcement with specified yield strength greater than $60 \mathrm{ksi}$ in 
special moment frames and special structural walls. Based on the findings of experimental research and analytical studies described elsewhere in this report, it is recommended that ACI 318 be changed to allow the use of Grade 80 flexural reinforcement in special moment frames and special structural walls.

\subsubsection{Discussion of Potential Changes to Seismic Provisions}

This section identifies and discusses provisions of ACI 318-11 that may require changes if Grade 80 reinforcement is permitted to be used in special moment frames and special structural walls. The boxes, interspersed in the sections that follow, are taken from ACI 318-11 to provide the reader with the existing provisions in a familiar context. Text in italics in the boxes indicate a summary of the provisions contained in the relevant section.

\subsubsection{ACI 318-11 Section 21.1.4.2 - Minimum Concrete Strength}

\subsection{4 - Concrete in special moment frames and special structural walls}

21.1.4.2 - Specified compressive strength of concrete, $\boldsymbol{f}_{c}^{\prime}$, shall be not less than 3000 psi.

The current lower limit on $f_{c}^{\prime}, 3,000 \mathrm{psi}$, was set when the highest permitted steel yield strength was Grade 60. Although concrete with strength greater than 3,000 psi may improve the efficiency of using Grade 80 reinforcement, a specific need to use higher concrete strength was not evident from the experimental studies reviewed in the preparation of this report. Therefore, no change is recommended to ACI 318-11 Section 21.1.4.2.

\subsubsection{ACI 318-11 Section 21.1.5.2 - Reinforcement Grade}

\subsection{5 - Reinforcement in special moment frames and special structural walls}

21.1.5.2 - Deformed reinforcement resisting earthquakeinduced flexure, axial force, or both, shall comply with ASTM A706, Grade 60....

Part of the initial motivation for this report was to review this particular provision of ACI 318-11. In October 2009, ASTM added Grade 80 to the available yield strength designations of ASTM A706 reinforcement, whereas previously the only available yield strength had been Grade 60 . However, because a review of the behavior of Grade 80 flexural reinforcement in special concrete moment frames and special structural walls had not yet been performed by the ACI Committee 318, ACI 318-11 continued to limit the permitted yield strength of ASTM A706 reinforcement for 
those applications to Grade 60 in Section R21.1.5 of the commentary to ACI 318-11, as follows: "...only Grade 60 is generally permitted because of insufficient data to confirm applicability of existing code provisions for structures using the higher Grade.” (ACI, 2011)

Based on the research findings described in this report, it is noted that sufficient experimental and analytical evidence exist to permit the use of ASTM A706 Grade 80 reinforcement for flexural reinforcement in special moment frames and special structural walls. It is recommended that ACI 318-11 Section 21.1.5.2 be changed to allow the use of Grade 80 reinforcement, provided that other necessary changes are incorporated into ACI 318. These other necessary changes are discussed in the remainder of this section.

\subsubsection{ACI 318-11 Section 21.1.5.2 - ASTM A615 Grades 40 and 60}

\subsection{5 - Reinforcement in special moment frames and special structural walls}

21.1.5.2 - ...ASTM A615 Grades 40 and 60 reinforcement shall be permitted if:

(a) The actual yield strength based on mill tests does not exceed $\boldsymbol{f}_{\boldsymbol{y}}$ by more than $18,000 \mathrm{psi}$; and

(b) The ratio of the actual tensile strength to the actual yield strength is not less than 1.25.

ACI 318-11 permits the use of ASTM A615 reinforcement for flexural reinforcement in special moment frames and special structural walls as long as certain limits on yield strength and tensile strength are met. As ASTM A706 reinforcement becomes more widely available, it may no longer be necessary to allow the use of ASTM A615 reinforcement for these seismic applications. Because ASTM A615 Grade 40 reinforcement is no longer widely available, and is rarely, if ever, specified today, this portion of ACI 318-11 Section 21.1.5.2 could be deleted without any appreciable effect on current design and construction practice.

Adequate bar elongation is essential for adequate earthquake resistance of special moment frames and special structural walls. Chapter 2 of this report presented data that show that ASTM A615 Grade 60, Grade 75, and Grade 80 reinforcement have lower elongations than ASTM A706 Grade 60 and Grade 80 reinforcement. If this provision is extended to include Grade 80 reinforcement, it is recommended that the minimum elongation requirements, as well as the strength requirements for ASTM A706 reinforcement, be applied to the ASTM A615 Grade 60, Grade 75, and Grade 80 reinforcement. 


\subsubsection{ACI 318-11 Section 21.1.6 - Mechanical Splices}

\subsection{6 - Mechanical splices in special moment frames and special structural walls}

21.1.6.1 - Mechanical splices shall be classified as either Type 1 or Type 2 mechanical splices, as follows:...

..(b) Type 2 mechanical splices shall conform to 12.14 .3 .2 and shall develop the specified tensile strength of the spliced bar.

As discussed in Chapter 3, statement (b) is likely inadequate for high-strength reinforcement in cases where the actual tensile strength is significantly higher than the specified tensile strength, or where the shape of the stress-strain curve is very rounded. The need for a new mechanical splice, such as the Type 3 splice discussed in Chapter 3 of this report, for which acceptability is strain-based rather than stressbased, should be considered. This is because the Type 2 splice, as currently defined, does not assure development of the actual tensile strength or a minimum specified bar elongation in the spliced bars, whether ASTM A615 or A706. However, Type 2 mechanical splices are likely no worse for splicing ASTM A706 Grade 80 reinforcement than for splicing Grade 60 reinforcement.

\subsubsection{ACI 318-11 Section 21.1.7 - Welded Splices}

\subsection{7 - Welded splices in special moment frames and special structural walls \\ This section defines requirements related to the allowable locations of welded splices.}

ASTM A706 Grade 80 reinforcement is weldable. ACI 318-11 Section 21.1.7 does not allow welded splices where yielding is expected in any type of reinforcement. There is no need to change the restrictions on locations of welded splices or to place new restrictions on locations for Grade 80 reinforcement.

\subsubsection{ACI 318-11 Section 21.3 - Intermediate Moment Frames}

21.3.5.2 - At both ends of the column, hoops shall be provided at spacing $s_{o}$ over a length $\ell_{0}$ measured from the joint face....

21.3.5.4 - Outside the length $\ell_{0}$, spacing of transverse reinforcement shall conform to 7.10 and 11.4.5.1.

Substitution of smaller diameter Grade 80 longitudinal column bars for larger diameter Grade 60 bars, without changing column hoop spacing, would increase the 
likelihood of longitudinal bar buckling. However, item (a) of ACI 318-11 Section 21.3.5.2 requires that the spacing of hoops not exceed eight times the diameter of the smallest longitudinal bar, so the smaller diameter bars would have a closer required hoop spacing. Based on the discussion and recommendation in Chapter 3 of this report, the spacing of hoops should be reduced to six times the diameter of the longitudinal bar for an appropriate level of buckling restraint applicable to Grade 60 and Grade 80 reinforcement. ACI 318-11 Section 21.3.4.2 also requires a similar change for beams of intermediate moment frames.

\subsubsection{ACI 318-11 Section 21.5.1 - Flexural Members of Special Moment Frames, Load and Geometry Limits}

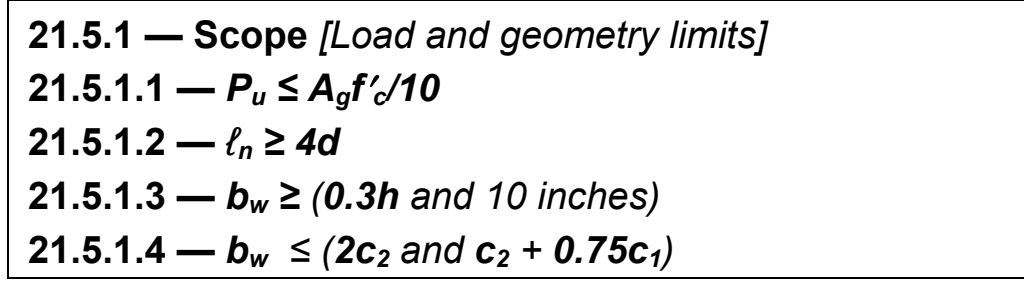

There does not appear to be any reason to modify the load and geometry limits if permitting ASTM A706 Grade 80 flexural reinforcement.

\subsubsection{ACI 318-11 Section 21.5.2 - Flexural Members of Special Moment Frames, Longitudinal Reinforcement}

\subsection{2 - Longitudinal reinforcement}

21.5.2.1 - This section defines minimum and maximum reinforcement limits; and requires at least two bars continuous top and bottom.

The minimum reinforcement ratio for flexural reinforcement is already a function of $f_{y}$, so further change is not required. The maximum flexural reinforcing ratio of 0.025 should be revised for Grade 80 reinforcement. It is recommended that the maximum reinforcement limit be based on achieving a minimum net tensile strain. As discussed in Chapter 3, a minimum net tensile strain of 0.0075 should be considered to ensure adequate yielding for beams with Grade 60 reinforcement. For Grade 80 and stronger reinforcement, a minimum net tensile strain could be set as $0.0075 \mathrm{x}$ $\left(f_{y} / 60,000\right)$; or 0.010 for Grade 80 . The requirement that there be at least two bars continuous on the top and bottom does not require modification for Grade 80 reinforcement.

\subsection{2 - Longitudinal reinforcement}

21.5.2.2 - This section contains requirements for positive and negative moment strength at joint faces. 
Modifying these design limits for special moment frames with Grade 80 reinforcement does not appear necessary.

\subsection{2 - Longitudinal reinforcement}

21.5.2.3 - This section contains requirements for confinement of lap splices, including spacing

of transverse reinforcement.

Transverse reinforcement for lap splices is mandatory because the shell concrete may be lost due to earthquake loading. The transverse reinforcement also limits widening of splitting cracks that may develop at the splice. Transfer of bond stress is limited by the size of bar deformation, so reducing the maximum spacing of hoop reinforcement at splices is not required for Grade 80 reinforcement, which has the same bar deformation requirements as Grade 60 reinforcement.

\subsection{2 - Longitudinal reinforcement}

21.5.2.4 - This section contains requirements for mechanical and welded splices. (Refers to 21.1.6 and 21.1.7, discussed earlier)

Refer to the discussion for Section 21.1.6 above and to Chapter 3 of this report regarding mechanical splices. Section 21.1.7 does not allow welded splices where yielding is expected, so no further restrictions on welded splices are required for Grade 80 reinforcement.

\subsection{2 - Longitudinal reinforcement}

21.5.2.5 - This section contains requirements for the use of prestressing in special moment frames

No changes are required related to the use of prestressing in special moment frames, as the requirements in this section relate only to prestressing and prestressed reinforcement, not non-prestressed Grade 80 reinforcement.

\subsubsection{ACI 318-11 Section 21.5.3 - Flexural Members of Special Moment Frames, Transverse Reinforcement}

\subsection{3 - Transverse reinforcement}

This section contains requirements for type, size, and spacing of hoops in flexural members of special moment frames.

Item (b) of ACI 318-11 Section 21 5.3.2 requires that the spacing of the hoops not exceed six times the diameter of the smallest longitudinal bar, so the required hoop spacing would be reduced for the smaller diameter bars. As discussed and recommended in Section 3.2 of this report, a maximum hoop spacing of six times the 
diameter of the smallest longitudinal bar provides an appropriate level of buckling restraint for Grade 60 reinforcement. However, ACI 117-10 (ACI, 2010b) defines the tolerance for spacing of stirrups (hoops) to be the smaller of 3 inches and 1 inch per foot depth of the beam. Furthermore, the actual yield strength could be as much as $98 \mathrm{ksi}$ for Grade 80 reinforcement. Therefore, a maximum hoop spacing of five times the diameter of the smallest longitudinal bar is recommended for Grade 80 reinforcement. In addition, the maximum placement tolerance for hoop spacing in ACI 117 should be reduced to \pm 1 inch in plastic hinge regions of beams. The other limits of $d / 4$ and 6 inches could remain unchanged. ACI Committee 318 should consider a requirement that each longitudinal beam bar be supported by a seismic hook in its end regions to control bar buckling.

Refer to ACI Section 21.6.4 below for further discussion related to current transverse reinforcement placement tolerances being too lenient,

\subsubsection{ACI 318-11 Section 21.5.4 - Flexural Members of Special Moment Frames, Shear Strength Requirements}

\subsection{4 - Shear strength requirements}

21.5.4.1 - This section contains requirements for design shear force $\boldsymbol{V}_{\mathbf{e}}$, which is partially a function of probable flexural moment strength, $\boldsymbol{M}_{\boldsymbol{p r}}$.

Minimum shear strength requirements should be reexamined in light of the effects that ASTM A706 Grade 80 reinforcement may have on probable flexural moment strength, $M_{p r}$, at joint faces. Since $M_{p r}$ is based on $1.25 f_{y}$, and since the shapes of the stress-strain curves for ASTM A706 Grade 60 and Grade 80 reinforcements are similar, the shear demands should also be similar, regardless of which grade reinforcement is used. Therefore, no change is recommended for this provision.

\subsubsection{ACI 318-11 Section 21.6.1 - Columns of Special Moment Frames, Load and Geometry Limits}

\subsection{1 - Scope [Load and geometry limits] Column definition: $\boldsymbol{P}_{u} \geq \boldsymbol{A}_{g} \boldsymbol{f}_{c}^{\prime} / \mathbf{1 0}$}

21.6.1.1 - Shortest dimension must be $\geq 12$ in.

21.6.1.2 - Short/long dimension must be $\geq 0.4$

No changes are recommended for these load and geometry limits for columns of special moment frames if Grade 80 reinforcement is introduced. 


\subsubsection{ACI 318-11 Section 21.6.2 - Columns of Special Moment Frames, Minimum Flexural Strength of Columns}

\subsection{2 - Minimum flexural strength of columns}

21.6.2.2 - strong column - weak beam

"Sixth-fifths rule": $\sum M_{n c} \geq(6 / 5) \sum M_{n b}$

21.6.2.3 - If "sixth-fifths rule" is not satisfied, then column

is not considered part of the seismic-force-resisting system

The sixth-fifths rule reflects a fundamental seismic design principle for moment frames: at a joint, the combined flexural strength of columns should be greater than the combined flexural strength of beams to favor the development of plastic hinges in beams before columns. This strong-column weak-beam concept applies regardless of the grade of the flexural reinforcement. Since the stress-strain curves for ASTM A706 reinforcement Grade 60 and Grade 80 have similar shapes, the effect of the sixth-fifths rule will be the same for both reinforcement grades. Likewise, strongcolumn weak-beam behavior will be similar, regardless of the grade of reinforcement used. Thus, no change in this provision is required with the introduction of Grade 80 reinforcement.

\subsubsection{ACI 318-11 Section 21.6.3 - Columns of Special Moment Frames, Longitudinal Reinforcement}

\subsection{3 - Longitudinal reinforcement}

21.6.3.1 - Reinforcement limits: $0.01 A_{g} \leq A_{s t} \leq 0.06 A_{g}$

21.6.3.2 - Circular columns, minimum 6 bars

21.6.3.3 - Mechanical and welded splice requirements; lap splices within center half of column height; tension lap splices; confining reinforcement for lap splices

The purpose of setting the minimum area of longitudinal bar as $0.01 A_{g}$ is to control time-dependent deformations and ensure that the yield moment exceeds the cracking moment. This is already applicable to Grade 80 bars in Chapter 10 of ACI 318, so it need not be adjusted in this provision.

The purpose of setting the maximum area of longitudinal reinforcement as $0.06 \mathrm{~A}_{\mathrm{g}}$ is to control congestion and address concerns of load transfer from floor elements to columns and the development of high shear stresses in the joint. Although reduction of reinforcement congestion is a practical concern, it is not a technical reason to limit the maximum allowed area of longitudinal reinforcement. Considerations of floor load transfer to the column and development of higher shear stresses, however, are valid technical concerns, especially if the joint size is decreased with the use of Grade 80 reinforcement. Although no change is recommended regarding this upper limit, ACI Committee 318 should consider whether it is necessary. 
Also in this section, requirements related to mechanical and lap splices should be reexamined in the light of decisions regarding ACI 318-11 Sections 21.1.6 and 21.1.7, discussed previously.

\subsubsection{ACI 318-11 Section 21.6.4-Columns of Special Moment Frames, Transverse Reinforcement}

\subsection{4 - Transverse reinforcement}

21.6.4.1 - Definition of length $\boldsymbol{\ell}_{\mathrm{o}}$

21.6.4.2 - Defines hoops, spirals, and crossties

21.6.4.3 - Spacing of transverse reinforcement within $\boldsymbol{\ell}_{\mathbf{o}}$

21.6.4.4 - Amount of transverse reinforcement within $\boldsymbol{\ell}_{\mathbf{0}}$

21.6.4.5 - Spacing of transverse reinforcement outside $\boldsymbol{\ell}_{\mathbf{0}}$

Item (b) of Section 21.6.4.3 requires that the spacing of the hoops not exceed six times the diameter of the smallest longitudinal bar. As discussed in Chapter 3 of this report, a maximum hoop spacing of six times the diameter of the smallest longitudinal bar provides an appropriate level of buckling restraint for Grade 60 reinforcement. However, the tolerance for spacing of column ties (hoops) in ACI 117-10 is the smaller of 3 inches or 1 inch per foot width of the column. Furthermore, the actual yield strength could be as much as $98 \mathrm{ksi}$ for Grade 80 reinforcement. Therefore, a maximum hoop spacing of five times the diameter of smallest longitudinal bar is recommended for Grade 80 reinforcement. Also, the maximum placement tolerance for hoop spacing in ACI 117 should be reduced to \pm 1 inch within $\ell_{0}$ of the top and bottom of columns.

ACI Committee 318 is considering a change to column confinement requirements as part of the 2014 code cycle. If this change occurs, the area of required confining reinforcement will depend on the compressive load. It will also require that more longitudinal bars be supported by corners of hoops or ties with hooks that are 135 degrees or more. If the proposal does not pass, ACI Committee 318 should consider additional requirements for support of Grade 80 longitudinal bars.

\subsubsection{ACI 318-11 Section 21.6.5 - Columns of Special Moment Frames, Shear Strength Requirements}

\subsubsection{1 - This section contains requirements for design} shear force $\boldsymbol{V}_{\mathbf{e}}$, which is a function of probable flexural moment strength, $\boldsymbol{M}_{\boldsymbol{p r}}$, or the applied design loads.

The required design shear force should not change with the introduction of Grade 80 reinforcement, because the ratios of the tensile to yield strength and the shapes of the stress-strain curves are similar for both Grade 60 and Grade 80. 


\subsubsection{ACI 318-11 Section 21.7.2 - Joints of Special Moment Frames, Forces in Longitudinal Beam Reinforcement}

21.7.2.1 - Forces in longitudinal beam reinforcement at the joint face shall be determined by assuming that the stress in the flexural tensile reinforcement is $\mathbf{1 . 2 5 f _ { y }}$.

As discussed in Chapter 2 of this report, the ratios of the tensile strength to yield strength and the shapes of the stress-strain curves are similar for Grade 60 and Grade 80 reinforcements. Therefore, the coefficient of 1.25 , which was written when only Grade 60 reinforcement was available, is also appropriate for ASTM A706 Grade 80 reinforcement.

\subsubsection{ACI 318-11 Section 21.7.2 - Joints of Special Moment Frames, Termination of Longitudinal Beam Reinforcement}

21.7.2.2 - Beam longitudinal reinforcement terminated in a column shall be extended to the far face of the confined column core and anchored in tension according to 21.7.5 and in compression according to Chapter 12.

The requirement that longitudinal bars terminating in a column shall be fully developed is valid regardless of reinforcement grade. Thus, no change is necessary with the introduction of Grade 80 reinforcement. However, it should be noted that, as a practical matter, supplying sufficient anchorage length within the column core becomes increasingly difficult as reinforcement yield strength increases for the same size bar.

\subsubsection{ACI 318-11 Section 21.7.2 - Joints of Special Moment Frames, Reinforcement Passing Through Joints}

21.7.2.3 - Where longitudinal beam reinforcement extends through a beam-column joint, the column dimension parallel to the beam reinforcement shall not be less than 20 times the diameter of the largest longitudinal beam bar for normal weight concrete. For lightweight concrete, the dimension shall be not less than 26 times the bar diameter.

This minimum column dimension is intended to provide reasonable control on longitudinal beam bar slip through a joint. It is not intended to fully prevent bar slip through the joint. Because higher bond stresses are developed with Grade 80 bars than with the same size Grade 60 bars, an increase in the minimum joint depth is required, as discussed in Chapter 4 of this report. Based on Equation 4-3 of this report, the required joint depth is a function of the longitudinal bar yield strength 
raised to a power of 1.3. This equation also includes a top bar factor for bars placed with more than 12 inches of concrete below them. For adoption of ASTM A706 Grade 80 reinforcement, it is recommended that joints with normal weight concrete shall have a minimum depth parallel to the bar of 26 times the bar diameter, as derived in Chapter 4.

\subsubsection{ACI 318-11 Section 21.7.3 - Joints of Special Moment Frames, Transverse Reinforcement}

\subsection{3 - Transverse reinforcement \\ This section describes requirements for confining reinforcement within joints of special moment frames.}

As discussed in Chapter 4 of this report, the results of tests reviewed while developing this report did not identify a need for increasing the joint reinforcement to obtain the performance expected using the ACI 318-11 approach to designing joints.

\subsubsection{ACI 318-11 Section 21.7.4 - Joints of Special Moment Frames, Maximum Permitted Shear Strength}

\subsection{4 - Shear strength}

This section describes maximum permitted shear strength of joints of special moment frames.

According to the principles currently adopted in ACI 318-11 for computing shear demand on joints of special moment frames (ACI 318-11 Section 21.7.2.1), introduction of Grade 80 reinforcement should not result in higher design shear forces for joints, unless shallower beams are used. However, in practice, introduction of $80 \mathrm{ksi}$ reinforcement presents a significant challenge to designers. It is difficult to meet joint shear strength requirements with $60 \mathrm{ksi}$ reinforcement. Despite these difficulties, it does not appear that any revisions to calculation of joint shear design forces or joint shear capacity provisions are necessary at this time.

\subsubsection{ACI 318-11 Section 21.7.5 - Joints of Special Moment Frames, Development Length of Bars in Tension}

\subsection{5 - Development length of bars in tension}

This section describes requirements for bar development length within joints of special moment frames.

The use of higher strength flexural reinforcement will require longer development lengths within joints. The provisions already relate required development length to the yield strength. As discussed in Chapter 3, the development lengths in ACI 318-11 are applicable to Grade 80 reinforcement, so it is not necessary to revise the requirements in this section. 


\subsubsection{ACI 318-11 Section 21.9.2 - Special Structural Walls and Coupling Beams, Distributed Web Reinforcement}

\subsection{2 - Reinforcement}

21.9.2.1 - The distributed web reinforcement ratios, $\rho_{\ell}$ and $\boldsymbol{\rho}_{t}$, for structural walls shall not be less than 0.0025 , except that if $\boldsymbol{V}_{u}$ does not exceed $\boldsymbol{A}_{c v} \lambda\left(\boldsymbol{f}_{c}^{\prime}\right)^{\mathbf{1 / 2}}, \boldsymbol{\rho}_{\boldsymbol{\ell}}$ and $\boldsymbol{\rho}_{\boldsymbol{t}}$ shall be permitted to be reduced to the values required in 14.3....

As discussed in Chapter 3, higher strength reinforcement sometimes results in a relaxation of required minimum reinforcing ratios. Therefore, Grade 80 reinforcement could be allowed without adjusting the minimum reinforcement ratio of 0.0025 (and those required in ACI 318-11 Section 14.3) for typical horizontal and vertical wall reinforcement. ACI Committee 318 could consider whether relaxation of the minimum shear reinforcement requirements are appropriate for Grade 80 and higher strength reinforcement. However, doing so is not recommended, given the poor performance of test specimens and observations of earthquake-damaged walls with distributed reinforcement ratios similar to the minimum currently required.

\subsubsection{ACI 318-11 Section 21.9.2 - Special Structural Walls and Coupling Beams, Development and Splices of Reinforcement}

\subsection{2 - Reinforcement}

21.9.2.3 - This section describes requirements for development and splice lengths of reinforcement in special structural walls.

As discussed in Chapter 3, the provisions for development and splice lengths in ACI 318-11 are applicable to Grade 80 reinforcement. However, the longer required development and splice lengths for Grade 80 reinforcement in walls could affect reinforcement detailing practice, with a preference for using mechanical splices or high-strength concrete to keep splices of Grade 80 reinforcement to reasonable lengths. ACI Committee 318 should consider whether there should be restrictions on locating splices in regions where yielding is expected to occur.

Section 21.1.6 allows the use of Type 2 mechanical couplers anywhere within the wall, including plastic hinge regions. As discussed in Chapter 3 of this report, the Type 2 mechanical splice may not be adequate in plastic hinge regions. The need for a new mechanical splice type for which acceptability is strain-based rather than stress-based should be considered. However, Type 2 mechanical splices are likely no worse for splicing ASTM A706 Grade 80 reinforcement than for splicing Grade 60 reinforcement. 


\subsubsection{ACI 318-11 Section 21.9.4 - Special Structural Walls and Coupling Beams, Limit on Allowable Shear Strength}

\subsection{4 - Shear strength}

This section describes upper limit on the shear strength of walls, $V_{n}$.

ACI 318-11 Section 21.9.4.4 limits shear strength of the combined area of walls to $8 A_{c v} \sqrt{f^{\prime}{ }_{c}}$ and the shear strength of an individual wall segment to $10 A_{c v} \sqrt{f^{\prime}}$ to prevent the crushing failure of concrete compression struts (web crushing or toe crushing) that develop in the wall.

The expression for shear strength, ACI 318-11 Equation 21-7, includes a term that reflects the influence of steel yield strength. Thus, the reinforcing ratio for horizontal wall reinforcement that controls the upper limits on strength will be lower for Grade 80 reinforcement than for Grade 60 reinforcement. Since the yield strength is already accounted for in ACI 318-11 Equation 21-7 for shear strength, a revision is not necessary for the adoption of Grade 80 reinforcement.

\subsubsection{ACI 318-11 Section 21.9.6 - Special Structural Walls and Coupling Beams, Boundary Elements}

\subsection{6 - Boundary elements of special structural walls This section describes detailing requirements for special boundary elements}

A reexamination of development and splice length requirements for Grade 80 reinforcement in special boundary elements of walls could affect reinforcement detailing practice. As a practical matter, designers may choose to increase specified concrete strength, $f_{c}^{\prime}$, as a strategy for keeping splices of Grade 80 reinforcement to reasonable lengths.

Where special boundary elements are required, the transverse reinforcement must comply with some of the transverse reinforcement requirements for columns, one of which is the maximum spacing of transverse reinforcement to control buckling of longitudinal bars. This is discussed in Chapter 3 of this report and in the discussion above for ACI 318-11 Section 21.6.4; it applies to boundary elements of walls.

Where special boundary elements are not required, ACI 318-11 Section 21.9.6.5 allows a maximum spacing of 8 inches for the longitudinal spacing of transverse reinforcement. This maximum spacing is greater than that allowed where special boundary elements are required because of the reduced deformation demands. However, this limit is likely necessary to prevent bar buckling, and so it should be a function of the yield stress and the bar diameter. 


\subsubsection{ACI 318-11 Section 21.9.7 - Special Structural Walls and Coupling Beams, Coupling Beams}

\subsection{7 - Coupling beams}

This section describes detailing requirements for coupling beams

For coupling beams constructed with Grade 80 reinforcement, the maximum spacing for transverse reinforcement to address bar buckling should be a function of the specified yield strength, $f_{y}$, as recommended for columns and beams of special moment frames. That is, it should not exceed five times the diameter of the smallest longitudinal bar.

\subsubsection{Discussion of Potential Changes to Non-Seismic Provisions}

Although this study has focused on adoption of high-strength reinforcement for flexural reinforcement in special seismic systems, the proposed changes to seismic provisions also create limited collateral effects on the non-seismic provisions of ACI 318-11. Therefore, several changes to non-seismic provisions are proposed, as discussed in this section.

\subsubsection{ACI 318-11 Section 7.1 - Standard Hooks}

\section{1 - Standard hooks}

The term "standard hook" as used in this Code shall mean one of the following:

7.1.1 - 180-degree bend plus $4 \boldsymbol{d}_{b}$ extension, but not less than $2-1 / 2$ in. at free end of bar.

7.1.2 - 90-degree bend plus $12 \boldsymbol{d}_{b}$ extension at free end of bar.

Standard hooks with Grade 80 reinforcement are already allowed for non-seismic applications. No change is recommended to the code provisions for standard hooks.

\subsubsection{ACI 318-11 Section 7.2 - Minimum Bend Diameters}

ACI 318-11 Section 7.2 describes minimum bend diameters for deformed reinforcing bars and welded wire reinforcement.

As the yield strength of reinforcement increases, reinforcing bars with smaller diameters may be substituted for bars of larger diameters and lower grade. The use of a smaller bend diameter, associated with the use of a smaller hooked bar of higher grade, induces larger compressive stresses in the concrete at the interior of the bend.

Regarding the bendability of steel bars, the minimum bend diameter should be defined proportional to the bar diameter regardless of the grade of reinforcement, as 
long as the measured uniform elongation is similar for the various grades of reinforcement.

ACI 318-11 provisions do not require an increase in bend diameter for Grade 80 reinforcement compared with those required for Grade 60 reinforcement. No change is recommended in the code provisions for bend diameter of Grade 80 reinforcement.

\subsubsection{ACI 318-11 Section 8.8 - Effective Stiffness to Determine Lateral} Deflections and ACI 318-11 Section 10.10 - Slenderness Effects in Compression Members

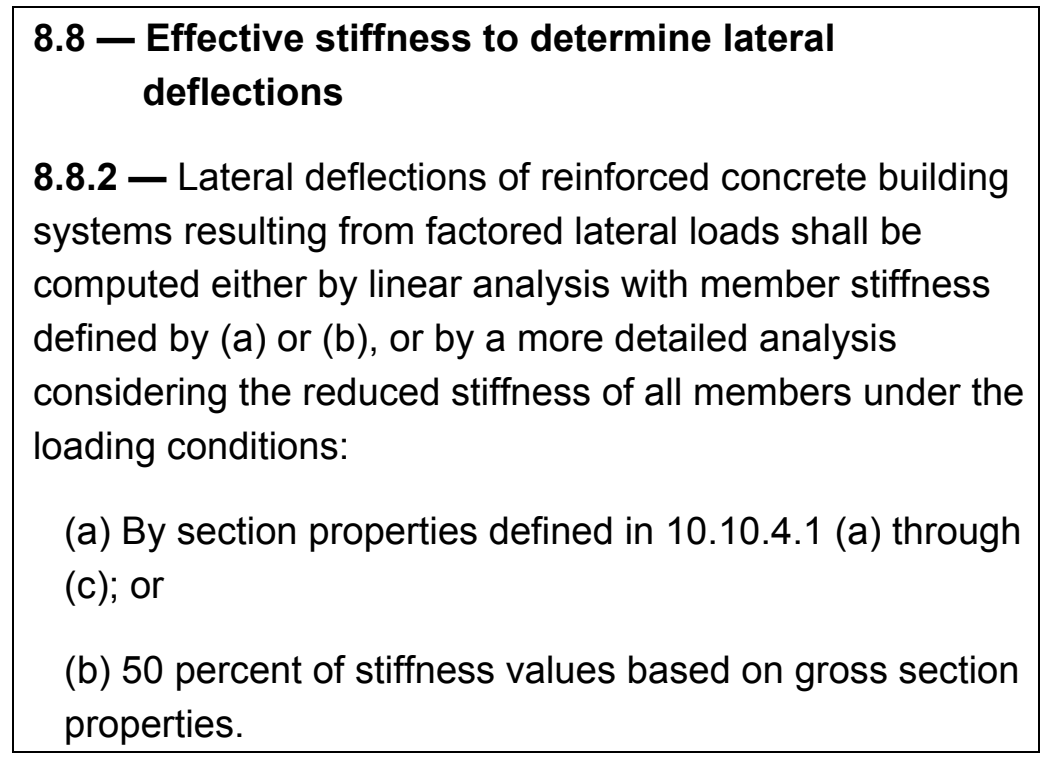

\subsection{4 - Elastic second-order analysis}

10.10.4.1 — It shall be permitted to use the following properties for the members in the structure:

(a) Modulus of elasticity...... $E_{c}$ from 8.5.1

(b) Moments of Inertia, I

Compression members:

Columns.... $.0 .70 I_{g}$

Walls-Uncracked. $0.70 I_{g}$

-Cracked $.0 .35 \mathrm{~g}$

\section{Flexural members:}

Beams. $.0 .35 I_{g}$

Flat plates and flat slabs $.0 .25 I_{g}$

(c) Area $1.0 A_{g}$

As discussed in Chapter 5 of this report, appropriate member stiffness values for linear-elastic seismic analysis have not been established within a narrow range. For a given cross section, replacing conventional strength reinforcement with high-strength 
reinforcement will generally lead to a reduced amount of reinforcement and, consequently, reduced cracked-section properties. However, the reduction in stiffness associated with the use of Grade 80 versus Grade 60 reinforcement is relatively modest in comparison with the wide range of stiffness values proposed by various researchers and ACI 318-11.

The current effective stiffness coefficients shown in ACI 318-11 Section 10.10.4.1 were developed for use in non-seismic applications of the moment magnification procedure for design of columns (ACI 318-11 Section 10.10.5). Although these coefficients are permitted to be used for seismic analyses of lateral force-resisting systems, the study performed for this report demonstrates that some revision to these coefficients is necessary for use in linear analysis of buildings for the design-level earthquake.

\subsubsection{ACI 318-11 Section 9.4 - Design Strength for Reinforcement}

\section{4 - Design strength for reinforcement}

The values of $\boldsymbol{f}_{\boldsymbol{y}}$ and $\boldsymbol{f}_{\boldsymbol{y} t}$ used in design calculations shall not exceed $80,000 \mathrm{psi}$, except for prestressing steel and for transverse reinforcement in 10.9.3 and 21.1.5.4

No change is required to Section 9.4 if both ASTM A706 Grade 60 and Grade 80 reinforcement are permitted in the seismic design provisions of Chapter 21.

\subsubsection{ACI 318-11 Section 10.3.2 - Balanced Strain Conditions}

\section{3 - General principles and requirements}

10.3.2 - Balanced strain conditions exist at a cross section when tension reinforcement reaches the strain corresponding to $\boldsymbol{f}_{\boldsymbol{y}}$ just as concrete in compression reaches its assumed ultimate strain of 0.003 .

No change to the definition of balanced strain conditions in ACI 318-11 Section 10.3.2 is recommended if Grade 80 reinforcement is introduced, provided the stressstrain curve of the Grade 80 reinforcement exhibits a yield plateau. Changes may be necessary in cases where high-strength reinforcement does not exhibit a yield plateau. 


\subsubsection{ACI 318-11 Section 10.3.4 - Tension-Controlled Sections}

\section{3 - General principles and requirements}

10.3.4 - Sections are tension-controlled if the net tensile strain in the extreme tension steel, $\boldsymbol{\varepsilon}_{\boldsymbol{t}}$, is equal to or greater than 0.005 when the concrete in compression reaches its assumed strain limit of 0.003 . Sections with $\varepsilon_{t}$ between the compression-controlled strain limit and 0.005 constitute a transition region between compression-controlled and tension-controlled sections.

Grade 80 flexural reinforcement is already allowed by ACI 318-11 Section 9.4 for non-seismic applications. If Grade 80 reinforcement is permitted for flexural reinforcement in special moment frames and special structural walls in ACI 318-11 Chapter 21, no change is required in the definition of tension-controlled sections in ACI 318-11 Section 10.3.4. It is recommended that the minimum net tensile strain for tension-controlled members be a function of the yield strength for uniform protection against non-ductile flexural failure.

Implementing this recommendation would ease the transition to allowing yield strengths that are greater than $80 \mathrm{ksi}$. The minimum net tensile strain could be presented as $2.5 \varepsilon_{y}$, where $\varepsilon_{y}$ is the yield strain of the reinforcement, which gives 0.005 for Grade 60 reinforcement and nearly 0.007 for Grade 80 reinforcement. Refer to the discussion above related to ACI 318-11 Section 21.5.2 for further discussion on having even stricter limits for special moment frame beams.

\subsubsection{ACI 318-11 Section 10.3.5.1 and 10.3.6 - Design Flexural and Axial Strength}

10.3 - General principles and requirements
10.3.5.1 - Use of compression reinforcement shall be
permitted in conjunction with additional tension
reinforcement to increase the strength of flexural members.
10.3.6 - Design axial strength $\phi \boldsymbol{P}_{n}$ of compression
members shall not be taken greater than $\phi \boldsymbol{P}_{n, \max }$,
computed by Eq. $(10-1)$ or $(10-2)$.

No change to these basic principles for computing design flexural and axial strength is recommended if ASTM A706 Grade 80 reinforcement is introduced for flexural reinforcement in special moment frames and special structural walls. These provisions already consider Grade 80 reinforcement, for non-seismic applications, as permitted by ACI 318-11 Section 9.4. 


\subsubsection{ACI 318-11 Sections 10.10.5 to 10.10.7 - Moment Magnification Procedure}

Sections 10.10.5, 10.10.6, and 10.10.7 describe moment

magnification procedures for nonsway and sway frames.

The moment magnification procedures are already applicable to non-seismic design of frames with Grade 80 flexural reinforcement, as permitted by ACI 318-11 Section 9.4. Introduction of Grade 80 reinforcement will not affect the applicability of ACI 318-11 Sections 10.10.5, 10.10.6, and 10.10.7 to non-seismic analysis of frames, so no change is recommended in these sections. As discussed above under ACI 318-11 Section 8.8, however, revised effective stiffness coefficients are under consideration by ACI Committee 318 for seismic analysis of lateral force-resisting systems in ACI 318-11 Chapter 21.

\subsubsection{ACI 318-11 Section 11.4.2 - Limits on $f_{y}$ and $f_{y t}$ for Shear Design}

11.4.2 - The values of $\boldsymbol{f}_{\boldsymbol{y}}$ and $\boldsymbol{f}_{\boldsymbol{y}}$ used in design of shear reinforcement shall not exceed 60,000 psi, except the value shall not exceed 80,000 psi for welded deformed wire reinforcement.

These limits on $f_{y}$ and $f_{y t}$ apply to both non-seismic and seismic evaluation of shear strength, as stated in ACI 318-11 Section 21.1.5.5. This limit on yield strength provides a control on diagonal crack widths. Sufficient research has demonstrated that shear strength reinforcement is effective at $80 \mathrm{ksi}$, as discussed in Chapter 3 of this report. It is recommend that the 60,000 psi upper limit on $f_{y}$ and $f_{y t}$ be increased to 80,000 psi for design of members resisting earthquake forces when computing design shear strength applicable to bad combinations that include earthquake loads.

\subsubsection{ACI 318-11 Chapter 12 - Development and Splices of Reinforcement}

This chapter describes provisions for development and splice lengths of reinforcement.

Changes to this chapter are not required if Grade 80 reinforcement is introduced in ACI 318-11 Chapter 21 for flexural reinforcement in special moment frames and special structural walls, because the development and splice provisions of ACI 31811 Chapter 12 already apply to Grade 80 reinforcement, as described in the discussion above for ACI 318-11 Section 9.4. However, it is recommended that splices with Grade 80 reinforcement be confined wherever possible.

Accordingly, changes are needed to ACI 318-11 Section 12.6.1, which governs the development of headed deformed bars in tension and requires that the specified yield strength, $f_{y}$, not exceed $60 \mathrm{ksi}$. Manufacturers can produce headed deformed bars 
with Grade 80 reinforcement, and research is underway on the use of high-strength headed deformed bars, as described in Chapter 3 of this report. Depending on the results, modifications to existing provisions may be required. The approval of Grade 80 headed deformed bars for seismic applications could be particularly important for applications where flexural bars are terminated within beam-column joints, such as the termination of beam flexural reinforcement within the exterior beam-column joints of special moment frames. However, research must be completed before an assessment can be made as to the acceptability of using high-strength headed deformed bars for design of members resisting earthquake forces.

It is recommended that ACI Committee 318 consider requiring head size larger than the minimum of $4 A_{b}$. ACI Committee 318 should also consider requiring that bar-tohead connections develop the actual tensile strength of the bar or a minimum specified elongation for use in members resisting earthquake effects. This may be achieved by requiring Class B connections in accordance with ASTM A970 (ASTM, 2013).

\subsection{Recommended Changes to $\mathrm{ACl} 318-11$ for Grade 100 and Stronger Reinforcement}

Sufficient data are not available at this time to recommend the use of Grade 100 or higher reinforcement as flexural reinforcement in special moment frames and special structural walls. However, additional research and development of steel alloys with appropriate material properties could lead to the future adoption of higher grade reinforcement for these applications.

As reinforcement yield strength increases to $100 \mathrm{ksi}$ and higher, there is greater uncertainty in the acceptability of applying current ACI 318 provisions. This uncertainty exists simply because less research has been conducted on members with reinforcement Grade 100 and higher than on members reinforced with bars of lower grades. The following sections describe considerations that will likely require careful attention.

\subsubsection{Minimum Concrete Strength}

Currently, the minimum permitted concrete strength for special moment frames and special structural walls is 3,000 psi. For Grade 100 and stronger reinforcement, the disparity between low concrete strength and high steel strength may result in undesirable forms of behavior. Practically speaking, the specified strength of concrete will tend to rise along with the specified yield strength of reinforcement. Consideration should be given to providing limits to the minimum compressive strength of concrete as a function of the specified yield strength of reinforcement. 


\subsubsection{Development Lengths, Lap Splices, Mechanical Couplers, Welded Splices, Hooked, Headed, and Mechanically Anchored Deformed Bars}

Design and detailing provisions for all of these methods of anchoring and joining bars have generally been developed considering steel grades in the 40 to $80 \mathrm{ksi}$ range. Some research has been completed, and more is underway, to explore the applicability of these provisions to yield strengths of $100 \mathrm{ksi}$ or greater, as presented in Chapter 3. For some forms of bar anchorage and connections, additional research may be required to further qualify and calibrate these methods. The equations for lap splice and development length require close scrutiny and likely modification. As detailed in Chapter 3, this can be partially addressed by requiring confining reinforcement for lap splices and bars being developed.

\subsubsection{Strong-Column Weak-Beam Design Provisions}

Special attention must be paid to adjusting the strong-column weak-beam provisions for the use of reinforcement Grade 100 and higher. The relative strengths of columns to beams could be influenced by the shapes of the stress-strain curves of bars if columns and beams are constructed with different grades or types of reinforcement. Revisions to the strong-column weak-beam design provisions could incorporate factors that account for the ratio of the expected yield strength to the minimum specified yield strength and the ratio of tensile strength to yield strength. Different factors could be used for beams and columns.

\subsubsection{Bar Anchorage in Joints of Special Moment Frames}

As the yield strength of reinforcement increases, so does the required development length for a constant concrete strength. The requirement to anchor flexural bars within the joints of special moment frames (both interior and exterior joints) becomes more difficult as the reinforcement grade increases. From a practical standpoint, it is already difficult to anchor Grade 60 bars within current designs for special concrete moment frames. If Grade 100 and higher reinforcement is allowed, it may be necessary to explore new mechanical methods for anchoring bars in joints that do not rely solely on bond and development of straight bars. If mechanical means are not employed, new provisions should be developed for the depth of the joint parallel to the length of Grade 100 longitudinal beam bars. A suggested formula is provided in Chapter 4 of this report. Another option is to provide reinforcement detailing alternatives that effectively relocate the plastic hinge region away from the face of the column and control the maximum tensile stress that develops in the reinforcement within the beam-column joint. 


\subsubsection{Buckling of Bars and Spacing of Confining Reinforcement}

If Grade 100 and higher reinforcement is permitted, there is the potential for reducing the required amount of reinforcement and selecting smaller bars compared with what would be required with Grade 60 reinforcement. If the spacing of the transverse reinforcement that laterally supports these smaller bars is not reduced, the compression buckling load of the smaller bars may be lower. Therefore, it will be important to understand the interaction between buckling of Grade 100 and stronger bars and the spacing of transverse reinforcement that provides lateral support to those bars. It may be necessary to change the requirements in ACI 318 related to the spacing of hoops and stirrups. For higher grade reinforcement, such as Grades 100 and 120, the required hoop spacing may need to be reduced to four times the diameter of the smallest longitudinal bar. Four times the diameter of the smallest longitudinal bar for Grade 100 reinforcement accounts for yield strength of reinforcement exceeding the specified yield strength. Additional consideration may need to be given to placing tolerances for the specified spacing of the transverse reinforcement.

\subsubsection{Strength and Detailing Requirements for Structural Walls}

At this time, there are insufficient test data of structural walls constructed with Grade 100 or higher reinforcement that are deemed representative of current proportioning and detailing practices in the United States. The design provisions for structural walls in ACI 318 will require close scrutiny to determine if they are applicable to structural walls with Grade 100 or stronger reinforcement, including cases with highstrength concrete in slender load-bearing walls. 



\section{Chapter 8}

\section{Research Needs}

This report identified considerations regarding the use of high-strength reinforcement. Some of these issues are adequately addressed by existing research while others are not. This chapter identifies gaps in existing research, and makes recommendations about research that could contribute to wider acceptance of the use of high-strength reinforcement in members resisting earthquake effects.

\subsection{Material-Related Issues}

Material-related issues concern the applicability of current design approaches to high-strength reinforcement or high-strength concrete. If these materials behave differently than the reinforcement and concrete currently in use, the behavior of structures and structural members may not be the same as the behavior expected under current code provisions and design methods. Currently, ASTM A706 Grade 60 reinforcement is the most common reinforcement specified for special moment frames and special structural wall systems in the United States. The minimum specified concrete strength permitted by ACI 318-11 for earthquake-resistant structures is 3,000 psi, but there is no specified upper limit for concrete strength.

\subsubsection{Impacts of Tensile Characteristics and Shape of Reinforcement Stress-Strain Curve on Member Behavior}

The mechanical properties of reinforcing bars affect the spread of plasticity within the plastic hinge region of a member and the member response to cyclic or earthquake loading, as described in Chapter 2. The shape of the stress-strain curve of the reinforcement has a direct impact on whether sectional strength is maintained or reduced over the range of expected deformation demands.

Future research to determine the effects of reinforcement tensile characteristics and the shape of the stress-strain curve on member cyclic loading response should focus on a review of previous tests. Specifically, the tests reviewed should include reports of stress-strain curves for the reinforcement. The test data should also be compared with analytical predictions of moment-curvature curves using various stress-strain relationships. Additional laboratory testing may also be required to confirm findings of the analyses.

The process of examining existing test data and analytically exploring the effects of the shape of the stress-strain curve began during the development of this report.

These initial studies analytically investigated the effects of various stress-strain curve 
shapes on the flexural behavior of beams, columns, and walls; Chapter 7 describes recommendations based on these initial studies. These analytical studies should be extended, and a test program should be performed, to improve the correlation between computed and measured deformation capacities of concrete members with high-strength reinforcement. The goal of the analytical efforts and test program should be to establish that the recommended limits on the mechanical properties in Chapter 7 are appropriate, or to recommend new limits to achieve the desired member performance. Desired performance would aim to maintain member strength for the deformation expected for design earthquakes, and would also maintain adequate strength necessary for structural stability for maximum considered earthquakes.

The limits to be focused on the most are minimum uniform elongation and minimum ratio of measured tensile strength to measured yield strength. These values may depend on the shape of the stress-strain curve. For example, limits for reinforcement with a rounded stress-strain curve may not be the same as limits for reinforcement with a nearly bilinear stress-strain curve.

\subsubsection{Impact of Fire on Reinforcement Properties}

High-strength reinforcement may be more susceptible to fires than normal-strength reinforcement because of differences in the manufacturing methods. It is recommended that further studies be conducted on concrete cover requirements and the influence of concrete cover on the strength of members containing high-strength reinforcement when they are subjected to fires.

\subsubsection{Development of a Specification for High-Strength Reinforcement}

Development of a specification for high-strength reinforcement used for members that provide earthquake resistance is recommended. The specification could be written with the intent that it would eventually become an ASTM standard specification. As a minimum, the standard specification should include required mechanical properties for reinforcement of Grade 80, Grade 100, and Grade 120 reinforcement. Another approach could be to include Grade 80, Grade 90, Grade 100, Grade 110, and Grade 120 reinforcement, which would better account for regional mill capabilities to produce stronger bars and allow for the marketplace to determine which grades are most cost-effective. Trial heats of reinforcing steel and rolling of sample reinforcing bars should accompany development of the specification to confirm that the requirements can be met. This new specification should address deformation requirements to minimize the effects of wiping, which is the formation of a small undercut or weakened area of steel at the base of deformations, and other deformation patterns that negatively affect ductility. 
This specification should not include chemical restrictions necessary to maintain the ability to weld bars, as few bars are spliced by welding. Mills are currently unable to produce bars that meet the elongation and measured tensile to yield ratio

recommendations if the chemistry requirements for welding are imposed. A separate specification for reinforcement that can be welded could be developed, or ASTM A706 could be maintained. Some chemical requirements may be necessary to maintain ductility at temperatures down to about $20^{\circ} \mathrm{F}$ for exterior use.

\subsection{Bar Continuity and Termination}

\subsubsection{Development and Splice Lengths}

Development and splice lengths have been investigated for deformed steel bars developing stresses up to $150 \mathrm{ksi}$, but the concrete strength in these tests was predominantly below $10,000 \mathrm{psi}$. Additional splice tests to determine required development lengths are needed for high-strength reinforcement placed in concrete with strength in the 10,000 psi to 15,000 psi range.

Practicing structural engineers in the United States generally do not check for prevention of splitting bond failure, because ACI 318-11 does not contain provisions intended to prevent it. Recommendations for how to account for splitting bond failure are included in Chapter 3 of this report. Although the New RC Project in Japan (Aoyama, 2001) addressed splitting bond failure, further investigation of the potential for splitting bond failure in short columns and beams is recommended. Investigations could consist of reviewing existing tests for this failure mechanism and performing additional tests if it is determined that the existing database is incomplete. For example, it is likely that insufficient tests have been performed with reinforcement having strengths of $120 \mathrm{ksi}$ or higher. Tests specifically targeting this potential failure mode could be included in overall test programs for beams and columns.

\subsubsection{Bar Anchorage}

At the time this report was written, a testing program on hooked and deformed headed bars for Grade 60, Grade 80, Grade 100, and Grade 120 reinforcement was underway by Darwin et al. at the University of Kansas. These bars were being placed in concrete with strengths of 5,000 psi, 8,000 psi, 12,000 psi, and 15,000 psi. Some of the tests include transverse reinforcement. Depending on the results of this test program, additional testing may be required to further explore the effects of transverse reinforcement to determine whether larger bend diameters are required, and to study performance under cyclic loading. Additional tests are likely needed to study the effect of closer spacing of hooked and headed bars, because the bar spacing used in the tests to date are generally greater than the bar spacing used in actual 
beams. Tests should also be performed to determine the effects of confinement from beams framing into the sides of the joint.

\subsubsection{Mechanical Splices}

For earthquake resistance, the requirements for Type 2 mechanical splices to develop $1.25 f_{\mathrm{y}}$ and the specified tensile strength of the bar may be inadequate if the actual tensile strength is significantly greater than the specified tensile strength, or if the stress-strain curve of the reinforcement has a rounded shape such that bar elongation at the minimum specified tensile strength is well below the bar's actual uniform elongation. The adequacy of mechanical splices for use in plastic hinge regions could also benefit from further studies.

In addition, requirements for new Type 3 strain-based mechanical splices should be developed. The minimum strain developed in a bar that is spliced should be closely related to the minimum required uniform strain of the bar. Chapter 7 of this report provides a recommendation for a minimum uniform strain of $8 \%$. The requirements should also include limitations of slip and the ability to maintain strength under cyclic loading. A testing protocol should be developed for qualification of these splices. After establishing requirements, mechanical splices should be identified or developed that meet the requirements for this Type 3 mechanical splice for reinforcement of Grade 60, Grade 80, Grade 100, and Grade 120. Then, laboratory specimens with the mechanical splices located in plastic hinges of beams, columns, and shear walls should be tested.

\subsection{Design Limits for Reinforcement in Beams, Columns, and Walls}

\subsubsection{Strain Limit for Tension-Controlled Members}

The minimum net tensile strain for tension-controlled members (beams) in ACI $318-11$ is 0.005 . This limit should be adjusted so that it is related to yield strength, as was recommended in ACI ITG-6 (ACI, 2010a). An increase in strain proportional to the yield strength may not be appropriate for bars with a rounded stress-strain curve, which may require an even higher strain. This is because tensile stress larger than the yield strength will develop at the tensile strain associated with the development of the design strength. Higher yield bar stress will increase strength, but it will also increase the neutral axis depth, making a compression failure more likely.

ACI 318-11 also requires a net tensile strain of at least 0.0075 for members with Grade 60 or Grade 80 reinforcement that rely on moment redistribution to achieve the required strength. This limitation does not apply to beams of moment frames or walls, even though much greater yielding is expected as compared to a gravity-loaded member designed to allow for moment redistribution. This report recommends requiring a net tensile strain of 0.0075 for beams of special moment frames using 
Grade 60 reinforcement and extrapolating based on proportionality to recommended required net tensile strains for beams with higher grade reinforcement. Nonetheless, research to determine the required minimum net tensile strain for beams of moment frames and walls is still suggested. This could be accomplished using analytical studies and confirmation tests and could be combined with other research recommended in this chapter. This research would apply to reinforcement Grade 60 and higher, but the tests should focus on beams with Grade 80 and higher reinforcement.

\subsubsection{Minimum Reinforcement Ratios for Walls}

Tests and actual earthquake damage indicate that minimum reinforcement ratios for walls need to be established. Design strength that is greater than the cracking moment might be appropriate for slender walls, but it may be unnecessary for squat walls. Existing research should be reviewed with an attempt to identify appropriate minimum reinforcement ratios. If necessary, confirmation tests should also be performed on walls with high-strength bars.

\subsubsection{Member Stiffness}

The effective moment of inertia of members, $I_{e}$, is used for modeling structures with linear analyses and affects calculations of period, base shear, and drift. Based on the studies performed during the development of this report, it was determined that there is a wide range of member effective stiffness values, $I_{e}$, that have been recommended or used in practice when computing earthquake-induced lateral displacements using linear analysis programs. A study is needed to develop a general formulation for computing effective member stiffness values to use when computing lateral deformations of buildings due to earthquakes. If possible, these drifts should be correlated to the measured responses of instrumented buildings during strong intensity earthquakes, or to the measured response of structures loaded by a shake table. It is likely that such correlation is only possible for buildings constructed with Grade 40 or Grade 60 reinforcement, simply because only these grades of reinforcement have been used in the construction of the existing building stock. Once appropriate member stiffness is determined for buildings constructed with Grade 60 reinforcement, adjustments could be made for buildings constructed with reinforcement of higher grades.

\subsubsection{Transverse Reinforcement Spacing to Restrain Bar Buckling}

Higher yield strength increases the likelihood of bar buckling for the same restraint spacing, i.e., the transverse reinforcement spacing. This report recommends spacing limits based on analytical studies and limited test results. Additional tests are needed for Grade 80 and higher reinforcement to confirm the recommendations and to establish whether each longitudinal bar must be supported by a transverse bar hook. 


\subsubsection{Shear Reinforcement for Beams, Columns, and Walls}

ACI 318-11 limits the reinforcement yield strength used to calculate the shear strength of beams, columns, and walls to $60 \mathrm{ksi}$. One reason for this limitation is to control crack widths under service load conditions. As discussed in Chapter 3, several tests have been performed that demonstrate that shear reinforcement remains effective at stress exceeding $60 \mathrm{ksi}$, but there appears to be a limit to its effectiveness for columns at about $80 \mathrm{ksi}$. Additional research is recommended to establish the maximum level of stress that may be used for shear reinforcement to resist earthquake loads in beams, columns, and walls.

\subsection{Moment Frames}

Additional component and sub-assemblage testing is recommended. Limited experimental research has been performed, and more is necessary to develop design rules for U.S. practice regarding the use of high-strength reinforcement for members of systems resisting earthquake effects. Acceptable performance of beams, columns, and joints should be established in terms of deformation, loss of strength, and level of damage before finalizing a testing program.

\subsubsection{Beams}

The majority of the testing performed as part of the New RC Project in Japan (Aoyama, 2001) consisted of relatively small beams with equal quantities of top and bottom reinforcement. More tests are needed, therefore, of beams with unequal amounts of top and bottom reinforcement. Beams of larger size, with depths on the order of 24 to 48 inches, should also be further tested. The effect of the shape of the stress-strain curve of the reinforcement on member performance should be explored to determine whether adequate rotational capacity can be developed. Tests should include flexural reinforcement with yield strengths of $100 \mathrm{ksi}$ and $120 \mathrm{ksi}$.

Additionally, these tests should investigate the viability of high-strength reinforcement for use as transverse reinforcement. The purpose of such testing would be to explore whether stresses greater than $60 \mathrm{ksi}$ in the transverse reinforcement are effective in resisting shear in the plastic hinge regions, and would evaluate the effectiveness of the reinforcement after the concrete in the plastic hinge has degraded. For instance: An Alternative Procedure for Seismic Analysis and Design of Tall Buildings Located in the Los Angeles Region (LATBSDC, 2011) requires transverse reinforcement to confine the concrete in compression in accordance with ACI 318-11 Equation 21-5. Tests should explore the required spacing of transverse reinforcement to confine the concrete core and inhibit buckling of longitudinal bars. The tests should also be used to determine whether each longitudinal bar needs to be located inside of a transverse bar hook, and should focus on beams reinforced with Grade 100 and Grade 120 bars. 


\subsubsection{Columns}

Despite the number of cyclic tests on columns that have been performed, additional column tests are required. The new RC Project tested columns with the intention that they would not yield. In addition to exploring the effects of using high-strength longitudinal reinforcement, tests should explore the effectiveness of high-strength transverse reinforcement for providing shear resistance, and the required spacing and arrangement to inhibit buckling of longitudinal bars. Additional tests with cyclic bidirectional loading should be included in the test program and should focus on columns reinforced with Grade 100 and Grade 120 bars.

\subsubsection{Joints}

The test data on beam-column joints obtained from the New RC Project in Japan should be reviewed in detail for its applicability to U.S. practice. Additional testing including tests of interior and exterior beam-column sub-assemblages, is recommended. The research should focus on determining the required joint depths for reinforcement with specified yield strengths of $80 \mathrm{ksi}, 100 \mathrm{ksi}$, and $120 \mathrm{ksi}$. Tests should explore the effect of floor slabs, the magnitude of compressive load on the top of the joint, and the strength of concrete. The test program should be developed so that the results can be used to determine how joint depth should vary with respect to both the yield strength of longitudinal bars and the concrete strength.

Future tests should also investigate the effectiveness of alternative means of developing or anchoring bars within a joint to minimize bar slip.

\subsection{Structural Walls}

There are a limited number of tests of structural walls with Grade 100 reinforcement (Aoyama, 2001; Kimura and Ishikawa, 2008), and only the tests by Kimura and Ishikawa were on walls rectangular in plan. The tests for the New RC Project reported by Aoyama were barbell-shaped walls with thin webs. U.S. practice often includes slender shear walls with constant thickness (rectangular). Core walls are often C-shaped or coupled C-shapes. For squat walls, all tested walls had a shear failure characterized by crushing the diagonal compression strut in the web.

Tests of wall specimens that are representative of those constructed in the United States are needed. The test specimens should use the same grade of reinforcement for both the vertical and horizontal wall reinforcement, and should be constructed with Grade 100 or Grade 120 reinforcement.

Tests of slender walls should explore the displacement capacity of walls with various reinforcement ratios, boundary element detailing, and levels of vertical compressive load. Some tests should include bi-directional loading to determine the effect of out- 
of-plane deformations on wall deformation capacity. Wall specimens should have the same grade reinforcement for horizontal and vertical bars.

The test program should determine the behavior of coupled slender walls with highstrength reinforcement. Tests of coupled wall sub-assemblages, coupling beams, wall piers, and wall segments are also needed.

Tests of squat walls with high-strength reinforcement representative of walls constructed in the United States are needed. Squat walls without boundary elements (Gulec et al., 2008; Gulec et al., 2009; Gulec et al., 2011) fail in a different manner than walls with boundary elements or flanges. To represent U.S. practice, most of the specimens should be rectangular in shape (not barbell-shaped).

Other items to address in the test program include bi-directional bending of C-shaped and L-shaped walls, slenderness effects in thin walls reinforced with reduced amounts of high-strength reinforcement, and the potential for buckling in the plastic hinge region.

\subsection{Full-Scale Tests}

Full-scale testing of multi-story two-bay moment frames constructed with highstrength flexural reinforcement is recommended. The frames could be subjected to pseudo-dynamic tests loaded using a strong wall, or the frames could be tested on a shake table. Full-scale testing of multi-story buildings with shear walls is also recommended. A primary objective of all of these tests would be to explore the strength and stiffness of lateral-force-resisting systems constructed with high-strength reinforcement.

\subsection{Analytical Studies to Confirm Adequate Collapse Resistance}

Analytical studies following the procedures specified in the FEMA P-695 report, Quantification of Building Seismic Performance Factors (FEMA, 2009), were previously performed on concrete moment frames (FEMA, 2009; Richard et al., 2010; Haselton et al., 2011). These analytical studies should be performed for structures designed using high-strength reinforcement to confirm that the collapse risk does not increase. The assessments should also confirm that the strong-column weak-beam provisions are adequate for beams and columns constructed with highstrength flexural reinforcement characterized by particular stress-strain curves.

The use of reinforcement with yield strengths of $100 \mathrm{ksi}$ and higher presents an opportunity to tune the strong-column weak-beam concept, maybe by placing different grades of flexural reinforcement in the beams and columns. If high-strength flexural reinforcement is used in columns, perhaps of $100 \mathrm{ksi}$ or $120 \mathrm{ksi}$ yield strength, and if the yield strength of flexural reinforcement in beams is lower, perhaps $60 \mathrm{ksi}$, then the flexural strength of columns could be increased to a point at 
which elastic response could essentially be assured in columns, while plastic hinges with high inelastic rotation capacity form in beams. The feasibility of such an arrangement could be explored through analysis, and selected configurations could be verified by testing before being used in practice.

\subsection{Considerations Unrelated to Earthquake Resistance}

This study intentionally did not address the use of high-strength reinforcement in applications not related to earthquake resistance. Issues might arise, however, when high-strength reinforcement is used with both non-seismic and seismic applications. ACI ITG-6R-10 (ACI, 2010a) addresses some issues related to design with highstrength reinforcement, such as how to compute flexural strength and how to consider compressive bar stresses due to strains in excess of 0.003 , as well as crack control, deflections, and reduced shear strength of members with high-strength longitudinal reinforcement without shear reinforcement.

During the development of this report, potential additional issues were identified. Some of these potential issues are not directly addressed in this report or are only partially addressed. Whether sufficient research exists to resolve these issues has not been determined. The following list of issues could be used as a starting point to identify what additional research is needed:

- Validity of design assumptions for computing moment and combined moment and axial strengths.

- Maximum strength of compressive reinforcement that may be relied upon; the current ACI 318-11 limit is 80 ksi.

- Minimum and maximum reinforcement ratios for flexural members and axially loaded members.

- Crack control under service loads.

- Deflection control and adjustments to minimum member depth tables.

- Potential reductions in shear strength of members without shear reinforcement due to increases in stress and strain of the flexural reinforcement.

- Effect of reduced stiffness on moment magnification of slender columns and walls.

- Development lengths for high-strength reinforcement placed in concrete with compressive strengths of 10,000 to 15,000 psi.

- Anchorage of multiple hooked flexural beam bars in joints at the perimeter of a building (exterior joints) and the requirements for transverse reinforcement in these joints. 
- Bar spacing requirements and possible modifications to reduce the possibility of splitting cracks.

- Spacing requirements of transverse reinforcement at bar offsets.

- Effects of using increased bar deformations (high relative rib area bars) on highstrength reinforcement. 


\section{Appendix A}

\section{Study of Deformation Capacity}

The limited set of experimental data presented in Chapter 4 suggest that the nonlinear cyclic response of concrete members reinforced with high-strength steel reinforcing bars is comparable to the response of members reinforced with conventional Grade 60 steel reinforcing bars, provided that the members are detailed to avoid brittle failures related to shear, bond stress, or bar buckling. In the following sections, conventional numerical models are used for calculating the monotonic flexural response of reinforced concrete members. The calculated data provide useful information on the relative influence of high-strength concrete and reinforcing steel.

\section{A.1 Material Properties}

\section{A.1.1 Stress-Strain Relationships for Reinforcing Steel}

Representative stress-strain curves for three grades of reinforcing steel are shown in Figure A-1, supported by the parametric values in Table A-1, including those based on Equation A-1, described later in this section. Grade 60 reinforcing steel is represented by a curve defined by three segments (Type 60-S3 in Figure A-1). The first segment defines the initial linear elastic portion with a modulus of elasticity of

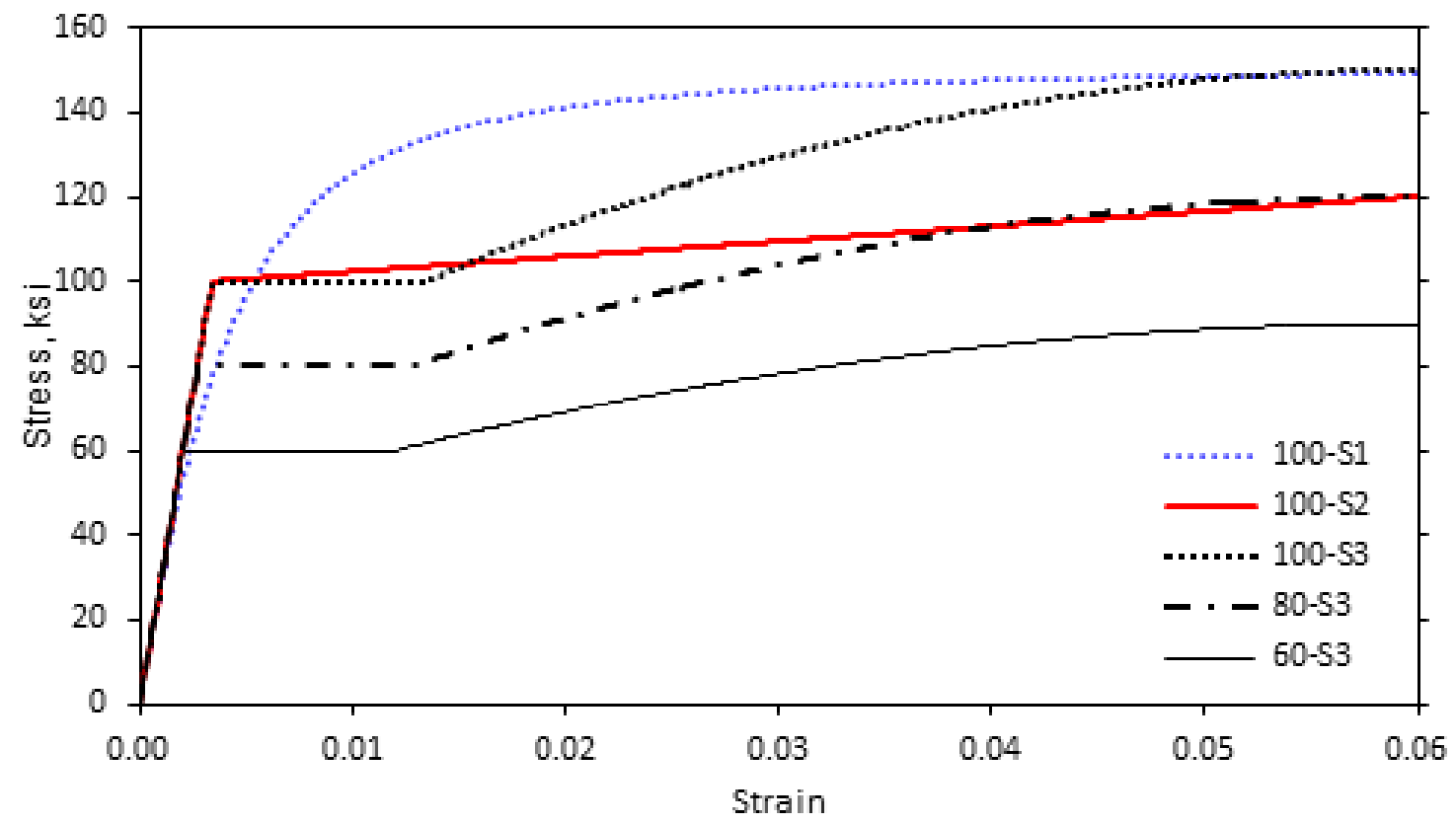

Figure A-1 Stress-strain relationships for reinforcing steel of various grades. 
Table A-1 Stress-Strain Parameters for Reinforcing Steel

\begin{tabular}{|c|c|c|c|c|}
\hline Reinf. Type & $f_{y}{ }^{2}$ & $\varepsilon_{s h}{ }^{3}$ & $\varepsilon_{s u}{ }^{4}$ & $f_{u} / f_{y}{ }^{5}$ \\
\hline $100-S 1^{6}$ & 100 ksi & - & 0.06 & 1.5 \\
\hline $100-S 2$ & 100 ksi & 0.00345 & 0.06 & 1.2 \\
\hline $100-\$ 3$ & 100 ksi & 0.0134 & 0.06 & 1.5 \\
\hline $80-\$ 3$ & 80 ksi & 0.0128 & 0.06 & 1.5 \\
\hline $60-\$ 3$ & $60 \mathrm{ksi}$ & 0.0121 & 0.06 & 1.5 \\
\hline
\end{tabular}

1 Refer to Figure A-1.

2 Yield strength of reinforcement based on the $0.2 \%$ Offset Method.

${ }^{3}$ Strain defining the onset of strain hardening.

${ }^{4}$ Maximum usable strain. For reinforcing steel models in Figure A-1, maximum usable strain coincides with the tensile strength. A value of $6 \%$ is a representative low-bound strain associated with the peak stress (tensile strength). In contrast, the strain associated with fracture elongation may be up to two times the strain associated with peak stress.

${ }^{5}$ Ratio of tensile strength to yield strength.

${ }^{6}$ Based on Equation A-1.

$29,000 \mathrm{ksi}$, the second segment defines a yield plateau, and the third segment defines a strain hardening range based on a quadratic function. Similar stress-strain curves are defined for Grade 80 and Grade 100 reinforcing (Types 80-S3 and 100-S3 in Figure A-1). Although the extension of a yield plateau is highly sensitive to the method of steel manufacturing and chemical components, the yield plateaus represented in Figure A-1 extend to a strain of 0.01 , which is beyond the yield point. The value of strain of 0.01 is attainable in high-strength reinforcement, as suggested by the specifications introduced in the Japanese New RC Project (Aoyama, 2001), where Grade 100 steel reinforcing bars are required to exhibit a "strain at yield plateau" of $1.4 \%$ (refer to Chapter 2, USD685 reinforcement).

Figure A-1 includes two other types of Grade 100 reinforcing steel, 100-S2 and 100-S1. Reinforcement type 100-S2 is represented by a stress-strain curve defined by two line segments, an initial elastic portion followed by a plastic portion with moderate strain hardening. 100-S1 reinforcement is represented by a continuous nonlinear segment. SAS 670 reinforcement typically exhibits a stress-strain relationship similar to 100-S2 reinforcement, while reinforcement meeting ASTM A1035 requirements may be represented with curves similar to 100-S1 reinforcement. The stress-strain curve defining 100-S1 reinforcement in Figure A-1 was based on the following equation by Menegotto and Pinto (1973):

$$
f_{s}=E_{s} \varepsilon\left[A+\frac{(1-A)}{\left[1+(B \varepsilon)^{C}\right]^{1 / C}}\right] \leq f_{u}
$$


where the stress, $f_{s}$, is defined in terms of strain, $\varepsilon ; E_{s}$ is the modulus of elasticity of reinforcing steel; and $f_{u}$ is the reinforcing steel tensile strength. Values of coefficients taken as $A=0, B=190$, and $C=1.6$ lead to a yield strength, $f_{y}$, and a tensile strength, $f_{u}$, in compliance with the minimum values specified for ASTM A1035 Grade 100 reinforcing steel bars. The maximum usable strain, $\varepsilon_{s u}$, equal to 0.06 in Figure A-1 and Table A-1, was selected because it corresponds to ASTM A706 reinforcing steel that has a required total elongation of $12 \%$. The uniform elongation (defined in Chapter 2) of ASTM A706 reinforcing steel is approximately 8\%. The uniform elongation represents a damage limit state of a bar measured in a tensile test. Under cyclic loading conditions, reinforcing steel bars may reach this damage limit state at a smaller elongation. This smaller elongation limit is herein referred to as usable elongation, $\varepsilon_{s u}$.

\section{A.1.2 Stress-Strain Relationships for Concrete Compressive Strength}

Representative stress-strain curves for compressed concrete (unconfined and confined) are shown in Figure A-2. Two concrete strengths are considered: normalstrength concrete with $f_{c}^{\prime}=5 \mathrm{ksi}$ and high-strength concrete with $f_{c}^{\prime}=10 \mathrm{ksi}$. The stress-strain relationships in Figure A-2 follow the model proposed by Park et al. (1982) using the parametric values listed in Table A-2. The behavior in tension is assumed to be linear up to a tensile strength of $7.5 \sqrt{f_{c}^{\prime}}(\mathrm{psi})\left(\right.$ or $\left.0.62 \sqrt{f_{c}^{\prime}}(\mathrm{MPa})\right)$ with no post-cracking strength.

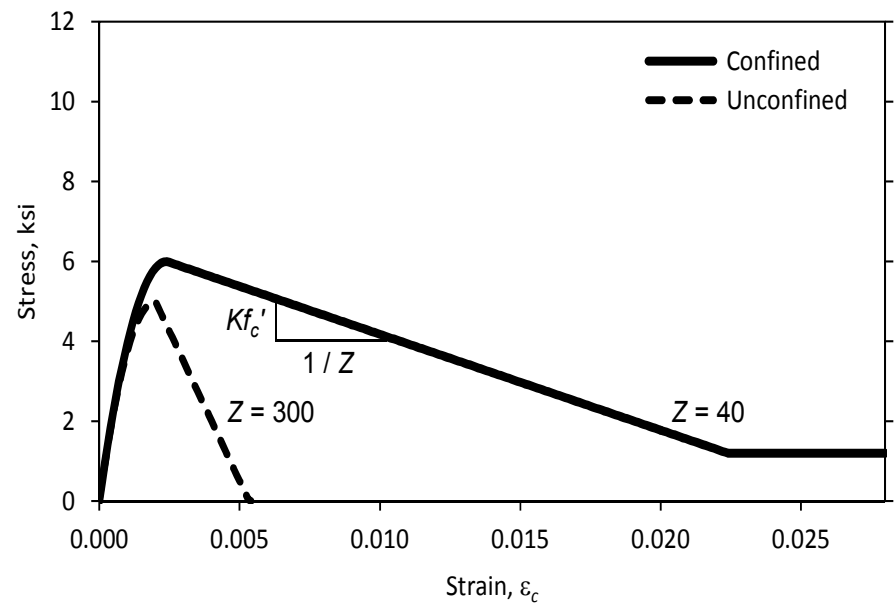

(a)

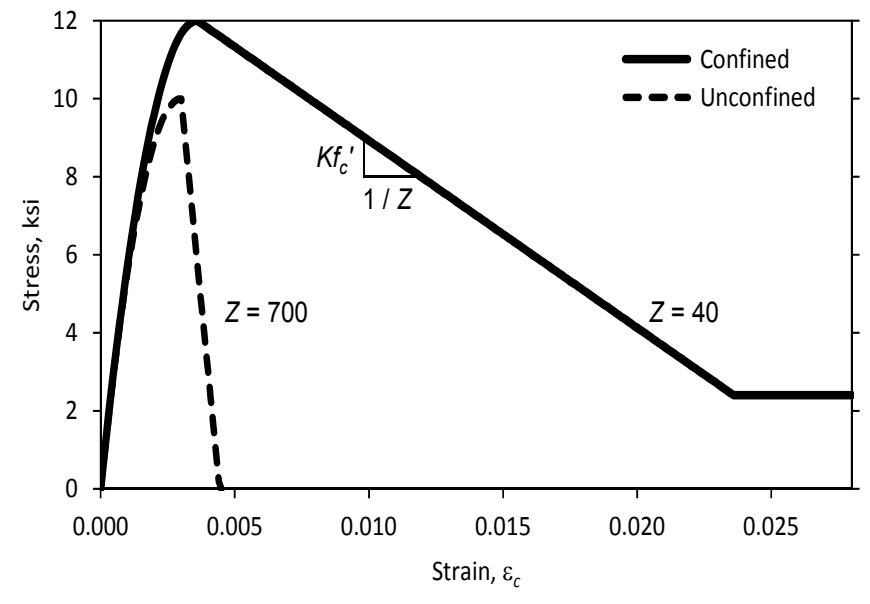

(b)

Figure A-2 Stress-strain relationships for compressed concrete: (a) $f_{c}^{\prime}=5 \mathrm{ksi}$; and (b) $f_{c}^{\prime}=10 \mathrm{ksi}$.

In the idealized stress-strain curve for concrete proposed by Park et al. (1982) the properties of confined concrete are related to those of unconfined concrete by means of the parameter, $K$, which depends on the amount of confinement due to transverse reinforcement in the form of rectangular stirrups or hoops. Volumetric transverse reinforcing steel ratios, $\rho_{s}$, in compliance with the minimum prescribed in ACI 
Table A-2 Stress-Strain Parameters for Concrete

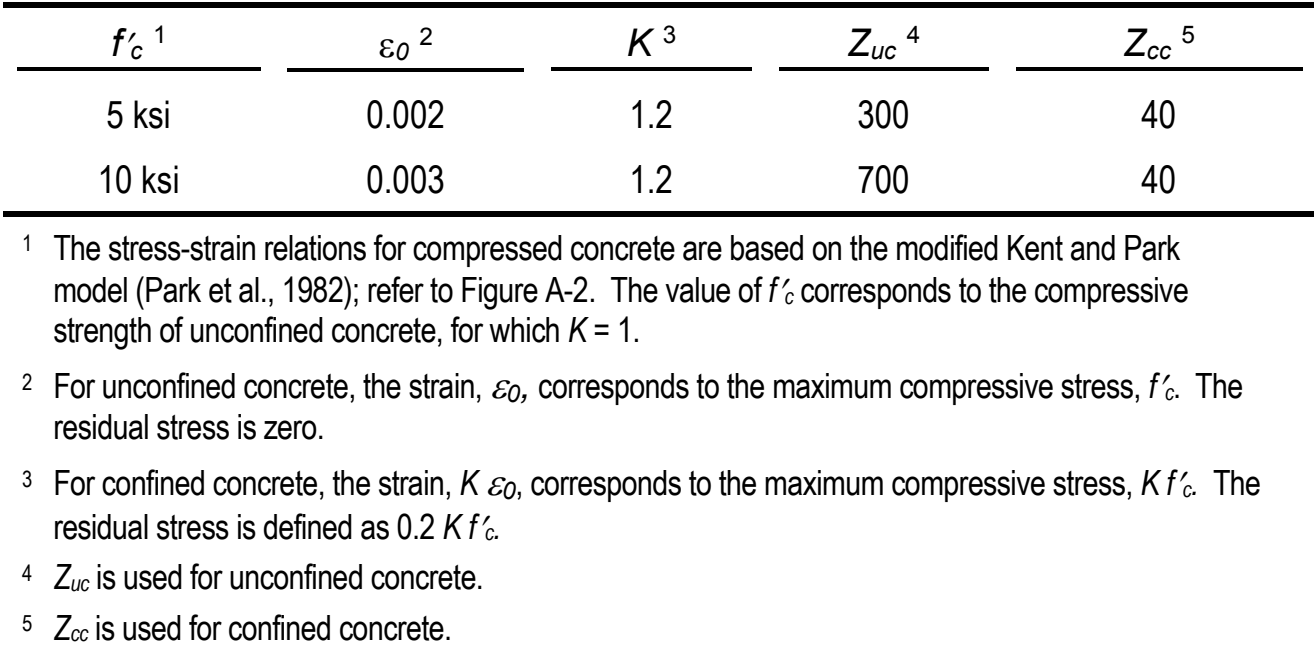

318-11 for seismic applications ( $\rho_{s} \geq 0.18 f_{c}^{\prime} / f_{y t}$ in columns), lead to values of $K$ approximately equal to 1.2 .

In Figure A-2, the descending slope of the stress-strain curve of compressed concrete is controlled by the parameter, $Z$. The values of $Z$ in Table A- 2 were adjusted considering the experimental data presented by Thorenfeldt et al. (1987) for unconfined concrete, $Z_{u c}$, and by Cusson and Paultre (1995) and Matamoros (1999) for confined concrete, $Z_{c c}$. It is of interest to examine the strength and deformation characteristics of members that use either normal-strength or high-strength concrete, because these types of concrete are characterized by stress-strain curves with significantly different post-peak slopes, based on the parameter, $1 / Z$. The post peak slope for confined high-strength concrete drops more rapidly than the post peak slope for confined normal-strength concrete.

\section{A.2 Calculation of Moment-Curvature Relationships}

\section{A.2.1 Assumptions}

The behavior of concrete members with high-strength reinforcing bars is evaluated in terms of the relationship between moment and curvature. This study focuses on members loaded monotonically into the post-yield range of the longitudinal reinforcement.

The computer program, QBIAX, developed by Dragovich (1996) for computing biaxial moment curvature of reinforced concrete sections, was used to calculate monotonic moment-curvature responses, assuming plane sections remain plane. The program operates by discretizing a rectangular cross-section into a dense array of subsections, each with a specified area and centroidal coordinates, to represent unconfined concrete, confined concrete, and reinforcing steel. Confined concrete in 
the cross-section extends to the outside of the transverse reinforcement. The stresses in the concrete and reinforcing steel at each subsection are found from the stressstrain relationships. For a target curvature, the program uses an iterative process to determine the location of the neutral axis based on axial force equilibrium. The moment corresponding to that curvature is determined by calculating the moments of the internal forces about the geometric centroid.

The assumed concrete and reinforcing steel properties were based on the stress-strain curves presented in Section A.1. To minimize the number of variables involved in the calculations, the effects of member sizes were not considered. The calculations were based on a single beam section (16 inches wide by 24 inches deep), a single column section ( 24 inches wide by 24 inches deep), and a single wall section (16 inches wide by 240 inches long). Results of the calculations are shown below in dimensionless form as plots of moment and curvature divided by the yield moment and yield curvature corresponding to the section with Grade 60 reinforcement.

The longitudinal reinforcing steel ratios for the members reinforced with conventional Grade 60 reinforcing steel bars comply with the seismic design provisions of ACI 318-11. All concrete members with high-strength reinforcing steel bars were reinforced with reduced reinforcing steel ratios relative to the members reinforced with Grade 60 steel reinforcement. The reduction in steel reinforcement ratio was proportional to the increase in the yield strength of reinforcement (i.e., constant $\rho f_{y}$ ).

\section{A.2.2 Moment-Curvature Relationships for Beams}

Moment-curvature relationships are calculated for the beam section shown in Figure A-3. This section represents a moment-frame beam near a column joint, where combined gravity and seismic effects lead to a greater amount of top reinforcement than bottom reinforcement. This occurs because seismic moments are typically additive with negative gravity moments at beam-column (support) joints, thus requiring greater amounts of top reinforcement. Seismic moments at the opposite beam-column (support) joint are not additive, and therefore require less bottom

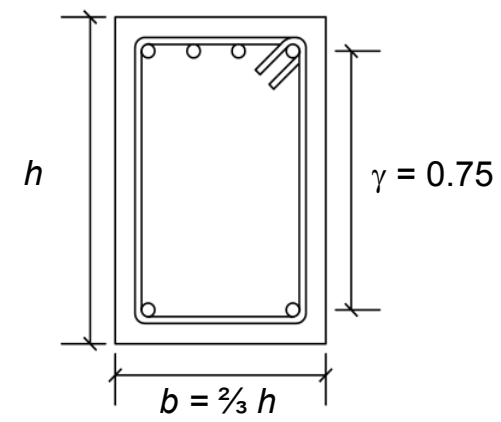

Figure A-3 Typical beam section used for moment-curvature study. 
reinforcement. However, considering that seismic loads reverse direction with reversing ground motion, all beam ends sustain both additive and non-additive end moments at all joints. According to the seismic provisions of ACI 318-11 for special moment frames, the ratio of the maximum positive moment strength (bottom reinforcement) to maximum negative moment strength (top reinforcement) at the face of column joints must be at least one-half. This is very close to the ratio of the amounts of top and bottom reinforcement as shown in the beam cross-section in Figure A-3.

Four cases of beams were analyzed considering two concrete compressive strengths and two reinforcement steel ratios. Figure A-4 shows the normalized moment-curvature relationships for these beams. Each of the four plots in Figure A-4 correspond to a constant value of the quantity $\rho f_{y}$ and $\rho^{\prime} f_{y}$, where $\rho$ and $\rho^{\prime}$ are the reinforcing steel ratios $\left(A_{s} / b d\right.$ and $\left.A_{s}^{\prime} / b d\right)$ referring to the tension (top bars) and compression reinforcement,

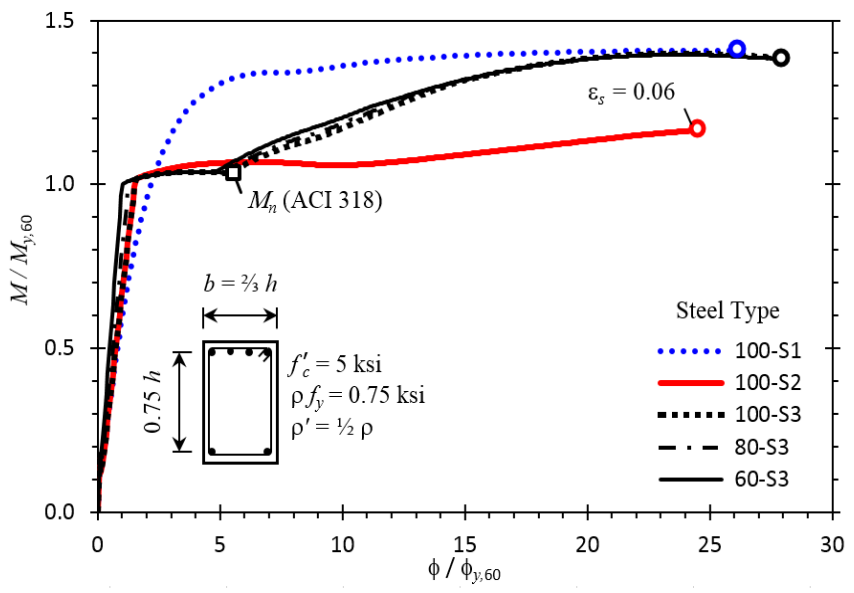

(a)

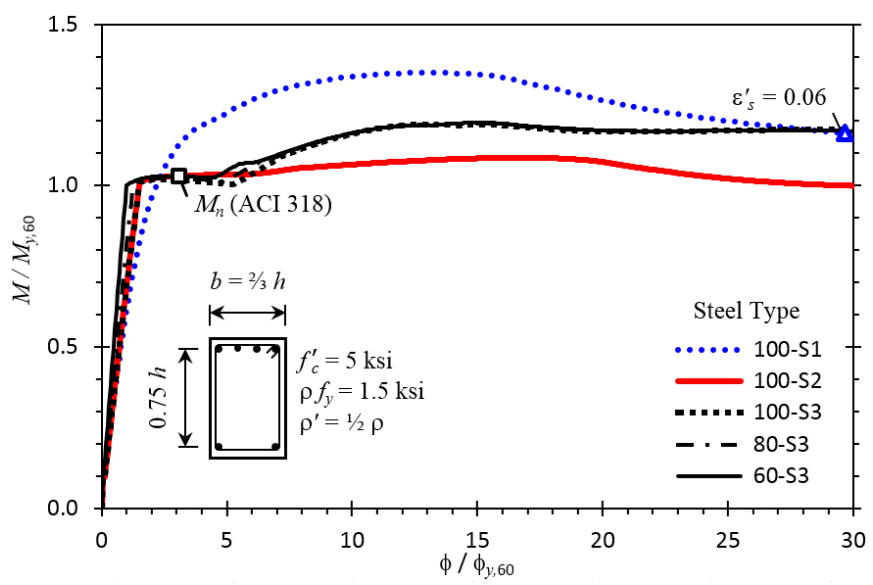

(c)

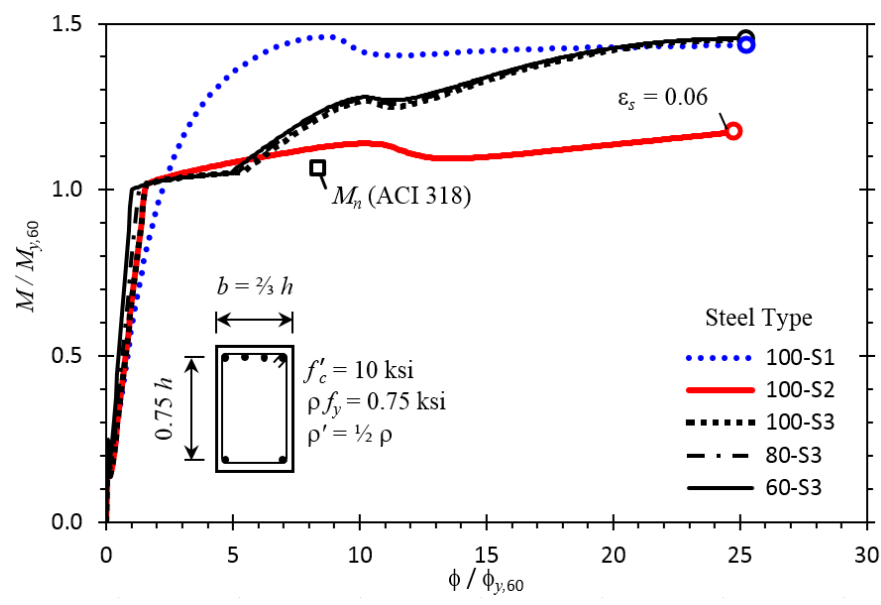

(b)

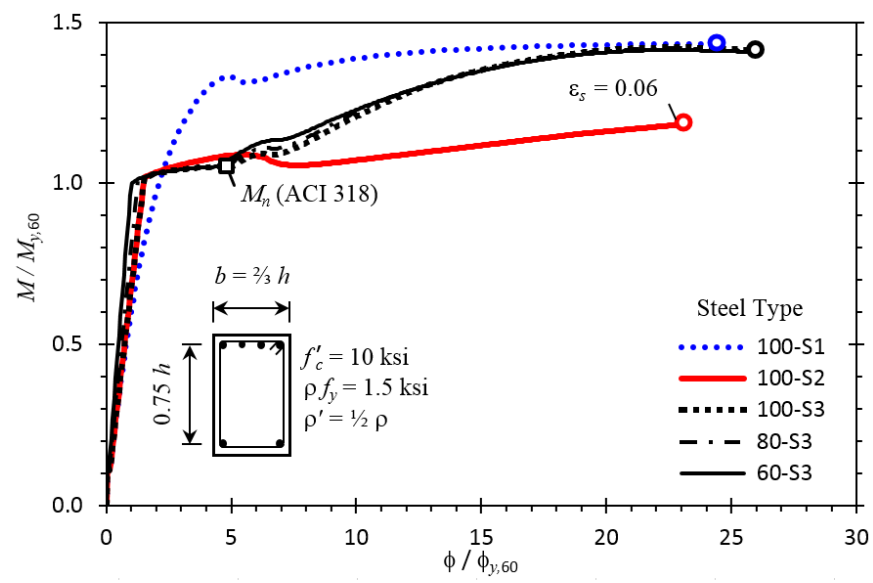

(d)

Figure A-4 Moment-curvature relationships for beams with different concrete compressive strengths and reinforcing steel ratios: (a) $f_{c}^{\prime}=5 \mathrm{ksi}$ and $\rho f_{y}=0.75 \mathrm{ksi}$; (b) $f_{c}^{\prime}=10 \mathrm{ksi}$ and $\rho f_{y}=0.75 \mathrm{ksi}$; (c) $f_{c}^{\prime}=5 \mathrm{ksi}$ and $\rho f_{y}=1.5 \mathrm{ksi}$; and (d) $f_{c}^{\prime}=10 \mathrm{ksi}$ and $\rho f_{y}=1.5 \mathrm{ksi}$. (Top bars are in tension.) 
respectively. The case of $\rho f_{y}=1.5 \mathrm{ksi}$ corresponds to a longitudinal reinforcement ratio of $2.5 \%$ (0.025) when using Grade 60 reinforcement, coinciding with the maximum allowed by ACI 318-11 for seismic applications for bemas in special moment frames. The reinforcing steel and concrete properties used to develop Figure A-4 are presented in Tables A-1 and A-2. The extent of the confined concrete core excludes the clear unconfined concrete cover outside of the transverse reinforcement.

The points associated with the calculated flexural strength, $M_{n}$, are identified in Figure A-4 for beams reinforced with Grade 60 reinforcement. The value of $M_{n}$ was determined using the general principles of reinforced concrete in Chapter 10 of ACI 318-11, where the reinforcing steel stress is limited to $f_{y}$ and the concrete strain is limited to 0.003 . Figure A- 4 shows that $M_{n}$ is consistently below the maximum moment calculated for the different reinforcing steel types, indicating that computing the flexural strength per ACI 318-11 is conservative for the reinforcing steel types considered.

The maximum curvatures shown in Figure A-4 were limited by the maximum usable strain of $\varepsilon_{s u}=0.06$ (see Table A-1) for the tension reinforcement. In Figure A-4c, the beam reinforced with steel type 100-S1 was controlled by the compression reinforcement reaching a strain of $\varepsilon_{s u}$ in compression. The beams with 100-S1 reinforcement generally developed larger moments than the beams reinforced with lower grades of reinforcing or other types, especially in the range of curvature ductilities $\left(\phi / \phi_{y}\right)$ between 5 and 15. The limiting curvatures in Figure A-4, for beams with highstrength longitudinal reinforcement types 100-S1 and 100-S2, were slightly lower, although they were within $15 \%$ of the limiting curvature ductility values for beams with reinforcement types $60-\mathrm{S} 3,80-\mathrm{S} 3$, or $100-\mathrm{S} 3$. The following sections show that these differences had a minor effect on the calculated deformation capacities of beams.

\section{A.2.3 Moment-Curvature Relationships for Columns}

Moment-curvature relationships were developed for the column section shown in Figure A-5. Two levels of axial load were considered, $P=0.2 f_{c}^{\prime} A_{g}$ and $P=0.3 f_{c}^{\prime}$ $A_{g}$. For each level of axial load, four column cases were analyzed considering two different concrete compressive strengths and two different reinforcing steel ratios. Figures A-6 and A-7 show the normalized moment-curvature relationships for these column cases.

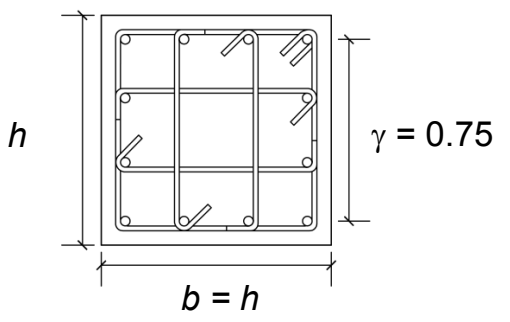

Figure A-5 Typical column section used for moment-curvature study. 


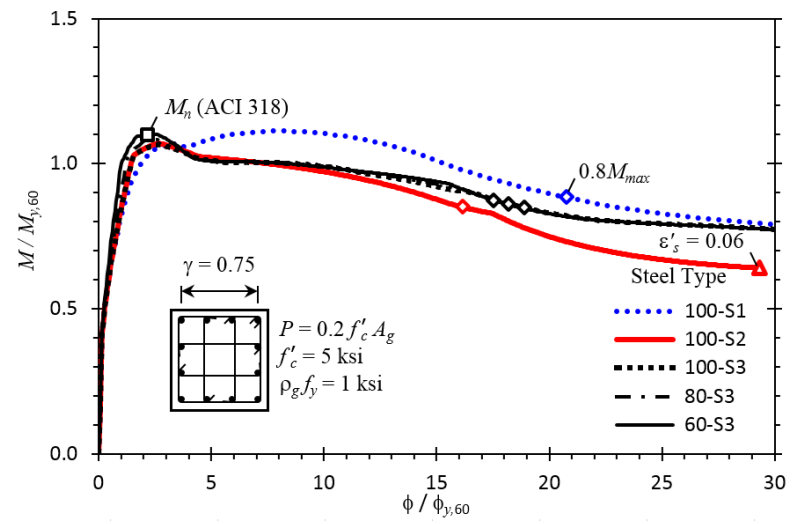

(a)

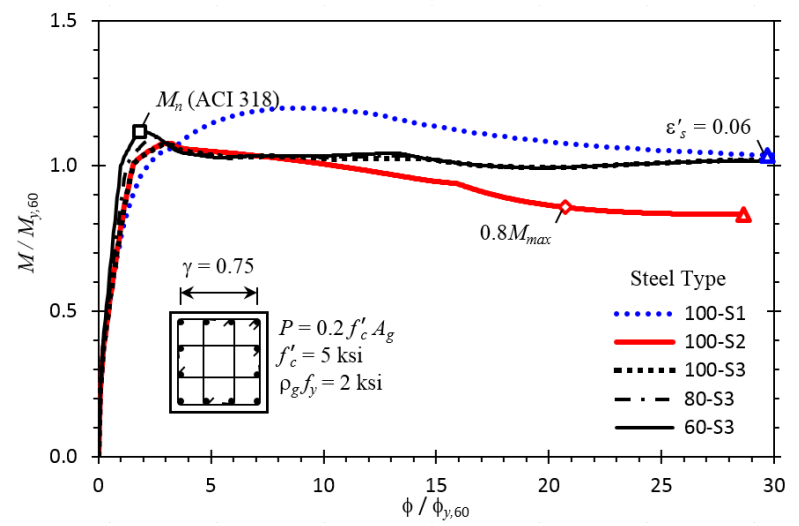

(c)

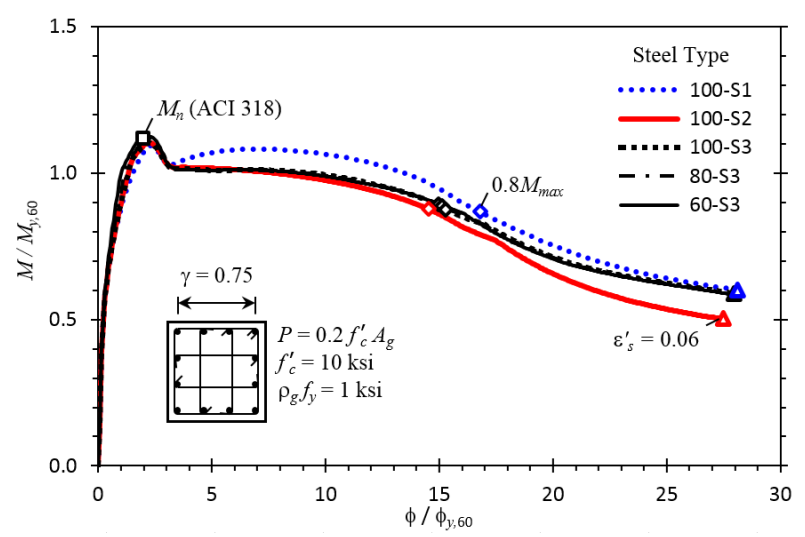

(b)

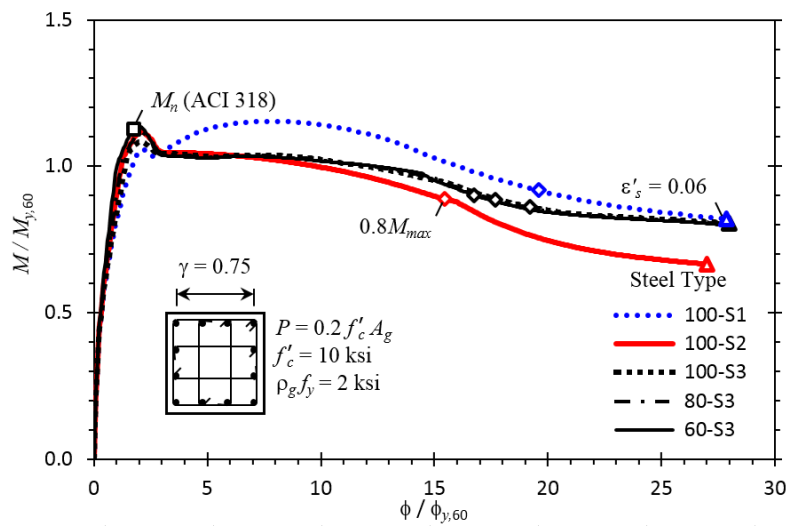

(d)

Figure A-6 Moment-curvature relationships for columns with different concrete compressive strengths and reinforcing steel ratios, with an axial load of $P=0.2 f^{\prime}{ }_{c} A_{g}:(a) f_{c}^{\prime}=5 \mathrm{ksi}$ and $\rho_{g} f_{y}=1 \mathrm{ksi}$; (b) $f_{c}^{\prime}=10 \mathrm{ksi}$ and $\rho_{g} f_{y}=1 \mathrm{ksi}$; (c) $f_{c}^{\prime}=5 \mathrm{ksi}$ and $\rho_{g} f_{y}=2 \mathrm{ksi}$; and (d) $f_{c}^{\prime}=10 \mathrm{ksi}$ and $\rho_{g} f_{y}=2 \mathrm{ksi}$.

Each of the four cases in Figure A-6 and A-7 corresponds to a constant value of $\rho_{g} f_{y}$, where $\rho_{g}$ is the total reinforcing steel ratio $\left(A_{s} / b h\right)$. The case of $\rho_{g} f_{y}=1 \mathrm{ksi}$ corresponds to a longitudinal reinforcement ratio of $1 \%(0.010)$ when using Grade 100 reinforcement, coinciding with the minimum reinforcement ratio required by ACI 31811 for columns to reduce the effects of creep and shrinkage. The reinforcing steel and concrete types identified in Figures A-6 and A-7 are identical to those described in Section A.1. The extent of the confined concrete core excludes the unconfined concrete cover outside of the transverse reinforcing steel.

The curves of Figure A-6 and A-7 identify the points associated with the calculated flexural strength, $M_{n}$, for columns reinforced with Grade 60 reinforcement. The value of $M_{n}$ was determined following the general principles of reinforced concrete in Chapter 10 of ACI 318-11, where the maximum stress in the reinforcing steel is limited to its yield strength and the maximum strain in the compressed concrete is 


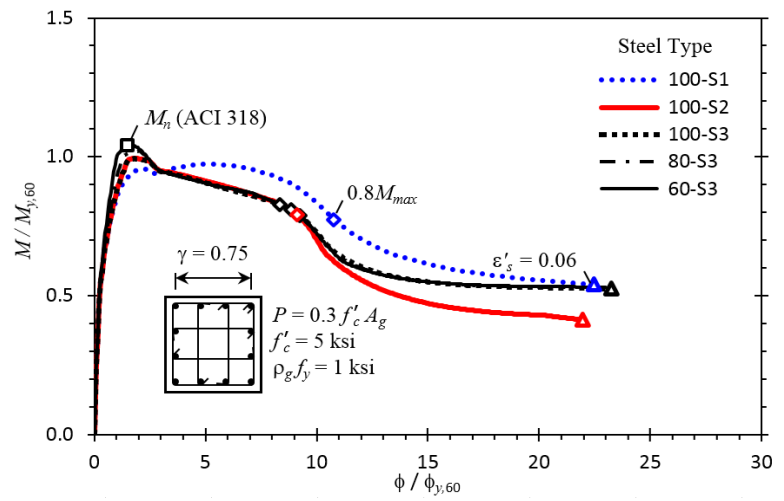

(a)

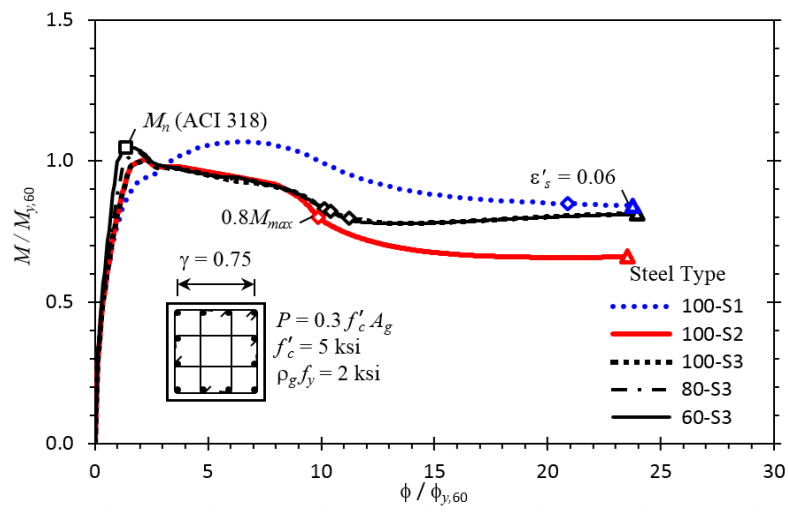

(c)

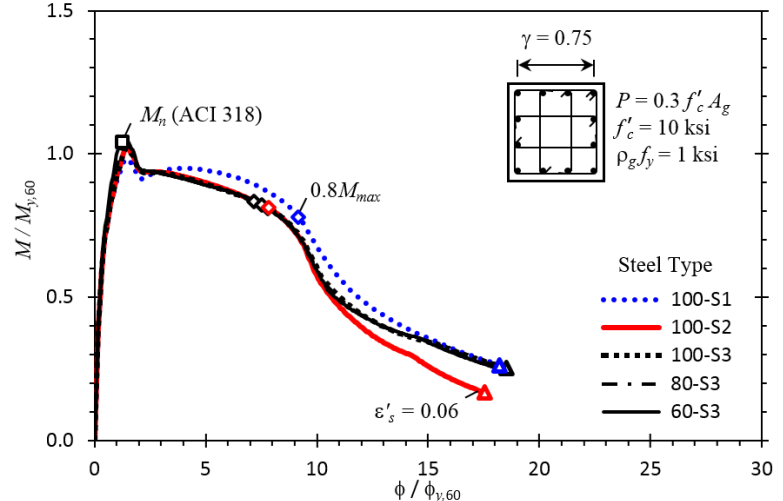

(b)

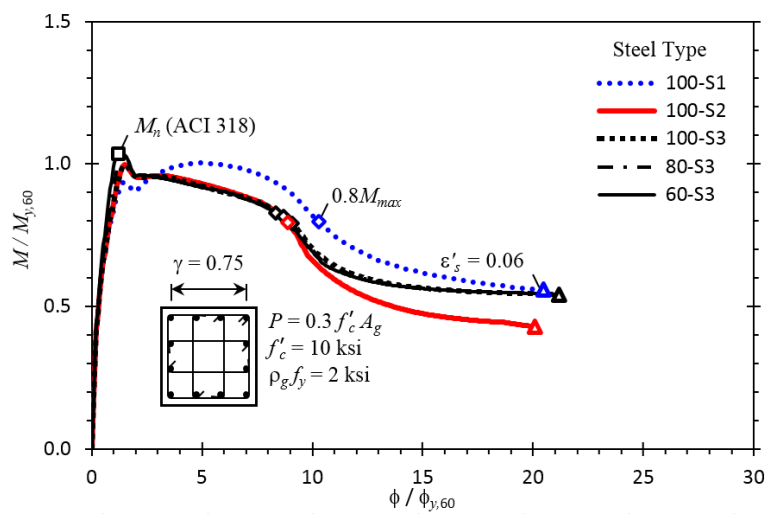

(d)

Figure A-7 Moment-curvature relationships for columns with different concrete compressive strengths and reinforcing steel ratios, with an axial load of $P=0.3 f_{c}^{\prime} A_{g}$ : (a) $f_{c}^{\prime}=5 \mathrm{ksi}$ and $\rho_{g} f_{y}=1 \mathrm{ksi}$; (b) $f_{c}^{\prime}=10 \mathrm{ksi}$ and $\rho_{g} f_{y}=1 \mathrm{ksi}$; (c) $f_{c}^{\prime}=5 \mathrm{ksi}$ and $\rho_{g} f_{y}=2 \mathrm{ksi}$; and (d) $f_{c}^{\prime}=10 \mathrm{ksi}$ and $\rho_{g} f_{y}=2$ ksi.

limited to 0.003 . The plotted data show that the computed value of $M_{n}$ is within $10 \%$ of the maximum moment determined for all reinforcing steel grades.

Other points of interest in Figures A-6 and A-7 include the identification of the limiting curvatures controlled by either: (1) the reinforcing steel reaching the maximum usable strain of 0.06 ( $\varepsilon_{s u}$ in Table A-1); or (2) the moment capacity reduction to less than $80 \%$ of the maximum moment, $M_{\max }$, at larger curvature ductilities. The plotted data show that the limiting curvature associated with a maximum usable compressive strain, $\varepsilon_{s}{ }^{\prime}$, of 0.06 was comparable for all of the reinforcing steel types considered. When curvature is controlled by limiting moment capacity to $0.8 M_{\max }$, column sections reinforced with steel type 100-S1 consistently reached greater curvatures than those reinforced with steel type 100-S2 and 60-S3.

\section{A.2.4 Moment-Curvature Relationships for Walls}

Moment-curvature relationships are provided below for the rectangular wall section shown in Figure A-8. Two levels of axial load are considered, $P=0.05 f_{c}^{\prime} A_{g}$ and 


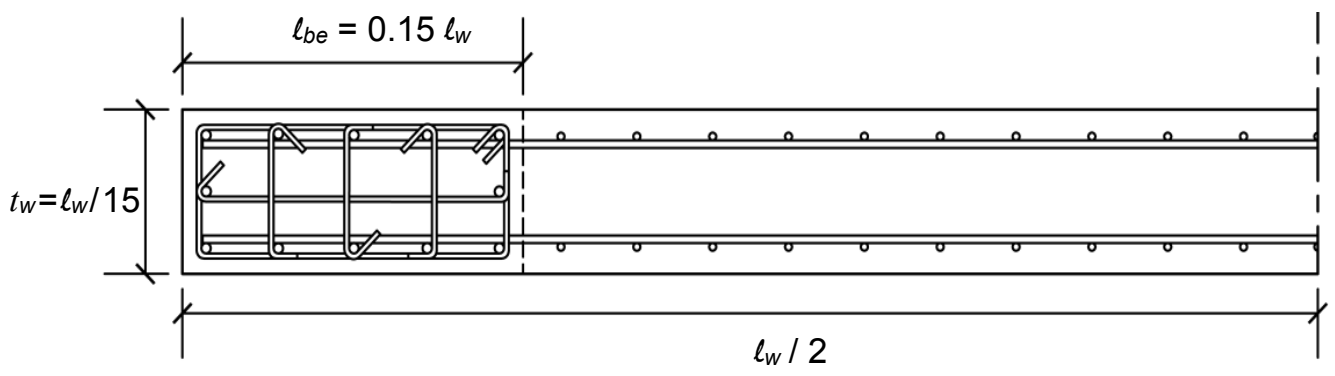

Figure A-8 Typical wall section used for moment-curvature study.

$P=0.1 f^{\prime} A_{g}$. For each level of axial load, two wall cases were analyzed, each corresponding to the two concrete compressive strengths described in Table A-2. Each case used the reinforcement types presented in Figure A-1. The wall sections were symmetrically reinforced, and the axial compressive loads were concentric on the wall sections. The confined concrete cores in the boundary elements extended to the outside of the transverse reinforcement, which had a concrete cover of 1.5 inches.

Each of the two cases in Figures A-9 and A-10 corresponds to wall sections with a constant value of $\rho_{b e} f_{y}$, where $\rho_{b e}=A_{s, b e} / t_{w} \ell_{b e}$ represents the reinforcing steel ratio in a wall boundary element of dimension $t_{w}$ by $\ell_{b e}$ (see Figure A-8); and $A_{s, b e}$ is the total area of longitudinal reinforcement in a boundary element. The reinforcing steel ratios in the webs of the walls (wall section excluding the boundary elements) was equal to $\rho_{b e} / 5$. The selected value of $\rho_{b e} f_{y}=1.5 \mathrm{ksi}$, corresponds to a $\rho_{b e}=2.5 \%(0.025)$ for Grade 60 reinforcement in each of the wall boundary elements.

The curves of Figures A-9 and A-10 identify points associated with the calculated flexural strength, $M_{n}$, for walls reinforced with Grade 60 reinforcement. The value of $M_{n}$ was calculated in accordance with Chapter 10 of ACI 318-11, where the maximum stress in the reinforcing steel is limited to its yield strength, and the maximum strain in the compressed concrete is limited to 0.003 . The plotted data show that the computed value of $M_{n}$ is consistently below the maximum moment calculated for the different reinforcing steel types. This indicates that the flexural strength per ACI 318-11 is conservative for all of the reinforcing steel types considered.

The maximum curvature values in Figures A- 9 and A-10 were controlled by two very different conditions. In Figure A-9, the maximum curvature was limited by the maximum usable strain $\left(\varepsilon_{s u}=0.06\right.$, see Table A-1) of the tension reinforcement, whereas in Figure A-10, the maximum curvature was controlled by the maximum compressive strength of the boundary element. The " $x$ " markers in Figure A-10 identify the onset of a severe loss of flexural strength from the inability of the confined boundary elements to continue resisting the compression force required to satisfy axial force equilibrium. The case of greater axial load on the wall of Figure A-10 may also be viewed as representative of a wall segment acting as the stem of a 


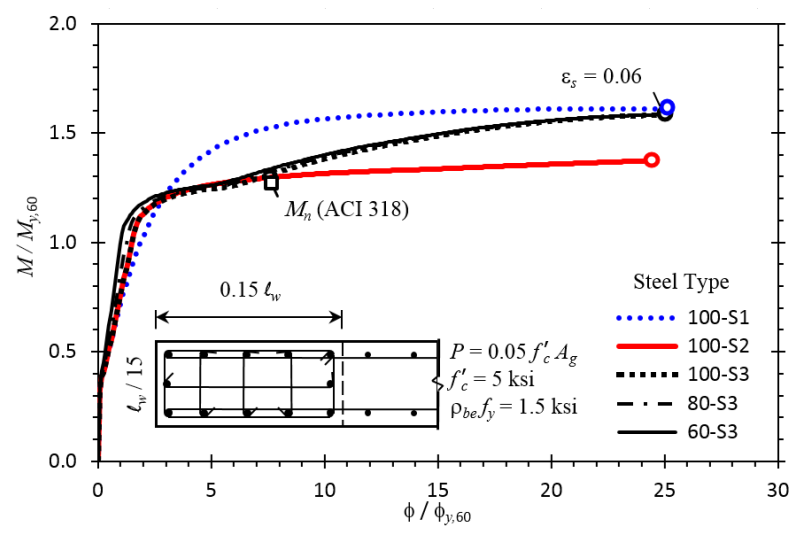

(a)

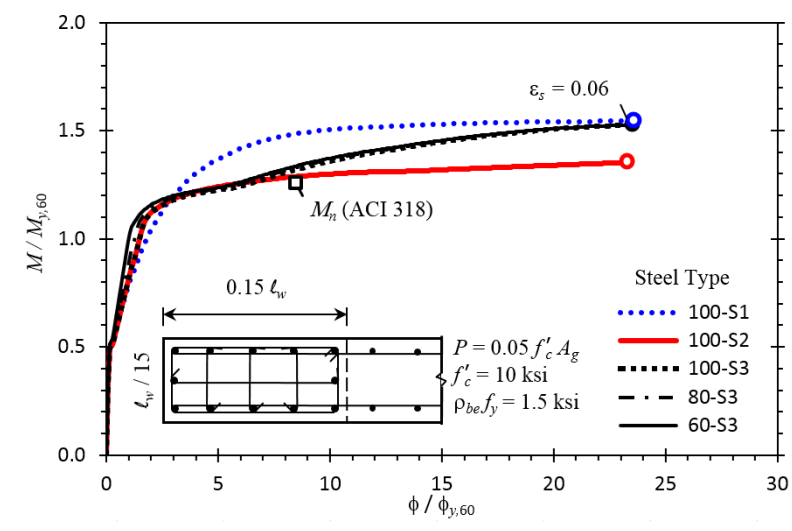

(b)

Figure A-9 Moment-curvature relationships for walls with different concrete compressive strengths, with an axial load of $P=0.05 f_{c}^{\prime} A_{g}$ : (a) $f_{c}^{\prime}=5 \mathrm{ksi}$ and $\rho_{b e} f_{y}=1.5 \mathrm{ksi}$; and (b) $f_{c}^{\prime}=10 \mathrm{ksi}$ and $\rho_{b e} f_{y}=1.5 \mathrm{ksi}$.

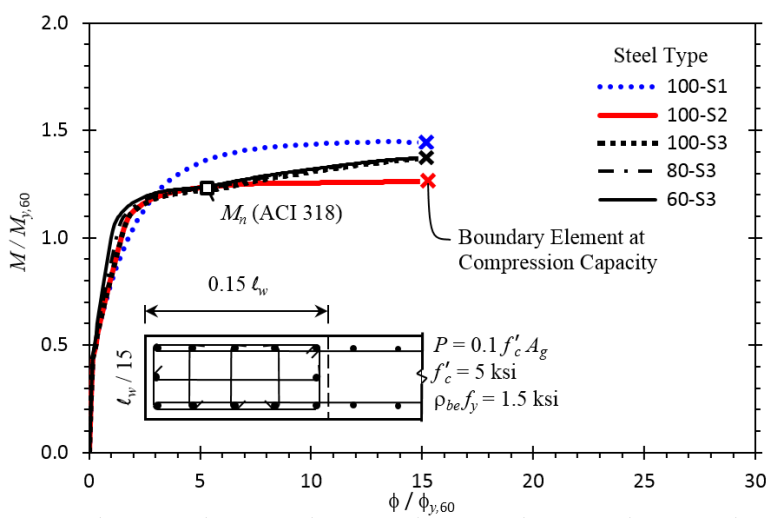

(a)

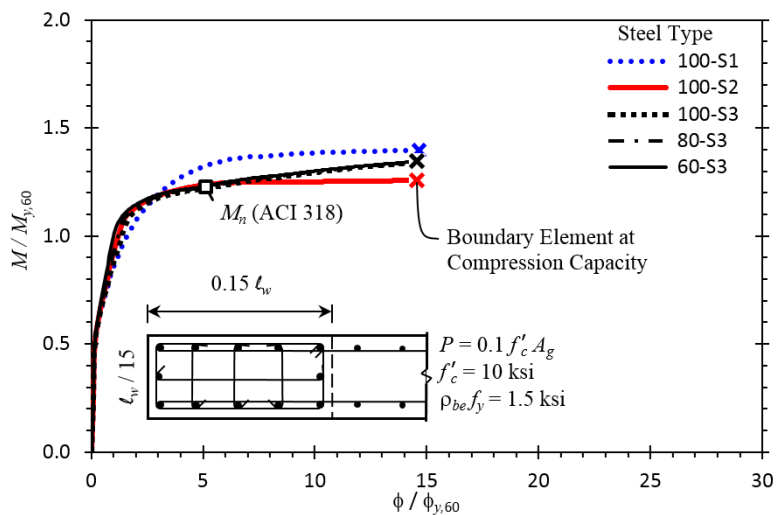

(b)

Figure A-10 Moment-curvature relationships for walls with different concrete compressive strengths, with an axial load of $P=0.1 f_{c}^{\prime} A_{g}$ : (a) $f_{c}^{\prime}=5 \mathrm{ksi}$ and $\rho_{b e} f_{y}=1.5 \mathrm{ksi}$; and (b) $f_{c}^{\prime}=10 \mathrm{ksi}$ and $\rho_{b e} f_{y}=1.5 \mathrm{ksi}$.

T-shaped wall, where compression in the stem rather than tension in the flange could lead to a controlling condition defining the limiting curvature. Figures A-9 and A-10 indicate that the moment-curvature relationships are nearly insensitive to the two types of concrete (normal-strength and high-strength) despite being characterized by very different stress-strain curves.

\section{A.3 Calculation of Flexural Deformation Capacities}

\section{A.3.1 Assumptions}

To evaluate the flexural deformation capacity of reinforced concrete members (beams, columns, and walls), a general simplified procedure was used, based on the plastic hinge model illustrated in Figure A-11. Elastic and plastic curvatures were 


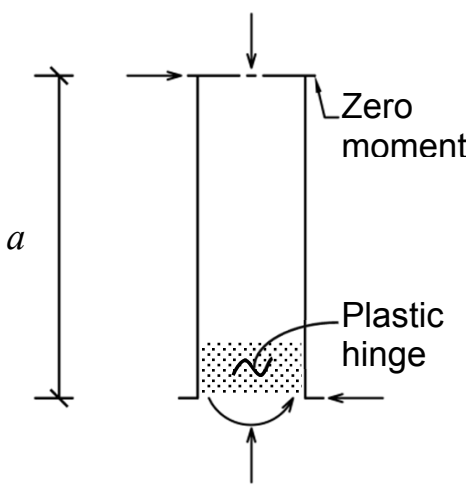

(a)

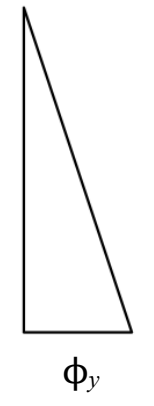

(b)

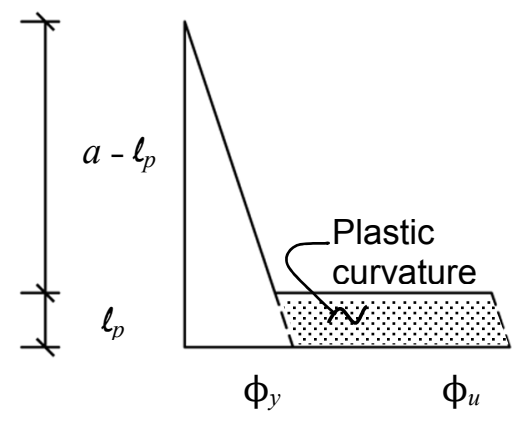

(c)

Figure A-11 Idealized curvature distributions for the plastic hinge model: (a) beam, column, or wall; (b) curvature at yield; (c) curvature at ultimate ductility.

considered the only source of deformation. The model relies on the calculated monotonic flexural response (moment vs. curvature) of member cross-sections. It was assumed that the members were not critically affected by problems related to shear and bond.

Although the plastic hinge model is not a perfect representation of reinforced concrete behavior, it has been used elsewhere (Park and Paulay, 1975; Priestley and Park, 1987; Moehle, 1992) to form the basis of simplified design procedures for earthquake-resistant structures. It was incorporated into the U. S. building code (the 1994 Uniform Building Code, ICBO, 1994) for determining the required extent of confined boundary elements in reinforced concrete walls resisting seismic forces. Though the plastic hinge model is imperfect, comparisons between measured and calculated deformation capacities have indicated that there is a correlation between the model and experimental data (Moehle, 1992).

For the beam, column, or wall segment represented in Figure A-11a, the plastic hinge model is used to determine the transverse displacement at the inflection point located at a distance $a$ from the face of the support (also called shear span). Figure A-11b gives the curvature distribution assuming a triangular moment diagram, with maximum moments at the supports, and linear-elastic behavior up to first yield of the tension reinforcement. The displacement, $\Delta_{y}$, associated with the yield curvature, $\phi_{y}$, is provided by the following expression:

$$
\Delta_{y}=\phi_{y} a^{2} / 3
$$

The idealized yield curvature in Figure A-11 ignores the effects of gravity loads in beams and that of distributed story forces in multi-story walls. Axial load in columns and walls is assumed constant throughout the shear span, $a$. 
Loading a member beyond flexural yielding is assumed to induce plastic curvature over an equivalent plastic hinge length, $\ell_{p}$. The displacement, $\Delta_{p}$, associated with the plastic curvature is given by Equation A-3 as the moment of the plastic curvature about the inflection point in Figure A-11c:

$$
\Delta_{p}=\left(\phi_{u}-\phi_{y}\right) \ell_{p}\left(a-\frac{\ell_{p}}{2}\right)
$$

where $\phi_{u}$ is the maximum curvature reached at the support. A variety of different expressions have been proposed for $\ell_{p}$, primarily as a function of the shear span ratio, ald (Park and Paulay, 1975; Priestley and Park, 1987). For values of $a / d$ between 2 and 5 , the values of $\ell_{p}$ vary between $0.4 d$ and $0.8 d$. The simple form, $\ell_{p}=0.5 d$, is adopted here, where $d$ is taken as the depth of the cross-section measured to the extreme layer of the longitudinal tension reinforcement. Variations in plastic hinge lengths due to differences in the shapes of stress-strain curves were not considered, but may exist.

Based on the displacements associated with the elastic and plastic curvatures, the total deformation capacity may be expressed in terms of rotation capacity, $\theta_{\text {cap }}$, using the following equation:

$$
\theta_{\text {cap }}=\theta_{y}+\theta_{p}=\left(\Delta_{y}+\Delta_{p}\right) / a
$$

The plastic hinge model described above considers only components of deformations due to flexure. It ignores deformations due to the following: (1) shear distortion along the shear span; (2) slip of the tensile reinforcement at the face of the support; and (3) joint flexibility or rotation of the support. Therefore, in most cases, it may be considered as a lower-bound estimate of the deformation capacity of reinforced concrete members.

The following sections examine the deformation capacities of beams, columns, and walls by means of Equation A-4, with the values of $\phi_{y}$ and $\phi_{u}$ obtained from the moment-curvature relationships presented in Section A.2. The value of $\phi_{y}$ was taken as the curvature where the extreme layer of the longitudinal tension reinforcement reaches the yield strain. The value of $\phi_{u}$ was defined by the lesser curvature for the following two modes of behavior: (1) the reinforcing steel reaches the usable strain ( $\varepsilon_{s u}$ in Table A-1); or (2) the moment carrying capacity reduces to less than $80 \%$ of the maximum capacity. The calculated moment-curvature relationships presented in Section A.2 have identified the controlling event.

\section{A.3.2 Deformation Capacity of Beams}

The calculated deformation capacity of beams, based on Equation A-4, is shown in Figure A-12. The four cases, (a) to (d), coincide with the cases for which moment- 


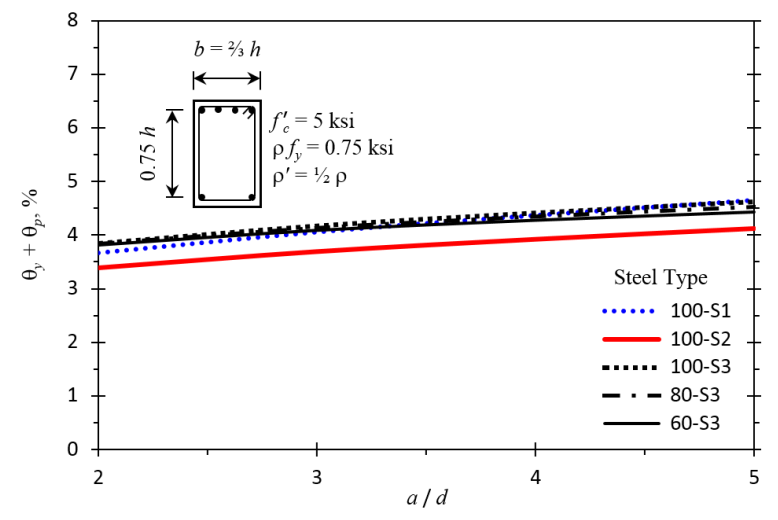

(a)

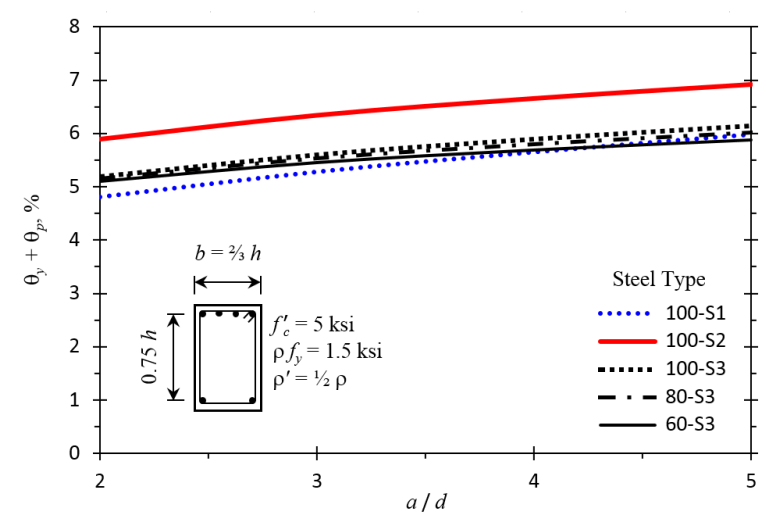

(c)

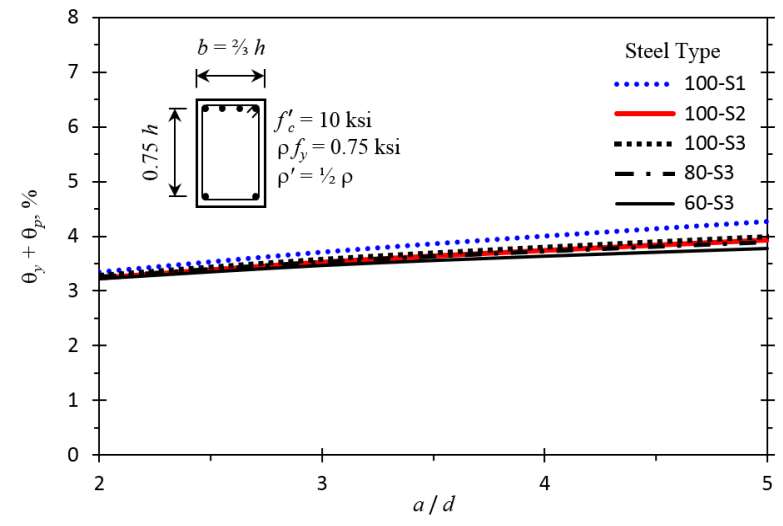

(b)

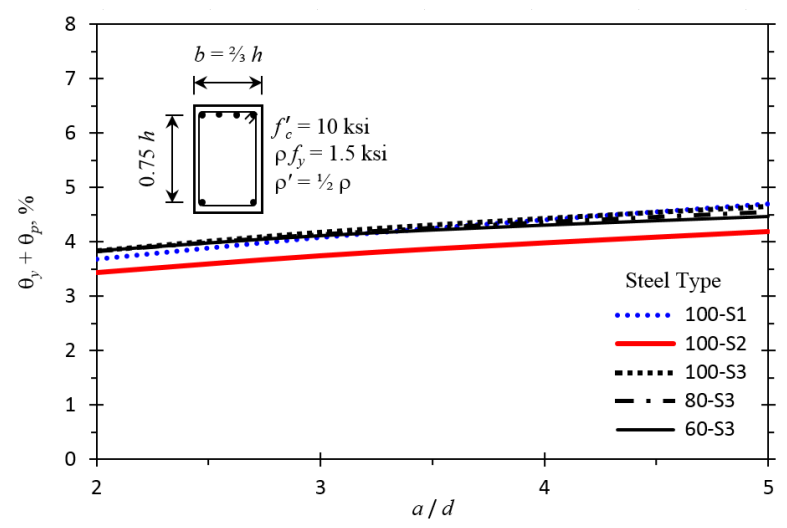

(d)

Figure A-12 Flexural deformation capacities of beams: (a) $f_{c}^{\prime}=5 \mathrm{ksi}$ and $\rho f_{y}=0.75 \mathrm{ksi}$; (b) $f_{c}^{\prime}=10 \mathrm{ksi}$ and $\rho f_{y}=0.75 \mathrm{ksi}$; (c) $f_{c}^{\prime}=5 \mathrm{ksi}$ and $\rho f_{y}=1.5 \mathrm{ksi}$; and $(\mathrm{d}) f_{c}^{\prime}=10 \mathrm{ksi}$ and $\rho f_{y}=1.5 \mathrm{ksi}$.

curvature analyses were performed in Section A.2.2. Figures A-4 and A-12 show Case (a) and Case (d) with nearly identical results, because both cases correspond to identical relative steel strength $\rho f_{y}$ to concrete strength $f_{c}^{\prime}$ ratios, leading to nearly identical curvatures $\phi_{y}$ and $\phi_{u}$. Both of these curvatures define Equations A-2 and A-3 for use in Equation A-4.

In general, the curves of Figure A-12 show a small spread in the deformation capacity of Case (a), Case (b), and Case (d), indicating a very small sensitivity to the variables considered ( $a / d, \rho f_{y}, f_{c}^{\prime}$, and reinforcing steel type). The greater value of $\rho f_{y}$, combined with the use of normal-strength concrete (Case (c)), led to greater deformation capacities because the limiting reinforcing steel strain was reached at larger curvatures (see Figure A-4c) as the controlling mode of behavior changed from the tension side in Case (a), Case (b), and Case (d), to the compression side in Case (c).

The greater deformation capacity achieved by the beams reinforced with steel type 100 -S2, in Figure A-12c, is driven by the reduced ultimate stress $f_{u}$ to yield stress $f_{y}$ 
ratio (see Table A-1), which causes lower tensile stresses that require smaller neutral axis depths, which in turn causes an increased value of maximum curvature $\phi_{u}$.

The values of $\phi_{u}$ in all beam cases were controlled by the usable reinforcing steel strain of 0.06 . Assuming that the calculated deformation capacity represents a lowerbound measure of actual capacity, concrete beams reinforced with the types of highstrength reinforcing steel described in Figure A-1 are expected to achieve a drift capacity in excess of $3 \%$.

\section{A.3.3 Deformation Capacity of Columns}

The calculated deformation capacity of columns, based on Equation A-4, is shown in Figure A-13 and A-14 for axial loads of $P=0.2 f_{c}^{\prime} A_{g}$ and $P=0.3 f_{c}^{\prime} A_{g}$. Each figure includes four cases, (a) to (d), that coincide with the cases for which momentcurvature analyses were performed in Section A.2.3. Figures A-6 and A-13 show Case (a) and Case (d) with nearly identical results because both cases correspond to identical relative steel strength $\rho f_{y}$ to concrete strength $f_{c}^{\prime}$ ratios, leading to very similar curvatures $\phi_{y}$ and $\phi_{u}$. Both cases define Equations A-2 and A-3 for use in Equation A-4. Similar observations apply to Figures A-7 and A-14 for Cases (a) and (d).

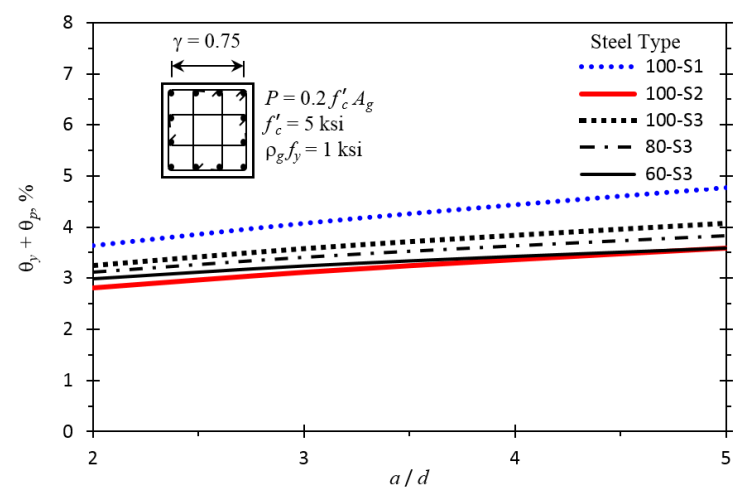

(a)

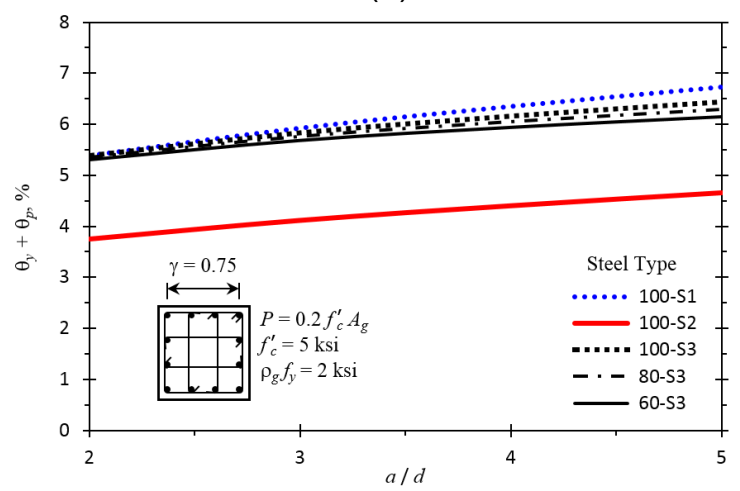

(c)

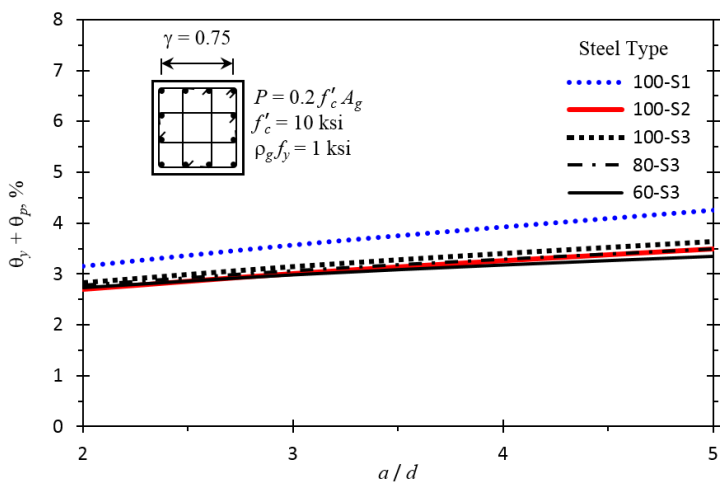

(b)

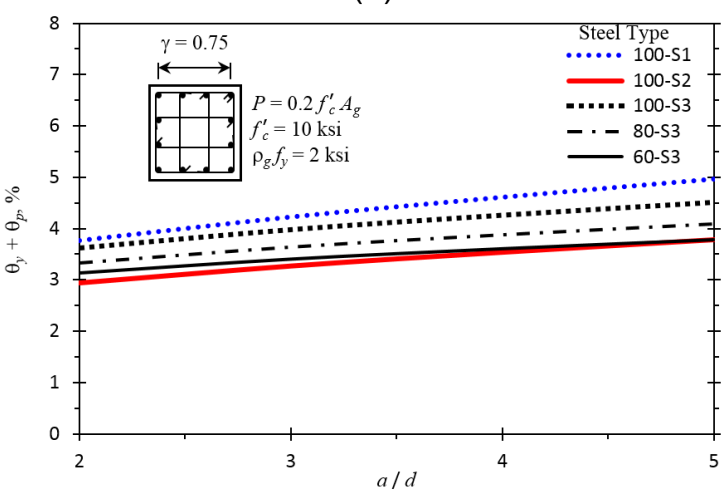

(d)

Figure A-13 Flexural deformation capacities of columns with an axial load of $P=0.2 f_{c}^{\prime} A_{g}:(a) f_{c}^{\prime}=5$ ksi and $\rho_{g} f_{y}=1 \mathrm{ksi}$; (b) $f_{c}^{\prime}=10 \mathrm{ksi}$ and $\rho_{g} f_{y}=1 \mathrm{ksi}$; (c) $f_{c}^{\prime}=5 \mathrm{ksi}$ and $\rho_{g} f_{y}=2 \mathrm{ksi}$; and (d) $f_{c}^{\prime}$ $=10 \mathrm{ksi}$ and $\rho_{g} f_{y}=2 \mathrm{ksi}$. 


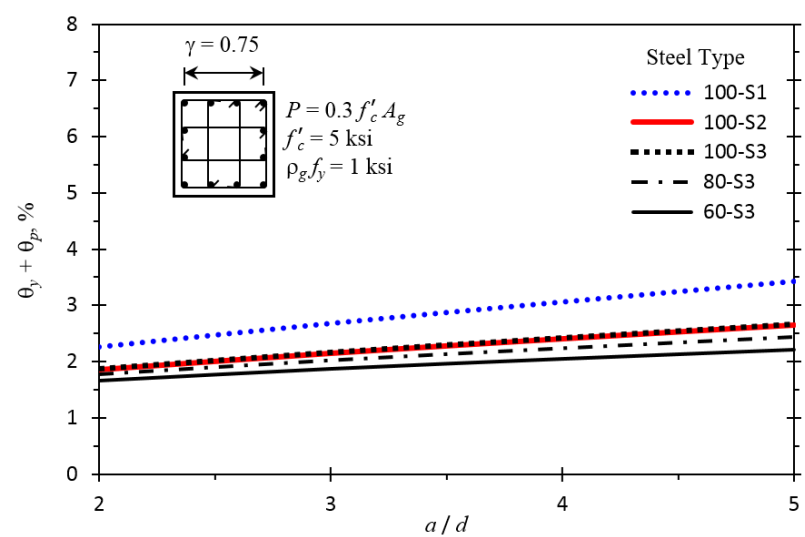

(a)

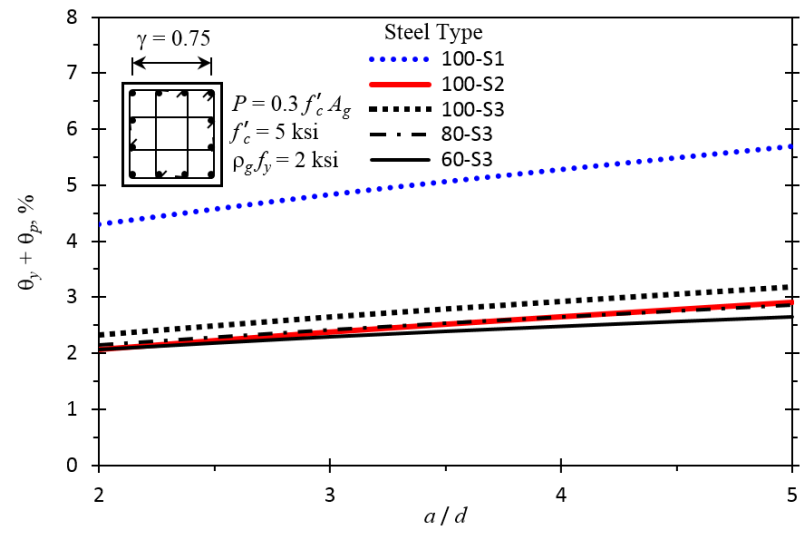

(c)

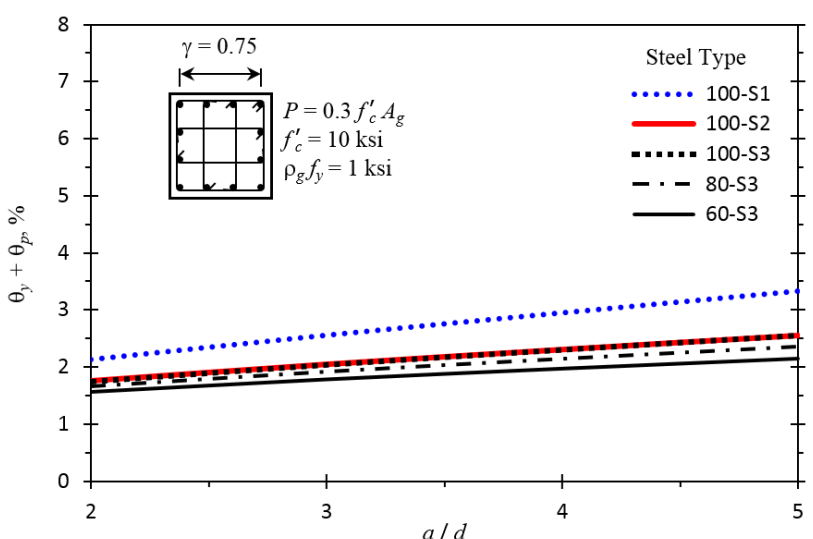

(b)

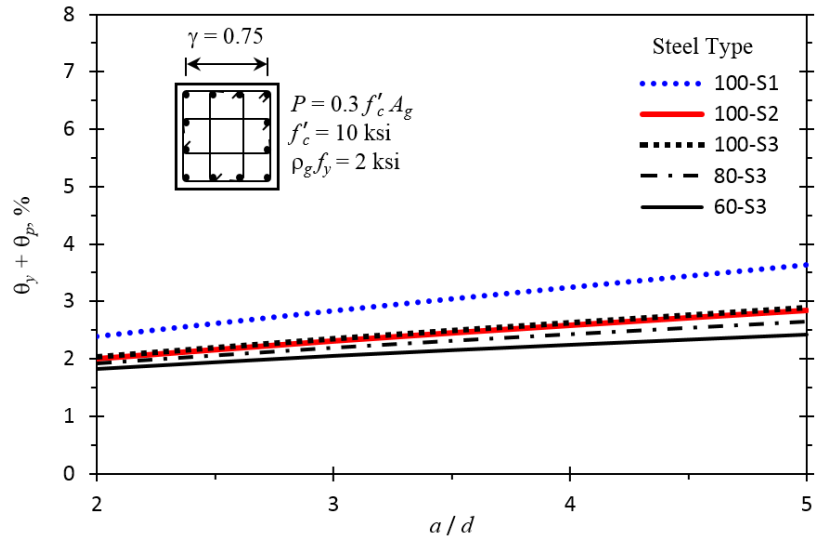

(d)

Figure A-14 Flexural deformation capacities of columns with axial load of $P=0.3 f_{c}^{\prime} A_{g}$ : (a) $f_{c}^{\prime}=5 \mathrm{ksi}$ and $\rho_{g} f_{y}=1 \mathrm{ksi}$; (b) $f_{c}^{\prime}=10 \mathrm{ksi}$ and $\rho_{g} f_{y}=1 \mathrm{ksi}$; (c) $f_{c}^{\prime}=5 \mathrm{ksi}$ and $\rho_{g} f_{y}=2 \mathrm{ksi}$; and (d) $f_{c}^{\prime}=10 \mathrm{ksi}$ and $\rho_{g} f_{y}=2 \mathrm{ksi}$.

In general, the curves of Figure A-13 and A-14 show a small spread in the deformation capacity of Case (a), Case (b), and Case (d), indicating a very small sensitivity to the variables considered ( $a / d, \rho_{g} f_{y}, f_{c}^{\prime}$, and reinforcing steel type). The greater the value of $\rho_{g} f_{y}$, combined with the use of normal-strength concrete (Case (c)), generally led to larger values of $\phi_{u}$ and, therefore, deformation capacity; the increased participation of reinforcing steel in resisting the compression forces reduced softening of the confined concrete.

The column cases in Figures A-13 and A-14, which lead to a deformation capacity below $3 \%$, had calculated values of $\phi_{u}$ controlled by a reduction in the moment carrying capacity $\left(0.8 M_{\max }\right)$. For these cases, the columns with reinforcing type 60-S3 were generally the ones with lower drift capacities. This observation suggests that columns reinforced with the types of high-strength reinforcing steel, Grade 80 and Grade 100 in Figure A-1, did not lead to a reduction in deformation capacity when compared to columns with Grade 60 reinforcement. 


\section{A.3.4 Deformation Capacity of Walls}

The calculated deformation capacity of walls, based on Equation A-4, is shown in Figure A-15 for an axial load of $P=0.05 f_{c}^{\prime} A_{g}$ and in Figure A-16 for $P=0.1 f_{c}^{\prime} A_{g}$. Each figure includes two cases, (a) and (b), that coincide with the cases for which moment-curvature analyses were performed in Section A.2.4. Moment-curvature relationships in Figures A-9 and A-10 and deformation capacities in Figures A-15 and A-16 show Case (a) and Case (b) with nearly identical results, indicating a very small sensitivity to the variables considered ( $a / d, \rho_{b e} f_{y}, f_{c}^{\prime}$, and reinforcing steel type). The limiting curvature $\phi_{u}$ in Figures A-9 and A-10 was sensitive to the axial load, where an increase from $P=0.05 f^{\prime} A_{g}$ to $P=0.1 f_{c}^{\prime} A_{g}$ changed the controlling mode of behavior that defined $\phi_{u}$.

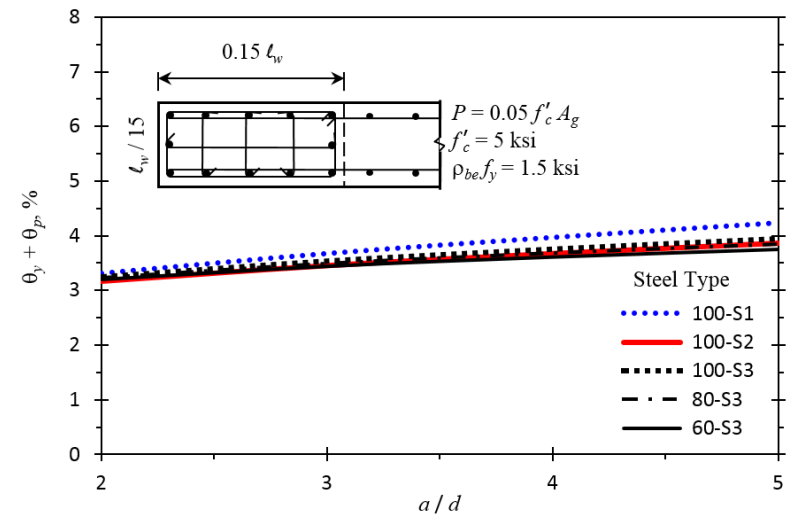

(a)

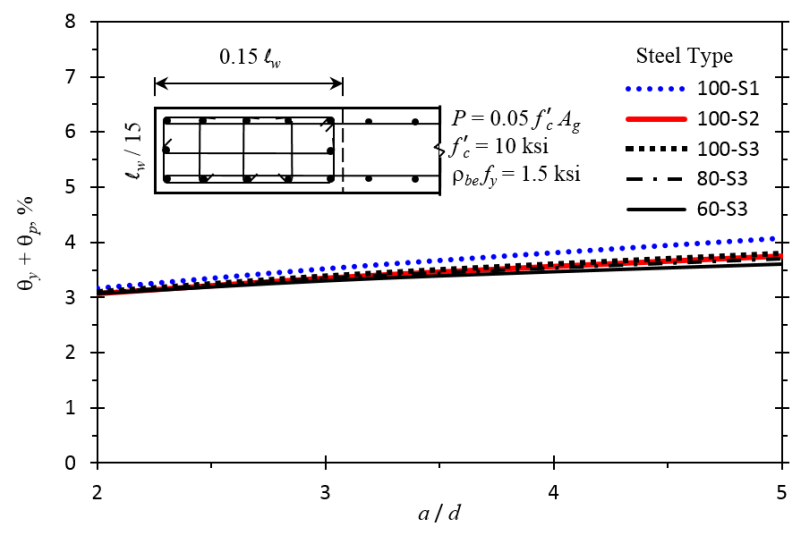

(b)

Figure A-15 Flexural deformation capacities of walls with axial load of $P=0.05 f_{c}^{\prime} A_{g}$ : (a) $f_{c}^{\prime}=5 \mathrm{ksi}$ and $\rho_{b e} f_{y}=1.5 \mathrm{ksi} ;$ and $(\mathrm{b}) f_{c}^{\prime}=10 \mathrm{ksi}$ and $\rho_{b e} f_{y}=1.5 \mathrm{ksi}$.

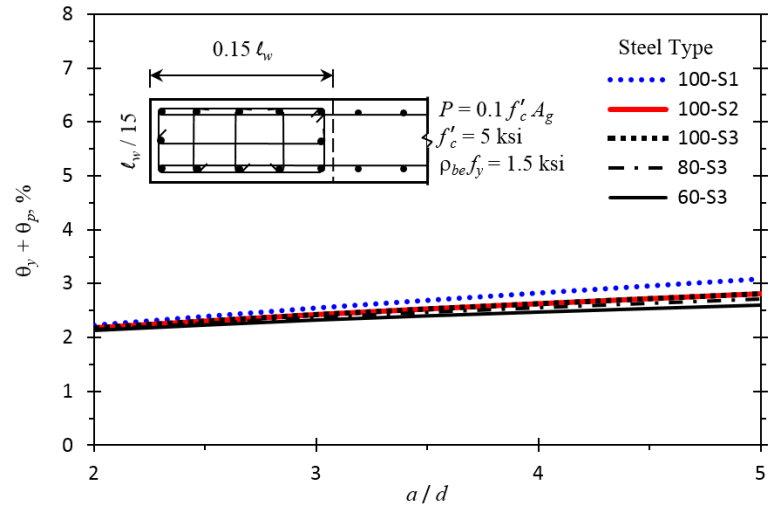

(a)

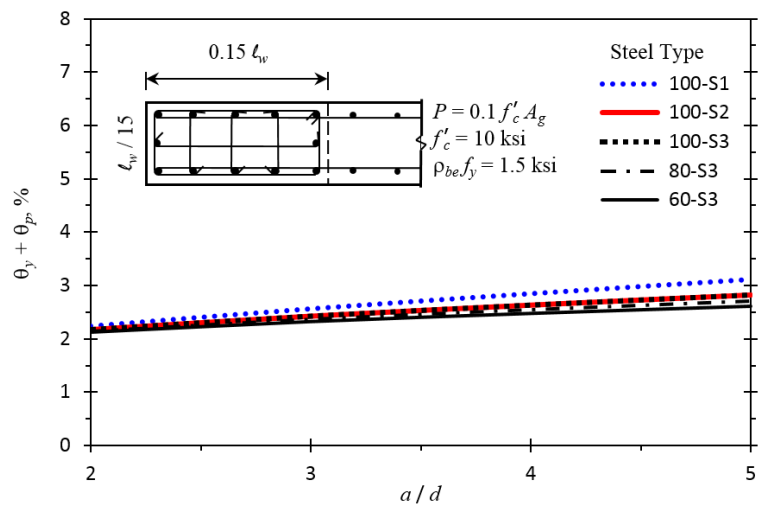

(b)

Figure A-16 Flexural deformation capacities of walls with axial load of $P=0.1 f_{c}^{\prime} A_{g}$ : (a) $f_{c}^{\prime}=5 \mathrm{ksi}$ and $\rho_{b e} f_{y}=1.5 \mathrm{ksi}$; and (b) $f_{c}^{\prime}=10 \mathrm{ksi}$ and $\rho_{b e} f_{y}=1.5 \mathrm{ksi}$.

For cases of walls in Figure A-9 with values of $\phi_{u}$ controlled by strain in the tensile reinforcement, $\varepsilon_{s}=0.06$, the calculated deformation capacities exceeded $3 \%$ (Figure A15). The cases of walls in Figure A-10 leading to deformation capacities below 3\% 
(Figure A-16) are associated with values of $\phi_{u}$ controlled by the compression capacity of the confined boundary element.

The above observations suggest that walls reinforced with the types of high-strength reinforcing steel, Grade 80 and Grade 100 in Figure A-1, did not have a critical reduction in deformation capacity compared to walls with Grade 60 reinforcement.

\section{A.4 Concluding Remarks}

Assuming that the calculated flexural strengths and deformation characteristics of reinforced concrete members (beams, columns, and walls) presented in the previous sections are an accurate measure of actual capacity, the following general observations can be made:

- In reinforced concrete members with axial loads at or below $P$ equal to $0.3 f_{c}^{\prime} A_{g}$, replacing conventional Grade 60 longitudinal reinforcement with reduced amounts of Grade 80 or Grade 100 reinforcement (reduced in proportion to the yield strength, i.e., constant $\rho f_{y}$ ) provides for similar flexural strengths.

- The limiting curvature in reinforced concrete beams and walls with $P$ equal to $0.05 f^{\prime} A_{g}$ was controlled by the assumed reinforcing steel strain limit of 0.06 , which led to rotation capacities consistently in excess of $3 \%$, regardless of the grade of reinforcing steel (Grade 60, Grade 80, or Grade 100). Thus, requiring a minimum usable strain (elongation) of 0.06 was sufficient for attaining a threshold drift of $3 \%$.

- The limiting curvature in reinforced concrete columns with axial loads $P$ between $0.2 f_{c}^{\prime} A_{g}$ and $0.3 f_{c}^{\prime} A_{g}$ and walls with $P$ equal to $0.1 f^{\prime} A_{g}$ was predominantly controlled by a reduction of moment capacity to below $80 \%$ of the maximum moment; this led to rotation capacities consistently between $1.5 \%$ and $3 \%$. For these cases, members with Grade 60 reinforcement generally exhibited slightly lower rotation capacities than members reinforced with Grade 80 or Grade 100 reinforcement.

These observations are based on monotonic flexural response and are considered to apply to reinforced concrete members having the amounts of reinforcement similar to the sections analyzed herein and detailed in compliance with the seismic design provisions of ACI 318-11. It was assumed that the members were not critically affected by problems related to shear, bond, bar buckling, or slenderness effects. Also, the results assume that $0.5 d$ is an appropriate estimation of the plastic hinge length for beams, columns, and walls reinforced with bars that have the stress-strain curves considered in this appendix. 


\section{Appendix B}

\section{Study on Development and Splice Lengths}

Several researchers and groups provide recommendations for development and splice lengths of reinforcing bars: ACI (2011); ACI (2003); Canbay and Frosch (2005); CEB-FIP (1990); and Orangun et al. (1975). This chapter presents study results on the development length provisions in ACI 318-11 (ACI, 2011) and the recommendations in ACI 408R-03, Bond and Development of Straight Reinforcing Bars in Tension (ACI, 2003). In particular, this report seeks to evaluate how development and splice lengths might vary when applied to high-strength reinforcing bars. Because ACI 318-11 development and splice length requirements are based primarily on splice test results for conventional strength reinforcing bars (Orangun et al., 1977; Orangun et al., 1975), the adequacy of development and splice lengths for high-strength reinforcing bars should be confirmed.

\section{B.1 Available Methods}

\section{B.1.1 ACI 318-11 Methods}

ACI 318-11, Building Code Requirements for Structural Concrete and Commentary, offers two options for calculating the development length, $\ell_{d}$, of reinforcing bars with diameter, $d_{b}$, in tension. A table in ACI 318-11 Section 12.2.2 separates reinforcing bars by bar size and for confined and unconfined conditions, resulting in the equations for $\ell_{d}$ presented in Table B-1.

\section{Table B-1 ACI 318-11 Section 12.2.2 Calculation Methods for Development} Lengths

\begin{tabular}{llll}
\hline \multicolumn{1}{c}{ Spacing and cover } & No. 6 and smaller & No. 7 and larger \\
$\begin{array}{l}\text { Clear spacing } \geq d_{b} \text {, clear cover } \geq d_{b} \text {, and } \\
\text { stirups or ties throughout } \ell_{d} \text { not less than } \\
\text { the code minimum }\end{array}$ or \\
$\begin{array}{ll}\text { Clear spacing } \geq 2 d_{b} \text { and clear cover } \geq d_{b} \\
\text { Other cases }\end{array}$ & $\left(\frac{f_{y} \psi_{t} \psi_{e}}{25 \lambda \sqrt{f_{c}^{\prime}}}\right) d_{b}$ & $\left(\frac{f_{y} \psi_{t} \psi_{e}}{20 \lambda \sqrt{f_{c}^{\prime}}}\right) d_{b}$ \\
\hline
\end{tabular}


ACI 318-11 Section 12.2.3 presents an alternate equation (Equation 12-1), repeated below as Equation B-1, that takes confinement into account directly:

$$
\ell_{d}=\left[\frac{3}{40} \frac{f_{y}}{\lambda \sqrt{f_{c}^{\prime}}} \frac{\psi_{t} \psi_{e} \psi_{s}}{\left(\frac{c_{b}+K_{t r}}{d_{b}}\right)}\right] d_{b}
$$

where:

$$
\begin{aligned}
& \left(c_{b}+K_{t r}\right) / d_{b} \leq 2.5 \\
& K_{t r}=\text { transverse reinforcement index, } 40 A_{t r} /(s n), \\
& s \text { = spacing of transverse reinforcement, in inches, } \\
& n \text { = number of reinforcing bars being spliced or developed along the plane of } \\
& \text { splitting, } \\
& A_{t r}=\text { total cross-sectional area of transverse reinforcing bars within a spacing, } s \text {, } \\
& \text { that crosses the potential plane of splitting, inches }{ }^{2} \text {, and } \\
& c_{b}=\text { smaller of (a) distance from center of bar to nearest concrete edge and (b) } \\
& \text { one-half the center-to-center spacing between reinforcing bars, in inches. }
\end{aligned}
$$

For both options, ACI 318-11 Section 12.2.4 defines the following variables (only partially defined here):

$$
\begin{aligned}
f_{y}= & \text { specified yield strength of reinforcement, psi or ksi, } \\
d_{b}= & \text { diameter of reinforcing bar being developed or spliced, in inches, } \\
f_{c}^{\prime}= & \text { concrete compressive strength, psi, } \\
\psi_{t}= & \text { reinforcement location factor equal to } 1.3 \text { for horizontal reinforcing bars } \\
& \text { with more than } 12 \text { inches fresh cast concrete below the reinforcement, or } \\
& \text { otherwise equal to } 1.0, \\
\psi_{e}= & \text { factor of } 1.3 \text { to account for epoxy coated reinforcement, or equal to } 1.0 \text { for } \\
& \text { uncoated reinforcement, } \\
\psi_{s}= & \text { factor to account for the size of reinforcing bars, equal to } 0.8 \text { for No. } 6 \\
& \text { bars and smaller, or equal to } 1.0 \text { for No. } 7 \text { bars and larger, and } \\
\lambda= & \text { modification factor equal to } 1.4 \text { reflecting the reduced mechanical } \\
& \text { properties of lightweight concrete, or equal to } 1.0 \text { for normal-weight } \\
& \text { concrete. }
\end{aligned}
$$


ACI 318-11 Section 12.2.5 allows for a reduction in development length where excess reinforcement is provided. This does not apply to splice lengths.

ACI 318-11 Section 12.15 defines a Class A splice as a splice in which the area of reinforcement is at least twice that required by analysis and that less than (or equal) to half of the reinforcing bars are spliced at the same lap location. Class A splices for development lengths or lap lengths must be at least $\ell_{d}$ in length. Class B splices for development lengths or lap lengths must be at least 1.3 times $\ell_{d}$ in length, (i.e., $30 \%$ longer).

ACI 318-11 also requires that the minimum tension development length be greater than or equal to a minimum of 12 inches and that the value of $\sqrt{f_{c}^{\prime}}$ may not exceed 100 psi.

\section{B.1.2 ACl 408R-03 Method}

ACI 408R-03, Bond and Development of Straight Reinforcing Bars in Tension, proposes alternate development and splice length equations and compares the results of the 2002 Edition of ACI 318, and other available test data. In ACI 408R-03, $\phi$ factors, based on corresponding load factors, are included in the development length equations. Whereas in ACI 318-11 a $\phi$-factor of 0.9 is used for a dead load factor of 1.2 and a live load factor of 1.6, the ACI 408 Committee (and ACI 408R-03) recommends a more conservative $\phi$-factor of 0.82 . This results in ACI 408R-03 Equations 4-19 and 4-20, as repeated below:

For confined bars:

$$
\ell_{d}=\left(\frac{f_{y}}{93 f_{c}^{1 / 4}}-21\right) \psi_{t} \psi_{e} \lambda d_{b}
$$

For unconfined bars:

$$
\ell_{d}=\left(\frac{f_{y}}{62 f_{c}^{\prime / 4}}-31\right) \psi_{t} \psi_{e} \lambda d_{b}
$$

Confined reinforcing bars are defined as having: (1) a clear spacing and cover thickness not less than $d_{b}$ and with stirrups resulting in $K_{t r} / d_{b} \geq 0.5$; or (2) a clear spacing not less than $2 d_{b}$ and a cover thickness not less than $d_{b}$.

ACI 408R-03 also provides Equation 4-21, repeated below, as an alternative:

$$
\ell_{d}=\frac{\left(\frac{f_{y}}{f_{c}^{\prime / / 4}}-1970 \omega\right) \psi_{t} \psi_{e} \lambda d_{b}}{62\left(\frac{c \omega+K_{t r}}{d_{b}}\right)}
$$


where:

$$
\begin{aligned}
& c=c_{\min }+0.5 d_{b} \\
& \omega=0.1 \mathrm{c}_{\max } / c_{\min }+0.9 \leq 1.25 \text {, or } \omega \text { can be taken as } 1.0, \\
& K_{t r}=\left[0.5 t_{d} A_{t r} /(s n)\right] \sqrt{f_{c}^{\prime}} \text { for conventional deformed reinforcing bars; another } \\
& \text { formula is provided for high rib area reinforcing bars, } \\
& t_{d}=0.78 d_{b}+0.22 \text {, inches, a term representing the effect of bar size on the } \\
& \text { contribution of transverse reinforcement to bond strength, } \\
& \left(c \omega+K_{t r}\right) / d_{b} \leq 4.0, \\
& c_{b}=\text { bottom cover, in inches, } \\
& \left.c_{s}=\text { minimum of (side cover, } 1 / 2 \text { clear spacing }+0.25\right) \text {, } \\
& c_{\max }=\text { maximum of }\left(c_{b}, c_{s}\right), \\
& c_{\text {min }}=\text { minimum of }\left(c_{b}, c_{s}\right), \\
& f_{c}^{\prime 1 / 4} \leq 11.0 \\
& f_{y} \leq 80 \mathrm{ksi} .
\end{aligned}
$$

The upper limit of $80 \mathrm{ksi}$ on specified yield strength was included because of the lack of splice tests on reinforcing bars with strengths greater than $80 \mathrm{ksi}$. Research since 2003 indicates that the ACI 408 equation works for Grade 120 reinforcing bars (Seliem et al., 2009). The specified yield strength, $f_{y}$, is used without the $80 \mathrm{ksi}$ upper limit in the calculations presented in this appendix.

The $\psi_{e}$ factor is modified slightly relative to the factor in ACI $318-11$, but it is still 1.0 for uncoated reinforcing bars. Modification of the development length is allowed for excess reinforcement, as in ACI 318-11. Unlike ACI 318-11, however, ACI 408R-03 does not require a 1.3 factor on splice length for Class B lap splices, as ACI 318-11 does. ACI 408R-03 also does not include a modification factor based on bar size.

Note that the $\left(c \omega+K_{t r}\right) / d_{b}$ term has a higher limit than in the ACI 318 equation. This means that the ACI 408R-03 equation allows for larger reductions in development length for corresponding increases in bar confinement. 


\section{B.1.3. ACI ITG-6R-10 Method}

ACI ITG-6R-10, Design Guide for the Use of ASTM A1035/A1035M Grade 100 Steel Bars for Structural Concrete (ACI, 2010a), includes a short discussion of development and lap splice lengths. It recommends using ACI 318 provisions for confined conditions only. Alternately, it recommends using a modified ACI 408R-03 equation, repeated below, with a revised $\phi$-factor of 0.80 (instead of 0.82 ) for both confined and unconfined conditions. This results in Equation B-5:

$$
\ell_{d}=\frac{\left(\frac{f_{y}}{f_{c}^{1 / 4}}-1920 \omega\right) \psi_{t} \psi_{e} \lambda d_{b}}{61\left(\frac{c \omega+K_{t r}}{d_{b}}\right)}
$$

All variables are defined in accordance with ACI 408R-03. Because this equation is nearly identical to the ACI 408R-03 equation, results are not presented below.

\section{B.2 Assumptions of the Study}

A study was conducted to evaluate ACI 318-11 Equation 12-1 (B-1) and ACI 408R-03 Equation 4-21 (B-4) for reinforcing bars sizes from No. 4 to No. 11. The following assumptions were maintained throughout the study:

- $\lambda=1.0$, for normal weight concrete.

- $\psi_{e}=1.0$, for uncoated reinforcing bars.

- $\psi_{t}=1.0$, for reinforcing bars with less than 12 inches of fresh concrete cast below the reinforcement.

- Transverse reinforcing bars: No. 3 with No. 5 longitudinal reinforcing bars or smaller, and No. 4 with larger longitudinal reinforcing bar sizes.

- Four transverse reinforcing bar legs (2 closed tie sets at a spacing $s$, where 4 transverse bars (legs) cross all shear planes) provided at typical cross sections.

- Four reinforcing bars developed or spliced at each location for columns and beams (not applicable for walls).

- All splices computed in accordance with ACI 318-11 and Class B splices, i.e., equal to 1.3 times the development length, $\ell_{d}$.

The following three confinement situations (or conditions) were evaluated:

1. Unconfined wall splices. No transverse reinforcing bars were provided. A cover thickness of 1.5 inches was provided from the face of a wall, and 8 inches of clear spacing were provided between bars. A large "end" cover was provided at the ends of the wall (this is the equivalent to a side cover for a beam), which does not affect ACI 318-11 development lengths, but results in a maximum $\omega$ in 
the ACI 408R-03 equation. Note that although these reinforcing bars are referred to as "unconfined" because there were no transverse reinforcing bars crossing potential splitting cracks, this definition of unconfined is not the same as the definition used to distinguish between the use of Equations B-2 and B-3 in ACI 408R-03, which would consider this situation as confined because the clear spacing is greater than $2 d_{b}$ and the cover of 1.5 inches is greater than $d_{b}$.

2. Confined column splices. Transverse reinforcing bars were spaced at a maximum of 6 inches on center. A clear cover of 1.5 inches to sides and bottom of transverse reinforcing bars was provided, with a 1 -inch minimum clear spacing for No. 6 reinforcing bars and smaller, and a 2-inch minimum clear spacing for larger reinforcing bars. The 6-inch spacing for transverse reinforcement was chosen based on Section 21.6.3.3 of ACI 318-11. This spacing is greater than the maximum spacing required for No. 7 and smaller reinforcing bars, but it is appropriate for No. 8 and larger reinforcing bars, which are more commonly used for column reinforcement that are part of typical special moment frames.

3. Highly confined beam splices. Transverse reinforcing bars were spaced at a maximum of 4 -inch centers. A clear cover of 1.5 inches to sides and bottom of the transverse reinforcing bars was provided, with a 1-inch minimum clear spacing for No. 6 longitudinal reinforcing bars and smaller, and a 2-inch minimum clear spacing for larger longitudinal reinforcing bars.

Some sample sketches of these confinement details are shown in Figure B-1.
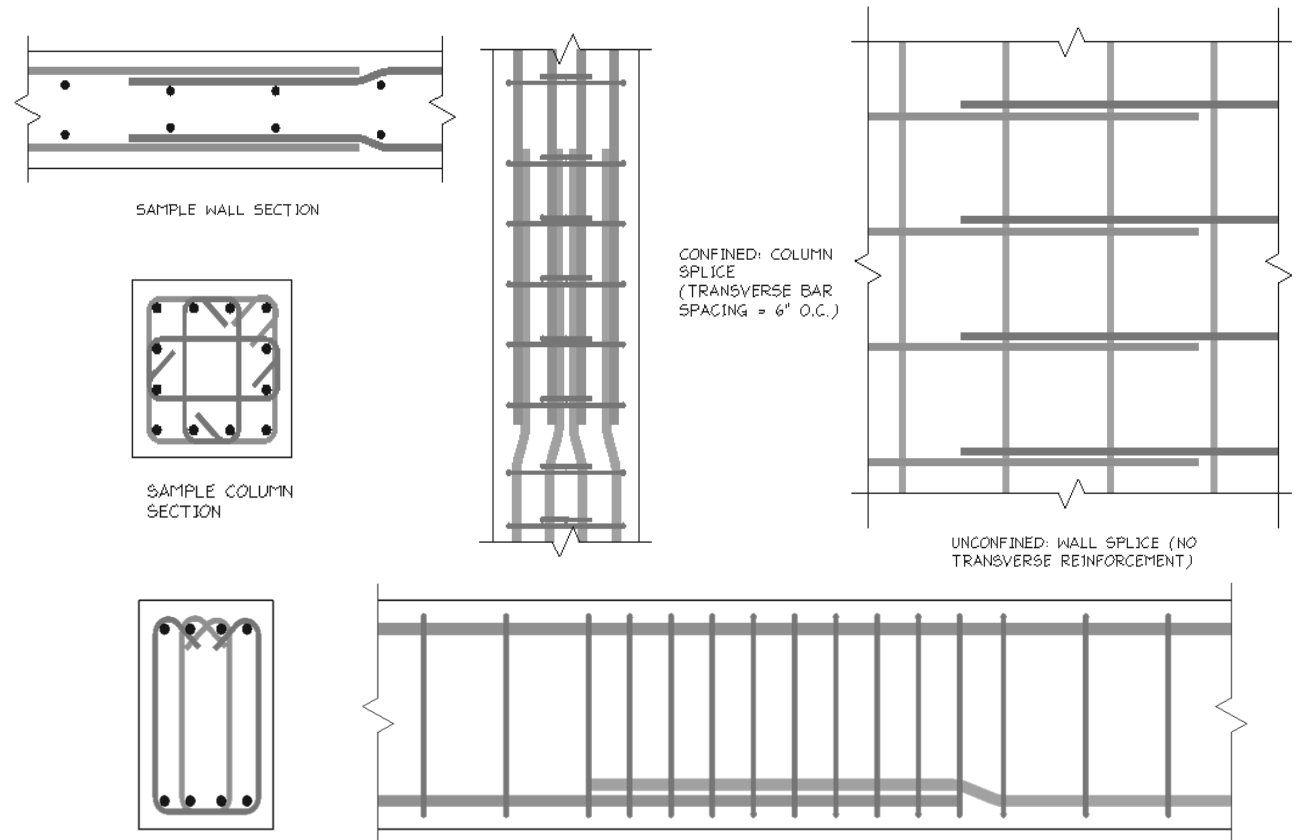
SAMPLE BEAM
SECTION

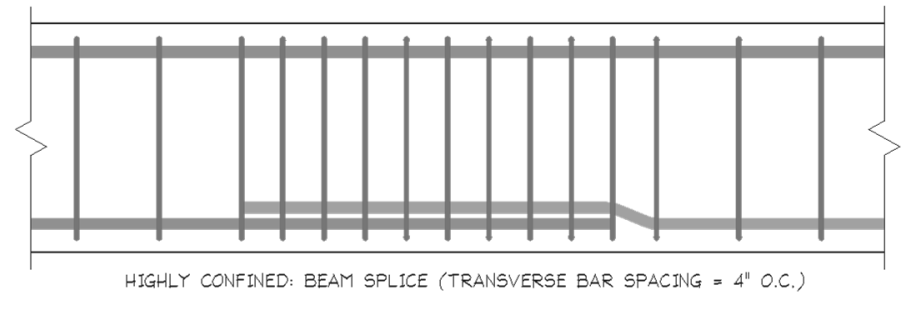

Figure B-1 Confinement scenarios used in development and splice length study. 


\section{B.3 Study Results}

Figures B-2 through B-5 compare the splice lengths calculated by ACI 318-11 Equation 12-1 (B-1) and ACI 408R-03 Equation 4-21 (B-4) for concrete strengths, $f_{c}^{\prime}$, of 5,000 psi and $10,000 \mathrm{psi}$, as well as reinforcement bar specified yield strengths, $f_{y}$, of $60 \mathrm{ksi}, 80 \mathrm{ksi}$, and $100 \mathrm{ksi}$. In each plot, the y-axis shows the ratio of the ACI 408R-03 splice length to the ACI 318-11 splice length. These plots compare splices with the 1.3 factor included, which represents ACI 318-11 Class B splice lengths. To compare development lengths, ACI 318-11 splice lengths should be divided by 1.3. ACI 408R-03 makes no distinction between lap splice lengths and development lengths. Values of the ratio that are more than 1.0 indicate conditions for which use of ACI 408R-03 results in longer splice lengths than use of ACI 318-11 does. Ratios less than 1.0 indicate that ACI 408R-03 requires shorter splice lengths for the conditions.

Figure B-5 compares only No. 8 reinforcing bars with the three confinement scenarios (unconfined, confined, and highly confined).

A complete list of development and splice lengths based on the equations is presented in Tables B-2, B-3, and B-4. The reinforcing bars in Table B-2 are identified as unconfined because the transverse reinforcement index, $K_{t r}$, equals zero. However, the confinement term is at the upper limit (for ACI 318-11) of 2.5 for No. 4 to No. 6

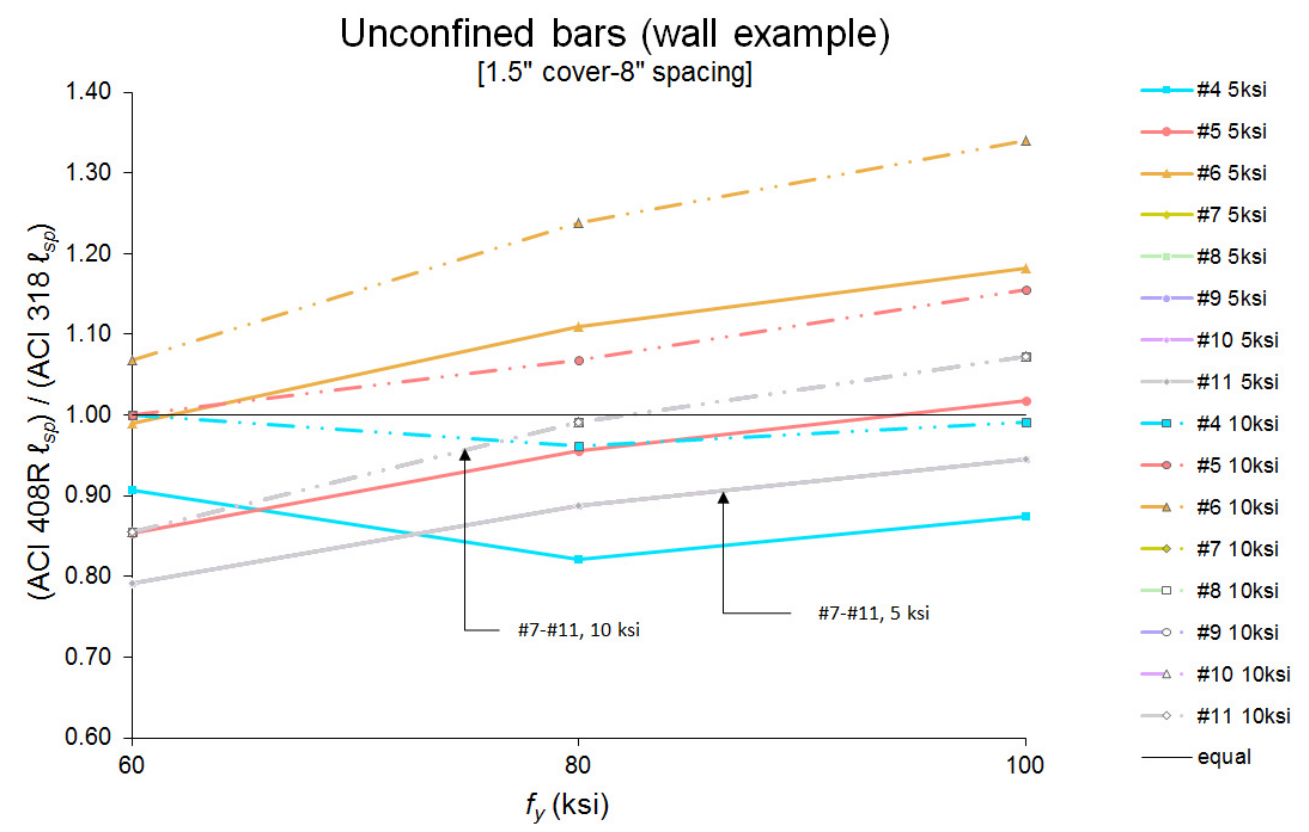

Figure B-2 Ratio of Class B splice lengths for unconfined reinforcing bars in a wall, calculated by dividing the results from $\mathrm{ACl} 408 \mathrm{R}-03$ Equation 421 (B-4) by the results from $A C I$ 318-11 Equation 12-1 (B-1), plotted for various values of reinforcement bar specified yield strengths, $f_{y}$. 


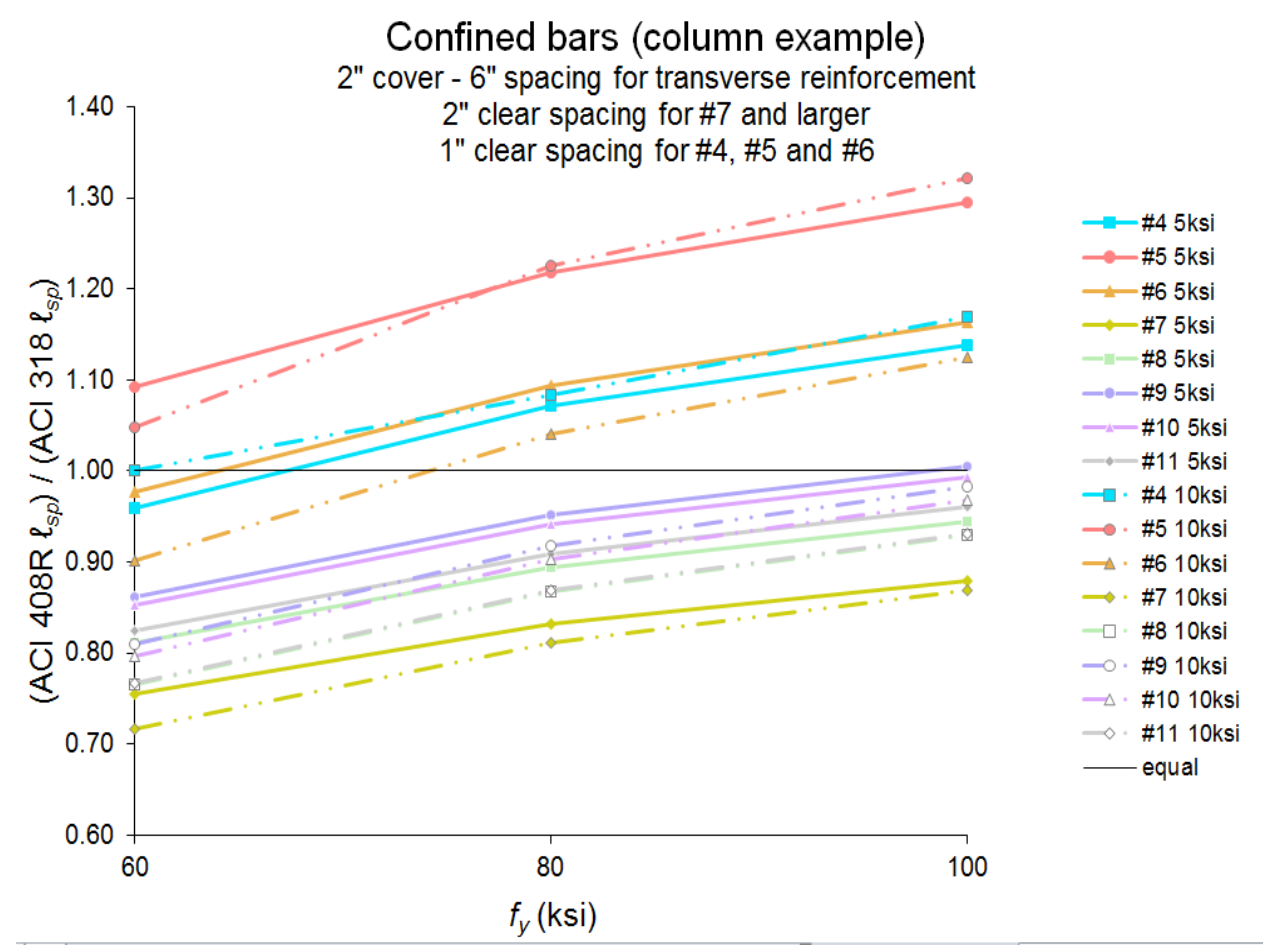

Figure B-3 Ratio of Class B splice lengths for unconfined reinforcing bars in a column, calculated by dividing the results from $\mathrm{ACl} 408 \mathrm{R}-03$ Equation 4-21 (B-4) by the results from ACl 318-11 Equation 12-1 (B-1), plotted for various values of reinforcement bar specified yield strengths, $f_{y}$.

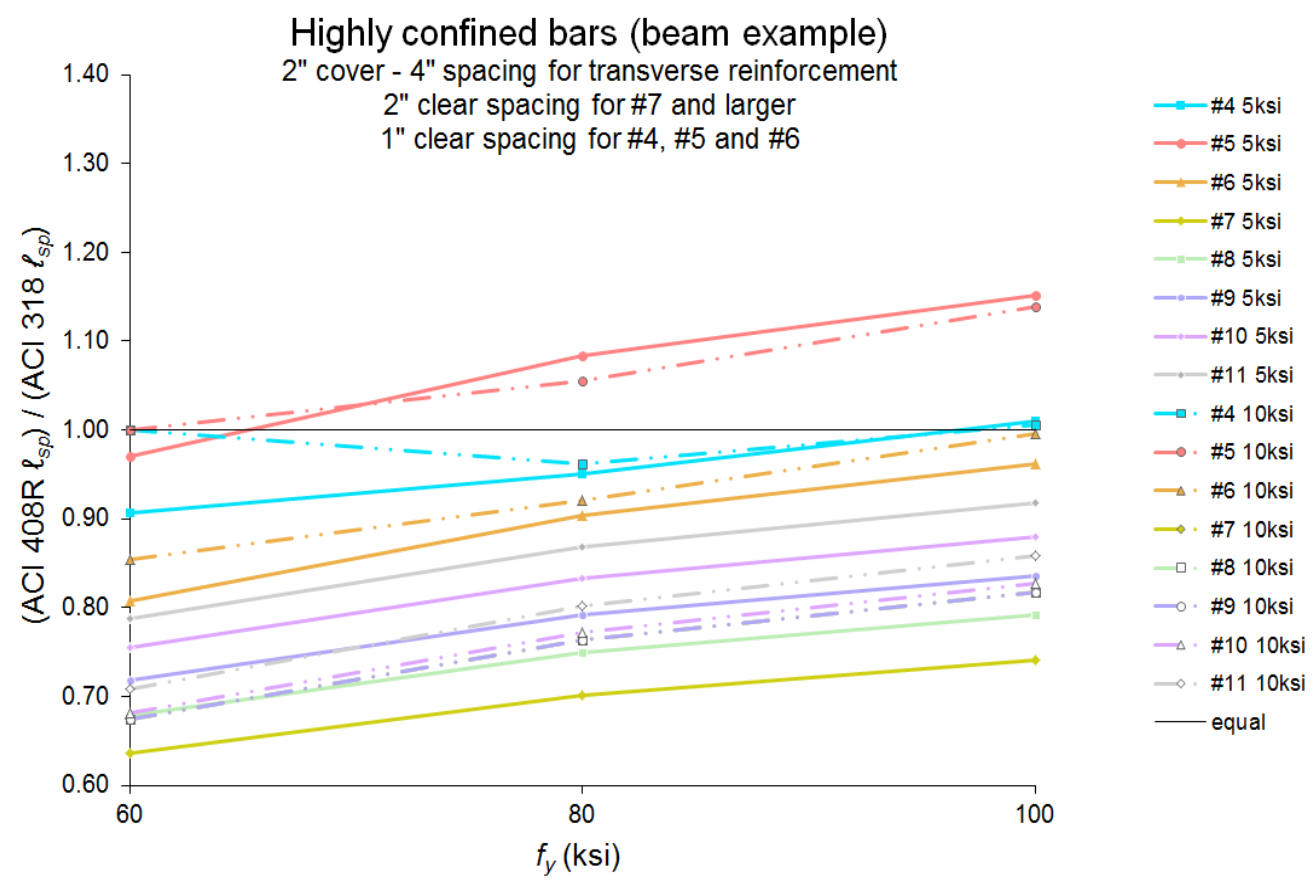

Figure B-4 Ratio of Class B splice lengths for unconfined reinforcing bars in a beam, calculated by dividing the results from $\mathrm{ACl}$ 408R-03 Equation 421 (B-4) by the results from $\mathrm{ACl}$ 318-11 Equation 12-1 (B-1), plotted for various values of reinforcement bar specified yield strengths, $f_{y}$. 
\#8 bars

unconfined, confined and highly confined

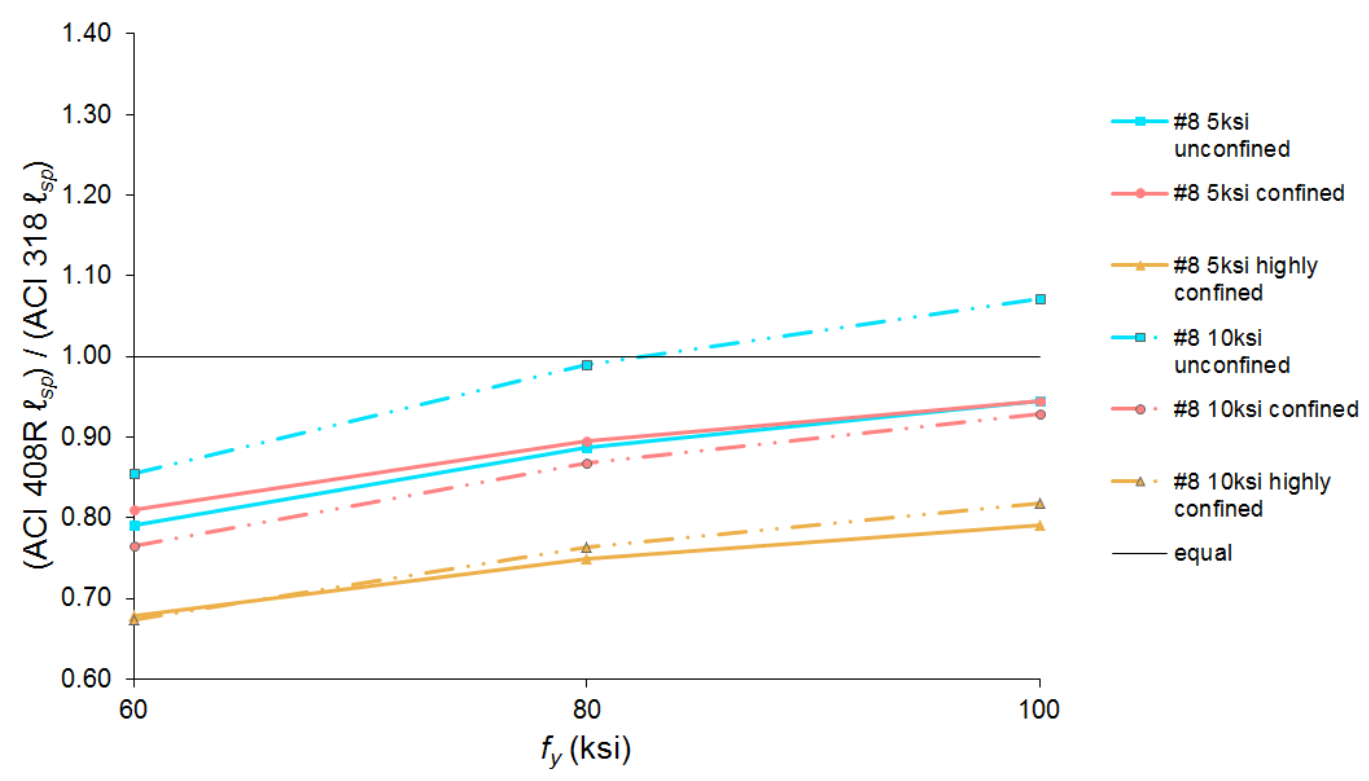

Figure B-5 Ratio of Class B splice length for unconfined, confined, and highly confined No. 8 reinforcing bars, calculated by dividing the results from $\mathrm{ACl}$ 408R-03 Equation 4-21 (B-4) by the results from ACl 318-11 Equation 12-1 (B-1), plotted for various values of reinforcement bar specified yield strengths, $f_{y}$.

reinforcing bars and at the upper limit of 4.0 (for ACI 408R-03) for No. 4 reinforcing bars. This occurs because the clear cover is proportionally larger for these reinforcing bars than for the larger reinforcing bars. For No. 11 reinforcing bars, the value of the confinement term is 1.56 (as computed per ACI 318-11), and the value is as low as 0.79 (as computed per ACI 408R-03).

In Table B-3, the reinforcing bars are defined as confined with transverse reinforcement spaced at 6 inches on center. For this case, the transverse reinforcement index, $K_{t r}$, equals 0.73 for No. 5 and smaller reinforcing bars, and 1.33 for No. 6 and larger reinforcing bars. The values of the confinement term (per ACI $318-11$ ) vary between 2.5 and 2.15 , but the value is 2.5 for the majority of the splices presented. The values of the confinement term (per ACI 408R-03) vary between a high of 3.76 for No. 7 reinforcing bars and a low of 2.57 for No. 11 reinforcing bars. The high value for No. 7 reinforcing bars occurs because the clear spacing between the reinforcing bars considered for the example increased from 1 inch for No. 6 and smaller reinforcing bars to 2 inches for No. 7 reinforcing bars.

In Table B-4, the reinforcing bars are defined as highly confined with transverse reinforcement spaced at 4 inches on center. For this case, the transverse reinforcement index, $K_{t r}$, equals 1.1 for No. 5 and smaller reinforcing bars and 2.0 for No. 6 and larger reinforcing bars. The values of the confinement term for ACI 
Table B-2 Development and Splice Lengths ${ }^{4}$ and Ratios Calculated per ACI 318-11 Equation 12-1 (B-1) and ACl 408R-03 Equation 4-21 (B-4) for the Unconfined Condition: Wall Example

\begin{tabular}{|c|c|c|c|c|c|c|c|c|c|}
\hline $\begin{array}{c}f_{y} \\
(\mathrm{ksi})\end{array}$ & $\begin{array}{c}f_{c}^{\prime} \\
\text { (ksi) }\end{array}$ & $\begin{array}{l}\text { Bar } \\
\text { size }\end{array}$ & $\begin{array}{c}\mathrm{ACl} 318^{1} \\
\text { Confinement } \\
\text { Term } \\
\left(c_{b}+K_{t r}\right) / d_{b} \\
\end{array}$ & $\begin{array}{c}\mathrm{ACl} 318^{1} \\
\ell_{d} \text { (in) } \\
\end{array}$ & $\begin{array}{c}\mathrm{ACl} 318^{1} \\
\text { Class B } \\
\ell_{s p}(\mathrm{in}) \\
\end{array}$ & $\begin{array}{c}\mathrm{ACl} 408 \mathrm{R}^{2} \\
\text { Confinement } \\
\text { Term } \\
\left(c \omega+K_{t r}\right) / d_{b} \\
\end{array}$ & $\begin{array}{c}\mathrm{ACl} 408 \mathrm{R}^{2} \\
\ell_{s p} \text { and } \ell_{d}(\mathrm{in}) \\
\end{array}$ & $\begin{array}{c}\ell_{s p} \\
\text { ratio }^{3} \\
\end{array}$ & $\begin{array}{c}\ell_{d} \\
\text { ratio }^{3} \\
\end{array}$ \\
\hline 60 & 5 & 4 & 2.50 & 12 & 13 & 4.00 & 12 & 0.91 & 1.00 \\
\hline 80 & 5 & 4 & 2.50 & 14 & 18 & 4.00 & 14 & 0.82 & 1.07 \\
\hline 100 & 5 & 4 & 2.50 & 17 & 22 & 4.00 & 19 & 0.87 & 1.14 \\
\hline 60 & 10 & 4 & 2.50 & 12 & 12 & 4.00 & 12 & 1.00 & 1.00 \\
\hline 80 & 10 & 4 & 2.50 & 12 & 12 & 4.00 & 12 & 0.96 & 1.00 \\
\hline 100 & 10 & 4 & 2.50 & 12 & 16 & 4.00 & 15 & 0.99 & 1.29 \\
\hline 60 & 5 & 5 & 2.50 & 13 & 17 & 3.43 & 14 & 0.85 & 1.11 \\
\hline 80 & 5 & 5 & 2.50 & 17 & 22 & 3.43 & 21 & 0.96 & 1.24 \\
\hline 100 & 5 & 5 & 2.50 & 21 & 28 & 3.43 & 28 & 1.02 & 1.32 \\
\hline 60 & 10 & 5 & 2.50 & 12 & 12 & 3.43 & 12 & 1.00 & 1.00 \\
\hline 80 & 10 & 5 & 2.50 & 12 & 16 & 3.43 & 17 & 1.07 & 1.39 \\
\hline 100 & 10 & 5 & 2.50 & 15 & 20 & 3.43 & 23 & 1.16 & 1.50 \\
\hline 60 & 5 & 6 & 2.50 & 15 & 20 & 2.96 & 20 & 0.99 & 1.29 \\
\hline 80 & 5 & 6 & 2.50 & 20 & 26 & 2.96 & 29 & 1.11 & 1.44 \\
\hline 100 & 5 & 6 & 2.50 & 25 & 33 & 2.96 & 39 & 1.18 & 1.54 \\
\hline 60 & 10 & 6 & 2.50 & 12 & 14 & 2.96 & 15 & 1.07 & 1.25 \\
\hline 80 & 10 & 6 & 2.50 & 14 & 19 & 2.96 & 23 & 1.24 & 1.61 \\
\hline 100 & 10 & 6 & 2.50 & 18 & 23 & 2.96 & 31 & 1.34 & 1.74 \\
\hline 60 & 5 & 7 & 2.21 & 25 & 33 & 2.62 & 26 & 0.79 & 1.03 \\
\hline 80 & 5 & 7 & 2.21 & 34 & 44 & 2.62 & 39 & 0.89 & 1.15 \\
\hline 100 & 5 & 7 & 2.21 & 42 & 54 & 2.62 & 51 & 0.95 & 1.23 \\
\hline 60 & 10 & 7 & 2.21 & 18 & 23 & 2.62 & 20 & 0.85 & 1.11 \\
\hline 80 & 10 & 7 & 2.21 & 24 & 31 & 2.62 & 31 & 0.99 & 1.29 \\
\hline 100 & 10 & 7 & 2.21 & 30 & 39 & 2.62 & 41 & 1.07 & 1.39 \\
\hline 60 & 5 & 8 & 2.00 & 32 & 41 & 2.37 & 33 & 0.79 & 1.03 \\
\hline 80 & 5 & 8 & 2.00 & 42 & 55 & 2.37 & 49 & 0.89 & 1.15 \\
\hline 100 & 5 & 8 & 2.00 & 53 & 69 & 2.37 & 65 & 0.95 & 1.23 \\
\hline 60 & 10 & 8 & 2.00 & 23 & 29 & 2.37 & 25 & 0.85 & 1.11 \\
\hline 80 & 10 & 8 & 2.00 & 30 & 39 & 2.37 & 39 & 0.99 & 1.29 \\
\hline 100 & 10 & 8 & 2.00 & 38 & 49 & 2.37 & 52 & 1.07 & 1.39 \\
\hline
\end{tabular}


Table B-2 Development and Splice Lengths ${ }^{4}$ and Ratios Calculated per ACI 318-11 Equation 12-1 (B-1) and ACI 408R-03 Equation 4-21 (B-4) for the Unconfined Condition: Wall Example (continued)

\begin{tabular}{|c|c|c|c|c|c|c|c|c|c|}
\hline $\begin{array}{c}f_{y} \\
\text { (ksi) } \\
\end{array}$ & $\begin{array}{r}f_{c}^{\prime} \\
(\mathrm{ksi}) \\
\end{array}$ & $\begin{array}{l}\text { Bar } \\
\text { size } \\
\end{array}$ & $\begin{array}{c}\mathrm{ACl} 318^{1} \\
\text { Confinement } \\
\text { Term } \\
\left(c_{b}+K_{t r}\right) / d_{b} \\
\end{array}$ & $\begin{array}{c}\mathrm{ACl} 318^{1} \\
\ell_{d} \text { (in) } \\
\end{array}$ & $\begin{array}{c}\mathrm{ACl} 318^{1} \\
\text { Class B } \\
\ell_{s p} \text { (in) } \\
\end{array}$ & $\begin{array}{c}\mathrm{ACl} 408 \mathrm{R}^{2} \\
\text { Confinement } \\
\text { Term } \\
\left(c \omega+K_{t r}\right) / d_{b} \\
\end{array}$ & $\begin{array}{c}\mathrm{ACl} 408 \mathrm{R}^{2} \\
\ell_{s p} \text { and } \ell_{d} \text { (in) } \\
\end{array}$ & $\begin{array}{c}\ell_{s p} \\
\text { ratio }^{3} \\
\end{array}$ & $\begin{array}{c}\ell_{d} \\
\text { ratio }^{3} \\
\end{array}$ \\
\hline 60 & 5 & 9 & 1.83 & 39 & 51 & 2.17 & 40 & 0.79 & 1.03 \\
\hline 80 & 5 & 9 & 1.83 & 52 & 68 & 2.17 & 60 & 0.89 & 1.15 \\
\hline 100 & 5 & 9 & 1.83 & 65 & 85 & 2.17 & 80 & 0.95 & 1.23 \\
\hline 60 & 10 & 9 & 1.83 & 28 & 36 & 2.17 & 31 & 0.85 & 1.11 \\
\hline 80 & 10 & 9 & 1.83 & 37 & 48 & 2.17 & 48 & 0.99 & 1.29 \\
\hline 100 & 10 & 9 & 1.83 & 46 & 60 & 2.17 & 64 & 1.07 & 1.39 \\
\hline 60 & 5 & 10 & 1.68 & 48 & 63 & 1.99 & 49 & 0.79 & 1.03 \\
\hline 80 & 5 & 10 & 1.68 & 64 & 83 & 1.99 & 74 & 0.89 & 1.15 \\
\hline 100 & 5 & 10 & 1.68 & 80 & 104 & 1.99 & 98 & 0.95 & 1.23 \\
\hline 60 & 10 & 10 & 1.68 & 34 & 44 & 1.99 & 38 & 0.85 & 1.11 \\
\hline 80 & 10 & 10 & 1.68 & 45 & 59 & 1.99 & 58 & 0.99 & 1.29 \\
\hline 100 & 10 & 10 & 1.68 & 57 & 74 & 1.99 & 79 & 1.07 & 1.39 \\
\hline 60 & 5 & 11 & 1.56 & 57 & 75 & 1.85 & 59 & 0.79 & 1.03 \\
\hline 80 & 5 & 11 & 1.56 & 77 & 99 & 1.85 & 88 & 0.89 & 1.15 \\
\hline 100 & 5 & 11 & 1.56 & 96 & 124 & 1.85 & 117 & 0.95 & 1.23 \\
\hline 60 & 10 & 11 & 1.56 & 41 & 53 & 1.85 & 45 & 0.85 & 1.11 \\
\hline 80 & 10 & 11 & 1.56 & 54 & 70 & 1.85 & 70 & 0.99 & 1.29 \\
\hline 100 & 10 & 11 & 1.56 & 68 & 88 & 1.85 & 94 & 1.07 & 1.39 \\
\hline
\end{tabular}

${ }^{1} \mathrm{ACl} 318-11$

${ }^{2} \mathrm{ACl} 408 \mathrm{R}-03$

${ }^{3}$ Ratio of $\mathrm{ACl} 408 \mathrm{R}-03$ values to $\mathrm{ACl} 318-11$ values

${ }^{4} \ell_{d}=$ development length; $\ell_{s p}=$ splice length

318-11 are all at the upper limit of 2.5. The values of the confinement term for ACI 408R-03 vary between a maximum of 4.0 for many splices and a minimum of 3.06 for No. 5 bars. The minimum value of the confinement term occurs for No. 5 bars because the clear spacing is 1.0 inch, and No. 3 reinforcing bars are used for transverse reinforcement. In contrast, No. 4 transverse reinforcing bars are used for longitudinal No. 6 reinforcing bars and larger. Ratios of splice lengths for ACI 408R-03 as compared to ACI 318-11 are smaller for the highly confined case than the confined case because of the lower upper limit that ACI 318-11 imposes on the confinement term. 
Table B-3 Development and Splice Lengths ${ }^{4}$ and Ratios Calculated per ACI 318-11 Equation 12-1 (B-1) and ACl 408R-03 Equation 4-21 (B-4) for the Confined Condition: Column Example

\begin{tabular}{|c|c|c|c|c|c|c|c|c|c|}
\hline $\begin{array}{c}f_{y} \\
(\mathrm{ksi}) \\
\end{array}$ & $\begin{array}{r}f_{c}^{\prime} \\
(\mathrm{ksi}) \\
\end{array}$ & $\begin{array}{l}\text { Bar } \\
\text { size } \\
\end{array}$ & $\begin{array}{c}\mathrm{ACl} 318^{1} \\
\text { Confinement } \\
\text { Term } \\
\left(c_{b}+K_{t r}\right) / d_{b} \\
\end{array}$ & $\begin{array}{c}\mathrm{ACl} 318^{1} \\
\quad \ell_{d} \text { (in) } \\
\end{array}$ & $\begin{array}{c}\mathrm{ACl} 318^{1} \\
\text { Class B } \\
\ell_{s p} \text { (in) } \\
\end{array}$ & $\begin{array}{c}\mathrm{ACl} 408 \mathrm{R}^{2} \\
\text { Confinement } \\
\text { Term } \\
\left(c \omega+K_{t r}\right) / d_{b} \\
\end{array}$ & $\begin{array}{c}\mathrm{ACI} 408 \mathrm{R}^{2} \\
\ell_{s p} \text { and } \ell_{d}(\mathrm{in})\end{array}$ & $\begin{array}{r}\ell_{s p} \\
\text { ratio }^{3} \\
\end{array}$ & $\begin{array}{c}\ell_{d} \\
\text { ratio }^{3} \\
\end{array}$ \\
\hline 60 & 5 & 4 & 2.50 & 12 & 13 & 3.09 & 13 & 0.96 & 1.06 \\
\hline 80 & 5 & 4 & 2.50 & 14 & 18 & 3.09 & 19 & 1.07 & 1.39 \\
\hline 100 & 5 & 4 & 2.50 & 17 & 22 & 3.09 & 25 & 1.14 & 1.48 \\
\hline 60 & 10 & 4 & 2.50 & 12 & 12 & 3.42 & 12 & 1.00 & 1.00 \\
\hline 80 & 10 & 4 & 2.50 & 12 & 12 & 3.42 & 14 & 1.08 & 1.13 \\
\hline 100 & 10 & 4 & 2.50 & 12 & 16 & 3.42 & 18 & 1.17 & 1.52 \\
\hline 60 & 5 & 5 & 2.47 & 13 & 17 & 2.69 & 18 & 1.09 & 1.42 \\
\hline 80 & 5 & 5 & 2.47 & 17 & 22 & 2.69 & 27 & 1.22 & 1.58 \\
\hline 100 & 5 & 5 & 2.47 & 21 & 28 & 2.69 & 36 & 1.29 & 1.68 \\
\hline 60 & 10 & 5 & 2.47 & 12 & 12 & 2.99 & 13 & 1.05 & 1.05 \\
\hline 80 & 10 & 5 & 2.47 & 12 & 16 & 2.99 & 19 & 1.23 & 1.59 \\
\hline 100 & 10 & 5 & 2.47 & 15 & 20 & 2.99 & 26 & 1.32 & 1.72 \\
\hline 60 & 5 & 6 & 2.50 & 15 & 20 & 3.01 & 19 & 0.98 & 1.27 \\
\hline 80 & 5 & 6 & 2.50 & 20 & 26 & 3.01 & 29 & 1.09 & 1.42 \\
\hline 100 & 5 & 6 & 2.50 & 25 & 33 & 3.01 & 38 & 1.16 & 1.51 \\
\hline 60 & 10 & 6 & 2.50 & 12 & 14 & 3.54 & 13 & 0.90 & 1.05 \\
\hline 80 & 10 & 6 & 2.50 & 14 & 19 & 3.54 & 19 & 1.04 & 1.35 \\
\hline 100 & 10 & 6 & 2.50 & 18 & 23 & 3.54 & 26 & 1.13 & 1.46 \\
\hline 60 & 5 & 7 & 2.50 & 22 & 29 & 3.26 & 22 & 0.75 & 0.98 \\
\hline 80 & 5 & 7 & 2.50 & 30 & 39 & 3.26 & 32 & 0.83 & 1.08 \\
\hline 100 & 5 & 7 & 2.50 & 37 & 48 & 3.26 & 42 & 0.88 & 1.14 \\
\hline 60 & 10 & 7 & 2.50 & 16 & 20 & 3.76 & 15 & 0.72 & 0.93 \\
\hline 80 & 10 & 7 & 2.50 & 21 & 27 & 3.76 & 22 & 0.81 & 1.06 \\
\hline 100 & 10 & 7 & 2.50 & 26 & 34 & 3.76 & 30 & 0.87 & 1.13 \\
\hline 60 & 5 & 8 & 2.50 & 25 & 33 & 3.03 & 27 & 0.81 & 1.05 \\
\hline 80 & 5 & 8 & 2.50 & 34 & 44 & 3.03 & 39 & 0.89 & 1.16 \\
\hline 100 & 5 & 8 & 2.50 & 42 & 55 & 3.03 & 52 & 0.95 & 1.23 \\
\hline 60 & 10 & 8 & 2.50 & 18 & 23 & 3.52 & 18 & 0.77 & 1.00 \\
\hline 80 & 10 & 8 & 2.50 & 24 & 31 & 3.52 & 27 & 0.87 & 1.13 \\
\hline 100 & 10 & 8 & 2.50 & 30 & 39 & 3.52 & 36 & 0.93 & 1.21 \\
\hline
\end{tabular}


Table B-3 Development and Splice Lengths ${ }^{4}$ and Ratios Calculated per ACI 318-11 Equation 12-1 (B-1) and ACl 408R-03 Equation 4-21 (B-4) for the Confined Condition: Column Example (continued)

\begin{tabular}{|c|c|c|c|c|c|c|c|c|c|}
\hline $\begin{array}{c}f_{y} \\
\text { (ksi) } \\
\end{array}$ & $\begin{array}{r}f_{c}^{\prime} c \\
(\mathrm{ksi}) \\
\end{array}$ & $\begin{array}{l}\text { Bar } \\
\text { size } \\
\end{array}$ & $\begin{array}{c}\mathrm{ACl} 318^{1} \\
\text { Confinement } \\
\text { Term } \\
\left(c_{b}+K_{t r}\right) / d_{b} \\
\end{array}$ & $\begin{array}{c}\mathrm{ACl} 318^{1} \\
\ell_{d} \text { (in) } \\
\end{array}$ & $\begin{array}{c}\mathrm{ACl} 318^{1} \\
\text { Class B } \\
\ell_{s p}(\mathrm{in}) \\
\end{array}$ & $\begin{array}{c}\mathrm{ACl} 408 \mathrm{R}^{2} \\
\text { Confinement } \\
\text { Term } \\
\left(c \omega+K_{t r}\right) / d_{b} \\
\end{array}$ & $\begin{array}{c}\mathrm{ACl} 408 \mathrm{R}^{2} \\
\ell_{s p} \text { and } \ell_{d} \text { (in) }\end{array}$ & $\begin{array}{c}\ell_{s p} \\
\text { ratio }^{3} \\
\end{array}$ & $\begin{array}{c}\ell_{d} \\
\text { ratio }^{3} \\
\end{array}$ \\
\hline 60 & 5 & 9 & 2.50 & 29 & 37 & 2.85 & 32 & 0.86 & 1.12 \\
\hline 80 & 5 & 9 & 2.50 & 38 & 50 & 2.85 & 47 & 0.95 & 1.24 \\
\hline 100 & 5 & 9 & 2.50 & 48 & 62 & 2.85 & 63 & 1.00 & 1.31 \\
\hline 60 & 10 & 9 & 2.50 & 20 & 26 & 3.33 & 21 & 0.81 & 1.05 \\
\hline 80 & 10 & 9 & 2.50 & 27 & 35 & 3.33 & 32 & 0.92 & 1.19 \\
\hline 100 & 10 & 9 & 2.50 & 34 & 44 & 3.33 & 43 & 0.98 & 1.28 \\
\hline 60 & 5 & 10 & 2.34 & 35 & 45 & 2.70 & 38 & 0.85 & 1.11 \\
\hline 80 & 5 & 10 & 2.34 & 46 & 60 & 2.70 & 56 & 0.94 & 1.22 \\
\hline 100 & 5 & 10 & 2.34 & 58 & 75 & 2.70 & 74 & 0.99 & 1.29 \\
\hline 60 & 10 & 10 & 2.34 & 24 & 32 & 3.16 & 25 & 0.80 & 1.04 \\
\hline 80 & 10 & 10 & 2.34 & 33 & 42 & 3.16 & 38 & 0.90 & 1.17 \\
\hline 100 & 10 & 10 & 2.34 & 41 & 53 & 3.16 & 51 & 0.97 & 1.26 \\
\hline 60 & 5 & 11 & 2.15 & 42 & 54 & 2.57 & 45 & 0.82 & 1.07 \\
\hline 80 & 5 & 11 & 2.15 & 56 & 72 & 2.57 & 66 & 0.91 & 1.18 \\
\hline 100 & 5 & 11 & 2.15 & 69 & 90 & 2.57 & 87 & 0.96 & 1.25 \\
\hline 60 & 10 & 11 & 2.15 & 29 & 38 & 3.03 & 29 & 0.77 & 1.00 \\
\hline 80 & 10 & 11 & 2.15 & 39 & 51 & 3.03 & 44 & 0.87 & 1.13 \\
\hline 100 & 10 & 11 & 2.15 & 49 & 64 & 3.03 & 59 & 0.93 & 1.21 \\
\hline
\end{tabular}

${ }^{1} \mathrm{ACl} 318-11$

${ }^{2} \mathrm{ACl} 408 \mathrm{R}-03$

${ }^{3}$ Ratio of $\mathrm{ACl} 408 \mathrm{R}-03$ values to $\mathrm{ACl} 318-11$ values

${ }^{4} \ell_{d}=$ development length; $\ell_{s p}=$ splice length 
Table B-4 Development and Splice Lengths ${ }^{4}$ and Ratios Calculated per ACI 318-11 Equation 12-1 (B1) and ACI 408R-03 Equation 4-21 (B-4) for the Highly Confined Condition: Beam Example

\begin{tabular}{|c|c|c|c|c|c|c|c|c|c|}
\hline $\begin{array}{c}f_{y} \\
\text { (ksi) }\end{array}$ & $\begin{array}{c}f_{c}^{\prime} \\
(\mathrm{ksi})\end{array}$ & $\begin{array}{l}\text { Bar } \\
\text { size }\end{array}$ & $\begin{array}{c}\mathrm{ACl} 318^{1} \\
\text { Confinement } \\
\text { Term } \\
\left(c_{b}+K_{t r}\right) / d_{b}\end{array}$ & $\begin{array}{c}\mathrm{ACl} 318^{1} \\
\ell_{d} \text { (in) }\end{array}$ & $\begin{array}{c}\mathrm{ACl} 318^{1} \\
\text { Class B } \\
\ell_{s p}(\mathrm{in})\end{array}$ & $\begin{array}{c}\mathrm{ACl} 408 \mathrm{R}^{2} \\
\text { Confinement } \\
\text { Term } \\
\left(c \omega+K_{t r}\right) / d_{b}\end{array}$ & $\begin{array}{c}\mathrm{ACl} 408 \mathrm{R}^{2} \\
\ell_{s p} \text { and } \ell_{d} \text { (in) }\end{array}$ & $\begin{array}{c}\ell_{s p} \\
\text { ratio }^{3}\end{array}$ & $\begin{array}{c}\ell_{d} \\
\text { ratio }^{3}\end{array}$ \\
\hline 60 & 5 & 4 & 2.50 & 12 & 13 & 3.49 & 12 & 0.91 & 1.00 \\
\hline 80 & 5 & 4 & 2.50 & 14 & 18 & 3.49 & 17 & 0.95 & 1.24 \\
\hline 100 & 5 & 4 & 2.50 & 17 & 22 & 3.49 & 22 & 1.01 & 1.31 \\
\hline 60 & 10 & 4 & 2.50 & 12 & 12 & 3.98 & 12 & 1.00 & 1.00 \\
\hline 80 & 10 & 4 & 2.50 & 12 & 12 & 3.98 & 12 & 0.96 & 1.00 \\
\hline 100 & 10 & 4 & 2.50 & 12 & 16 & 3.98 & 16 & 1.01 & 1.31 \\
\hline 60 & 5 & 5 & 2.50 & 13 & 17 & 3.06 & 16 & 0.97 & 1.26 \\
\hline 80 & 5 & 5 & 2.50 & 17 & 22 & 3.06 & 24 & 1.08 & 1.41 \\
\hline 100 & 5 & 5 & 2.50 & 21 & 28 & 3.06 & 32 & 1.15 & 1.50 \\
\hline 60 & 10 & 5 & 2.50 & 12 & 12 & 3.51 & 12 & 1.00 & 1.00 \\
\hline 80 & 10 & 5 & 2.50 & 12 & 16 & 3.51 & 16 & 1.06 & 1.37 \\
\hline 100 & 10 & 5 & 2.50 & 15 & 20 & 3.51 & 22 & 1.14 & 1.48 \\
\hline 60 & 5 & 6 & 2.50 & 15 & 20 & 3.65 & 16 & 0.81 & 1.05 \\
\hline 80 & 5 & 6 & 2.50 & 20 & 26 & 3.65 & 24 & 0.90 & 1.18 \\
\hline 100 & 5 & 6 & 2.50 & 25 & 33 & 3.65 & 32 & 0.96 & 1.25 \\
\hline 60 & 10 & 6 & 2.50 & 12 & 14 & 4.00 & 12 & 0.85 & 1.00 \\
\hline 80 & 10 & 6 & 2.50 & 14 & 19 & 4.00 & 17 & 0.92 & 1.20 \\
\hline 100 & 10 & 6 & 2.50 & 18 & 23 & 4.00 & 23 & 1.00 & 1.29 \\
\hline 60 & 5 & 7 & 2.50 & 22 & 29 & 3.87 & 18 & 0.64 & 0.83 \\
\hline 80 & 5 & 7 & 2.50 & 30 & 39 & 3.87 & 27 & 0.70 & 0.91 \\
\hline 100 & 5 & 7 & 2.50 & 37 & 48 & 3.87 & 36 & 0.74 & 0.96 \\
\hline 60 & 10 & 7 & 2.50 & 16 & 20 & 4.00 & 14 & 0.67 & 0.88 \\
\hline 80 & 10 & 7 & 2.50 & 21 & 27 & 4.00 & 21 & 0.76 & 0.99 \\
\hline 100 & 10 & 7 & 2.50 & 26 & 34 & 4.00 & 28 & 0.82 & 1.06 \\
\hline 60 & 5 & 8 & 2.50 & 25 & 33 & 3.62 & 22 & 0.68 & 0.88 \\
\hline 80 & 5 & 8 & 2.50 & 34 & 44 & 3.62 & 33 & 0.75 & 0.97 \\
\hline 100 & 5 & 8 & 2.50 & 42 & 55 & 3.62 & 44 & 0.79 & 1.03 \\
\hline 60 & 10 & 8 & 2.50 & 18 & 23 & 4.00 & 16 & 0.67 & 0.88 \\
\hline 80 & 10 & 8 & 2.50 & 24 & 31 & 4.00 & 24 & 0.76 & 0.99 \\
\hline 100 & 10 & 8 & 2.50 & 30 & 39 & 4.00 & 32 & 0.82 & 1.06 \\
\hline
\end{tabular}


Table B-4 Development and Splice Lengths ${ }^{4}$ and Ratios Calculated per ACI 318-11 Equation 12-1 (B-1) and ACI 408R-03 Equation 4-21 (B-4) for the Highly Confined Condition: Beam Example (continued)

\begin{tabular}{|c|c|c|c|c|c|c|c|c|c|}
\hline $\begin{array}{c}f_{y} \\
\text { (ksi) }\end{array}$ & $\begin{array}{c}f_{c}^{\prime} \\
\text { (ksi) }\end{array}$ & $\begin{array}{l}\text { Bar } \\
\text { size }\end{array}$ & $\begin{array}{c}\mathrm{ACl} 318^{1} \\
\text { Confinement } \\
\text { Term } \\
\left(c_{b}+K_{t r}\right) / d_{b} \\
\end{array}$ & $\begin{array}{c}\mathrm{ACl} 318^{1} \\
\ell_{d} \text { (in) } \\
\end{array}$ & $\begin{array}{c}\mathrm{ACl} 318^{1} \\
\text { Class B } \\
\ell_{s p}(\mathrm{in}) \\
\end{array}$ & $\begin{array}{c}\text { ACI 408R }{ }^{2} \\
\text { Confinement } \\
\text { Term } \\
\left(c \omega+K_{t r}\right) / d_{b} \\
\end{array}$ & $\begin{array}{c}\mathrm{ACl} 408 \mathrm{R}^{2} \\
\ell_{s p} \text { and } \ell_{d} \text { (in) }\end{array}$ & $\begin{array}{c}\ell_{s p} \\
\text { ratio }^{3} \\
\end{array}$ & $\begin{array}{c}\ell_{d} \\
\text { ratio }^{3} \\
\end{array}$ \\
\hline 60 & 5 & 9 & 2.50 & 29 & 37 & 3.43 & 27 & 0.72 & 0.93 \\
\hline 80 & 5 & 9 & 2.50 & 38 & 50 & 3.43 & 39 & 0.79 & 1.03 \\
\hline 100 & 5 & 9 & 2.50 & 48 & 62 & 3.43 & 52 & 0.84 & 1.09 \\
\hline 60 & 10 & 9 & 2.50 & 20 & 26 & 4.00 & 18 & 0.67 & 0.88 \\
\hline 80 & 10 & 9 & 2.50 & 27 & 35 & 4.00 & 27 & 0.76 & 0.99 \\
\hline 100 & 10 & 9 & 2.50 & 34 & 44 & 4.00 & 36 & 0.82 & 1.06 \\
\hline 60 & 5 & 10 & 2.50 & 32 & 42 & 3.26 & 32 & 0.75 & 0.98 \\
\hline 80 & 5 & 10 & 2.50 & 43 & 56 & 3.26 & 47 & 0.83 & 1.08 \\
\hline 100 & 5 & 10 & 2.50 & 54 & 70 & 3.26 & 62 & 0.88 & 1.14 \\
\hline 60 & 10 & 10 & 2.50 & 23 & 30 & 3.96 & 20 & 0.68 & 0.89 \\
\hline 80 & 10 & 10 & 2.50 & 30 & 40 & 3.96 & 31 & 0.77 & 1.00 \\
\hline 100 & 10 & 10 & 2.50 & 38 & 50 & 3.96 & 41 & 0.83 & 1.08 \\
\hline 60 & 5 & 11 & 2.50 & 36 & 47 & 3.12 & 37 & 0.79 & 1.02 \\
\hline 80 & 5 & 11 & 2.50 & 48 & 62 & 3.12 & 54 & 0.87 & 1.13 \\
\hline 100 & 5 & 11 & 2.50 & 60 & 78 & 3.12 & 71 & 0.92 & 1.19 \\
\hline 60 & 10 & 11 & 2.50 & 25 & 33 & 3.81 & 23 & 0.71 & 0.92 \\
\hline 80 & 10 & 11 & 2.50 & 34 & 44 & 3.81 & 35 & 0.80 & 1.04 \\
\hline 100 & 10 & 11 & 2.50 & 42 & 55 & 3.81 & 47 & 0.86 & 1.12 \\
\hline
\end{tabular}

${ }^{1} \mathrm{ACl} 318-11$

${ }^{2} \mathrm{ACl} 408 \mathrm{R}-03$

${ }^{3}$ Ratio of $\mathrm{ACl} 408 \mathrm{R}-03$ values to $\mathrm{ACl} 318-11$ values

${ }^{4} \ell_{d}=$ development length; $\ell_{s p}=$ splice length

\section{B.4 Discussion of Results}

Results from this study indicate:

- For unconfined reinforcing bars (wall condition), ACI 408R-03 generally requires shorter splice lengths than ACI 318-11 (see Figure B-2). This is due in part to the $\omega$ factor in ACI 408R-03, which increases (up to a maximum value) for situations such as walls without any cracking potential in one perpendicular direction. For stresses of 60 and $80 \mathrm{ksi}, \mathrm{ACI} 408 \mathrm{R}-03$ requires longer splice lengths for smaller reinforcing bars (No. 6 and smaller) for which ACI 318-11 applies a $20 \%$ reduction in length. For $100 \mathrm{ksi}$ reinforcing bars in $10 \mathrm{ksi}$ 
concrete, ACI 408R-03 requires longer splice lengths for larger reinforcing bars (No. 7 to No. 11).

- For confined reinforcing bars (column condition with transverse reinforcement at 6 inch spacing), ACI 408R-03 generally requires longer splice lengths, relative to ACI 318-11, for smaller high-strength reinforcing bars (No. 6 and smaller and for $80 \mathrm{ksi}$ and $100 \mathrm{ksi}$ ). ACI 408R-03 generally requires shorter splice lengths, relative to ACI 318-11, for larger high-strength reinforcing bars (No. 7 and larger and for $80 \mathrm{ksi}$ and $100 \mathrm{ksi}$ ) (see Figure B-3)

- For highly confined reinforcing bars (beam condition), ACI 408R-03 requires equivalent or shorter splice lengths in all cases except for No. 5 bars. The ACI 408R-03 equation includes a confinement term that has a higher upper limit than ACI 318-11 allows, which results in reduced development and splice lengths relative to ACI 318-11 (see Figure B-4).

- ACI 318-11 development lengths are shorter than the values shown in the graphs by a factor of 1.3 for all but a few smaller reinforcing bars controlled by the 12-inch minimum development or splice length. ACI 408R-03 does not distinguish between development and splice lengths. As a result, ACI 408R-03 generally requires longer development lengths relative to ACI 318-11, for unconfined and confined high-strength reinforcing bars and for some highstrength, highly confined reinforcing bars (particularly 100 ksi reinforcing bars).

- $\mathrm{ACI}$ 408R-03 development lengths increase more quickly as bar strengths increase than is the case for development lengths specified in ACI 318-11. As a result, larger development and splice lengths are more likely required for highstrength reinforcing bars using ACI 408R-03.

- ACI 408R-03 generally has longer relative development and splice lengths for smaller bar sizes. This is because ACI 408R-03 does not allow the small bar factor (size factor) from ACI 318-11, which allows a $20 \%$ reduction in development and splice length for small bars.

In conclusion, it is recommended that ACI 318-11 development and splice length provisions be reevaluated for applications with high-strength reinforcing bars. This is important when considering development lengths for Class A splices. For Class B splices, the 1.3 factor increases the required development and splice lengths. Based on tests by Seliem et al. (2009), the ACI 408R-03 approach to computing development and splice lengths is applicable for high-strength reinforcing bars. ACI 408R-03 and other research involving high-strength bar development should serve as a resource for this reassessment. Further discussion and recommendations are provided in the body of the report in Chapter 3. 
a shear span, inches

$A_{g} \quad$ gross cross-sectional area of a beam, column or wall, $\mathrm{in}^{2}$

$A_{g t} \quad$ total elongation of reinforcement under maximum load, \% (AS/NZS, 2001)

$A_{s} \quad$ area of tension reinforcement in a beam, column or wall, in ${ }^{2}$

$A_{s}^{\prime} \quad$ area of compression reinforcement in a beam, column or wall, in ${ }^{2}$

$A_{s t} \quad$ area of tension reinforcement, $i^{2}$

$A_{t r} \quad$ total cross-sectional area of transverse reinforcing steel within a spacing, $s$, that crosses the potential plane of splitting, in ${ }^{2}$

$A_{w t}$ total cross-sectional area of transverse reinforcing steel within a spacing, $s$, that crosses the potential plane of splitting, in ${ }^{2}$

$b \quad$ width of a beam or column, inches

$c \quad c_{\min }+0.5 d_{b}$, inches

$c_{b} \quad$ smaller of: (1) distance from the center of a bar to the nearest concrete edge; or (2) one-half of the center-to-center spacing between reinforcing bars, inches

$c_{b} \quad$ bottom cover, inches

$c_{\max }$ maximum of $\left(c_{b}, c_{s}\right)$, inches

$c_{\text {min }} \quad$ minimum of $\left(c_{b}, c_{s}\right)$, inches

$c_{s} \quad$ minimum of (side cover, $1 / 2$ clear spacing +0.25 inch)

$d \quad$ depth from extreme compression fiber to centroid of reinforcing steel for a beam, column, or wall, inches

$d_{b} \quad$ diameter of a reinforcing bar (longitudinal or transverse), inches

$E I_{g}$ gross cross-sectional stiffness for a beam, column, or wall, kips-inch ${ }^{2}$

$f_{c} \quad$ concrete compressive stress, psi or ksi

$f_{c}^{\prime} \quad$ specified compressive strength of concrete, psi or ksi

$f_{u} \quad$ ultimate strength of reinforcing steel, psi or ksi 
$f_{y} \quad$ specified yield strength of reinforcing steel, psi or ksi

$f_{y t} \quad$ specified yield strength of transverse reinforcing steel, psi or ksi

$E_{c} \quad$ Young's Modulus of Elasticity for concrete, psi or ksi

$E_{s} \quad$ Young's Modulus of Elasticity for reinforcing steel, psi or ksi

$h \quad$ overall depth of a beam or column, inches

$h_{r} \quad$ height of reinforcement bar deformations (ribs), inches

$I_{e} \quad$ effective cross-sectional moment of inertia for a beam, column, or wall, $\mathrm{in}^{3}$

$I_{g} \quad$ gross cross-sectional moment of inertia for a beam, column, or wall, in ${ }^{3}$

$K_{t r} \quad$ transverse reinforcement index

$\ell \quad$ length of wall, beam, or column, inches

$\ell_{b e} \quad$ length of boundary element in a wall, inches

$\ell_{d} \quad$ development length of reinforcing bar, inches

$\ell_{n} \quad$ length of the column clear span, measured face-to-face from joint above to joint below, inches

$\ell_{s p} \quad$ splice length, inches

$\ell_{w} \quad$ length of wall, inches

M moment in a beam, column, or wall, kip-inches

$M / V \ell_{w}$ shear span ratio for a wall

$M_{c r} \quad$ cracking moment, kip-inches

$M_{n} \quad$ nominal moment strength in a beam, column, or wall, kip-inches

$M_{n b} \quad$ nominal moment strength in a beam at a beam-column joint, kip-inches

$M_{n c} \quad$ nominal moment strength in a column at a beam-column joint, kip-inches

$M_{p r} \quad$ probable moment strength at $1.25 f_{y}$, kip-inches

$M_{u} \quad$ factored moment demand in a beam, column, or wall, kip-inches

$n$ number of reinforcing bars being spliced or developed along the plane of splitting

$N \quad$ axial load, kips 


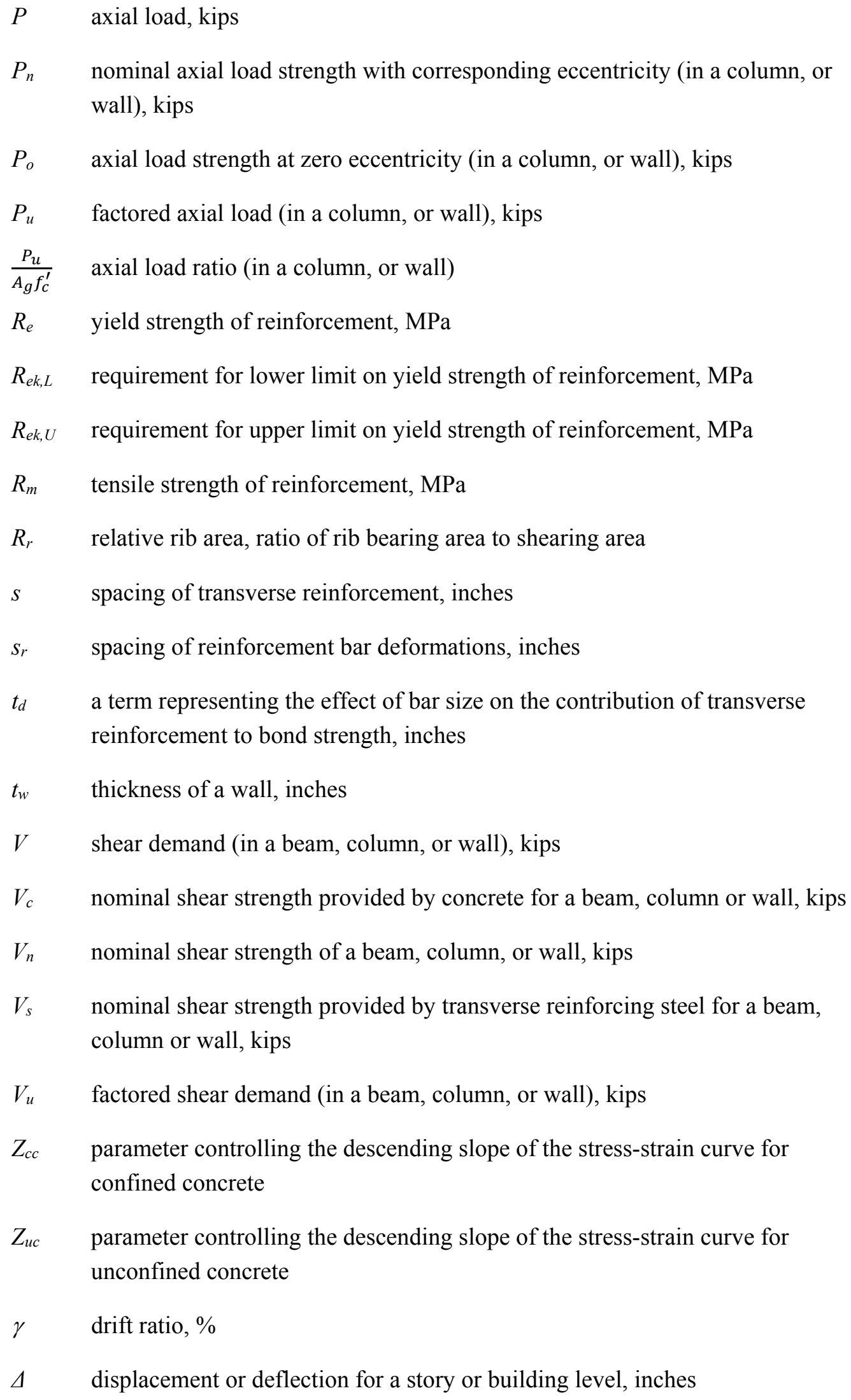


$\Delta_{p} \quad$ post yield (plastic) displacement, inches

$\Delta y \quad$ yield displacement, inches

$\varepsilon \quad$ strain, in/in

$\varepsilon_{\mathrm{c}} \quad$ compressive strain in concrete, in/in

$\varepsilon_{0} \quad$ compressive strain in unconfined concrete corresponding to compressive stress $f_{c}^{\prime}$, in/in

$\varepsilon_{s} \quad$ tensile strain in reinforcing steel, in/in

$\varepsilon_{s h} \quad$ tensile strain in reinforcing steel defining the onset of strain hardening, in/in

$\varepsilon_{s u} \quad$ maximum useable tensile strain in reinforcing steel, $0.06 \mathrm{in} / \mathrm{in}$

$\varepsilon_{y} \quad$ tensile strain in reinforcing steel at yield, in/in

$\lambda$ modification factor reflecting the reduced mechanical properties of lightweight concrete, equal to 1.4 for lightweight concrete, or 1.0 for normal weight concrete

$\mu_{\Delta} \quad$ ductility displacement, $\%$

$\phi \quad$ strength reduction factors per ACI 318

$\phi \quad$ curvature for moment-curvature relationships, radians/inch

$\phi_{u} \quad$ ultimate curvature reached at support, radians/inch

$\phi_{y} \quad$ yield curvature, radians/inch

$\rho \quad$ ratio of longitudinal tension reinforcement steel for a beam, column or wall, $A_{s} / b d$

$\rho^{\prime} \quad$ ratio of longitudinal compression reinforcement steel for a beam, column or wall, $A_{s}^{\prime} / b d$

$\rho_{b e} \quad$ ratio of longitudinal reinforcement steel for a wall boundary element, $A_{s} / t_{w} \ell_{b e}$

$\rho_{\ell} \quad$ ratio of distributed longitudinal (vertical) reinforcement steel for a wall (between boundary elements), $A_{s} / t_{w}\left(\ell_{w}-2 \ell_{b e}\right)$

$\rho_{t} \quad$ ratio of transverse reinforcement steel for a beam, column or wall, $A_{v} / b s$ or $A_{v} / t_{w} S$

$\rho_{t} \quad$ ratio of distributed transverse reinforcement for a wall, $A_{s} / t_{w} S$ 
$\rho_{v} \quad$ ratio of transverse reinforcement steel for a beam, column or wall, $A_{v} / b s$ or $A_{v} / t_{w} S$

$\rho_{w t} \quad$ ratio of transverse reinforcement steel for a beam, column or wall, $A_{v} / b s$

$\theta_{\text {cap }} \quad$ rotation capacity, radians

$\theta_{p} \quad$ post yield (plastic) rotation, radians

$\theta_{u} \quad$ ultimate draft ratio

$\theta_{y} \quad$ rotation at yield, radians

$\psi_{e} \quad$ factor to account for epoxy coated reinforcement, equal to 1.0 for uncoated reinforcing bars, 1.2 for epoxy coated reinforcing bars

$\psi_{s} \quad$ factor to account for size of reinforcing bars, equal to 0.8 for No. 6 bars and smaller, 1.0 for No. 7 bars and larger.

$\psi_{t} \quad$ reinforcement location factor equal to 1.3 for horizontal reinforcing bars with more than 12 inches fresh cast concrete below the horizontal reinforcement, or 1.0 otherwise.

$\omega \quad 0.1 \mathrm{c}_{\max } / c_{\min }+0.9 \leq 1.25$, or can take $\omega=1.0$ 

ACI, 1973, "Uses and limitations of high strength steel reinforcement $f_{y} \geq 60 \mathrm{ksi}$ (44.2 kgf $\left./ \mathrm{mm}^{2}\right)$," ACI Committee 439, ACI Structural Journal, Vol. 70, No. 2, pp. 77-104.

ACI, 2002, Recommendations for Design of Beam-Column Joints in Monolithic Reinforced Concrete Structures, ACI 352R-02, Joint ACI-ASCE Committee 352, American Concrete Institute, Farmington Hills, Michigan.

ACI, 2003, Bond and Development of Straight Reinforcing Bars in Tension, ACI 408R-03, American Concrete Institute, Farmington Hills, Michigan.

ACI, 2008, Building Code Requirements for Structural Concrete and Commentary, ACI 318-08, American Concrete Institute, Farmington Hills, Michigan.

ACI, 2009, Guide for Lap Splice and Development Length of High Relative Rib Area Reinforcing Bars in Tension and Commentary, ACI 408.3R-09, American Concrete Institute, Farmington Hills, Michigan.

ACI, 2010a, Design Guide for the Use of ASTM A1035/A1035M Grade 100 Steel Bars for Structural Concrete, ACI ITG-6R-10, American Concrete Institute, Farmington Hills, Michigan.

ACI, 2010b, Specification for Tolerances for Concrete Construction and Materials and Commentary, ACI 117-10, American Concrete Institute, Farmington Hills, Michigan.

ACI, 2011, Building Code Requirements for Structural Concrete and Commentary, ACI 318-11, American Concrete Institute, Farmington Hills, Michigan.

Angelakos, D., Bentz, E., and Collins, M., 2001, "Effect of concrete strength and minimum stirrups on shear strength of large members," ACI Structural Journal, Vol. 98, No. 3, pp. 290-300.

Aoyama, H., 2001, Design of Modern Highrise Reinforced Concrete Structures, Imperial College Press, London, United Kingdom.

AS/NZS, 2001, AS/NZS 4671 Steel Reinforcing Materials, Joint Standards Australia/Standards New Zealand, Wellington, New Zealand and Sydney, Australia.

ASCE, 2010, Minimum Design Loads for Buildings and Other Structures, ASCE/SEI 7-10, American Society of Civil Engineers, Structural Engineering Institute, Reston, Virginia. 
ASTM, 1974, Standard Specification for Low-Alloy Steel Deformed and Plain Bars for Concrete Reinforcement, ASTM A706, ASTM International, West Conshohocken, Pennsylvania.

ASTM, 2009a, Standard Specification for Deformed and Plain Carbon-Steel Bars for Concrete Reinforcement, ASTM A615-09b, ASTM International, West Conshohocken, Pennsylvania.

ASTM, 2009b, Standard Specification for Low-Alloy Steel Deformed and Plain Bars for Concrete Reinforcement, ASTM A706-09b, ASTM International, West Conshohocken, Pennsylvania.

ASTM, 2011, Standard Specification for Deformed and Plain, Low-Carbon, Chromium, Steel Bars for Concrete Reinforcement, ASTM A1035, ASTM International, West Conshohocken, Pennsylvania.

ASTM, 2012a, Standard Specification for Deformed and Plain Stainless-Steel Bars for Concrete Reinforcement, ASTM A955, ASTM International, West Conshohocken, Pennsylvania.

ASTM, 2012b, Standard Specification for Uncoated High-Strength Steel Bars for Prestressing Concrete, ASTM A722, ASTM International, West Conshohocken, Pennsylvania.

ASTM, 2012c, Standard Test Methods and Definitions for Mechanical Testing of Steel Products, ASTM A370, ASTM International, West Conshohocken, Pennsylvania.

ASTM, 2013, Standard Specification for Headed Steel Bars for Concrete Reinforcement, ASTM A970, ASTM International, West Conshohocken, Pennsylvania.

ATC, 2003, The Missing Piece: Improving Seismic Design and Construction Practices, ATC-57 Report, Applied Technology Council, Redwood City, California.

Bachmann, H., Falkner, H., Gerritzen, D., and Wlodkowski, H., 2008, "Das neue Bewehrungssystem; Druckglieder mit Hochfestem Betonstahl SAS 670/800: Part II: Opernturm Frankfurt-Anwendung," Beton- und Stahlbetonbau, (in German), Ernst \& Sohn, Berlin, Germany.

Barbosa, A., 2011, Simplified Vector-Valued Probabilistic Seismic Hazard Analysis and Probabilistic Seismic Demand Analysis: Application to the 13-Story NEHRP Reinforced Concrete Frame-Wall Building Design Example, Ph.D. Thesis, University of California, San Diego, California. 
Birely, A.C., 2011, Seismic Performance of Slender Reinforced Concrete Structural Walls, proposal for Ph.D. Thesis, University of Washington, Seattle, Washington.

Bournonville, M., Dahnke, J., and Darwin, D., 2004, Statistical Analysis of the Mechanical Properties and Weight of Reinforcing Bars, SL Report 04-1, Structural Engineering and Materials Laboratory, University of Kansas, Lawrence, Kansas.

Brown, M., Bayrak, O., and Jirsa, J., 2006, "Design for shear based on loading conditions," ACI Structural Journal, Vol. 103, No. 4, pp. 541-550.

Budek, A., Priestley, M., and Lee, C., 2002, "Seismic design of columns with highstrength wire and strand as spiral reinforcement," ACI Structural Journal, Vol. 99, No. 5, pp. 660-670.

Burns, N.H., and Seiss, C.P., 1962, Load Deformation Characteristics of BeamColumn Connections in Reinforced Concrete, Structural Research Series No. 234, University of Illinois, Urbana, Illinois.

Caifu, Y., 2010, "Development of high strength construction rebars," Proceedings, International Seminar on Production and Application of High Strength Seismic Grade Rebar Containing Vanadium, Central Iron \& Steel Research Institute, Beijing, China.

Caltrans, 2010, Prequalification Procedures and Acceptance Criteria for Headed ASTM A706 Reinforcing Steel Bars, http://www.dot.ca.gov/hq/esc/approved products list/pdf/HeadedBarReinfPrequalCriteria.pdf, last accessed October 28, 2013.

Canbay, E., and Frosch, R.J., 2005, "Bond strength of lap-spliced bars," $A C I$ Structural Journal, Vol. 102, No. 4, pp. 605-614.

CEB-FIP, 1990, Model Code for Concrete Structures, Comite Euro-International du Beton, Lausanne, Switzerland.

Chang, B., Hutchinson,T., and Englekirk, R., 2008, Experimental Seismic Performance Evaluation of Innovative Beam-Column Subassemblies, Structural Systems Research Project, SSRP Report 08/01, University of California at San Diego, San Diego, California.

Chen, M., Pantoli, E., Wang, X., Espino, E., Mintz, S., Conte, J., Hutchinson, T., Marin, C., Meacham, B., Restrepo, J.I., Walsh, K., Englekirk, R., Faghihi, M., and Hoehler, M., 2012, "Design and construction of a full-scale 5-story base isolated building outfitted with nonstructural components for earthquake testing at the UCSD-NEES facility," Proceedings, ASCE Structures Congress 2012, pp. 1349-1360. 
Chen, M.C., Pantoli, E., Astroza, R., Ebrahimian, H., Mintz, S., Wang, X., Hutchinson, T., Conte, J., Restrepo, J., Meacham, B., Kim, J., and Park, H., 2013, BNCS Report \#1: Full-Scale Structural and Nonstructural Building System Performance during Earthquakes and Post-Earthquake Fire Specimen Design, Construction and Test Protocol, Structural Systems Research Project Report Series, SSRP 13/9, University of California, San Diego, California.

Collins, M., and Kuchma, D., 1999, "How safe are our large, lightly reinforced, concrete beams, slabs, and footings?" ACI Structural Journal, Vol. 96, No. 4, pp. 482-490.

CRSI, 2013, data from an unpublished database of the Concrete Reinforcing Steel Institute, September 2013.

CSA, 2009, G30.18 Carbon Steel Bars for Concrete Reinforcement, Canadian Standards Association, Toronto, Canada.

Cusson, D., and Paultre, P., 1995, "Stress-strain model for confined high-strength concrete," Journal of Structural Engineering, Vol. 121, No. 3, pp. 468-477.

Darwin, D., Lutz, L.A., and Zuo, J., 2005, "Recommended provisions and commentary on development and lap splice lengths for deformed reinforcing bars in tension," ACI Structural Journal, Vol. 102, No. 6, pp. 892-900.

Dazio, A.D.A., Beyer, K., and Bachmann, H., 2009, "Quasi-static cyclic tests and plastic hinge analysis of RC structural walls," Engineering Structures, Vol. 31, pp. 1556-1571.

Dodd, L., and Restrepo-Posada, J.I., 1995, "Model for predicting cyclic behavior of reinforcing steel," Journal of Structural Engineering, Vol. 121, No. 3, pp. 433-445.

Dragovich, J.J., 1996, An Experimental Study of Torsional Response of Reinforced Concrete Structures to Earthquake Excitation, Ph.D. Thesis, University of Illinois, Urbana, Illinois.

Eligehausen, R., Popov, E.P., and Bertero, V.V., 1983, Local Bond Stress-Slip Relationships of Deformed Bars under Generalized Excitations, Report No. UCB/EERC-83/23, Earthquake Engineering Research Center, University of California, Berkeley, California.

Elwood, K., and Eberhard, M., 2009, "Effective stiffness of reinforced concrete columns," ACI Structural Journal, Vol. 106, No. 4, pp. 476-484.

Erasmus, L., and Pussegoda, N., 1978, "Safe bend radii for deformed reinforcing bar to avoid failure by strain age embrittlement," New Zealand Engineering, Vol. 33, No. 8, pp. 170-177. 
ETABS, 2006, Extended Analysis of 3D Building Systems, Plus version 9.1.1, Computers and Structures, Inc., Berkeley, California, http://www.csiamerica.com/

Falkner, H., Gerritzen, D., Jungwirth, D., and Sparowitz, L., 2008, “The new reinforcement system; compression members with SAS 670 high-strength reinforcement steel—Part I: Development, testing, design and construction,” Beton- und Stahlbetonbau, Ernst \& Sohn, Berlin, Germany.

FEMA, 2000, Prestandard and Commentary for the Seismic Rehabilitation of Buildings, FEMA 356 Report, prepared by the American Society of Civil Engineers for the for the Federal Emergency Management Agency, Washington, D.C.

FEMA, 2006, NEHRP Recommended Provisions: Design Examples, FEMA 451 Report, prepared by the Building Seismic Safety Council for the Federal Emergency Management Agency, Washington, D.C.

FEMA, 2007, Interim Testing Protocols for Determining the Seismic Performance Characteristics of Structural and Nonstructural Components, FEMA 461 Report, prepared by the Applied Technology Council for the Federal Emergency Management Agency, Washington, D.C.

FEMA, 2009, Quantification of Building Seismic Performance Factors, FEMA P-695 Report, prepared by Applied Technology Council for the Federal Emergency Management Agency, Washington, D.C.

Garay-Moran, J.D., and Lubell, A.S., 2008, "Behavior of concrete deep beams with high strength reinforcement," Proceedings, ASCE Structures Congress, Reston, Virginia.

Gaston, J.R., and Hognestad, E., 1962, "High strength bars as concrete reinforcement, Part 3-Tests of full-scale roof girder," Journal of the PCA Research and Development Laboratories, Vol. 4, No. 2, pp. 10-23.

Gulec, C., Whittaker, A., and Stojadinovic, B., 2008, "Shear strength of squat rectangular reinforced concrete walls," ACI Structural Journal, Vol. 108, No. 4, pp. 488-497.

Gulec, C., Whittaker, A., and Stojadinovic, B., 2009, "Peak shear strength of squat reinforced concrete walls with boundary barbells or flanges," ACI Structural Journal, Vol. 106, No. 3, pp. 368-377.

Gulec, C., and Whittaker, A., 2011, "Empirical equations for peak shear strength of low aspect ratio reinforced concrete walls," ACI Structural Journal, Vol. 108, No. 1, pp. 80-89. 
Gustafson, D.P., 2007, "Revisiting low-alloy steel reinforcing bars," Concrete International, Vol. 29, No. 1, pp. 55-59.

Gustafson, D.P., and Felder, A.L., 1991, "Questions and answers on ASTM A706 reinforcing bars," Concrete International, Vol. 13, No. 7, pp. 54-57.

Haselton, C., Liel, A., Deierlein, G., Dean, B., and Chou, J., 2011, "Seismic collapse safety of reinforced concrete buildings, Part I: Assessment of ductile moment frames," Journal of Structural Engineering, Vol. 137, No. 4, pp. 481-491.

Hognestad, E., 1961, "High strength bars as concrete reinforcement, Part 1Introduction to a series of experimental reports," Journal of the PCA Research and Development Laboratories, Vol. 3, No. 3, pp. 23-29.

Hognestad, E., 1962, "High strength bars as concrete reinforcement, Part 2-Control of flexural cracking," Journal of the PCA Research and Development Laboratories, Vol. 4, No. 1, pp. 46-63.

Hopkins, D., and Poole, R., 2005, Grade 500E Reinforcing Steel, Tests on MicroAlloy and Quenched and Tempered Samples Available in New Zealand, Department of Building and Housing, Wellington, New Zealand.

ICBO, 1994, Uniform Building Code, Vol.2, International Conference of Building Officials, Whittier, California.

ICC, 2009, Acceptance Criteria for Threaded High-Strength Steel Bars for Concrete Reinforcement, AC237, International Code Council Evaluation Services, Whittier, California.

ICC, 2011, Evaluation Subject: SAS Stressteel Grade 97 Thread Bar Steel Reinforcing Bars and Couplers, ESR-1163, International Code Council Evaluation Services, Whittier, California.

Ichinose, T., 1995, "Splitting bond failure of columns under seismic action," $A C I$ Structural Journal, Vol. 92, No. 5, pp. 535-541.

Ishikawa, Y., Kimura, H., Takatsu, H., and Ousalem, H., 2008, "Ultimate deformation of R/C columns using high-strength concrete and high-strength steel bars under earthquake loading," Proceedings, 8th International Symposium on Utilization of High-Strength and High-Performance Concrete, S1-5-4, Tokyo, Japan.

ISO, 2010a, Steel for the Reinforcement and Prestressing of Concrete-Test Methods-Part 1: Reinforcing Bars, Wire Rod and Wire, ISO 15630-1, International Organization for Standardization, Geneva, Switzerland. ISO, 2010b, Steel for the Reinforcement and Prestressing of Concrete-Test Methods-Part 2: Welded Fabric, ISO 15630-2, International Organization for Standardization, Geneva, Switzerland. 
JIS, 2010, Steel Bars for Concrete Reinforcement (in Japanese), JIS G3112, Japanese Industrial Standards Committee, Tokyo, Japan.

Kaar, P.H., 1966, "High strength bars as concrete reinforcement, Part 8-Similitude in flexural cracking of T-beam flanges," Journal of the PCA Research and Development Laboratories, Vol. 8, No. 2, pp. 2-12.

Kaar, P.H., and Hognestad, E., 1965, "High strength bars as concrete reinforcement, Part 7-Control of cracking in T-beam flanges," Journal of the PCA Research and Development Laboratories, Vol. 7, No. 1, pp. 42-53.

Kaar, P.H., and Mattock, A.H., 1963, "High strength bars as concrete reinforcement, Part 4-Control of cracking," Journal of the PCA Research and Development Laboratories, Vol. 5, No. 1, pp. 15-38.

Kabeyasawa, T., and Hiraishi, H., 1998, "Tests and analyses of high-strength reinforced concrete shear walls in Japan," High-Strength Concrete in Seismic Regions, ACI Special Publication SP-176, American Concrete Institute, Farmington Hills, Michigan.

Kimura, H., and Ishikawa, Y., 2008, "Seismic performance of high-strength reinforced concrete slender walls subjected to high axial loading," Proceedings, 8th International Symposium on Utilization of High-Strength and High-Performance Concrete, pp. 945-950, Tokyo, Japan.

Kimura, H., Sugano, S., Nagashima, T., and Ichikawa, A., 1993, "Seismic loading tests of reinforced concrete beams using high strength concrete and high strength steel bars," Proceedings, $3^{\text {rd }}$ International Symposium on Utilization of High-Strength Concrete, pp. 377-384, Tokyo, Japan.

LATBSDC, 2011, An Alternative Procedure for Seismic Analysis and Design of Tall Buildings Located in the Los Angeles Region, Los Angeles Tall Buildings Structural Design Council, Los Angeles, California.

Lee, H., 2012, Development of High-Strength Reinforcing Bars, PowerPoint presentation for Taiwan Concrete Institute and Tung Ho Steel Enterprise Corporation.

Lepage, A., Tavallali, H., Pujol, S., and Rautenberg, J., 2012, "High-performance steel bars and fibers as concrete reinforcement for seismic-resistant frames," Advances in Civil Engineering Journal, Hindawi Publishing Corporation, Article Id. 450981.

Li, H., Deeks, A., Liu, L., and Su, X., 2010, “Comparison of Chinese and Australian $500 \mathrm{MPa}$ reinforcing steel," Australian Journal of Structural Engineering, Vol. 10, No. 2, pp. 137-144. 
Lin, C.M., Restrepo, J.I., and Park, R., 2000, Seismic Behaviour and Design of Reinforced Concrete Interior Beam Column Joints, Research Report 2000-1, Department of Civil Engineering, University of Canterbury, New Zealand.

Lowes, L.N., Lehman, D.E., Birely, A.C., Kuchma, D.A., Marley, K.P., and Hart, C.R., 2012, "Earthquake response of slender planar concrete walls with modern detailing," Engineering Structures, Vol. 43, pp. 31-47.

Lu, Y., and Panagiotou, M., 2013, "Three-dimensional cyclic beam-truss model for non-planar reinforced concrete walls," Journal of Structural Engineering, Vol. 140, No. 1.

Lubell, A., Sherwood, T., Bentz, E., and Collins, M.P., 2004, "Safe shear design of large, wide beams," ACI Concrete International, Vol. 26, No. 1, pp. 66-78.

Marques, J., and Jirsa, J., 1975, “A study of hooked bar anchorages in beam-column joints," ACI Structural Journal, Vol. 72, No. 5, pp. 198-209.

Matamoros, A.B., 1999, Study of Drift Limits for High-Strength Concrete Columns, Ph.D. Thesis, University of Illinois, Urbana, Illinois.

Mazzoni, S., McKenna, F., Scott, M.H., and Fenves, G.L., 2009, OpenSees Command Language Manual, Pacific Earthquake Engineering Research Center, Berkeley, California.

Miyajima, M., 2010, "The Japanese experience in design and application of seismic grade rebar," Proceedings, International Seminar on Production and Application of High Strength Seismic Grade Rebar Containing Vanadium, Central Iron and Steel Research Institute, Beijing, China.

Moehle, J.P., 1992, "Displacement-based design of RC structures subjected to earthquakes," Earthquake Spectra, Vol. 8, No. 3, pp. 403-428.

Moyer, M., and Kowalsky, M., 2003, "Influence of tension strain on buckling of reinforcement in concrete columns," ACI Structural Journal, Vol. 100, No. 1, pp. 75-85.

Munikrishna, A., 2008, Shear Behavior of Concrete Beams Reinforced with High Performance Steel Shear Reinforcement, M.S. Thesis, North Carolina State University, Raleigh, North Carolina.

Nishiyama, M., 2009, "Mechanical properties of concrete and reinforcement-Stateof-the-art report on HSC and HSS in Japan," Journal of Advanced Concrete Technology, Vol. 7, No. 2, pp. 157-182.

NIST, 2010, Seismic Design of Cast-in-Place Concrete Diaphragms, Chords, and Collectors-A Guide for Practicing Engineers, NIST GCR 10-917-4 Report, prepared by the NEHRP Consultants Joint Venture, a partnership of the 
Applied Technology Council and the Consortium of Universities for Research in Earthquake Engineering, for the National Institute of Standards and Technology, Gaithersburg, Maryland.

Nucor Steel, 2012a, Test Data for Stress-Strain Curves for A706 G80 4bar, provided to J. I. Restrepo, Nucor Steel, Seattle, Washington.

Nucor Steel, 2012b, Test Data for Stress-Strain Curves for A706 G80 7bar1, provided to J. I. Restrepo, Nucor Steel, Seattle, Washington.

Nucor Steel, 2012c, Test Data for Stress-Strain Curves for A706 G80 7bar2, provided to J. I. Restrepo, Nucor Steel, Seattle, Washington.

Nucor Steel, 2012d, Test Data for Stress-Strain Curves for A706 G80 8bar1, provided to J. I. Restrepo, Nucor Steel, Seattle, Washington.

Nucor Steel, 2012e, Test Data for Stress-Strain Curves for A706 G80 8bar2, provided to J. I. Restrepo, Nucor Steel, Seattle, Washington.

Nucor Steel, 2012f, Test Data for Stress-Strain Curves for A706 G80 8bar3, provided to J. I. Restrepo, Nucor Steel, Seattle, Washington.

Nucor Steel, 2012g, Test Data for Stress-Strain Curves for A706 G80 18bar, provided to J. I. Restrepo, Nucor Steel, Seattle, Washington.

NZS, 1982, Code of Practice for the Design of Concrete Structures, NZS 3101, Standards New Zealand, Wellington, New Zealand.

NZS, 2006, Concrete Structures Standard - The Design of Concrete Structures, NZS 3101-1, Standards New Zealand, Wellington, New Zealand.

Okamoto, M., Sato, T., Tanimura, Y., and Kuroiwa, T., 2004, "Experimental study on seismic performance verification method for RC members using highstrength materials," Journal of Advanced Concrete Technology, Vol. 2, No. 2, pp. 223-231.

OpenSees, 2011, Open System for Earthquake Engineering Simulation, Pacific Earthquake Engineering Research Center, Berkeley, California, http://opensees.berkeley.edu, last accessed October 28, 2013.

Orangun, C., Jirsa, J., and Breen, J., 1975, The Strength of Anchor Bars: A Reevaluation of Test Data on Development Length and Splices, Research Report 154-3F, Center for Highway Research, The University of Texas at Austin, Texas.

Orangun, C., Jirsa, J., and Breen, J., 1977, “A reevaluation of test data on development length and splices," ACI Structural Journal, Title No. 74-11, pp. 114-122. 
Otani, S., Nagai, S., and Aoyama, H., 1996, "Load-deformation relationship of highstrength reinforced concrete beams," Mete A. Sozen Symposium - A Tribute From His Students, ACI SP-162-2, pp. 35-52, American Concrete Institute, Farmington Hills, Michigan.

Ou, Y., Kurniawan, D., and Handika, N., 2012, "Shear behavior of reinforced concrete columns with high strength steel and concrete under low axial load," Proceedings, ACI Fall Convention, Toronto, Ontario, Canada.

Ousalem, H., Takatsu, H., Ishikawa, Y., and Kimura, H., 2009, "Use of high-strength bars for the seismic performance of high-strength concrete columns," Journal of Advanced Concrete Technology, Vol. 7, No. 1, pp. 123-134.

Panagiotou, M., and Restrepo, J.I., 2011, "Displacement-based method of analysis for regular reinforced-concrete wall buildings: application to a full-scale 7story building slice tested at UC San Diego." Journal of Structural Engineering, Vol. 137, No. 6, pp. 677-690.

Panagiotou, M., Restrepo, J.I., and Conte, J., 2011, "Shake-table test of a full-scale 7story building slice, Phase I: Rectangular wall." Journal of Structural Engineering, Vol. 137, No. 6, pp. 691-704.

Park, R., 1996, "Structural behaviour of high strength concrete columns," Worldwide Advances in Structural Concrete and Masonry: Proceedings of the CCMS Symposium Held in Conjunction with Structures Congress XIV, Chicago, Illinois.

Park, R., and Paulay, T., 1975, Reinforced Concrete Structures, John Wiley \& Sons, New York.

Park, R., Priestley, M.J.N., and Gill, W.D., 1982, "Ductility of square-confined concrete columns," Journal of the Structural Division, Vol. 108, No. ST4, pp. 929-950.

Paulay, T., and Priestley, M.J.N., 1992, Seismic Design of Reinforced Concrete and Masonry Buildings, John Wiley \& Sons, New York, New York.

PEER, 2010, PEER Ground Motion Database, Pacific Earthquake Engineering Research Center, Berkeley, California, http://peer.berkeley.edu /peer_ground_motion_database, last accessed October 28, 2013.

Pfister, J.F., and Hognestad, E., 1964, "High strength bars as concrete reinforcement, Part 6-Fatigue tests," Journal of the PCA Research and Development Laboratories, Vol. 6, No. 1, pp. 65-84.

Pfister, J.F., and Mattock, A.H., 1963, "High strength bars as concrete reinforcement, Part 5-Lapped splices in concentrically loaded columns," Journal of the PCA Research and Development Laboratories, Vol. 5, No. 2, pp. 27-40. 
Pfund, S.J., 2012, Cyclic Response of Concrete Beams Reinforced with ASTM A1035 Grade-120 Steel Bars, M.S. Thesis, The Pennsylvania State University, University Park, Pennsylvania.

Priestley, M.J.N., and Park, R., 1987, "Strength and ductility of concrete bridge columns under seismic loading," ACI Structural Journal, Vol. 84, No. 1, pp. 61-76.

Qazi, A.U., Ye, L., and Lu, X., 2008, "Performance of mixed ordinary and high strength reinforced concrete frames against earthquakes," WIT Transactions on the Built Environment, Vol. 97, pp. 347-357.

Rautenberg, J.M., 2011, Drift Capacity of Concrete Columns Reinforced with High Strength Steel, Ph.D. Thesis, Purdue University, West Lafayette, Indiana.

Reineck, K.H., Kuchma, D.A., Kim, K.S., and Marx, S., 2003, "Shear database for reinforced concrete members without shear reinforcement," ACI Structural Journal, Vol. 100, No. 2, pp. 240-249.

Restrepo, J.I., 2000, "Issues related to the seismic design of reinforced concrete structural systems," SESOC Journal, New Zealand Structural Engineering Society, Auckland, New Zealand, Vol. 13, No. 1, pp. 50-58.

Restrepo, J.I., Seible, F., Stephan, B., and Schoettler, M.J., 2006, "Seismic testing of bridge columns incorporating high-performance materials," ACI Structural Journal, Vol. 103, No. 4, pp. 496-504.

Restrepo-Posada, J.I., 1992, Seismic Behaviour of Connections Between Precast Concrete Elements, Ph.D. Thesis, University of Canterbury, Christchurch, New Zealand.

Restrepo-Posada, J.I., Dodd, L., Park, R., and Cooke, N., 1994, "Variables affecting cyclic behavior of reinforcing steel," Journal of Structural Engineering, Vol. 120, No. 11, pp. 3178-3196.

Richard, M.J., Albano, L.D., Kelly, D.J., and Liel, A., 2010, "Case study on the seismic performance of reinforced-concrete intermediate-moment frames using ACI design provisions," Proceedings, NASCC Steel Conference/ASCE Structures Congress, Orlando, Florida.

Richart, F.E., and Brown, R.L., 1934, An Investigation of Reinforced Concrete Columns: A Report of an Investigation, The Engineering Experiment Station, University of Illinois, in cooperation with the American Concrete Institute, University of Illinois, Urbana, Illinois.

Rodriguez, M., Botero, J., and Villa, J., 1999, "Cyclic stress-strain behavior of reinforcing steel including effect of buckling," Journal of Structural Engineering, Vol. 125, No. 6, pp. 605-612. 
Rosenblueth, E., and Arciniega, A., 1992, "Response spectral ratios," Earthquake Engineering Structural Dynamics, Vol. 21, No. 6, pp. 483-492.

Sato, Y., Tanaka, H., and Park, R., 1993, Reinforced Concrete Columns with Mixed Grade Longitudinal Reinforcement, Research Report 93-7, University of Canterbury, Christchurch, New Zealand.

Satyarno, I., 1993, Concrete Columns Incorporating Mixed Ultra High and Normal Strength Longitudinal Reinforcement, M.S. Thesis, University of Canterbury, Christchurch, New Zealand.

Schotanus, M. IJ., and Maffei, J., 2007, “Appropriate stiffness and modeling assumptions for high-rise concrete wall buildings," Blind Prediction of the Shake Table Response of a 7-story Building, Structural Systems Research Report SSRP 07-30, Department of Structural Engineering, University of California, San Diego, California.

Seliem, H.M., Lucier, G., Rizkalla, S.H., and Zia, P., 2008, "Behavior of concrete bridge decks reinforced with high-performance steel," ACI Structural Journal, Vol. 105, No. 1, pp. 78-86.

Seliem, H.M., Hosny, A., Rizkalla, S., Zia, P., Briggs, M., Miller, S., Darwin, D., Browning, J., Glass, G.M., Hoyt, K., Donnelly, K., and Jirsa, J.O., 2009, "Bond characteristics of high-strength ASTM A1035 steel reinforcing bars," ACI Structural Journal, Vol. 106, No. 4, pp. 530-539.

Shahrooz, B. M., Miller, R.A., Harris, K. A., and Russell, H. G., 2011, Design of Concrete Structures Using High-Strength Steel Reinforcement, National Cooperative Highway Research Program Report 679, Transportation Research Board of the National Academies, Washington, D.C.

Sugano, S., 2008, Application of High-Strength and High-Performance Concrete in Seismic Regions, Power Point presentation, at the $8^{\text {th }}$ Symposium (8HSC/HPC) for Utilization of High Strength Concrete/High Performance Concrete, Tokyo, Japan.

Sugano, S., Nagashima, T., Kimura, H., and Ichikawa, A., 1990, "Experimental study on high-strength concrete beams using high-strength main bars," Proceedings of the Japan Concrete Institute, Vol. 12, No. 2, pp. 215-220.

Sumpter, M.S., Rizkalla, S.H., and Zia, P., 2009, "Behavior of high-performance steel as shear reinforcement for concrete beams," ACI Structural Journal, Vol. 106, No. 2, pp. 171-177.

Tanaka, H., 1990, Effect of Lateral Confining Reinforcement on the Ductile Behaviour of Reinforced Concrete Columns, Ph.D. Thesis, University of Canterbury, Christchurch, New Zealand. 
Tang, J., and Lubell, A.S., 2008, "Influence of longitudinal reinforcement strength on one-way slab deflection," Canadian Journal of Civil Engineering, Vol. 35, No. 10, pp. 1076-1087.

Tavallali, H., 2011, Cyclic Response of Concrete Beams Reinforced with Ultrahigh Strength Steel, Ph.D. Thesis, Pennsylvania State University, University Park, Pennsylvania.

Thomas, K., and Sozen, M.A., 1965, A Study of the Inelastic Rotation Mechanism of Reinforced Concrete Connections, Civil Engineering Studies, Structural Research Series No. 301, University of Illinois, Urbana, Illinois.

Thorenfeldt, E., Tomaszewicz, A., and Jensen, J.J., 1987, "Mechanical properties of high-strength concrete and application in design," Proceedings of the Symposium on Utilization of High Strength Concrete, pp. 149-159, Stavanger, Norway.

Todeschini, C.E., Bianchini, A.C., and Kesler, C.E., 1964, "Behavior of concrete columns reinforced with high strength steels," ACI Structural Journal, Vol. 61, No. 6, pp. 701-715.

Tretiakova, K., 2013, Cyclic Response of Concrete Columns Reinforced with SAS 670 Grade-97 Steel Bars, M.S. Thesis, Pennsylvania State University, University Park, Pennsylvania.

Wallace, J.W., 1998, "Behavior and design of high-strength RC walls," HighStrength Concrete in Seismic Regions, ACI Special Publication SP-176, American Concrete Institute, Farmington Hills, Michigan.

Wang, Y., and Restrepo, J.I., 2001, "Investigation of concentrically loaded reinforced concrete columns confined with glass fiber-reinforced polymer jackets," $A C I$ Structural Journal, Vol. 98, No. 3, pp. 377-385.

Watanabe, F., Lee, J.Y., and Nishiyama, M., 1995, "Structural performance of reinforced concrete columns with different grade longitudinal bars," $A C I$ Structural Journal, Vol. 92, No. 4, pp. 412-418.

Watanabe, F., Osumi, K., and Muguruma, H., 1990, "Control of flexural behaviour of reinforced concrete section by mixed use" (in Japanese), Proceedings of the Annual Meeting of the Architectural Institute of Japan, pp. 501-508.

Wood, S.L., 1990, "Shear strength of low-rise reinforced concrete walls," ACI Structural Journal, Vol. 87, No. 1, pp. 99-107.

Xiao, X., Guan, F.L., and Yan, S., 2008, "Use of ultra-high-strength bars for seismic performance of rectangular high-strength concrete frame columns," Magazine of Concrete Research, Vol. 60, No. 4, pp. 253-259. 
Zhu, S., and Jirsa, J.O., 1983, A Study of Bond Deterioration in Reinforced Concrete Beam-Column Joints, PMFSEL Report No. 83-1, Department of Civil Engineering, University of Texas at Austin, Austin, Texas.

Zuo, J., and Darwin, D., 2000, "Splice strength of conventional and high relative rib area bars in normal and high-strength concrete," ACI Structural Journal, Vol. 97, No. 4, pp. 630-641. 


\section{Project Participants}

National Institute of Standards and Technology

John (Jack) R. Hayes, Jr.

Engineering Laboratory (MS8604)

National Institute of Standards and Technology

100 Bureau Drive

Gaithersburg, Maryland 20899

www.NEHRP.gov

\section{NEHRP Consultants Joint Venture}

APPLIED TECHNOLOGY COUNCIL

201 Redwood Shores Parkway, Suite 240

Redwood City, California 94065

www.ATCouncil.org

\section{Joint Venture Management Committee}

James R. Harris

J.R. Harris \& Company

1775 Sherman Street, Suite 2000

Denver, Colorado 80203

Robert Reitherman

Consortium of Universities for Research in

Earthquake Engineering

1301 S. $46^{\text {th }}$ Street, Building 420

Richmond, California 94804

\section{Joint Venture Program Committee}

Jon A. Heintz (Program Manager)

Applied Technology Council

201 Redwood Shores Parkway, Suite 240

Redwood City, California 94065

Michael Constantinou

University at Buffalo

Dept. of Civil, Structural, and Environ. Engin.

132 Ketter Hall

Buffalo, New York 14260

C.B. Crouse

URS Corporation

$15014^{\text {th }}$ Avenue, Suite 1400

Seattle, Washington 98101
Steven L. McCabe

Engineering Laboratory (MS8604)

National Institute of Standards and Technology

100 Bureau Drive

Gaithersburg, Maryland 20899

www.NEHRP.gov

\section{CONSORTIUM OF UNIVERSITIES FOR}

RESEARCH IN EARTHQUAKE ENGINEERING

1301 S. $46^{\text {th }}$ Street, Building 420

Richmond, California 94804

www.CUREE.org

Christopher Rojahn

Applied Technology Council

201 Redwood Shores Parkway, Suite 240

Redwood City, California 94065

Andrew Whittaker

University at Buffalo

Dept. of Civil, Structural, and Environ. Engin.

230 Ketter Hall

Buffalo, New York 14260

William T. Holmes

Rutherford + Chekene

55 Second Street, Suite 600

San Francisco, California 94105

Jack Moehle

University of California, Berkeley

Dept. of Civil and Environmental Engineering

775 Davis Hall

Berkeley, California 94720

James R. Harris (ex-officio)

Andrew Whittaker (ex-officio) 


\section{Project Managers}

Laura Dwelley Samant

Consultant

2547 Diamond Street

San Francisco, California 94131

\section{Project Technical Committee}

Dominic J. Kelly (Technical Director)

Simpson Gumpertz \& Heger, Inc.

41 Seyon Street

Building 1, Suite 500

Waltham, Massachusetts 02453

Andres Lepage

University of Kansas

Dept. of Civil, Environmental, and Arch. Engin.

2150 Learned Hall

$1530 \mathrm{~W} .15^{\text {th }}$ Street

Lawrence, Kansas 66045

David Mar

Tipping + Mar

1906 Shattuck Avenue

Berkeley, California 94704

\section{Project Review Panel}

Tony Ghodsi

Englekirk Structural Engineers

3621 Harbor Boulevard., Suite125

Santa Ana, California 92704

James O. Jirsa

University of Texas at Austin

Dept. of Civil, Architectural, and Environ. Engin.

ECJ Hall, Suite 4.726

Austin, Texas 78712

Conrad Paulson

Wiss, Janney, Elstner Associates, Inc.

225 South Lake Avenue, Suite 1260

Pasadena, California 91101

\section{Working Group Members}

Abby Enscoe

Tipping + Mar

1906 Shattuck Avenue

Berkeley, California 94704
Thomas McLane

Applied Technology Council

2111 Wilson Boulevard, Suite 700

Arlington, Virginia 22201

José I. Restrepo

Dept. of Structural Engineering

University of California, San Diego

9500 Gilman Drive

La Jolla, California 92093

Joseph C. Sanders

Charles Pankow Builders, Ltd.

199 South Los Robles Avenue, Suite 300

Pasadena, California 91101

Andrew W. Taylor

KPFF Consulting Engineers

$16015^{\text {th }}$ Avenue, Suite 1600

Seattle, Washington 98101

Mete Sozen

Purdue University

Lyles School of Civil Engineering

G129 Hampton Hall

550 Stadium Mall Drive

West Lafayette, Indiana 47907

Loring A. Wyllie, Jr.

Degenkolb Engineers

235 Montgomery Street, Suite 500

San Francisco, California 94104

Arpit Nema

University of California, San Diego

9500 Gilman Drive

La Jolla, California 92093 


\section{Workshop Participants}

Neal Anderson

Concrete Reinforcing Steel Institute (CRSI)

933 North Plum Grove Road

Schaumburg, Illinois 60173

Mark Aschheim

Santa Clara University

Dept. of Civil Engineering

500 El Camino Real

Santa Clara, California 95053

David Darwin

University of Kansas

Dept. of Civil, Environmental, and Arch. Engin.

2150 Learned Hall

1530 W. $15^{\text {th }}$ Street

Lawrence, Kansas 66045

David Fields

Magnusson Klemencic Associates

$13015^{\text {th }}$ Avenue, Suite 3200

Seattle, Washington 98101

S.K. Ghosh

S.K. Ghosh Associates Inc.

334 E. Colfax St

Palatine, Illinois 60067

John Gordon

Skidmore, Owings \& Merrill LLP

One Front Street, Suite 2500

San Francisco, California 94111

Larry Karlson

PCL Constructors Inc

$541099^{\text {th }}$ Street NW,

Edmonton, AB T6E 3P4, Canada

Bijan Khaleghi

Washington State

Department of Transportation

310 Maple Park Avenue, SE

Olympia, Washington 98504
Laura N. Lowes

University of Washington

Dept. of Civil and Environmental Engineering

233 C More Hall

Seattle, Washington 98195

Bob Mast

BergerABAM

33301 Ninth Avenue South, Suite 300

Federal Way, Washington 98003

Ted Mize

Harris Salinas Rebar Inc.

355 S. Vasco Road

Livermore, California 94550

Jack Moehle

University of California, Berkeley

Dept. of Civil and Environmental Engineering

775 Davis Hall

Berkeley, California 94720

Santiago Pujol

Purdue University

Lyles School of Civil Engineering

550 Stadium Mall Drive

West Lafayette, Indiana 47907

Karl Telleen

Maffei Structural Engineering

148 Hermosa Avenue

Oakland, California 94618

John Wang

Midstate Precast

2323 Dairy Avenue

Corcoran, California 93212 